\title{
Barbers Point Harbor, Nighttime Simulation
}

Gary C. Lynch

May 2007

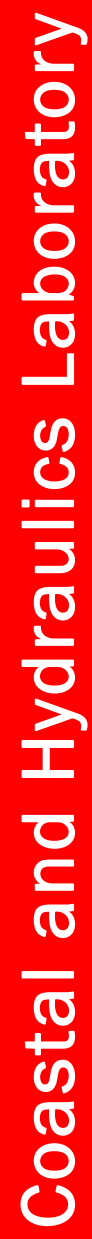

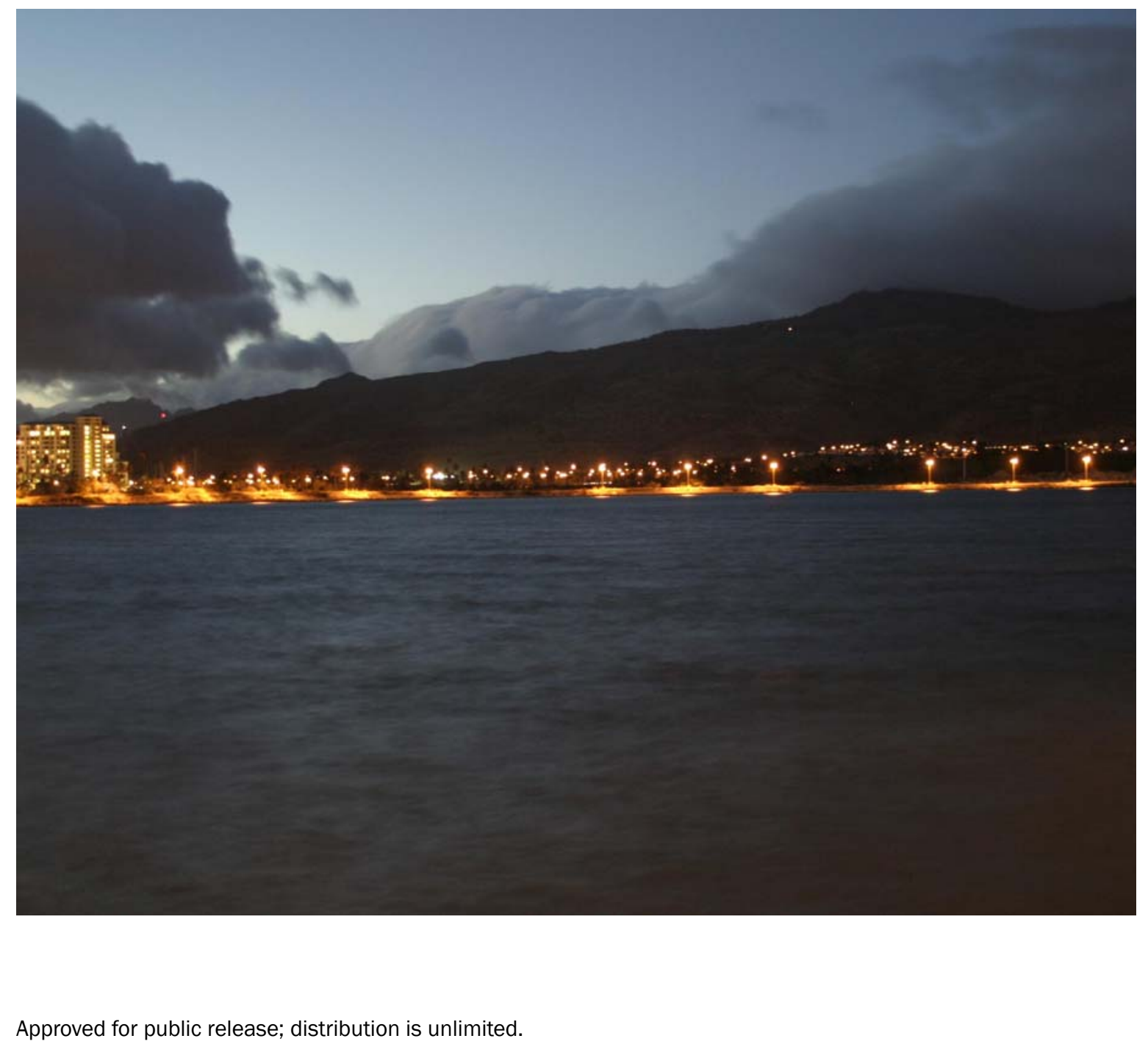


ERDC/CHL TR-07-1

May 2007

\title{
Barbers Point Harbor, Nighttime Simulation
}

\author{
Gary C. Lynch \\ Coastal and Hydraulics Laboratory \\ U.S. Army Engineer Research and Development Center \\ 3909 Halls Ferry Road \\ Vicksburg, MS 39150-6199
}

Final report

Approved for public release; distribution is unlimited.

Prepared for U.S. Army Engineer District, Honolulu

Fort Shafter, HI 96858-5440 


\begin{abstract}
Kalaeloa Barbers Point Harbor is located on the southwestern side of Oahu, HI. The purpose of this study was to analyze the possibility of nighttime transit into and out of the harbor. Changes in navigational aids as well as the addition of shoreline lighting were tested in the U.S. Army Engineer Research and Development Center's Ship/ Tow Simulator with the assistance of Pilots from Hawaii. For the possibility of nighttime transit to exist, improvements to the navigational aids, as well as improved methods of predicting the currents at the approach, would first have to be implemented.
\end{abstract}

DISCLAIMER: The contents of this report are not to be used for advertising, publication, or promotional purposes. Citation of trade names does not constitute an official endorsement or approval of the use of such commercial products. All product names and trademarks cited are the property of their respective owners. The findings of this report are not to be construed as an official Department of the Army position unless so designated by other authorized documents. 


\section{Contents}

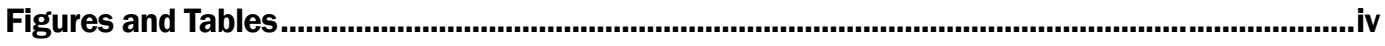

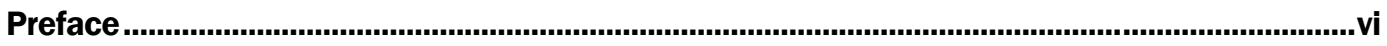

Unit Conversion Factors................................................................................................................ti

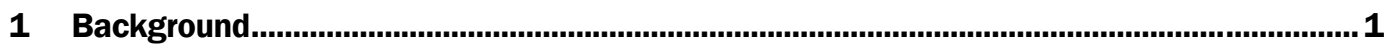

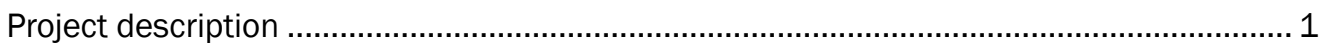

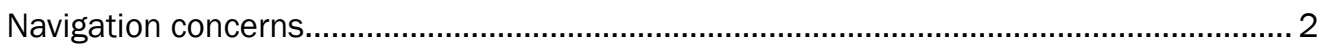

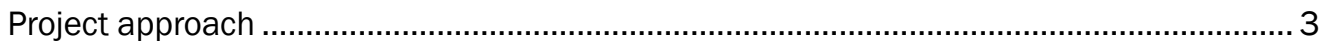

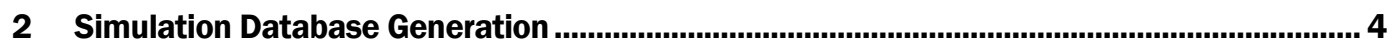

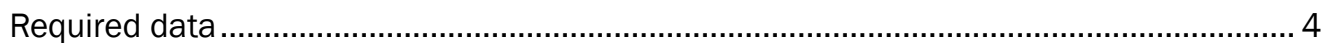

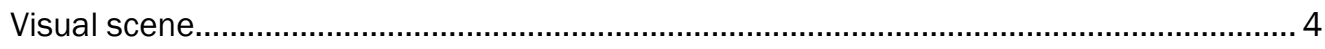

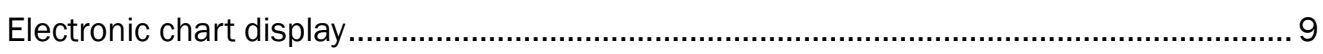

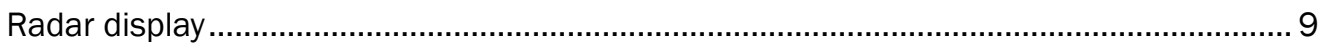

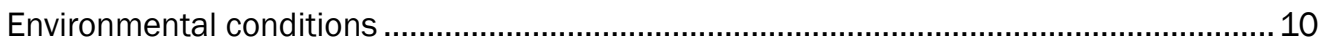

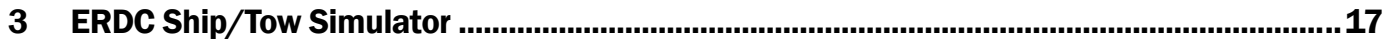

4 Testing Matrix

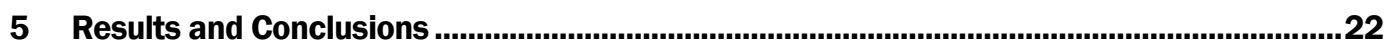

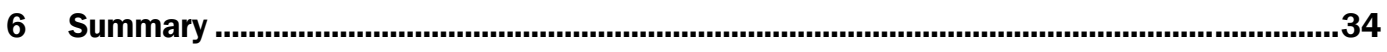

Plates 1-81

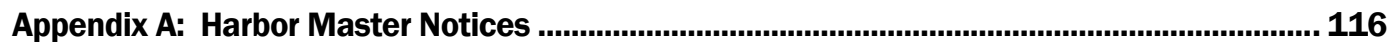




\section{Figures and Tables}

\section{Figures}

Figure 1. Project location map.

Figure 2. Kalaeloa Barbers Point Harbor existing navigational ranges................................................ 3

Figure 3. Recon photo for visual scene development.................................................................... 5

Figure 4. Recon photo of harbor area for scene development........................................................ 5

Figure 5. Recon photo of dry dock.......................................................................................... 6

Figure 6. Nighttime recon photo from eastern side of harbor............................................................ 6

Figure 7. Nighttime recon photo of northern jetty inside of harbor area with existing lights. ............. 7

Figure 8. Project layout for Kalaeloa Barbers Point Harbor................................................................. 8

Figure 9. Nighttime visual scene for Kalaeloa Barbers Point Harbor............................................... 8

Figure 10. Example of ECDIS display..................................................................................... 9

Figure 11. Example radar image display..................................................................................... 10

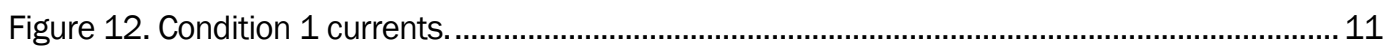

Figure 13. Condition 2 currents. ......................................................................................... 11

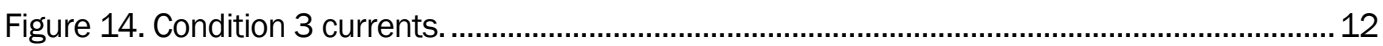

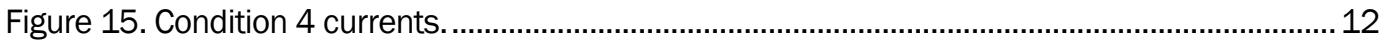

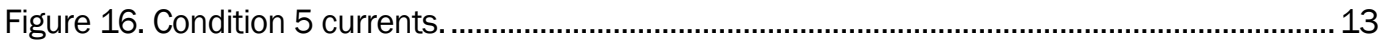

Figure 17. Condition 6 currents............................................................................................... 13

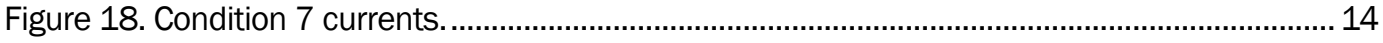

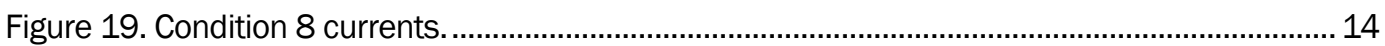

Figure 20. Final current conditions used in testing. ……………………………….................. 15

Figure 21. ERDC Ship/Tow Simulator layout. ……………….................................................. 17

Figure 22. Arrangement of ERDC Ship/Tow Simulator bridge module.......................................... 18

Figure 23. Linear ship position in channel for range viewpoint on Figure 28................................ 24

Figure 24. Kalaeloa Barbers Point Harbor with quartering ranges in place, ship at entrance to channel (Continued).

Figure 25. Difference in freeboard area (i.e., "sail area") affected by wind between a loaded tanker and a tanker in ballast. .......................................................................................... 27

Figure 26. Difference in current and bank force areas of influence................................................28

Figure 27. Proposed new and modified buoy location....................................................................

Figure 28. Proposed jetty at harbor entrance. ............................................................................. 31

Figure 29. Obstructed view looking forward. .................................................................................

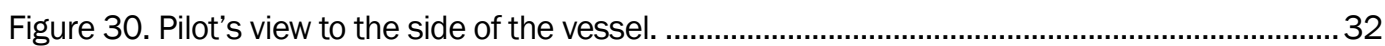




\section{Tables}

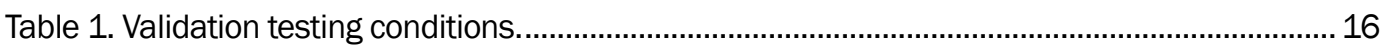

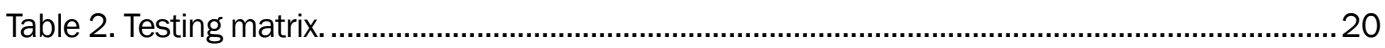

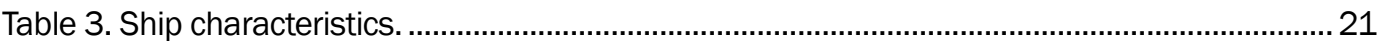




\section{Preface}

This navigation study was performed by the Coastal and Hydraulics Laboratory (CHL), U.S. Army Engineer Research and Development Center (ERDC), Vicksburg, MS, for the U.S. Army Engineer District, Honolulu.

The investigation was conducted by Gary C. Lynch, with the assistance of Sally Harrison, Donna Derrick, and Peggy Van Norman, Deep Draft Navigation Group, Navigation Branch, CHL, under the direct supervision of Dennis Webb, Chief, Navigation Branch. Simulation tests were conducted at the ERDC Ship/Tow Simulator Facility located in Vicksburg, MS.

Acknowledgment is made to Thomas Smith, Honolulu District, for cooperation and assistance. Special thanks are extended to the Department of Transportation of Hawaii and the Hawaii Pilot Association for their participation in the study.

This study was performed under the supervision of Thomas W. Richardson, Director, CHL.

COL Richard B. J enkins was Commander and Executive Director of ERDC. Dr. J ames R. Houston was Director. 


\section{Unit Conversion Factors}

\begin{tabular}{|l|c|l|}
\hline Multiply & By & To Obtain \\
\hline acres & $4,046.873$ & square meters \\
\hline feet & 0.3048 & meters \\
\hline knots & 0.5144 & meters per second \\
\hline
\end{tabular}




\section{Background}

\section{Project description}

Kalaeloa Barbers Point Harbor is located on the southwestern side of Oahu (Figure 1).

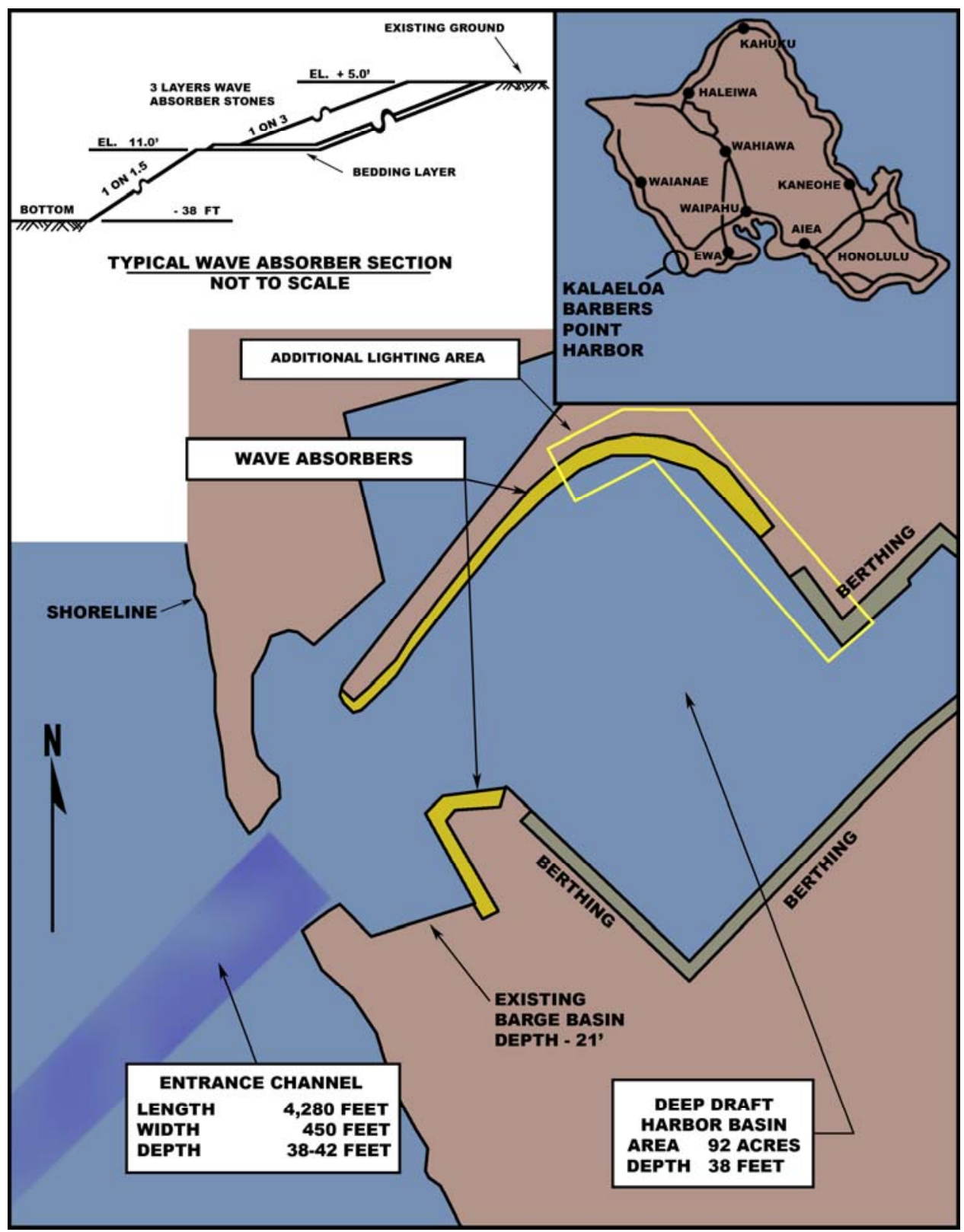

Figure 1. Project location map. 
The entrance channel for the harbor is $450 \mathrm{ft}$ wide, 3,100 ft long, and $42 \mathrm{ft}$ deep, transitioning into a 38-ft-deep inner channel $980 \mathrm{ft}$ long that flares into the harbor itself. At this time, traffic in Kalaeloa Barbers Point Harbor is limited by the conditions set forth in Harbor Master's Notices 5-92 and 7-92 (Appendix A).

The purpose of this study was to analyze the possibility of safe nighttime navigation with additional shoreline lighting inside the harbor (Figure 1). The proposed terminal improvements for the harbor would increase the amount of light illuminating the northeastern shoreline of the harbor possibly making it accessible $24 \mathrm{hr}$ a day.

\section{Navigation concerns}

At first glance, Kalaeloa Barbers Point Harbor appears to be a simple harbor with deep water up to the short entrance channel and a fairly small basin. The harbor is compact and unobtrusive. However, wind and wave conditions as well as cross currents can make the entrance difficult. Vessel maneuvering speed must be reduced quickly once inside the protected harbor to avoid damage to docked vessels. Since currents in the area do not necessarily follow the wind and wave patterns, reading the currents is next to impossible. A deep draft vessel, such as a loaded tanker, will be affected more by the currents, whereas a light vessel, containership, or passenger vessel, would be more affected by the wind and waves.

Because the entrance channel is short, when using the ranges (Figure 2) there are several concerns that are unique to Kalaeloa Barbers Point Harbor. One concern is the fact that by the time the ranges show a significant distance off track, the vessel is already in trouble. Also, on outbound transits there are only three sets of navigation aids to guide the ship out of the navigation channel. These concerns would be further exacerbated in the anticipated nighttime operation, as well as the deeper drafting ships in conjunction with the proposed deepened channel. Most of the visual cues that a pilot relies upon during a daytime transit are absent during nighttime runs. Cultural lights (i.e., distant - town, business, factory, subdivision type lights), navaid lights, and objects that are lit and close enough to the channel to be distinguishable (such as buildings and tanks in and around the harbor) are all that remain. 


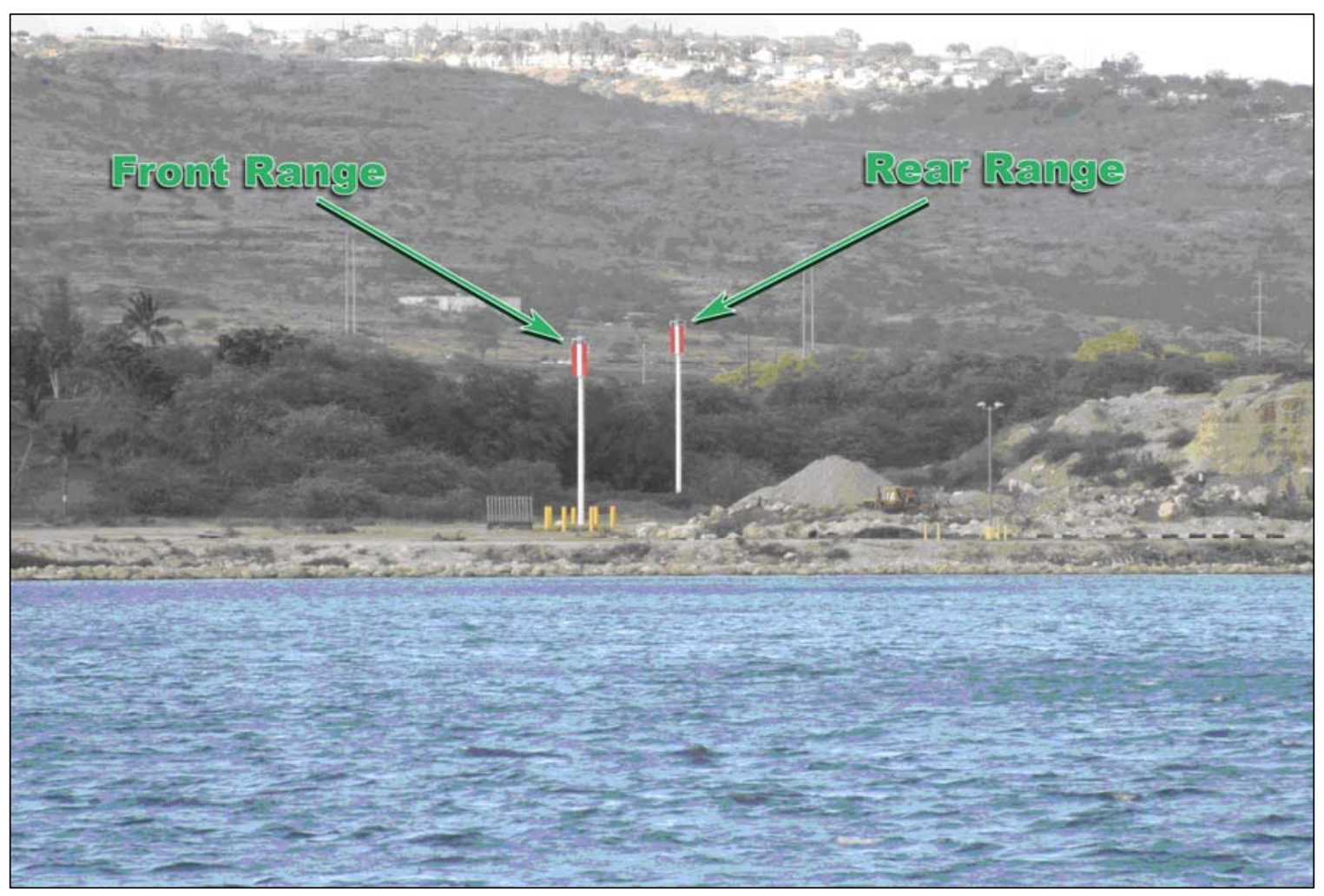

Figure 2. Kalaeloa Barbers Point Harbor existing navigational ranges.

\section{Project approach}

This navigation simulation project uses results of the "Physical and Numerical Model Studies of Barbers Point Harbor, Oahu, Hawaii"1 as well as input from the locally licensed pilots (Hawaii Pilots), the Honolulu District, and the Hawaii Department of Transportation - Harbor's Division (DOT-H). The actual testing schedule that was developed will be discussed in the Simulation Testing Program section; however, it should be noted that the District, DOT-H, and Hawaii Pilots were all involved in the coordinated design effort.

\footnotetext{
1 Michael J. Briggs, Linda S. Lillycrop, Gordon S. Harkins, Edward F. Thompson, and Debra R. Green. 1994. Physical and numerical model studies of Barbers Point Harbor, Oahu, Hawaii. TR CERC-94-14. Vicksburg, MS: U.S. Army Engineer Waterways Experiment Station.
} 


\section{Simulation Database Generation}

\section{Required data}

Data necessary for the creation of a navigation simulation study include the channel and harbor layout, bathymetry, and currents, for both the existing and the design conditions. There are several ways to obtain and/ or collect these data. The data used for each component of the simulation database will be discussed later in this report.

\section{Visual scene}

The visual scene is the most involved of the simulation study components and is typically carried out after a reconnaissance (recon) trip to the Project Site has been completed. During the recon trip, digital video and still photos are taken of the area to help in the design and construction of the existing visuals. In this particular project, nighttime photos were also taken to show the amount of light that normally comes from the lights at the harbor terminals. It is at this time that the pilot experiences are gleaned for any abnormalities in the area that might not be readily apparent from the navigational charts, photos, etc. Any landmarks that the pilots might use for navigation are also noted to be included in the visual scene. Figures 3 - 5 show examples of recon still photos taken during the May 2004 recon trip.

These photos were taken during the daytime. Since this project was designed for nighttime runs, photos were also taken at night to see how much the pilot would actually be able to see (Figures 6 and 7).

In addition to the recon photos and video, recent aerial photos of the project area were obtained if possible, along with navigation charts and design plan drawings for any changes to be made. With these items in place, the basic layout for the project was assembled in a threedimensional, computer-aided design package (Figure 8).

Included in the project layout was the Point of Origin -- the point at which coordinates for the simulator are measured from (in meters). For Kalaeloa Barbers Point Harbor, the point of origin was $21 \mathrm{deg} 19 \mathrm{~min}$ North by 158 deg 8 min West. 


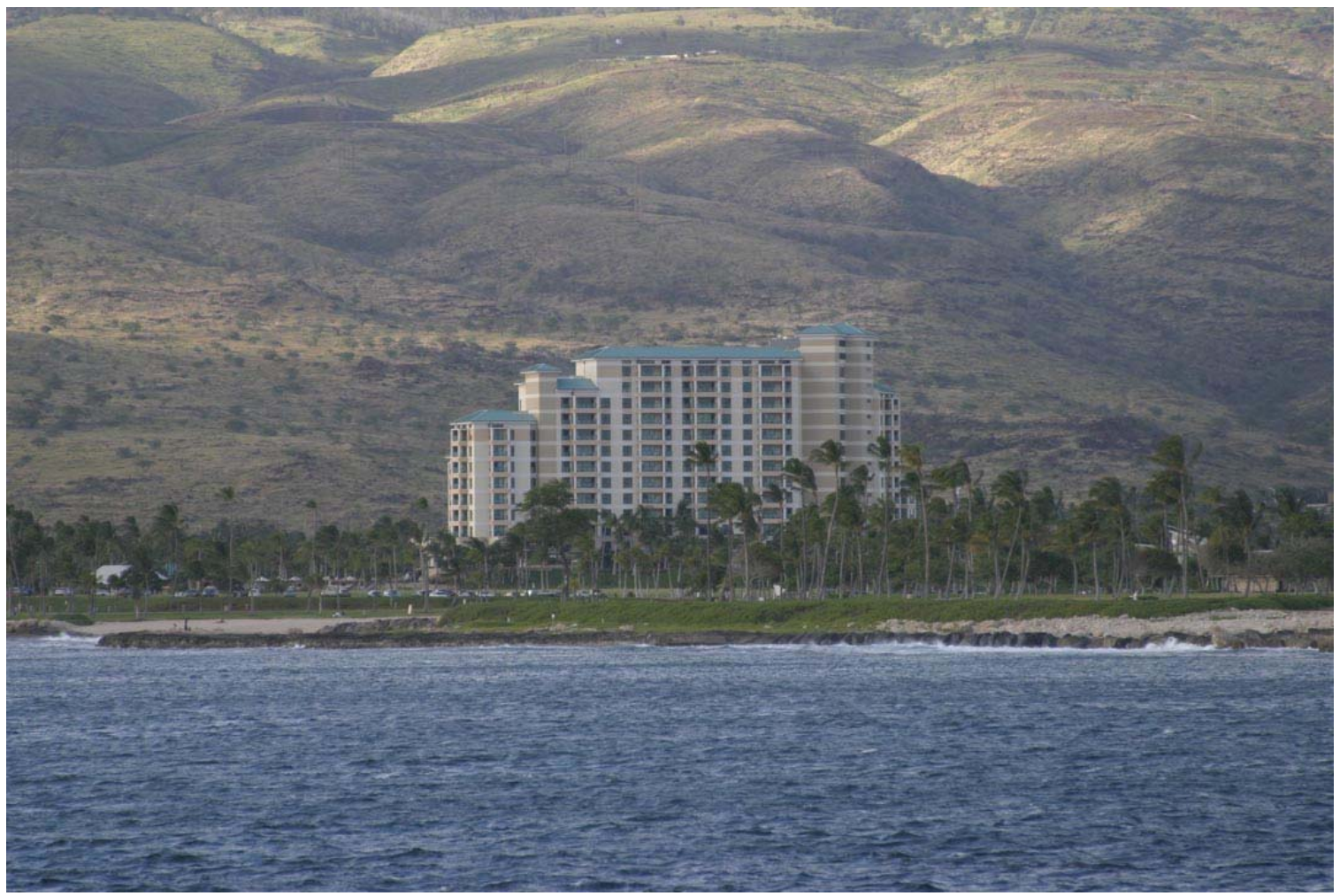

Figure 3. Recon photo for visual scene development.

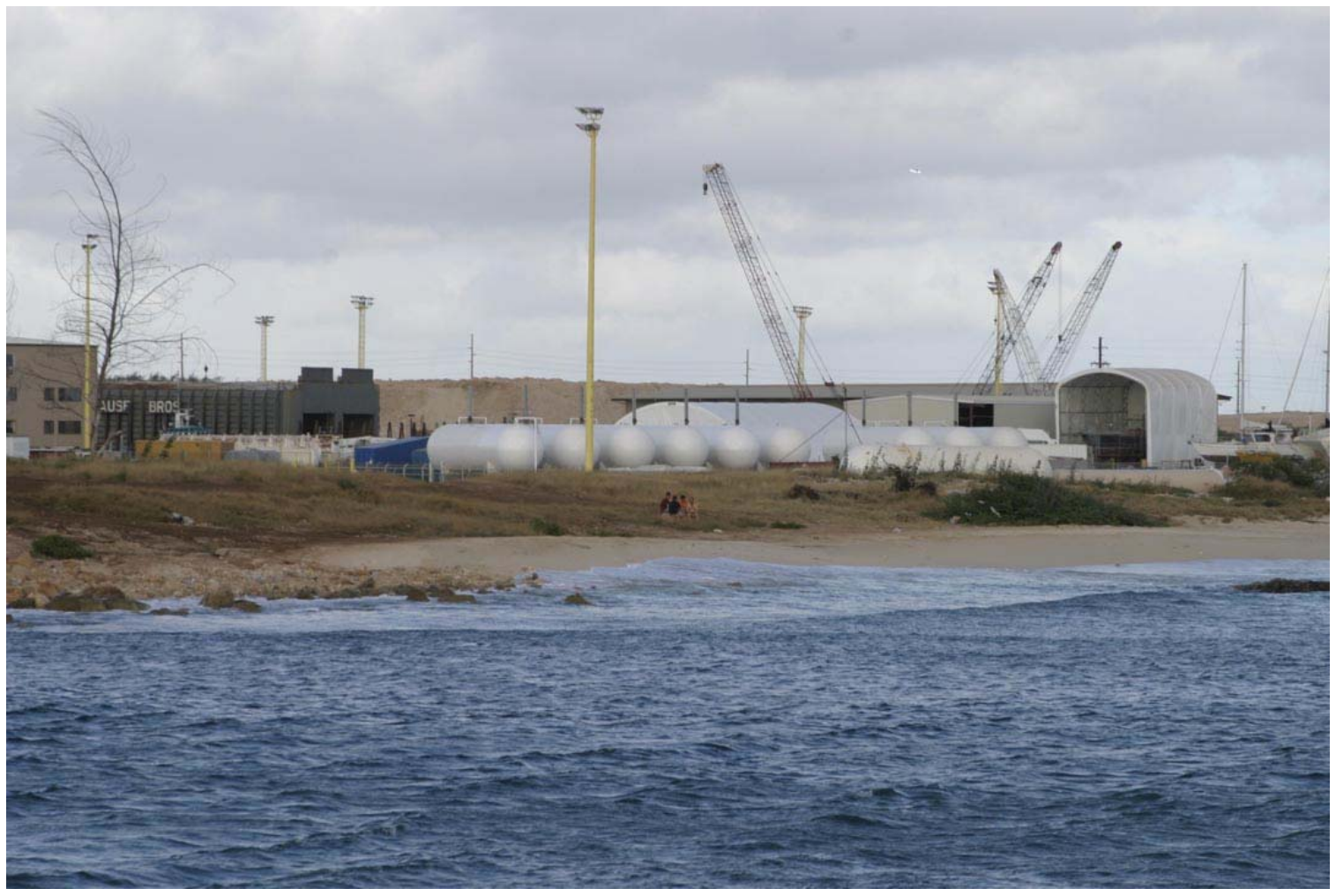

Figure 4. Recon photo of harbor area for scene development. 


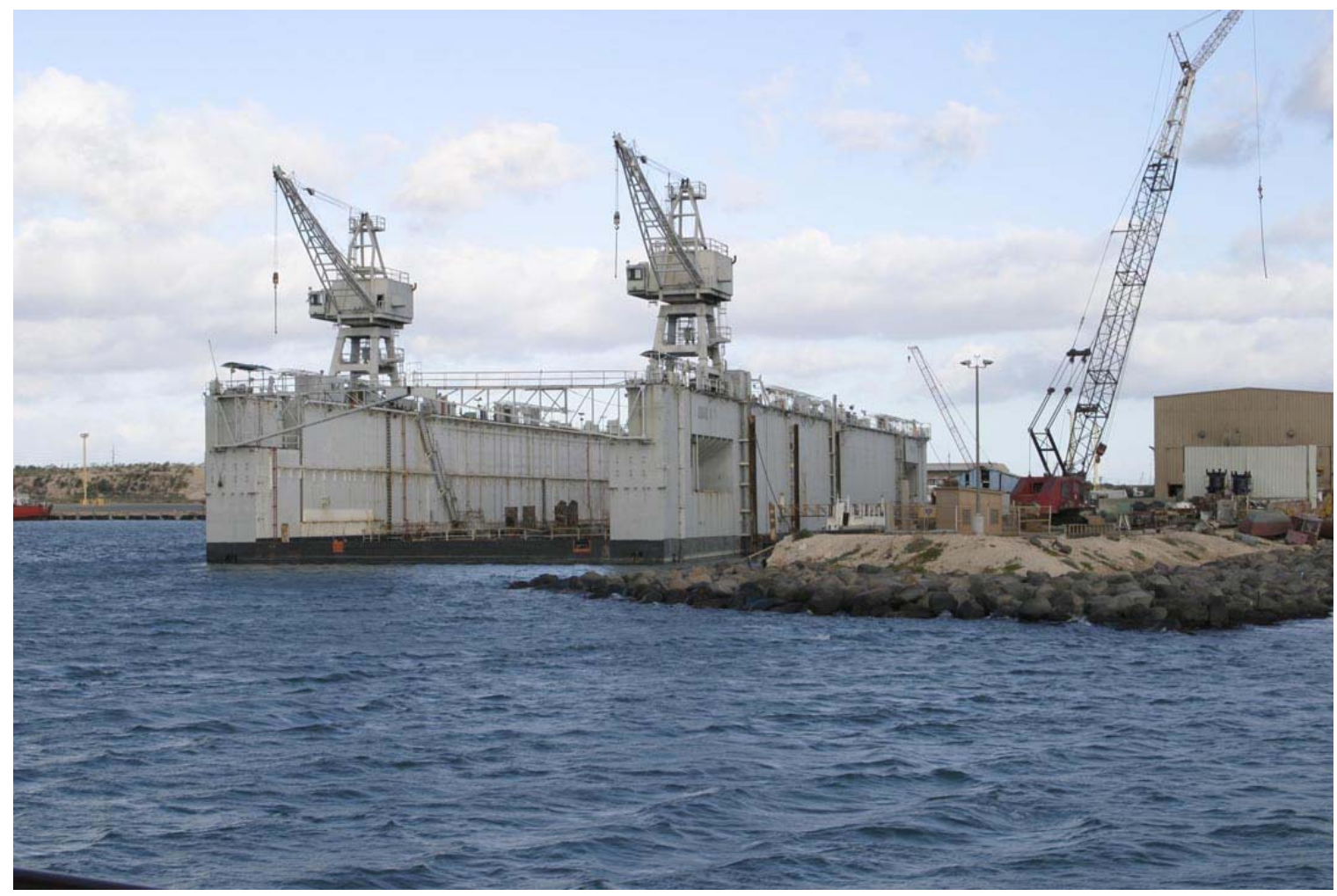

Figure 5. Recon photo of dry dock.

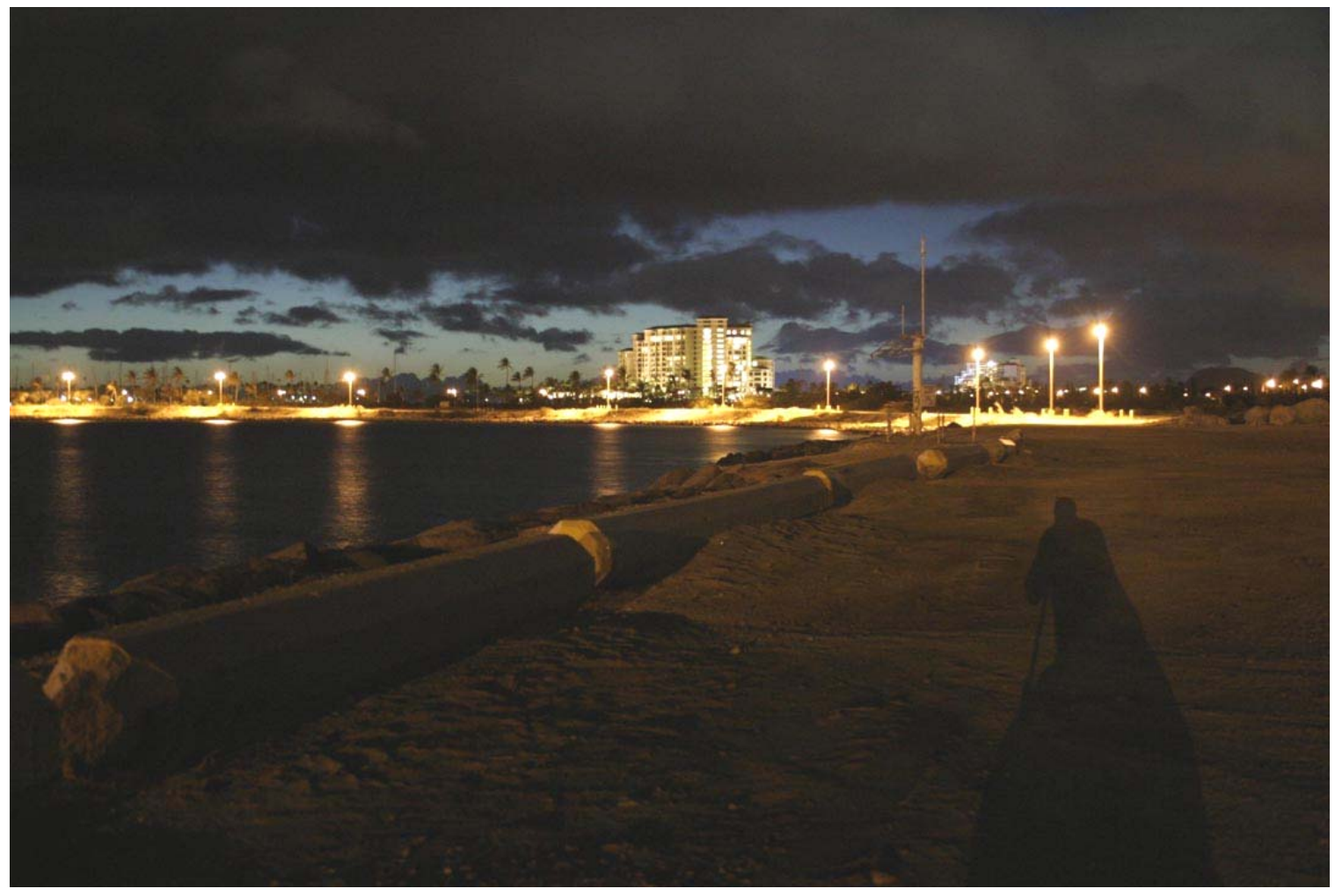

Figure 6. Nighttime recon photo from eastern side of harbor. 


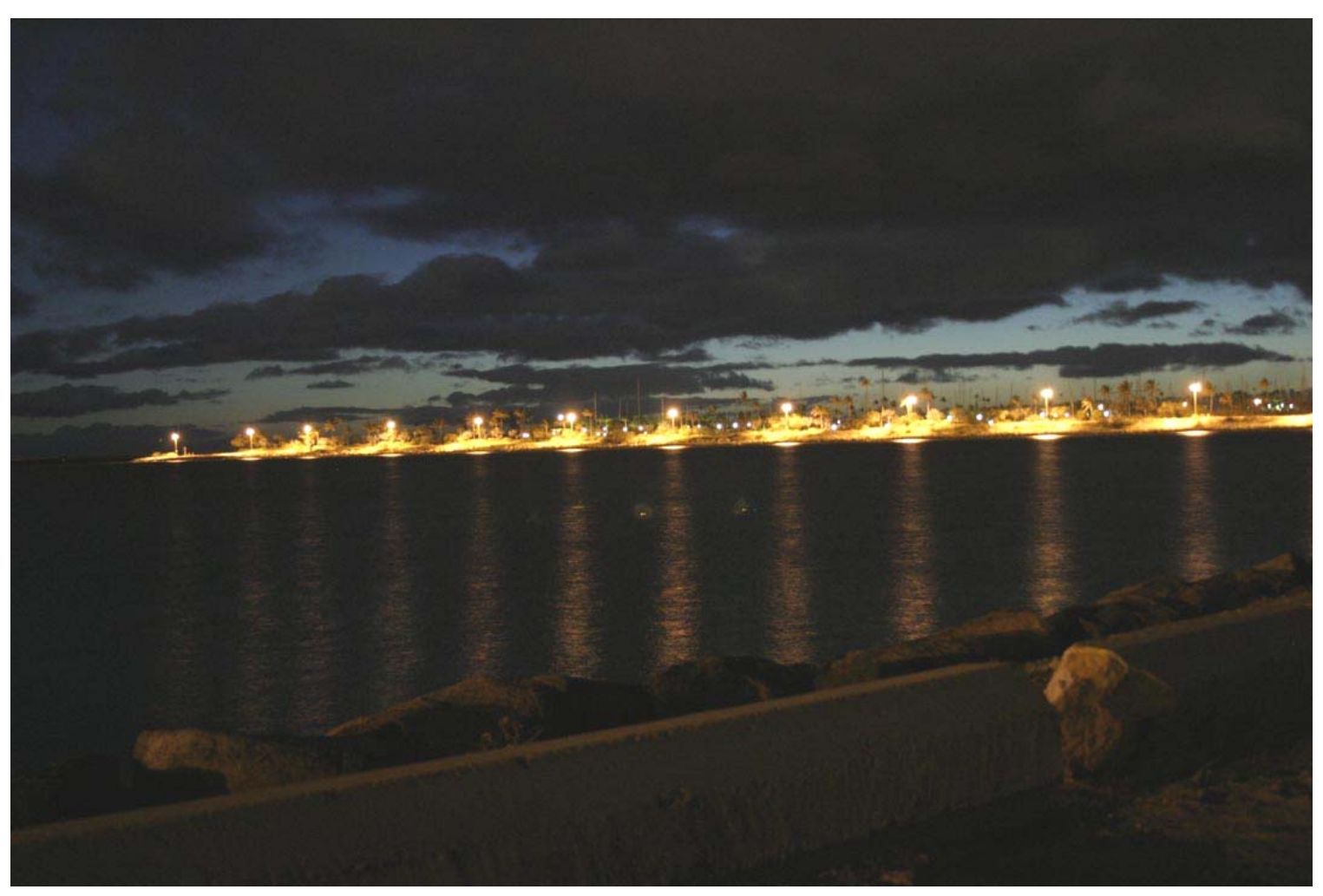

Figure 7. Nighttime recon photo of northern jetty inside of harbor area with existing lights.

Once the layout of the project is decided, the terrain is constructed from elevation data. Objects are then built and added to the visual scene using the program CREATOR from MultiGen-Paradigm. Objects include buildings, trees, navaids, and bridges in the project area. These objects are included based upon their importance to navigation and their contribution to the overall atmosphere of the simulation program. This program creates objects in the OpenFlight or "flt" format. Objects are colored and/ or textured before adding them to the finished visual scene. An example of the finished visual scene is shown in Figure 9.

One concern during testing was the fact that pilots do not currently bring vessels in at night. This fact led to speculation as to how accurate the nighttime visual would be compared with what the pilot would see from a ship during nighttime transits. Fortunately, these concerns were resolved prior to the end of the testing. A vessel approached Kalaeloa Barbers Point Harbor in February 2005, but before the pilot could board the vessel, it grounded to the southern side of the channel. Once grounded, the ship was required to have a pilot onboard $24 \mathrm{hr}$ a day until it could be salvaged. 


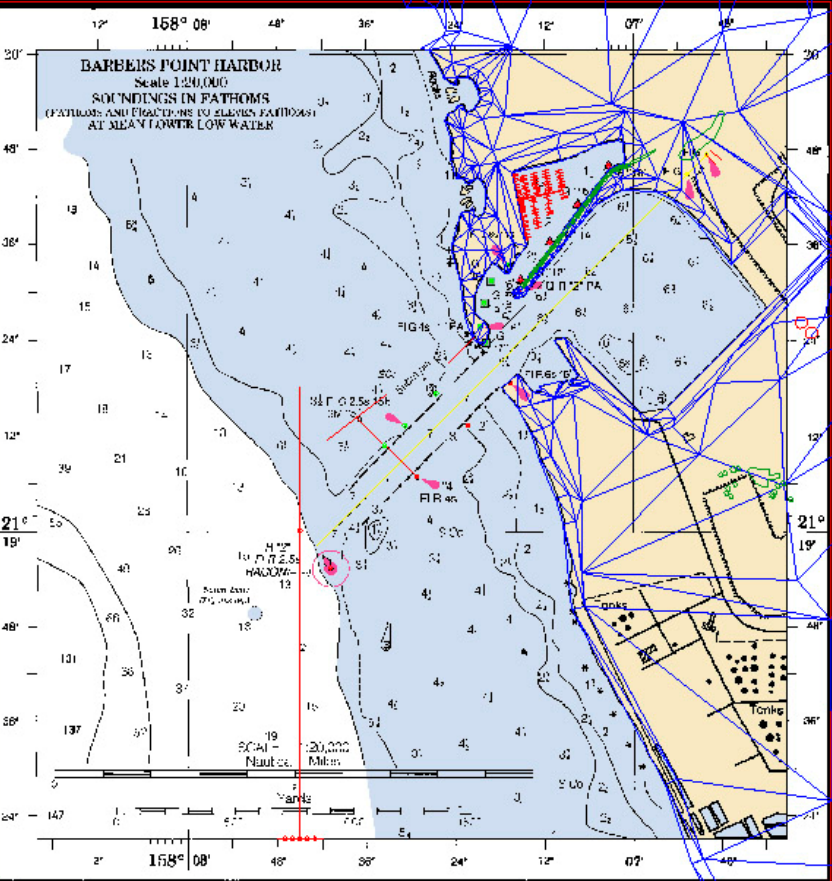

Figure 8. Project layout for Kalaeloa Barbers Point Harbor.

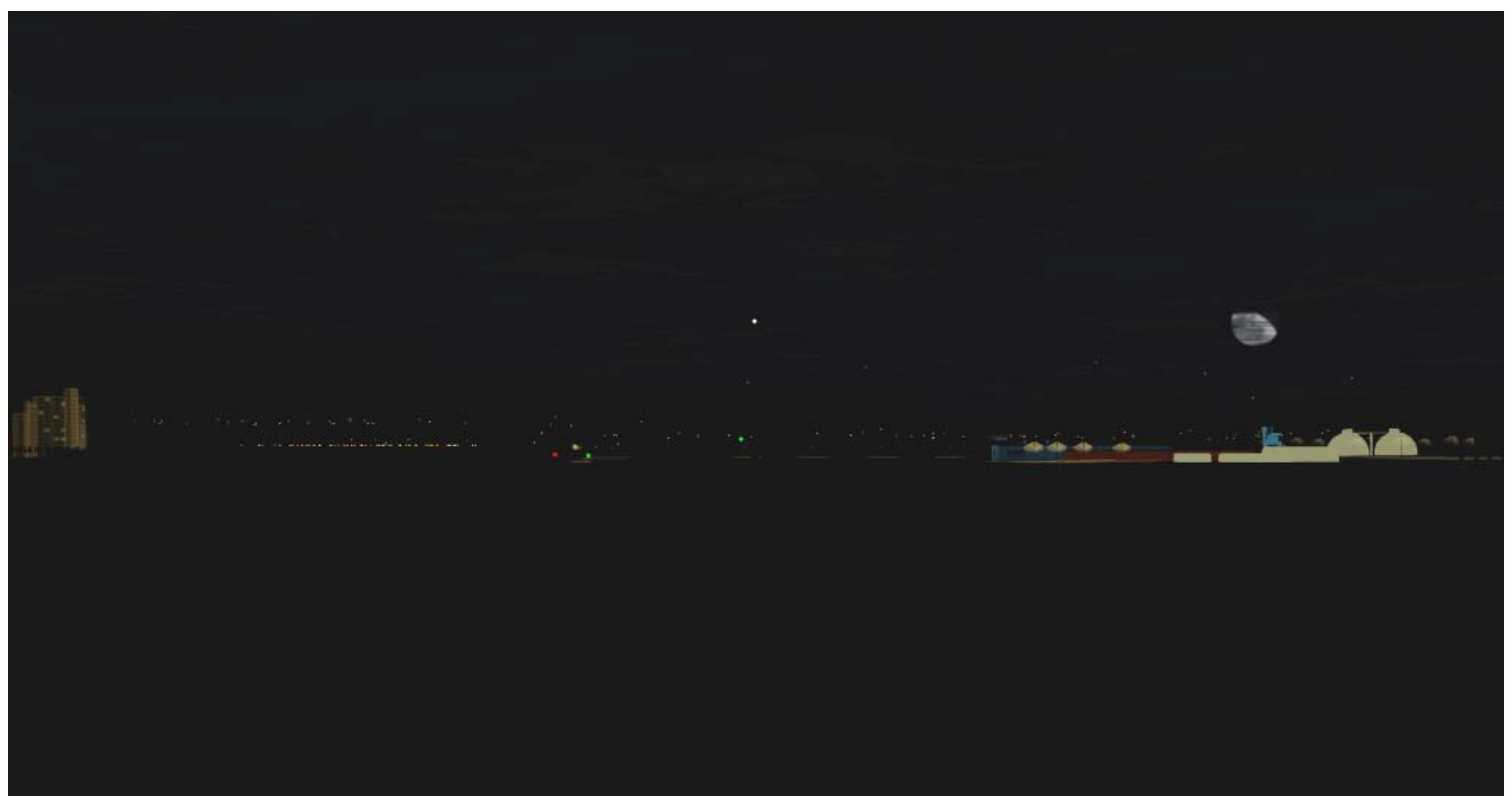

Figure 9. Nighttime visual scene for Kalaeloa Barbers Point Harbor. 
The last set of pilots to test in the U.S. Army Engineer Research and Development Center's (ERDC's) Ship/ Tow Simulator had been onboard the grounded vessel several times at night and agreed that the simulator did provide a reasonably accurate representation of the nighttime visual scene.

\section{Electronic chart display}

The electronic chart display (ECDIS) used for this project was obtained from the C-Map database used in the simulator. This image is adjustable in its scale and the degree of detail shown. It is typical of an ECDIS that many ships are beginning to carry on the bridge. An example screen is shown in Figure 10.

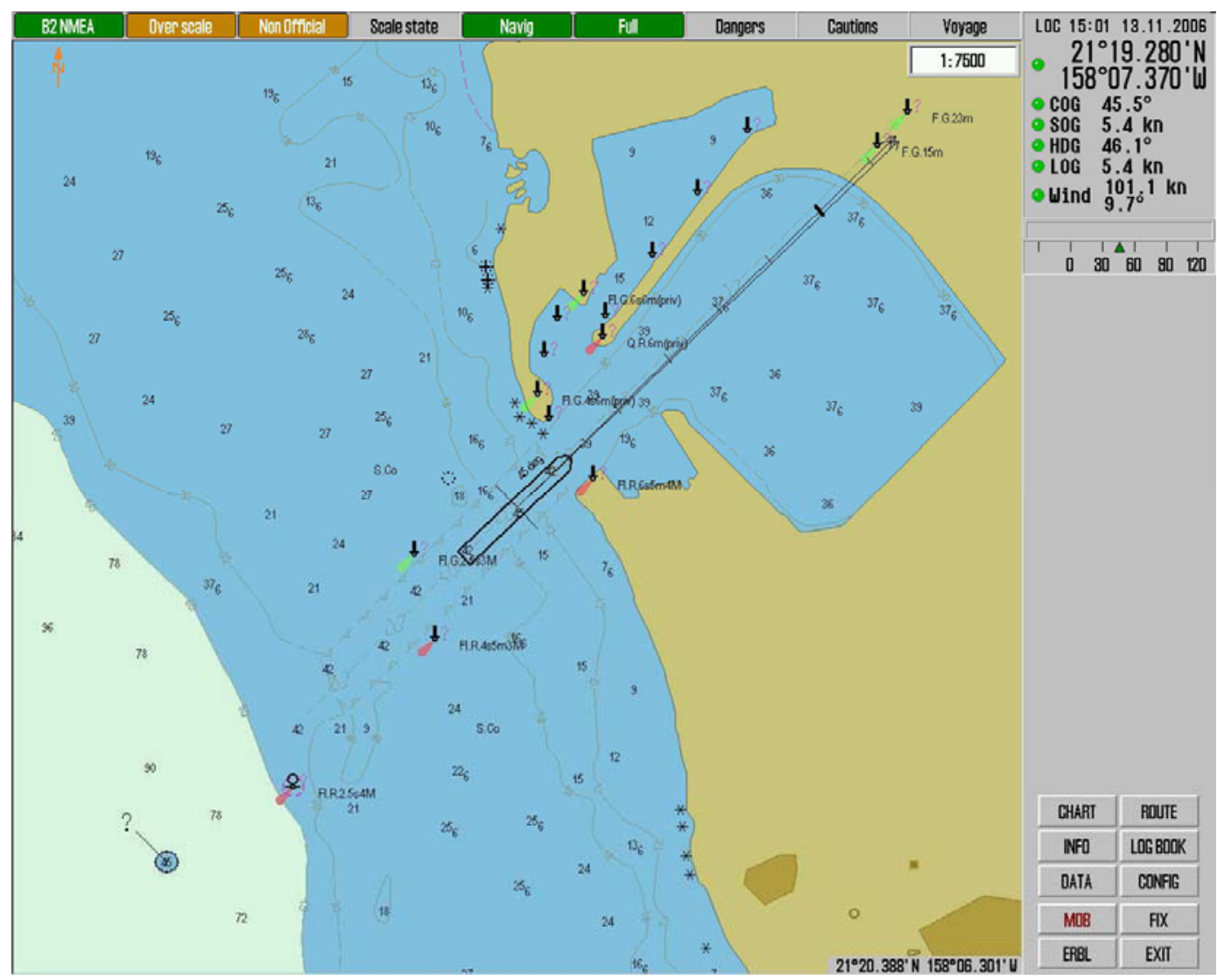

Figure 10. Example of ECDIS display.

\section{Radar display}

The radar display database is created directly from the visual scene base drawing and is displayed as a typical radar image (Figure 11). 


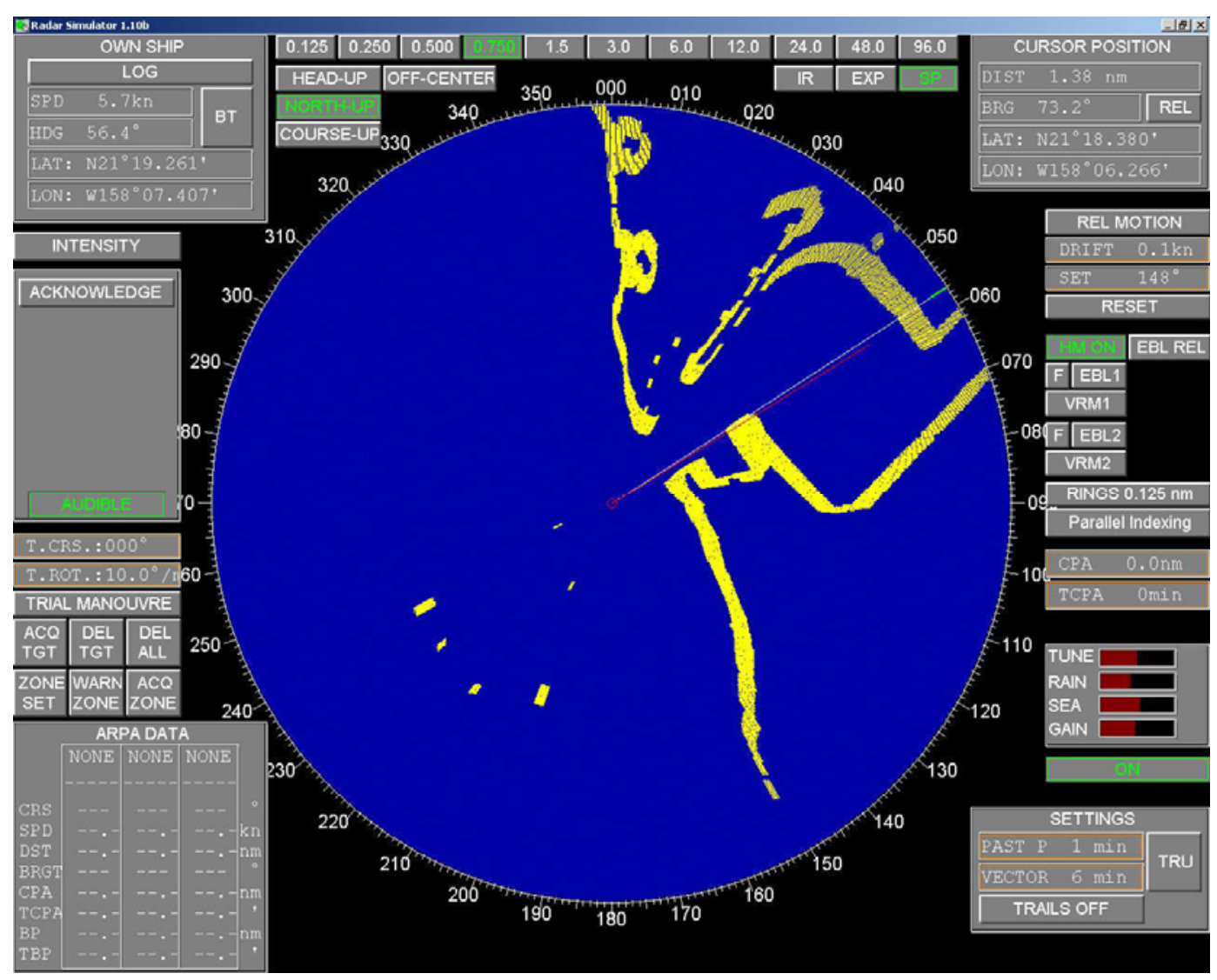

Figure 11. Example radar image display.

\section{Environmental conditions}

Environmental conditions include currents in the transit zone, wind forces, and wave forces. Currents were taken from Briggs et al. (1994) along with observations from the pilots. Wind and wave conditions were derived from talks with the pilots and District personnel. The initial sets of currents are shown in Figures 12 - 19. These figures show the direction and magnitude for "regions" of currents bounded by the double arrows. Currents between these regions are interpolated between the end of one region and the beginning of the next.

For most of these conditions, the currents increase approaching the sea buoy. These are currents driven by ocean currents. Once beyond the first set of buoys, currents are mostly wind-driven. 


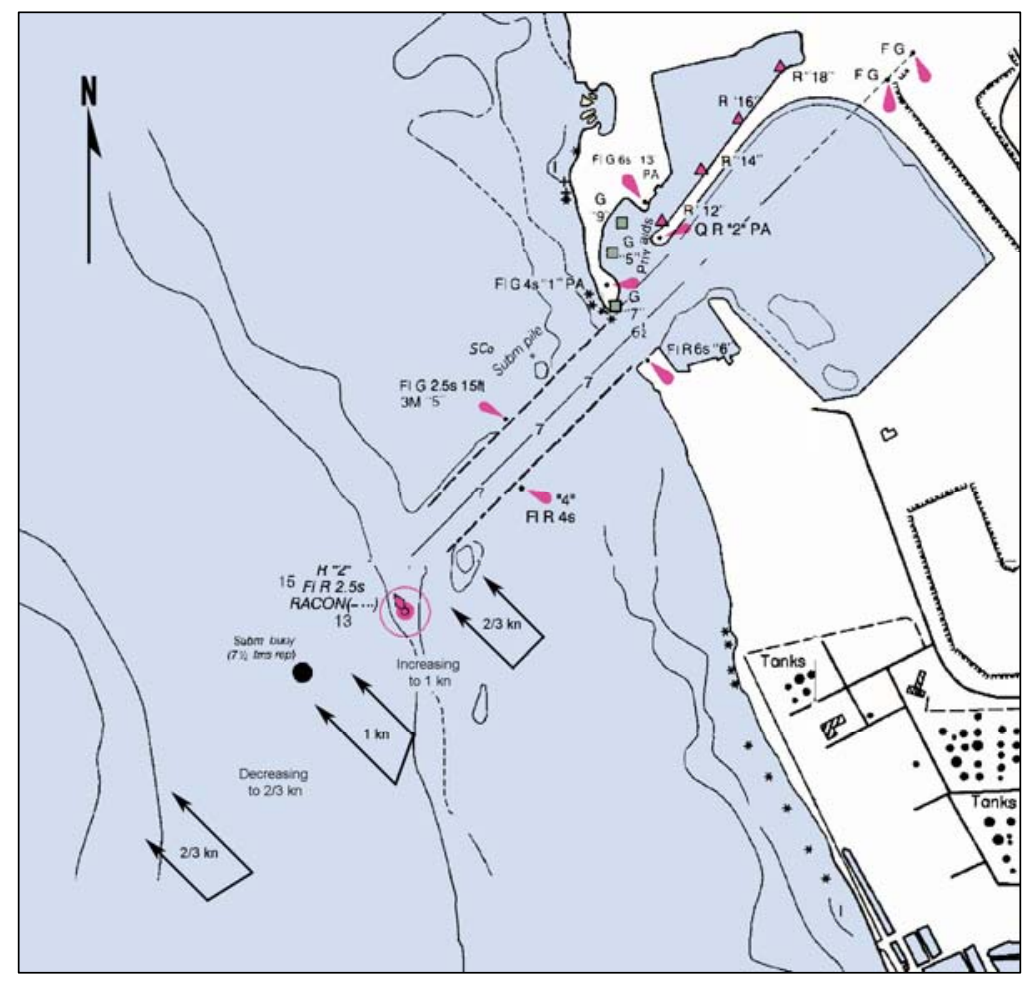

Figure 12. Condition 1 currents.

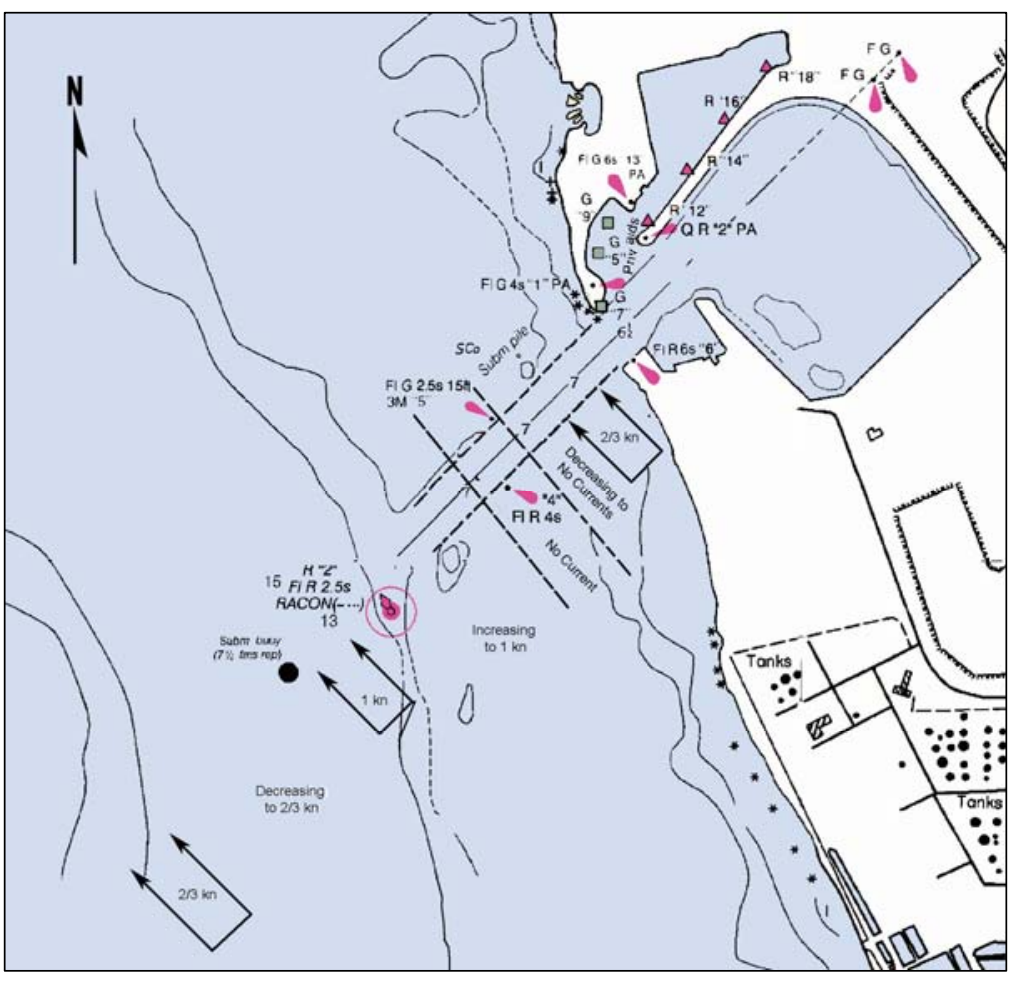

Figure 13. Condition 2 currents. 


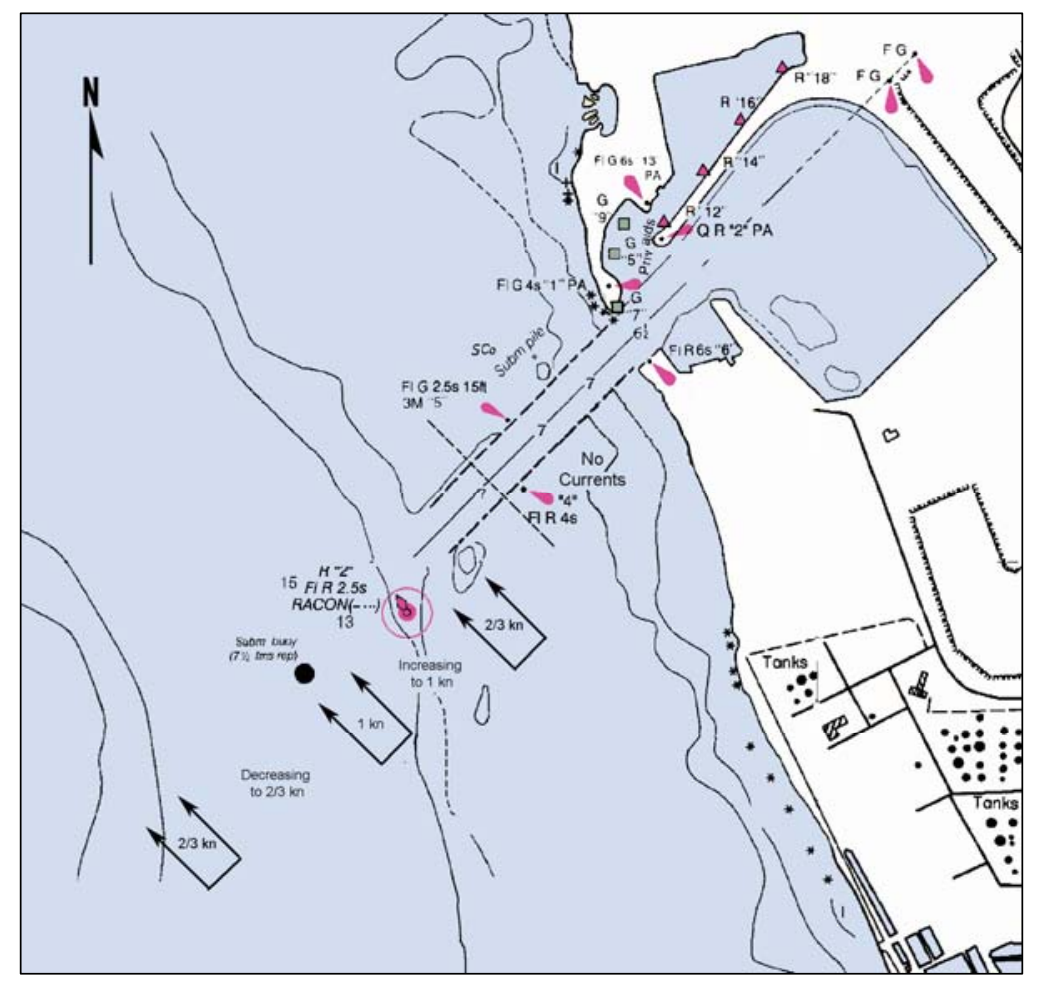

Figure 14. Condition 3 currents.

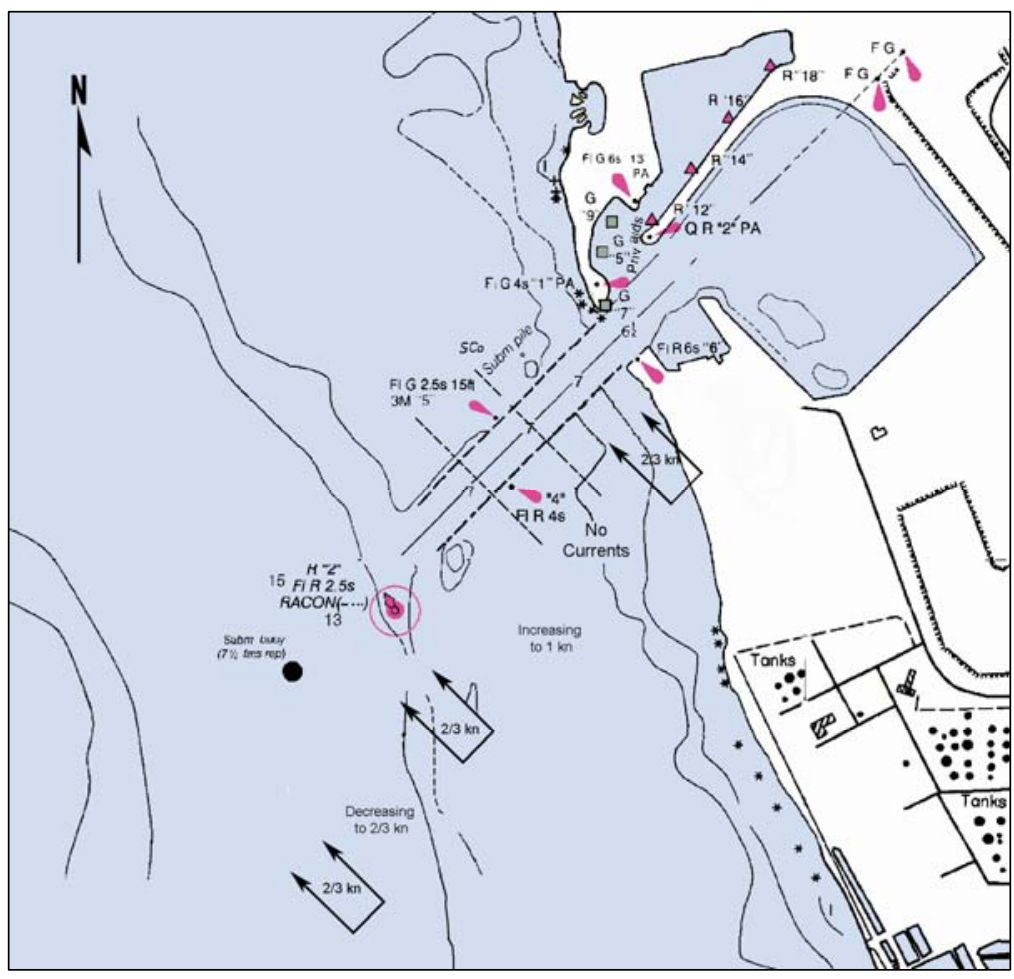

Figure 15. Condition 4 currents. 


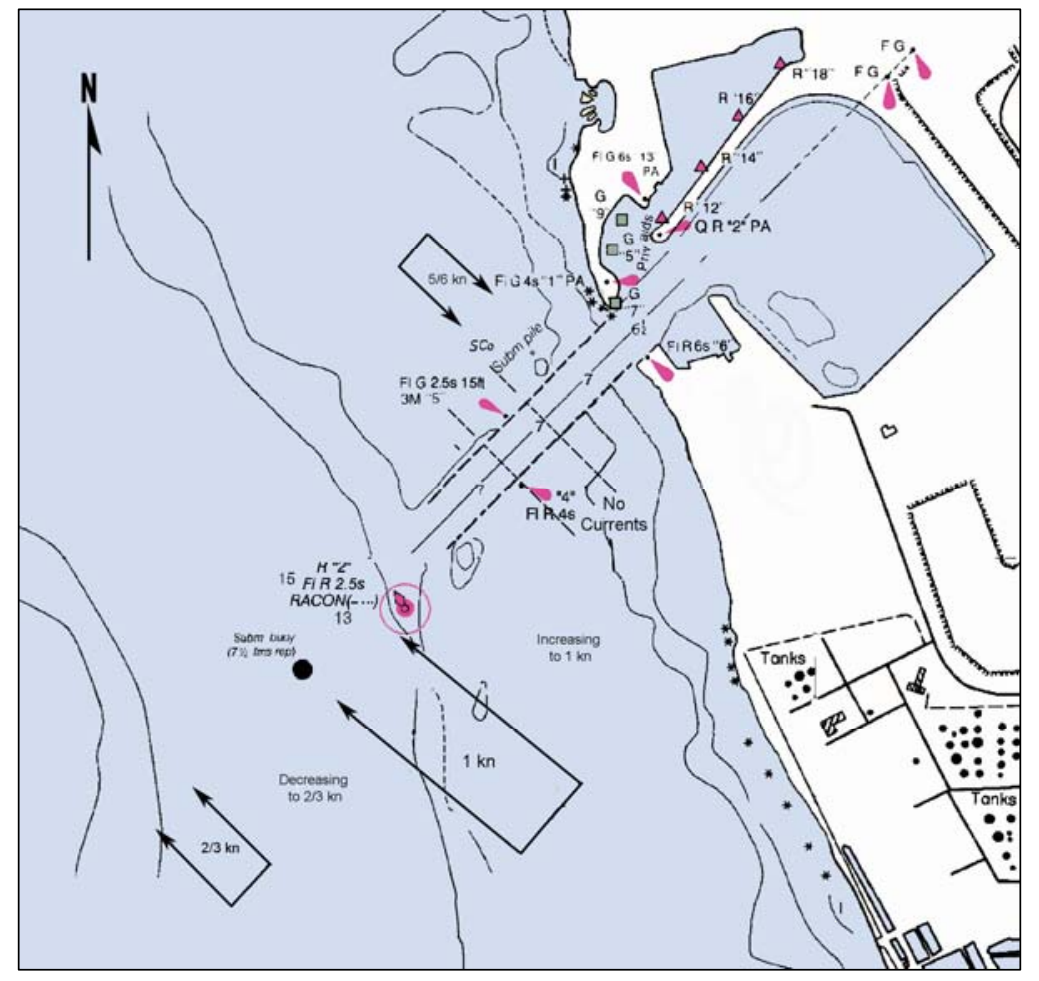

Figure 16. Condition 5 currents.

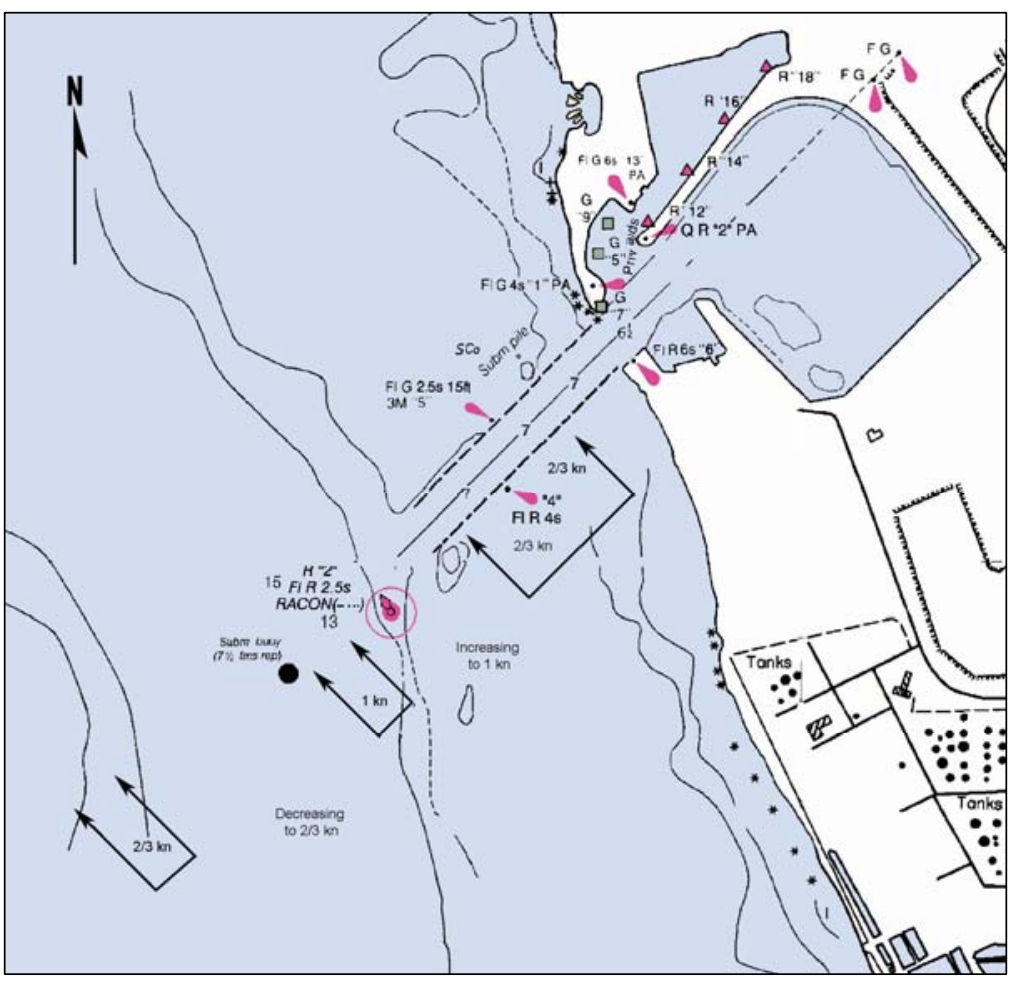

Figure 17. Condition 6 currents. 


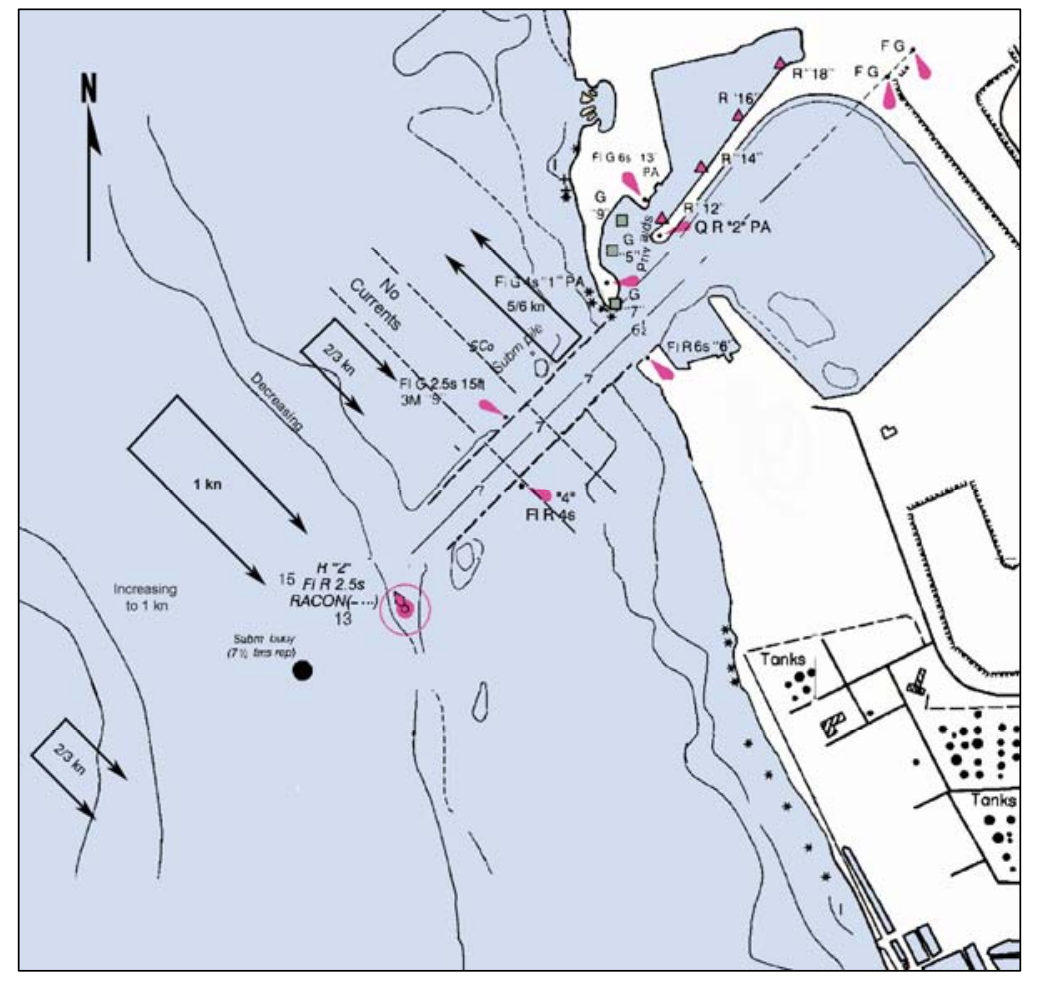

Figure 18. Condition 7 currents.

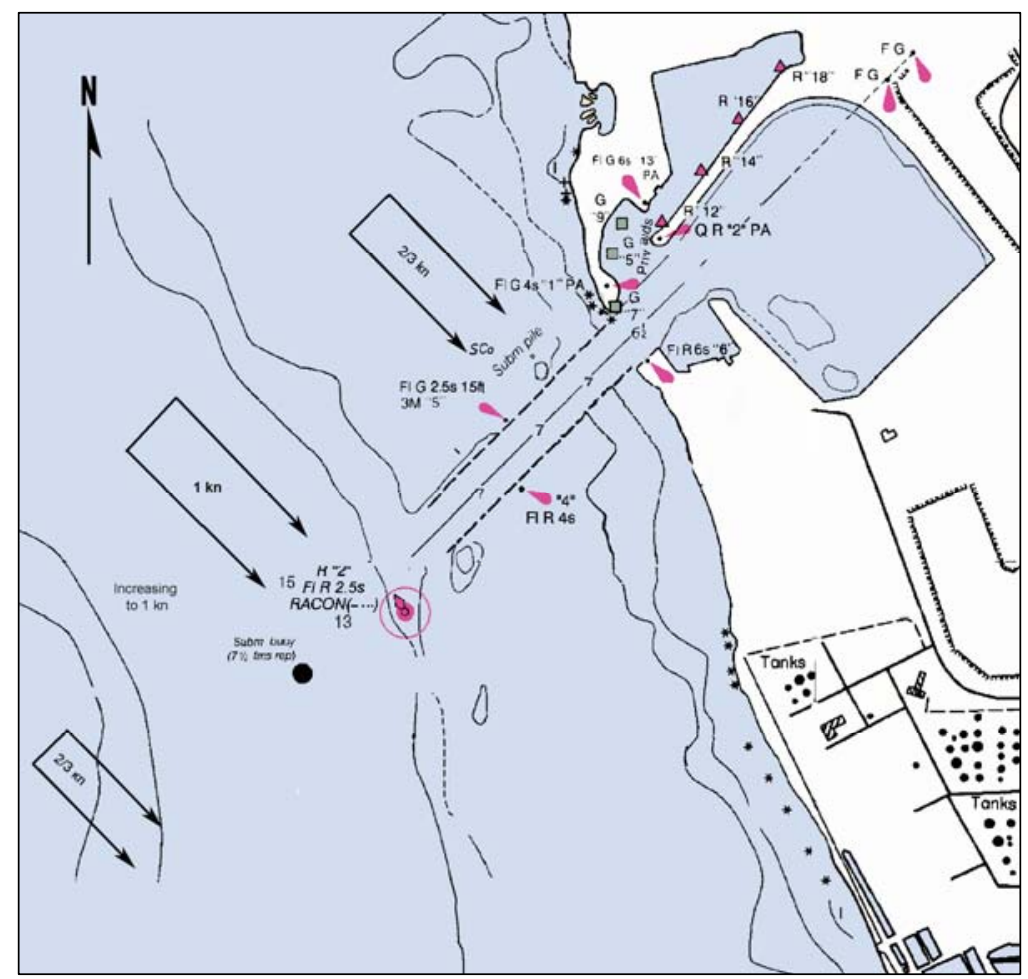

Figure 19. Condition 8 currents. 
Once the amount of time per run was determined during validation, an effort to reduce the number of current conditions was made. Care was taken to address as many concerns as possible with the current conditions that remained, with all critical concerns being addresses. Since this reduction was accomplished with only one pilot present, the next set of pilots were also consulted, and the final conditions were agreed upon. These conditions were narrowed down to the ones shown in Figure 20.

For the purposes of this report, and to avoid confusion, the currents were renamed to sequential order, i.e., Condition 1 to Condition 1, Condition 5 to Condition 2, and Condition 8 to Condition 3.

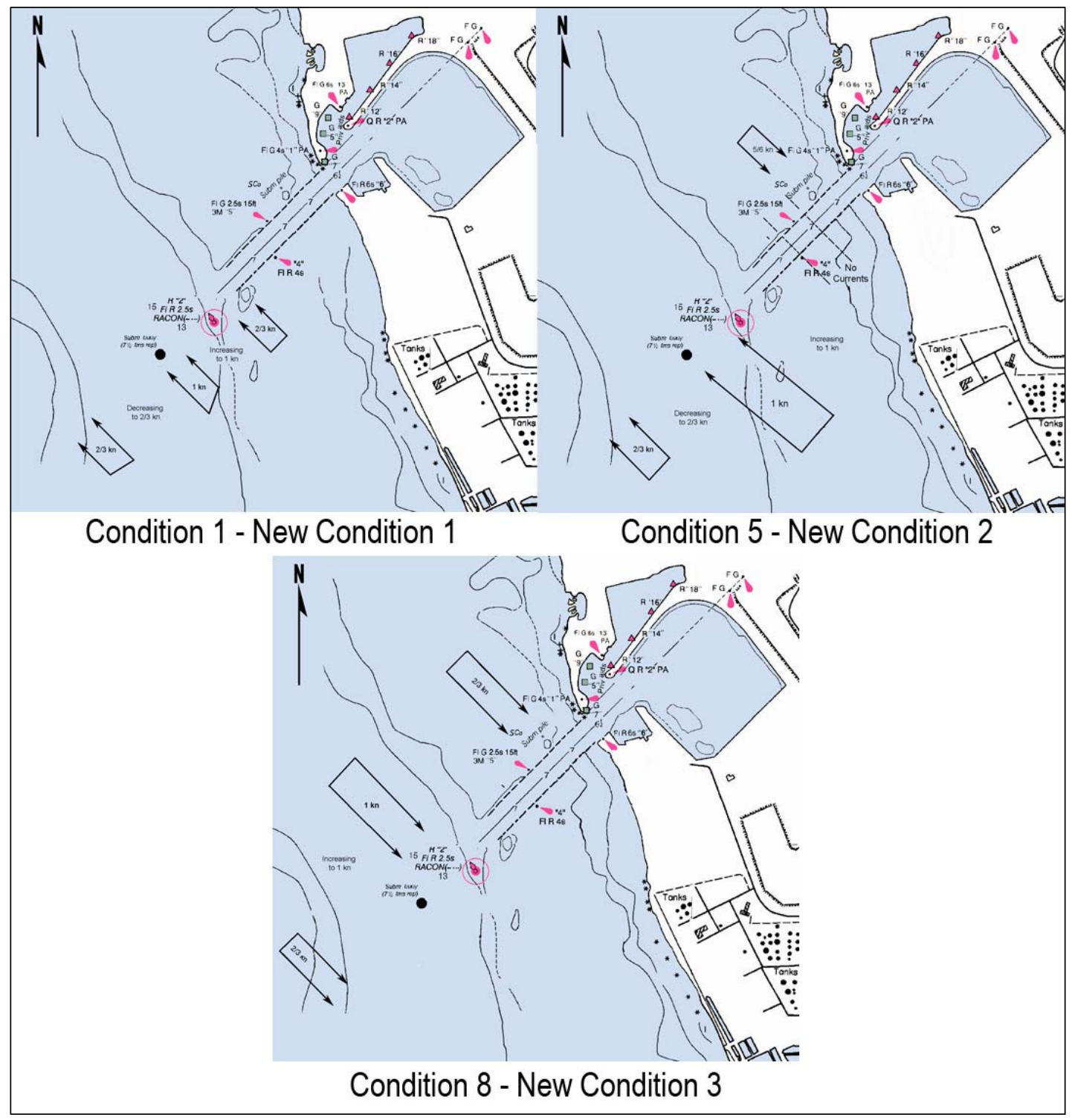

Figure 20. Final current conditions used in testing. 
For each of the currents used, possible wave and wind conditions were also analyzed by the pilots, District, DOT-H, and ERDC Coastal and Hydraulics Laboratory (CHL) personnel. The possible conditions for testing during the week of validation are shown in Table 1.

Table 1. Validation testing conditions.

\begin{tabular}{|l|l|l|l|l|}
\hline Component & Type & Direction & Speed/Height & Identified on Plates As \\
\hline Wind & Trade wind & $62 \mathrm{deg}$ & $20 \mathrm{knots}$ & stated \\
\hline Wind & SE wind & $125 \mathrm{deg}$ & $20 \mathrm{knots}$ & stated \\
\hline Wind & SW wind & $225 \mathrm{deg}$ & $20 \mathrm{knots}$ & stated \\
\hline Wind & N wind & $0 \mathrm{deg}$ & $20 \mathrm{knots}$ & stated \\
\hline Wind & Calm & NA & NA & stated \\
\hline Wave & NW swell & $315 \mathrm{deg}$ & $5 \mathrm{ft}$ & Condition A \\
\hline Wave & SW wind waves & $225 \mathrm{deg}$ & $3 \mathrm{ft}$ & Condition B \\
\hline Wave & SE wind waves & $135 \mathrm{deg}$ & $3 \mathrm{ft}$ & Condition C \\
\hline Wave & S swell & $180 \mathrm{deg}$ & $5 \mathrm{ft}$ & Condition D \\
\hline Wave & Calm & NA & NA & Condition E \\
\hline
\end{tabular}

The wind component in the simulator has some variability in strength and direction to approximate natural conditions. It can be set to straight line winds; however, this was not the case for these tests. The wave component remained constant up until the point of entry into the sheltered harbor. On outbound runs the waves began to take effect as the vessel was leaving the harbor. When performing a navigation simulation study, the conditions tested should be environmental conditions during which navigation would still take place, but that test the limits of the design.

During validation it was decided that in Current Condition 2, the 5- to 6-knot current by the harbors entrance did not accurately reflect a realistic extreme. After discussions with the District and the pilots, the current in that section was reduced to $0.5 \mathrm{knot}$. 
3 ERDC Ship/Tow Simulator

A floor plan of the Ship/ Tow Simulator is shown in Figure 21.

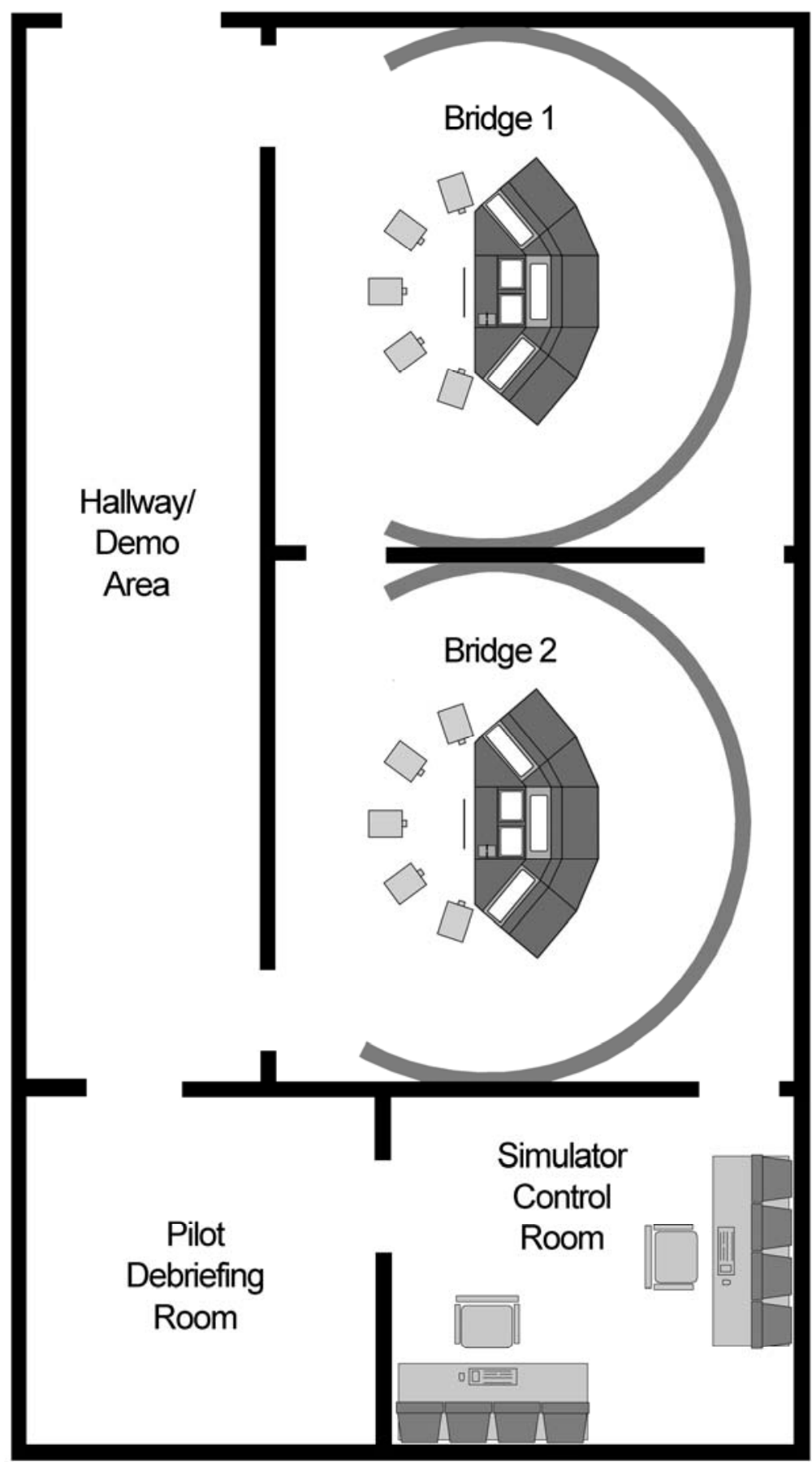

Figure 21. ERDC Ship/Tow Simulator layout. 
The simulator is comprised of two bridge modules (Bridge 1 and Bridge 2), a viewing area, a pilot debriefing room, and a simulator operator station (SOS) located in the simulator control room. The bridge module is shown in Figure 22.

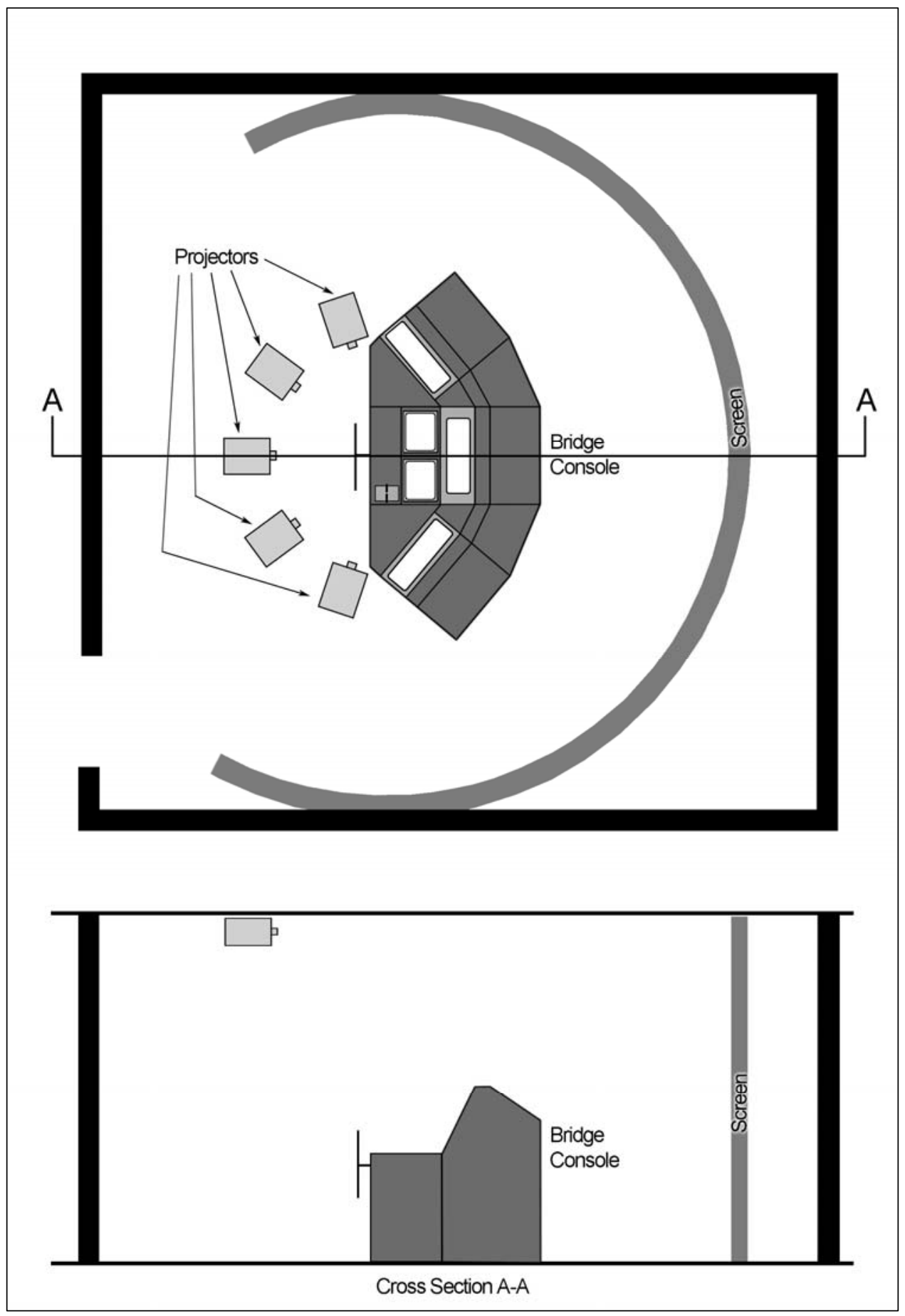

Figure 22. Arrangement of ERDC Ship/Tow Simulator bridge module. 
The Ship/ Tow Simulator is a "real time" simulator, i.e., ship movements on the simulator require the same amount of time as in real life. Environmental forces such as currents, wind, banks, shallow water, ship-ship interactions, and waves all act upon the vessel during a transit. The pilot controls the simulated vessel's engine speed and rudder and then sees the effects of his changes depicted on the visual screen and console screens. At regular time intervals, defined by the operator, the vessel's heading, speed, navigational parameters, etc., are written to an output file and saved for analysis. The time duration of the interval spacing is only limited by the speed of the simulator computer's processor.

Bridges 1 and 2 can be coupled together for two-way, fully interactive traffic. In that case, the two vessels being used would be visible on the visual scene screen of the other ship, and the hull forces of the opposing ship would affect the handling characteristics of the vessel. In addition to the two-way interactive traffic, the simulator can also be run with "lo-resolution" traffic ships. These ships affect the vessel being piloted, while their handling remains unchanged. This type of traffic ship is controlled from the SOS.

The simulator was used in "stand alone" mode for this study. In this mode, both simulator bridges run independent of each other, with no interaction. If two pilots are participating and "one-way" transits are all that is required, then twice as many runs can be performed during the testing cycle as both simulators are utilized for different tests. 


\section{Testing Matrix}

The matrix in Table 2 was used in the simulation tests for Kalaeloa Barbers Point Harbor.

Table 2. Testing matrix.

\begin{tabular}{|c|c|c|c|c|c|}
\hline Run & $\begin{array}{l}\text { Modified } \\
\text { Navaids }\end{array}$ & $\begin{array}{l}\text { Current } \\
\text { Condition }\end{array}$ & Ship & Wind Type & $\begin{array}{l}\text { Wave Direction/ } \\
\text { (SL)-swell, (WW)-wind waves }\end{array}$ \\
\hline 1 & No & 1 & El Garo & Trade wind & SE/WW \\
\hline 2 & No & 1 & El Garo & Trade wind & $\mathrm{S} / \mathrm{SL}$ \\
\hline 3 & No & 1 & El Garo & SE wind & SE/WW \\
\hline 4 & No & 2 & El Garo & Trade wind & NW/SL \\
\hline 5 & No & 2 & El Garo & SW wind & SW/WW \\
\hline 6 & No & 2 & El Garo & SW wind & NW/SL \\
\hline 7 & No & 3 & El Garo & Calm & NW/SL \\
\hline 8 & No & 3 & El Garo & Calm & Calm \\
\hline 9 & No & 3 & El Garo & $\mathrm{N}$ wind & NW/SL \\
\hline 10 & No & 2 -outbound & New Amity in ballast & SW wind & NW/SL at Moles \\
\hline 11 & No & 1 & Hayden & Trade wind & SE/WW \\
\hline 12 & No & 1 & Hayden & Trade wind & $\mathrm{S} / \mathrm{SL}$ \\
\hline 13 & No & 1 & Hayden & SE wind & SE/WW \\
\hline 14 & No & 2 & Hayden & Trade wind & NW/SL \\
\hline 15 & No & 2 & Hayden & SW wind & SW/WW \\
\hline 16 & No & 2 & Hayden & SW wind & NW/SL \\
\hline 17 & No & 3 & Hayden & Calm & NW/SL \\
\hline 18 & No & 3 & Hayden & Calm & Calm \\
\hline 19 & Yes & 1 & El Garo & Trade wind & SE/WW \\
\hline 20 & Yes & 1 & El Garo & Trade wind & $S / S L$ \\
\hline 21 & Yes & 1 & El Garo & SE wind & SE/WW \\
\hline 22 & Yes & 2 & El Garo & Trade wind & NW/SL \\
\hline 23 & Yes & 2 & El Garo & SW wind & SW/WW \\
\hline 24 & Yes & 2 & El Garo & SW wind & NW/SL \\
\hline 25 & Yes & 3 & El Garo & Calm & NW/SL \\
\hline 26 & Yes & 3 & El Garo & Calm & Calm \\
\hline
\end{tabular}




\begin{tabular}{|l|l|l|l|l|l|}
\hline Run & $\begin{array}{l}\text { Modified } \\
\text { Navaids }\end{array}$ & $\begin{array}{l}\text { Current } \\
\text { Condition }\end{array}$ & Ship & Wind Type & $\begin{array}{l}\text { Wave Direction/ } \\
\text { (SL)-swell, (WW)-wind waves }\end{array}$ \\
\hline 27 & Yes & 3 & El Garo & N wind & NW/SL \\
\hline 28 & Yes & 2 -outbound & New Amity in ballast & SW wind & NW/SL at Moles \\
\hline 29 & Yes & 1 & Hayden & Trade wind & SE/WW \\
\hline 30 & Yes & 1 & Hayden & Trade wind & S/SL \\
\hline 31 & Yes & 1 & Hayden & SE wind & SE/WW \\
\hline 32 & Yes & 2 & Hayden & Trade wind & NW/SL \\
\hline 33 & Yes & 2 & Hayden & SW wind & SW/WW \\
\hline 34 & Yes & 2 & Hayden & SW wind & NW/SL \\
\hline 35 & Yes & 3 & Hayden & Calm & NW/SL \\
\hline 36 & Yes & 3 & Hayden & Calm & Calm \\
\hline 37 & Yes & 3 & Hayden & N wind & NW/SL \\
\hline
\end{tabular}

These runs were all carried out with the existing depths in the navigation channel and harbor, as well as the design lighting on the northern shoreline. Tests with more complex conditions were added to the testing schedule later and are not listed on this matrix; those cases will be discussed in the "Results and Conclusions" section of this report.

The ship characteristics used in this study are shown in Table 3.

Table 3. Ship characteristics.

\begin{tabular}{|l|l|l|l|l|}
\hline Ship Name & Ship Type & Length Overall, ft & Beam, ft & Draft, ft \\
\hline El Garo & Bulk carrier & 740 & 106 & 36 \\
\hline Hayden & Tanker & 583 & 86 & 36 \\
\hline New Amity & Tanker & 810 & 138 & 23 \\
\hline
\end{tabular}




\section{Results and Conclusions}

Results of the navigation study are presented in several forms: trackplots, pilot comments, and pilot ratings. Trackplots show icons for the vessel that convey position and heading at regular time intervals during a test. For the purposes of this study, the time interval used was $30 \mathrm{sec}$ between icons. This interval puts each icon fairly close to the next and gives a good visual representation of the "swept path" that the vessel goes through during maneuvering in the channel and harbor. "Composite" for this report indicates that the runs for all of the pilots testing a particular set of conditions were placed upon a single plate (see Plates 1- 81). This composite gives the reader a general feel for the overall effect that an alternative has on the navigational approach that the pilots use on the channel. Pilot comments pertinent to the viability of the design are inset on each plate. If there were no comments made for a particular run, then the inset box will simply state "No Comments." Because of the complexity of the conditions studied for this project, there are 81 plates of the composite runs; therefore, the plates will be listed separately, and only the effects upon navigation will be discussed in the main body of the report.

The lack of comments for a particular run should not automatically imply that it was good or bad. Pilot ratings rank on a 1 to 10 scale with 1 being the easiest and 10 being the hardest. The ratings for the difficulty of the run will typically be given as an average of all pilot ratings for that test and will be included in the comment inset box. Any rating deviating significantly from the average (at least three increments) will be listed with that pilot's comments from the run to give an idea of what was occurring during the test. These ratings are intended to give the pilot a way to judge the overall feel of the run, even though the trackplot may not be ideal due to unfamiliarity with the design. With the focus of this study being the viability of nighttime transits, very few runs were made using daylight conditions. However, the daytime runs were done in order to ascertain whether the difficulty ratings associated with the designs were due to the nighttime transit, or if they were in part caused by the design conditions.

The average level of difficulty rating for the existing ranges at night was 8.1. The average difficulty rating for the modified buoys at night was 7.9. The average difficulty rating for the quartering ranges was 7.1. For the runs 
performed with daylight conditions, the average rating was 3.4. While the difficulty rating dropped for those runs with the modified buoys and quartering ranges for the nighttime runs, there were still groundings, but not as many as with the existing ranges. The pilot's confidence for navigating the channel at night did increase with the quartering ranges; typical statements for quarter range runs were:

- Extra lighting and quartering ranges helped

- Overall, ranges (quartering) made a big difference

- Quartering ranges very helpful

Even with these positive statements, however, it must be noted that the pilots still had problems navigating the channel.

This project marked the first use of quartering ranges by the Ship/ Tow Simulator. Although the purpose of quartering ranges is the same as any other range (to assist the pilot in keeping the vessel inside the confines of the channel), the implementation of that purpose is more refined. For those unfamiliar with this type of range system, the side-to-side position of the vessel within the channel can be determined with greater accuracy than a single set of centerline ranges. Figure 23 shows the positions of the vessel making an inbound approach that would give the pilot the view of the quartering ranges shown in Figure 24. The ability to more quickly ascertain what the vessel is doing within the channel as well as where it is in the channel is imperative to safe operation when the channel is as short and confined as Kalaeloa Barbers Point Harbor's channel. The quartering ranges enhance that ability because a slight deviation from the center of the channel is more pronounced when comparing the distances between the two outside ranges.

The 7.1 for the quartering ranges is still an above average difficulty rating. These ratings are in large part due to the fact that the pilots do not now take ships into the harbor at night and are therefore unfamiliar with nighttime transits. For this reason the project was unusual in that the existing conditions are not really the normal existing conditions. Normal for this harbor are daylight transits. However, to compare the daylight transits with the nighttime runs would distort the results for the changes to the navigation aids. One other note is that until the last set of tests, the geometry of the channel does not change from the current conditions. This means that the same problems are there for each set of runs, the only 


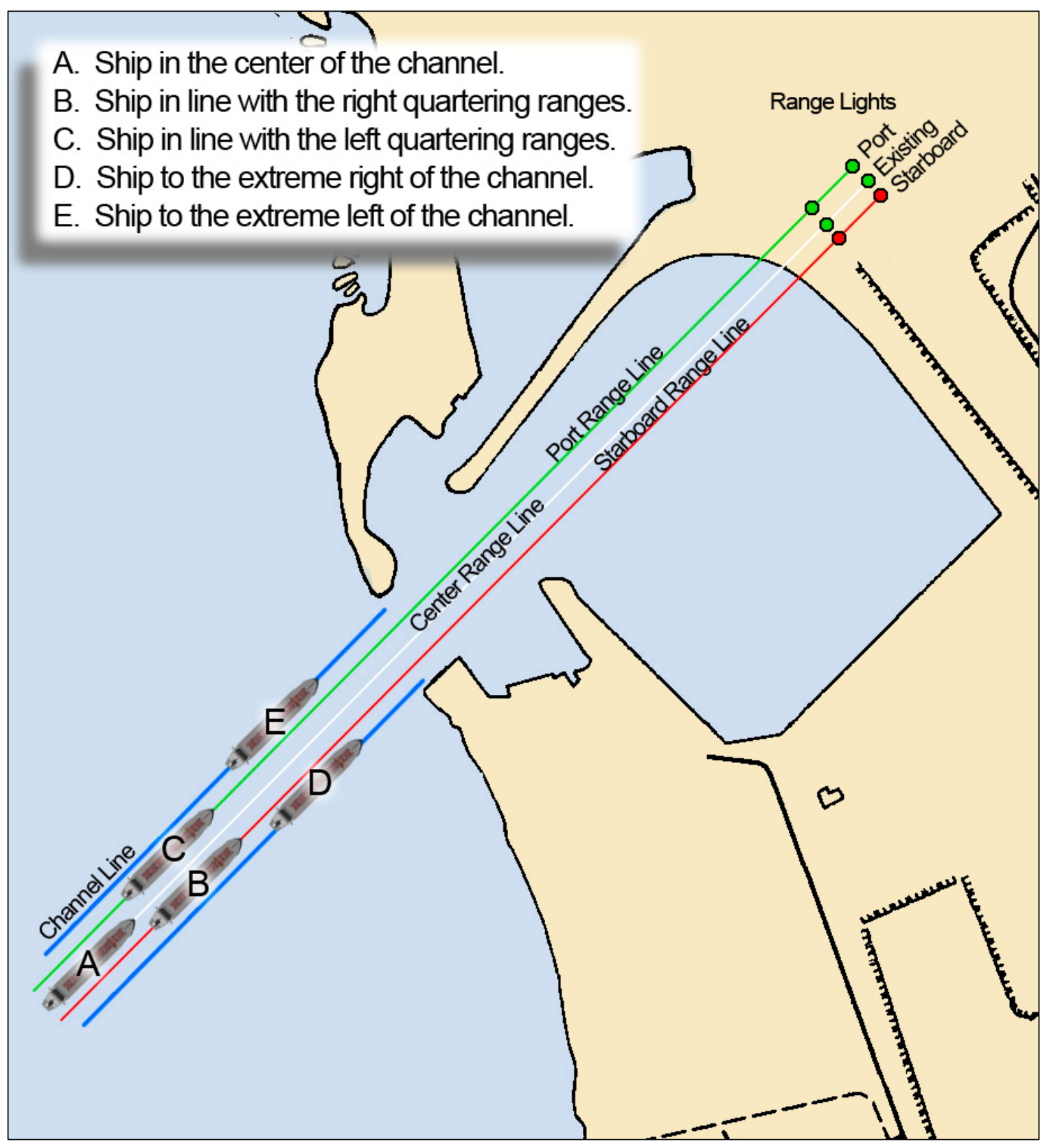

Figure 23. Linear ship position in channel for range viewpoint on Figure 28.

difference being the tools available to try to solve those problems, i.e., the modified navigational aids. For this reason, composite trackplots do not show as many differences between test and existing conditions as a normal project might, and the pilot's experience and point of view come into play even more. 


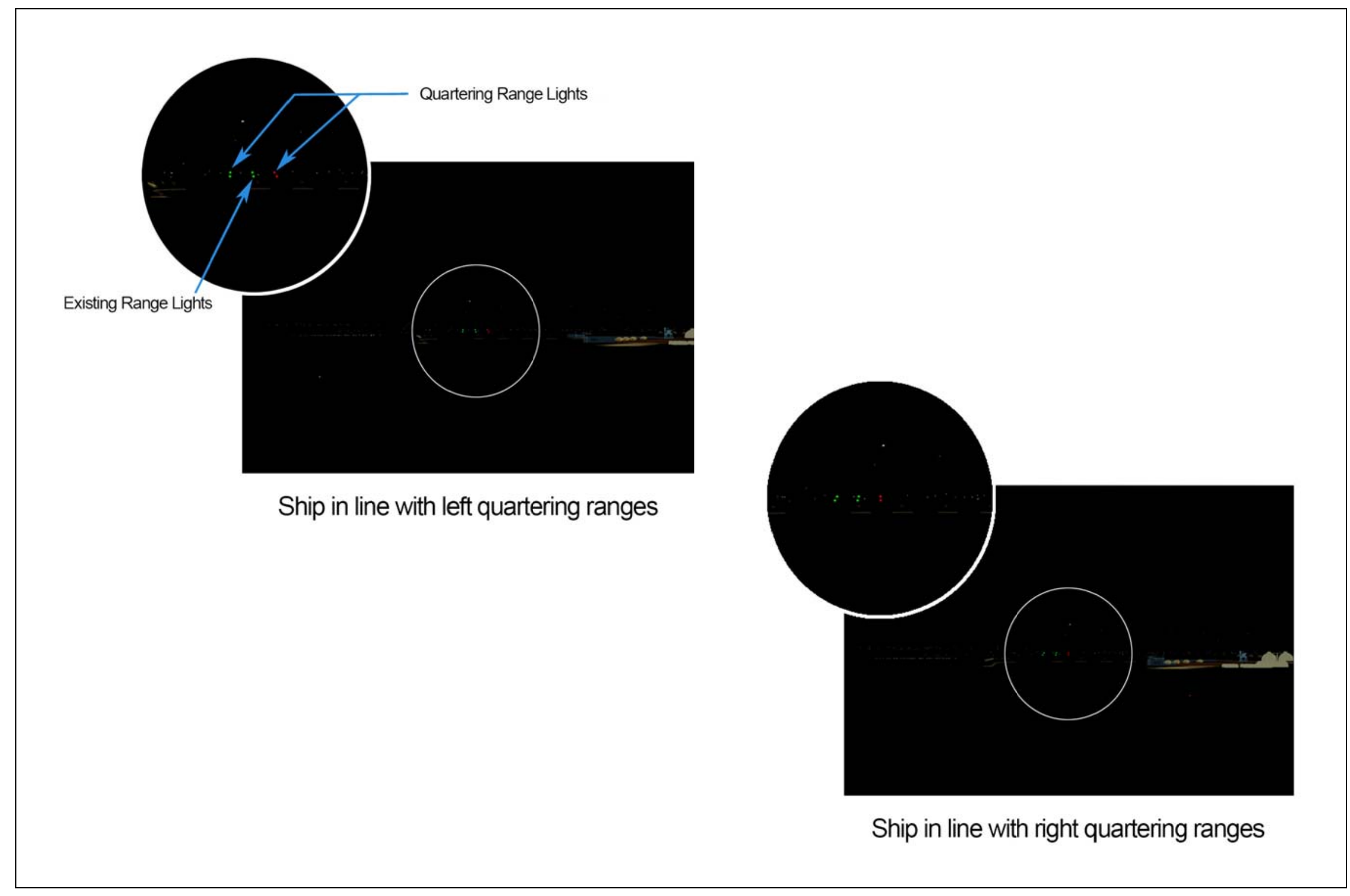

Figure 24. Kalaeloa Barbers Point Harbor with quartering ranges in place, ship at entrance to channel (Continued). 


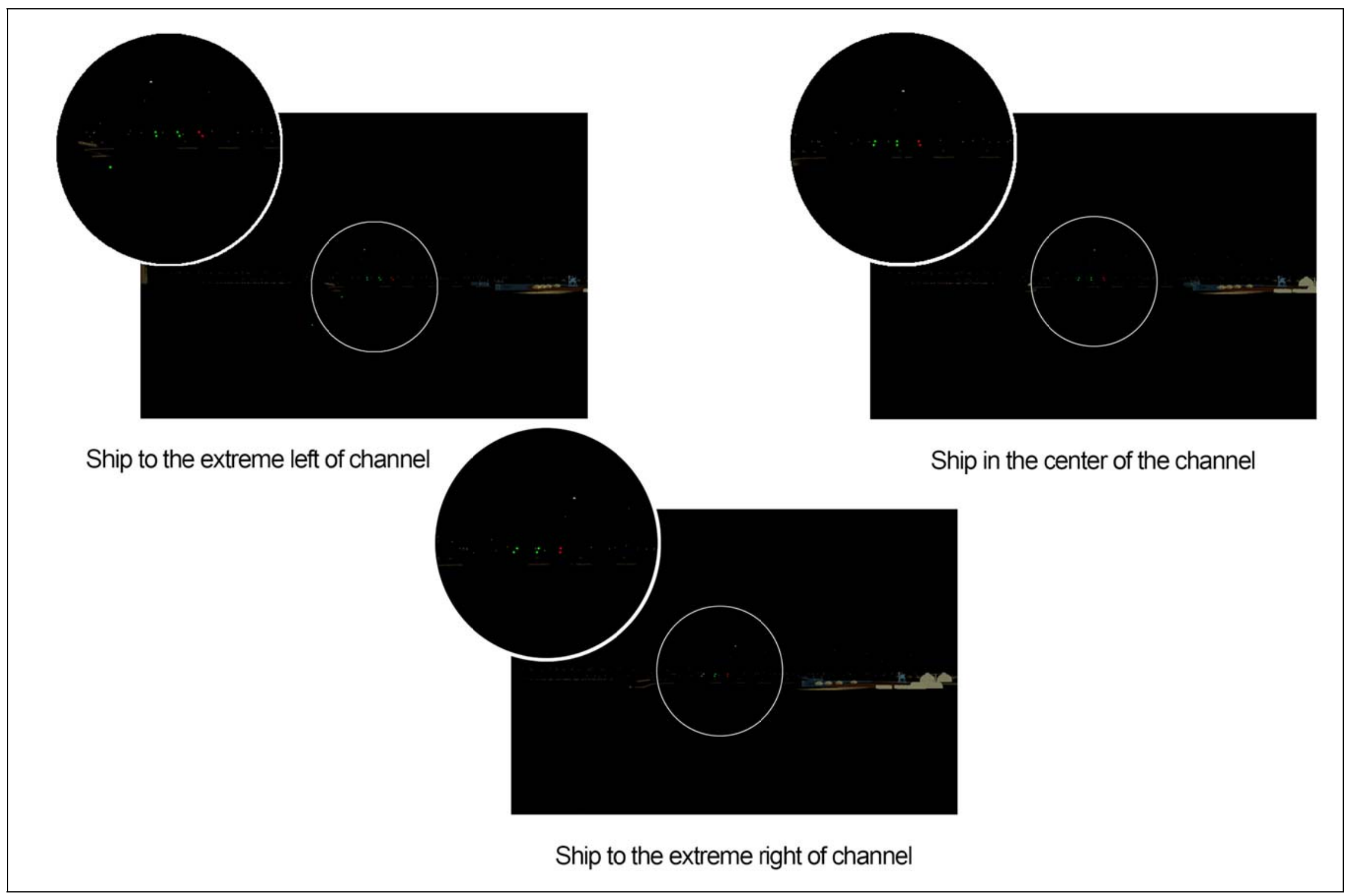

Figure 24. (Concluded). 
Whether daytime or nighttime runs are being tested, the forces acting upon the ship remain the same. Generally, wind forces were a significant factor only in the outbound runs, when the vessels were carrying a light load. The reason for this can easily be shown with Figure 25.

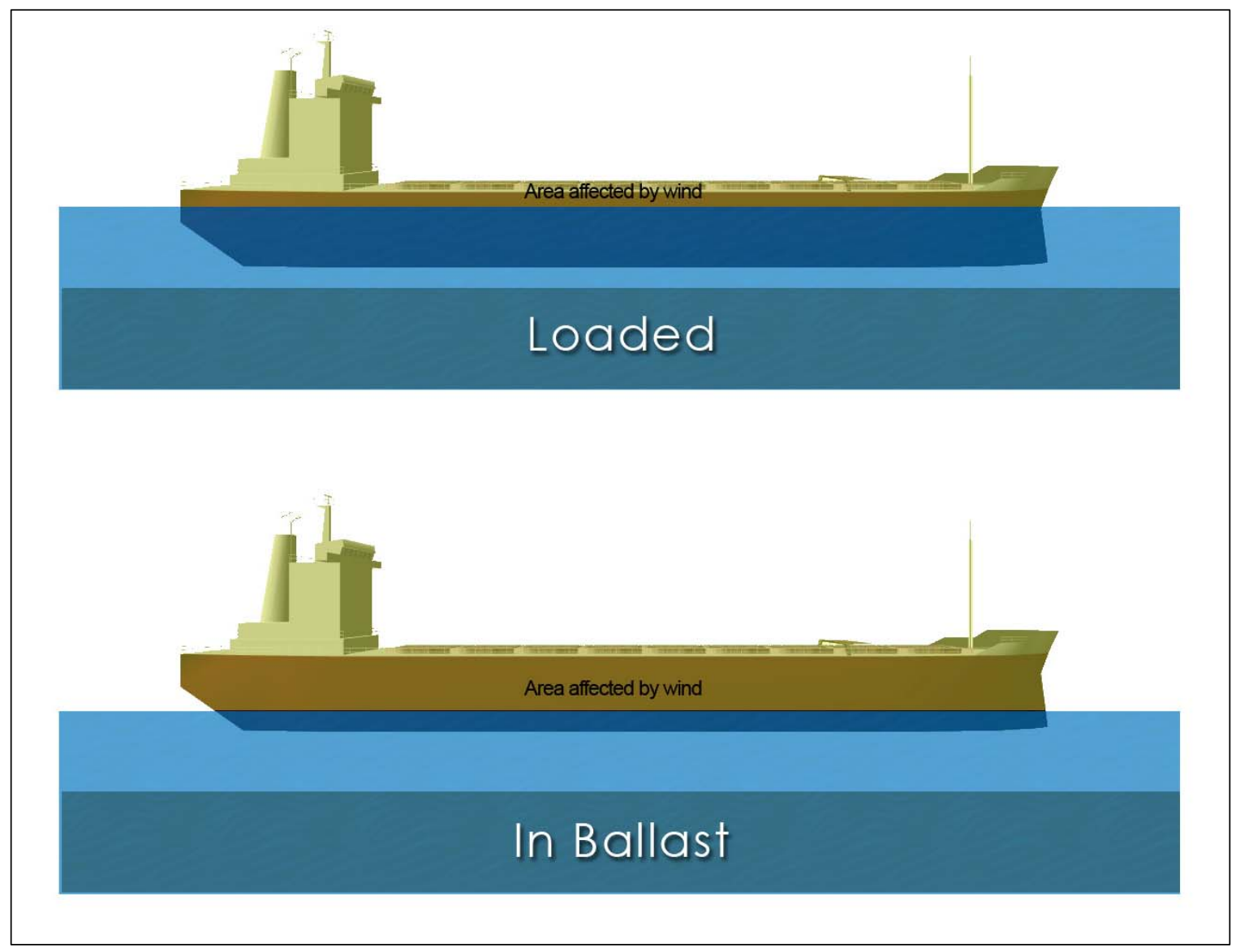

Figure 25. Difference in freeboard area (i.e., "sail area") affected by wind between a loaded tanker and a tanker in ballast.

The longitudinal cross-section area that the wind can act upon is greatly reduced when the ship is loaded. In addition, the mass of the vessel is greatly increased, making it harder to deviate it from its path. In addition, unlike the graphic above, a ballasted ship does not normally sit on an even keel, making the wind force action uneven from the bow to the stern.

Unlike wind forces, the opposite is true for the bank forces and currents acting upon the vessel, as shown in Figure 26. 


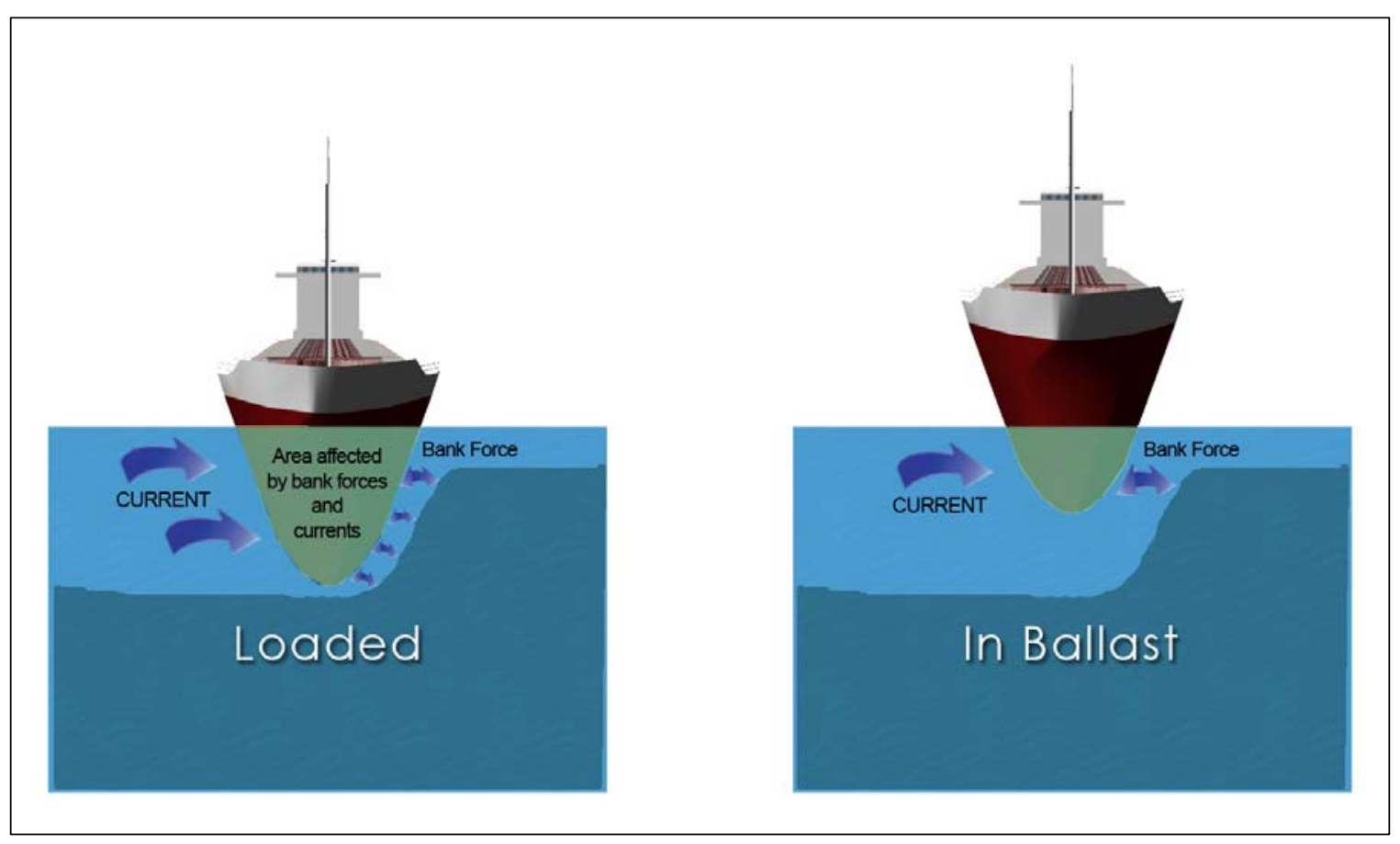

Figure 26. Difference in current and bank force areas of influence.

The effect of waves upon the vessel's maneuverability is inversely linked to its mass. Therefore, even though the waves affect both the loaded and light loaded vessels, it is the vessel with the shallowest draft (the one that has less mass) that is typically affected the most for a particular type and size of ship.

The pilot must deal with all of these forces working together on the vessel as it approaches or exits the harbor. He will be able to ascertain the wind and wave conditions in the area easily during daylight. However, he will not know how the currents in the area are acting, although he may get a general idea from someone who has just left the area. He will also have to compensate for the vessel's handling characteristics, generally unknown unless he has piloted the ship several times in the past. All of these conditions are much more "readable" during daylight; it is the changes between the daytime and nighttime transits that drive this navigation study. Daytime visual cues help the pilot decide what the currents in the channel are doing as the vessel is affected by them; these cues are almost nonexistent at night. The installation of one or two buoys with the capability of transmitting current data (i.e., data buoys) to a location that the pilot could have access to would remove this unknown factor. While these buoys would certainly be invaluable even for daytime transits, their addition would be a major step forward towards the safety of nighttime runs. It 
is fairly easy to overlook the lack of current data at first as being a problem for the pilot; one would assume that the Hawaii pilots have all of the devices at their disposal as other pilot groups. However, it must be understood that, while rivers are somewhat constant in the current patterns, and many harbors located in estuaries have currents that are tidally driven and therefore fairly predictable with the tide charts, Kalaeloa Barbers Point Harbor is neither. In fact there are times that the wind-generated waves may be going opposite the currents in the channel. The pilot cannot rely solely on visual cues for the crosscurrent patterns, and therefore, does not know what to expect until the ship is within the influence of the current.

The implementation of these data buoys for simulation purposes was a simple matter of informing the pilot of the current conditions inside the start of the channel and before the entrance of the harbor at the beginning of the run. This is a realistic depiction of how they would work during a transit. The data buoys, once in place at the channel, would send a data stream to a facility where the pilots could call or log in and receive up-todate current information before entrance into or departure from the harbor.

In addition to the data buoys, the other improvement for inbound nighttime transits would be the addition of quartering range lights, as mentioned earlier in this report.

Due to circumstances at the time of their construction, the existing ranges are fairly close together; this makes it more difficult to see relatively small errors in alignment. A greater differential in elevation between the front and rear range light would help increase the error sensitivity. Also, the rear range light is on a 7-sec cycle. During the nighttime runs, since very few other visual cues were available, this left the pilot waiting for the range light to come back on so he could tell the vessel's placement in the channel.

The design modification primarily studied for outbound runs was the addition of a new gated set of buoys. There is no feasible way to place ranges for the outbound transit, and the inbound ranges are too close to be of much value. However, buoys can, in a limited way, be used as ranges as well as marking the channel limits. The addition of a new gated pair of buoys between the two at the entrance ("6" and "7") and " 4 " and " 5 " 
(Figure 27), as well as moving " 5 " into a gated position with " 4 ," would improve the ability of the pilot to determine where he needs to be as he picks up speed outbound, before he is affected by crosscurrents and waves.

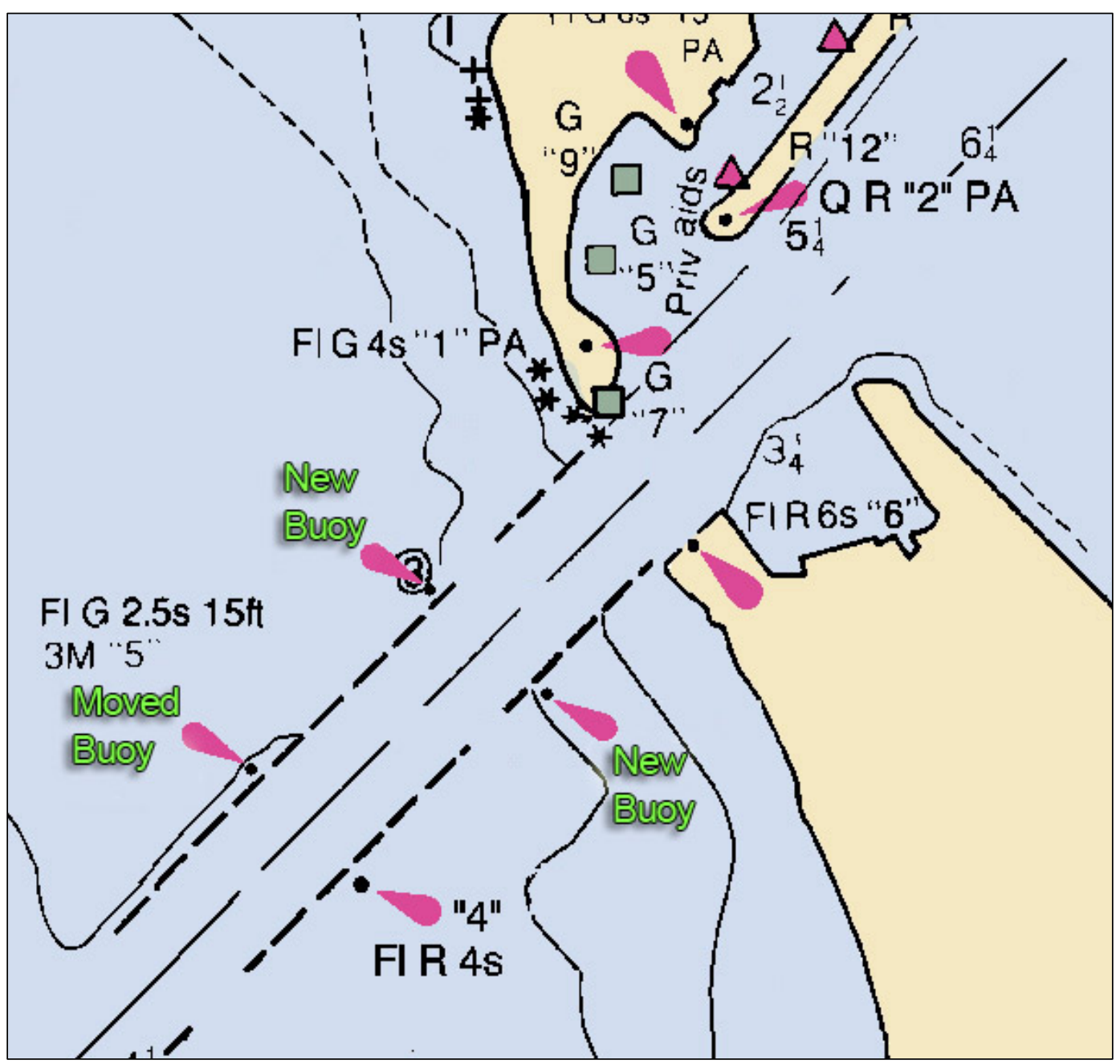

Figure 27. Proposed new and modified buoy location.

The last part of this study analyzed the effects of a 375-ft jetty extending from the northwestern corner of the harbor entrance (Figure 28). This jetty was tested in the physical model study completed in Sept. 1994. The jetty served to remove and/ or reduce wave forces and current forces acting on the vessel as it enters the harbor, thus giving the pilot more time to set up his approach and lower his speed. 


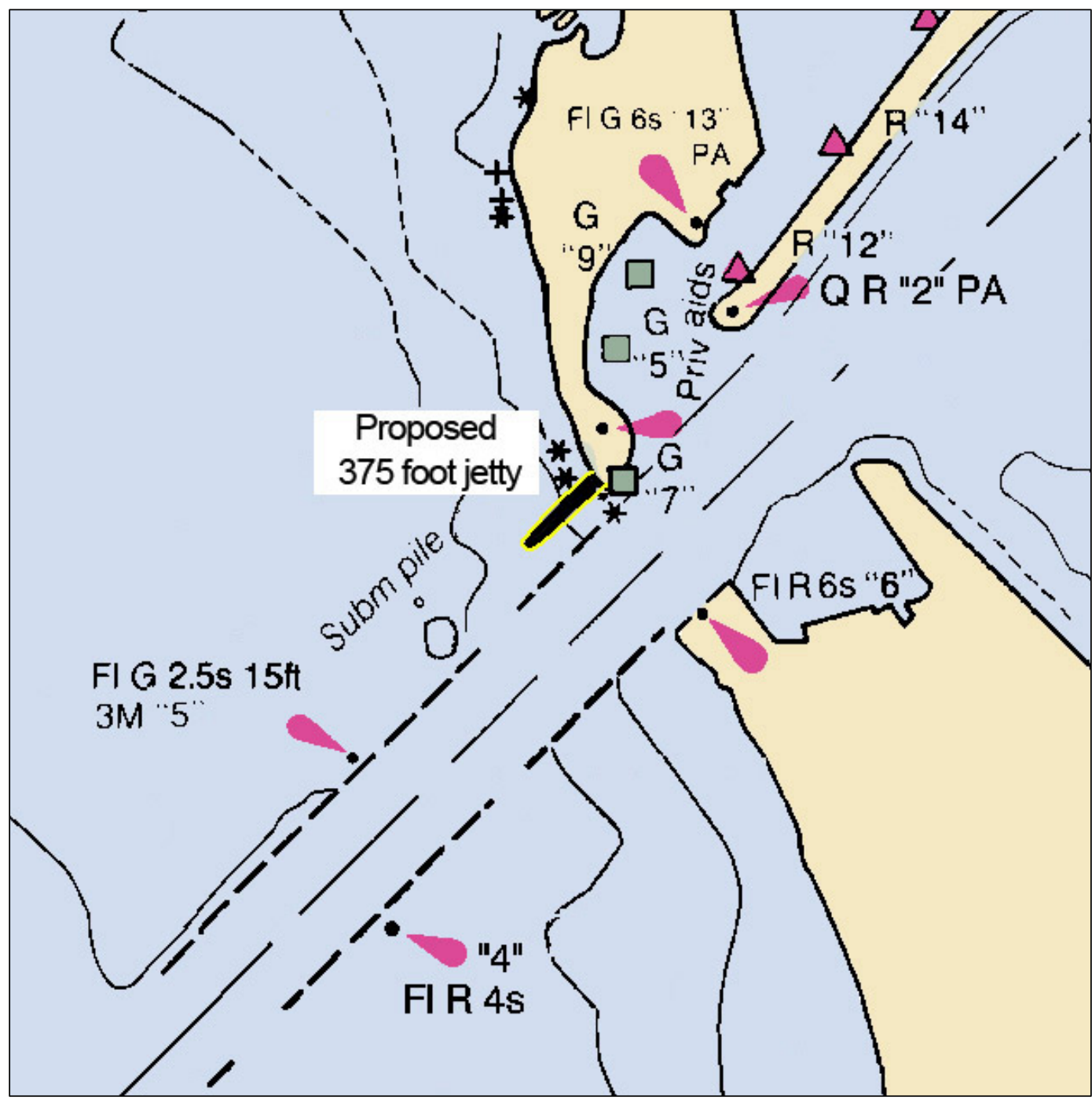

Figure 28. Proposed jetty at harbor entrance.

While the jetty does not afford any protection from the wind, it does provide shelter from currents and waves. These findings are discussed in Briggs et al. (1994). The jetty does provide an improvement in navigation conditions near the entrance to the harbor. The greatest benefit is to the outbound light loaded vessels, allowing them to pick up more speed coming out of the harbor before being fully influenced by the waves and current.

The results indicate that modifications to the existing navaids will need to be made. Since the U.S. Coast Guard is responsible for channel marking, they should be furnished a copy of this report to initiate discussions on the best plan of action to introduce nighttime transits into the harbor. Of the changes in buoys, the addition of the data buoys that would enable the 
pilot to find out what the current and crosscurrents are doing would be the most advantageous, while the addition of new gated buoys would be an improvement that could possibly be accomplished at the same time the data buoys are added.

The changes to the shoreline lighting were somewhat effective, with the greatest advantage coming when the ships were close to shore and maneuvering. Much of the time, lighting close to the shoreline can be obscured by the vessel itself. The view from the ship's main bridge can be limited when looking forward towards the waterline (Figure 29) or even to the side (Figure 30).

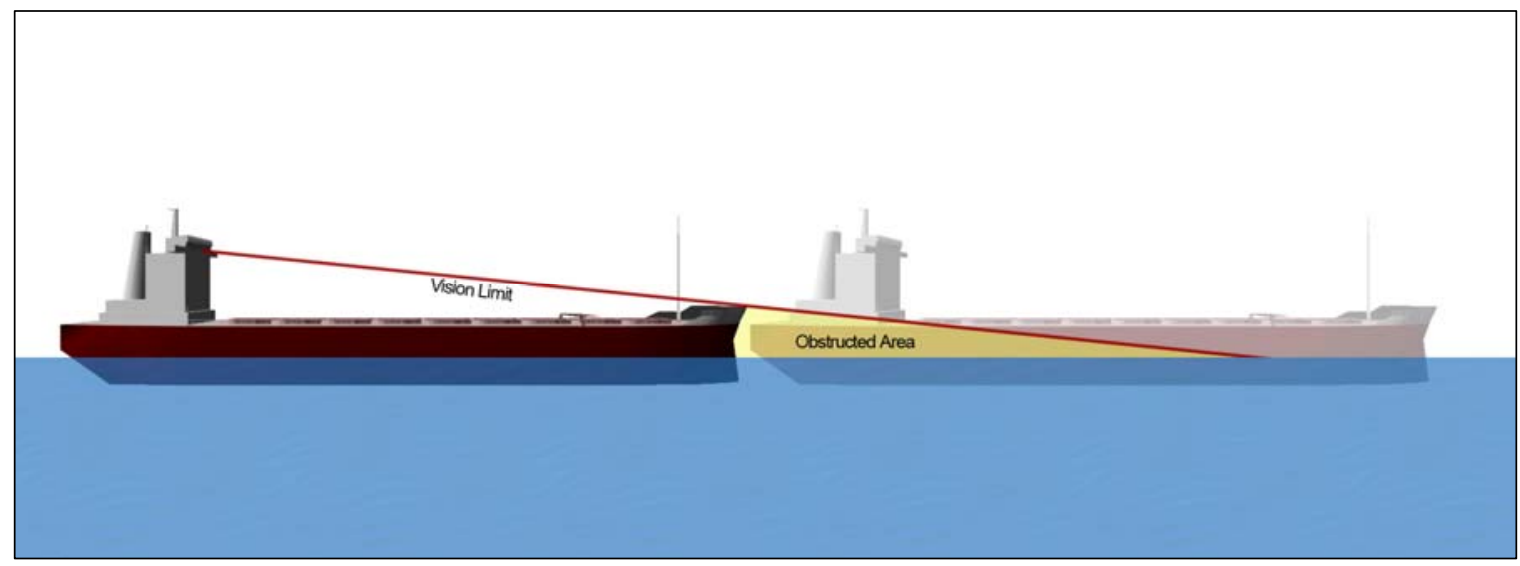

Figure 29. Obstructed view looking forward.

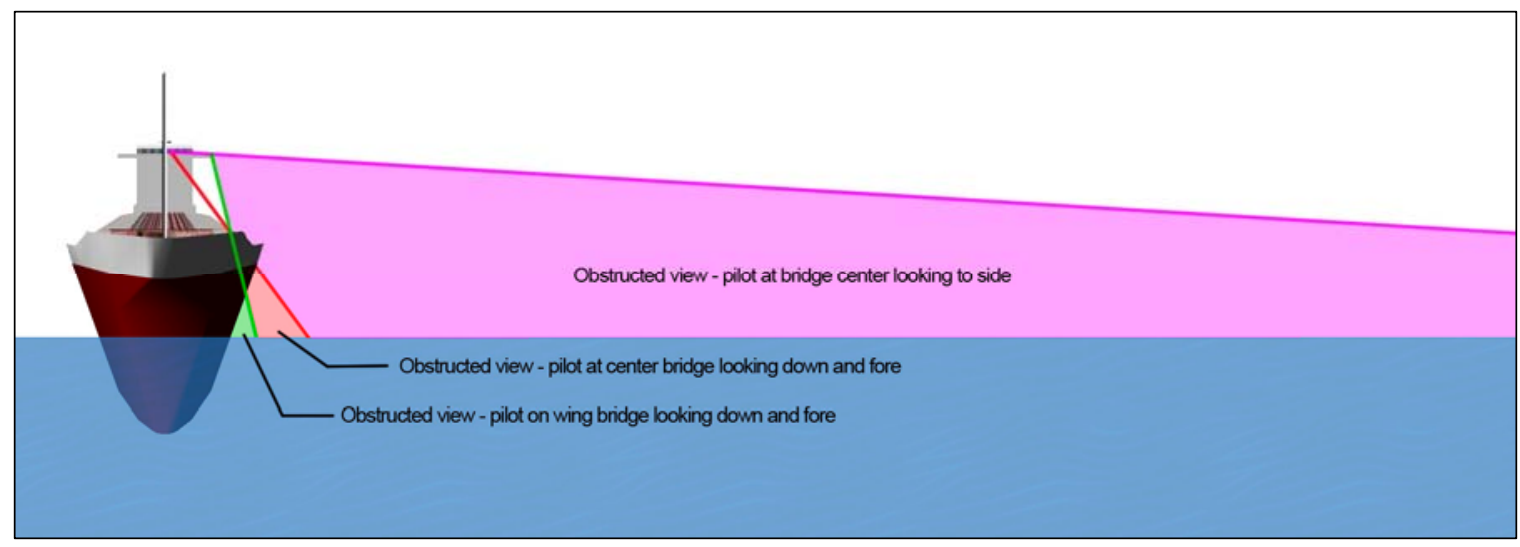

Figure 30. Pilot's view to the side of the vessel.

Because of this limited view, docking maneuvers almost always require the pilot to walk out on the wing and look over the side to determine what the vessel is doing. Depending upon the vessel type, the bow can obscure the length of the vessel or more. Although this problem is something that 
pilots deal with on a continual basis and have learned to compensate for, the fact remains that elevated ranges and navaids that are still some distance away are better indicators of ship position and attitude for the pilot as the vessel approaches the harbor. Once inside the harbor, the shoreline/ terminal lights would provide some assistance for the tugs and/ or ship. 


\section{Summary}

The pilots' main concern during these tests was their ability to determine the ship's position during nighttime transits in order to prevent casualties. The modifications studied included:

1. The new lighting to be added for the harbor improvements alone did not provide enough visual cues for the pilot's entrance into the harbor to decrease the risk of casualties. Once inside the harbor, these additional lights would provide guidance for docking the ship.

2. For entrance to the harbor, the addition of data buoys (or replacement of existing buoys) and quartering ranges provided the most beneficial information to the pilots. The quartering ranges would enable the pilots to determine their location in the channel to a greater degree of accuracy than the existing single range. The data buoys would provide the current information before the approach to the harbor.

3. For departure from the harbor, the addition of an extra gated pair of buoys, and the relocation of buoy " 5 " (Figure 27), did improve the ability of the pilot to determine the vessel location during the transit.

4. The addition of the jetty and the subsequent increased length of the protected entrance reach into the harbor simplified currents at the harbor entrance, and thereby eased the departure from the harbor by protecting the ship from crosscurrents as the ship builds speed.

At the end of the testing program, as well as during the runs themselves, the pilots maintained the infeasibility of nighttime transits into Kalaeloa Barbers Point Harbor for vessels of the size tested in this study (over $500 \mathrm{ft}$ length overall). Even with the changes made during testing, the pilots were not totally comfortable with the resulting transit conditions. Improving the feasibility of nighttime transits of large vessels into and out of this harbor has to begin with improving the existing system of navigational aids. Subsequently, the pilots would start with smaller vessels that they would be comfortable navigating into and out of the harbor, then expand the range of viable ships as experience and knowledge dictate. 


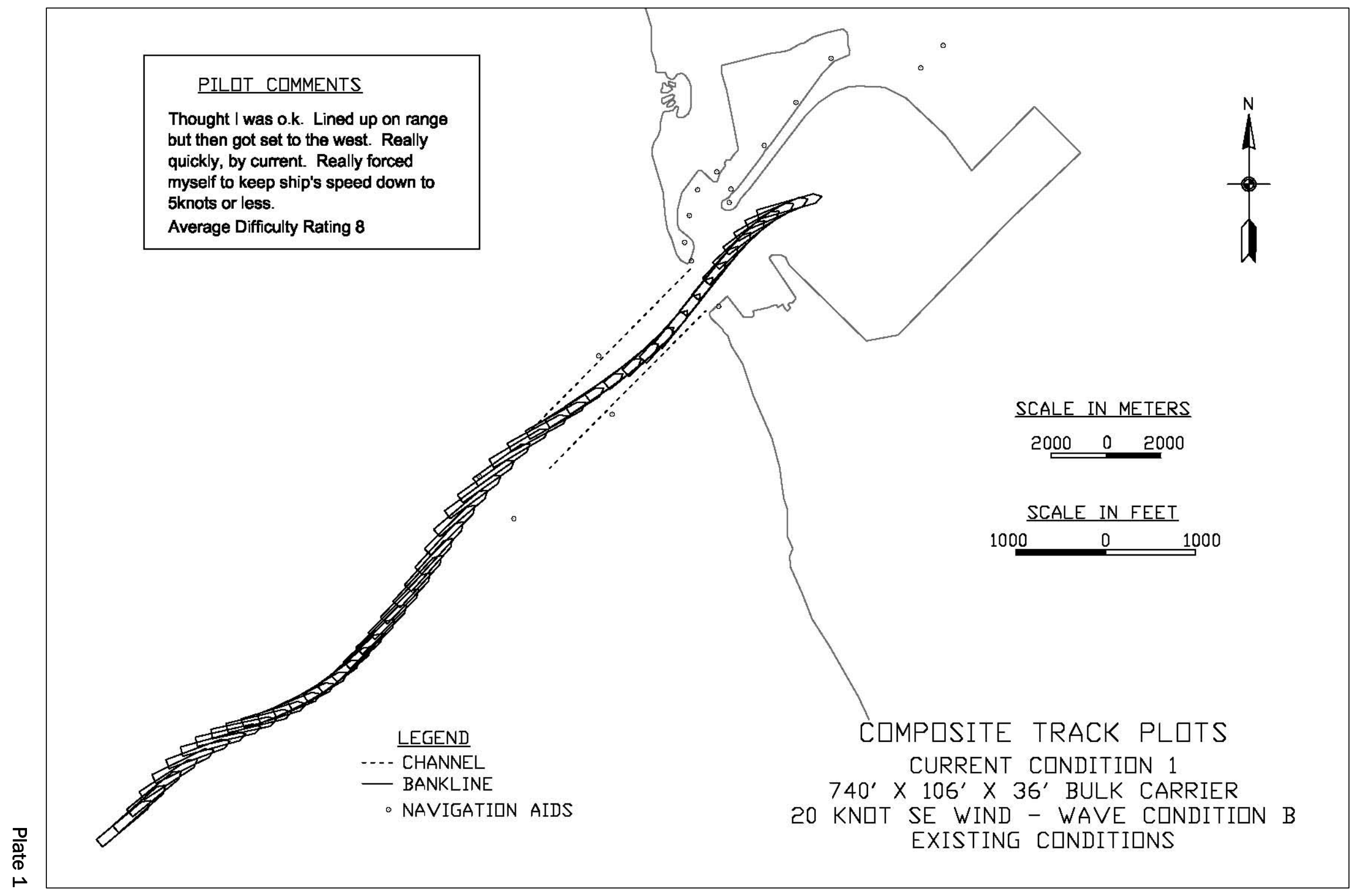




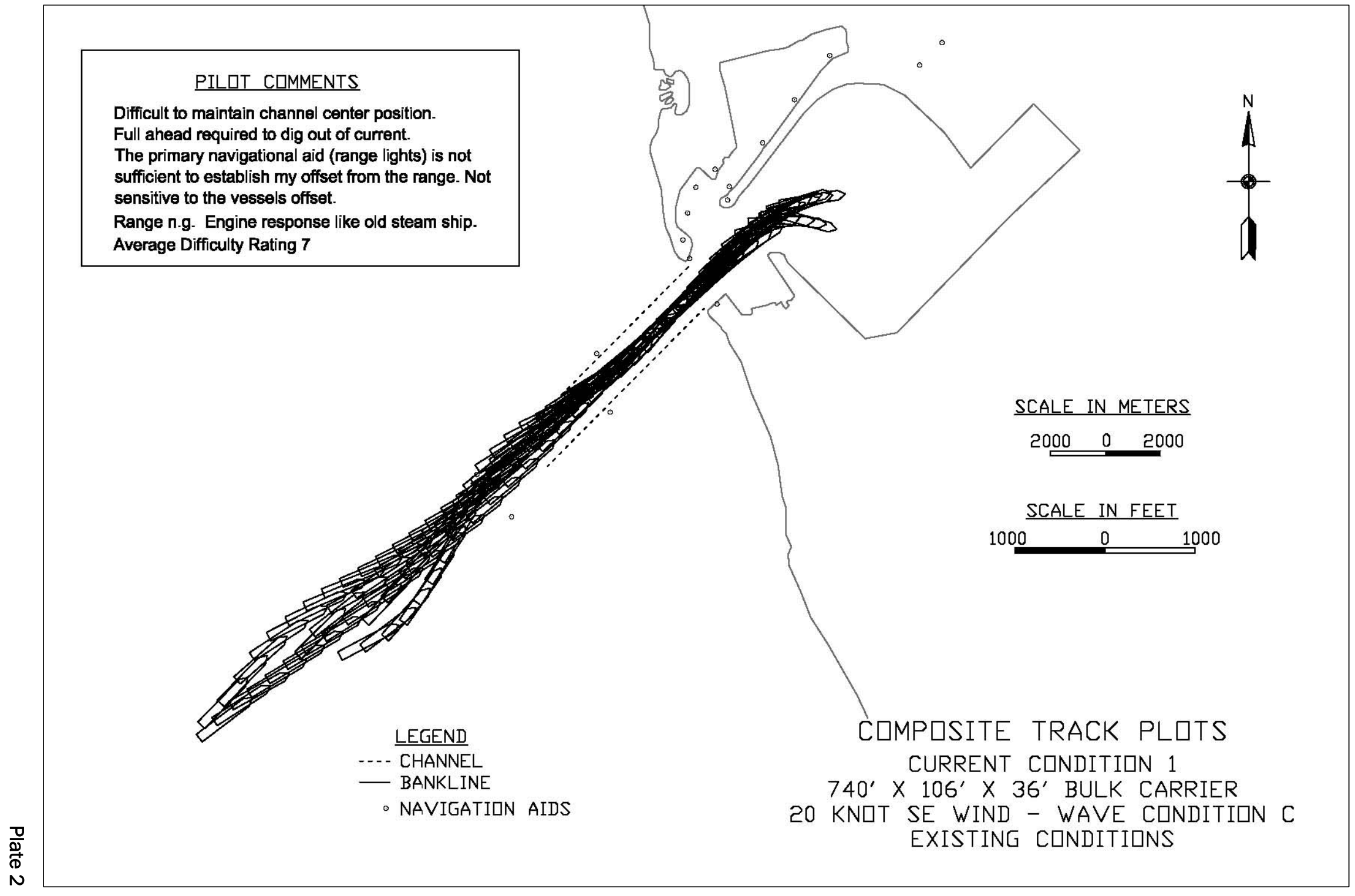




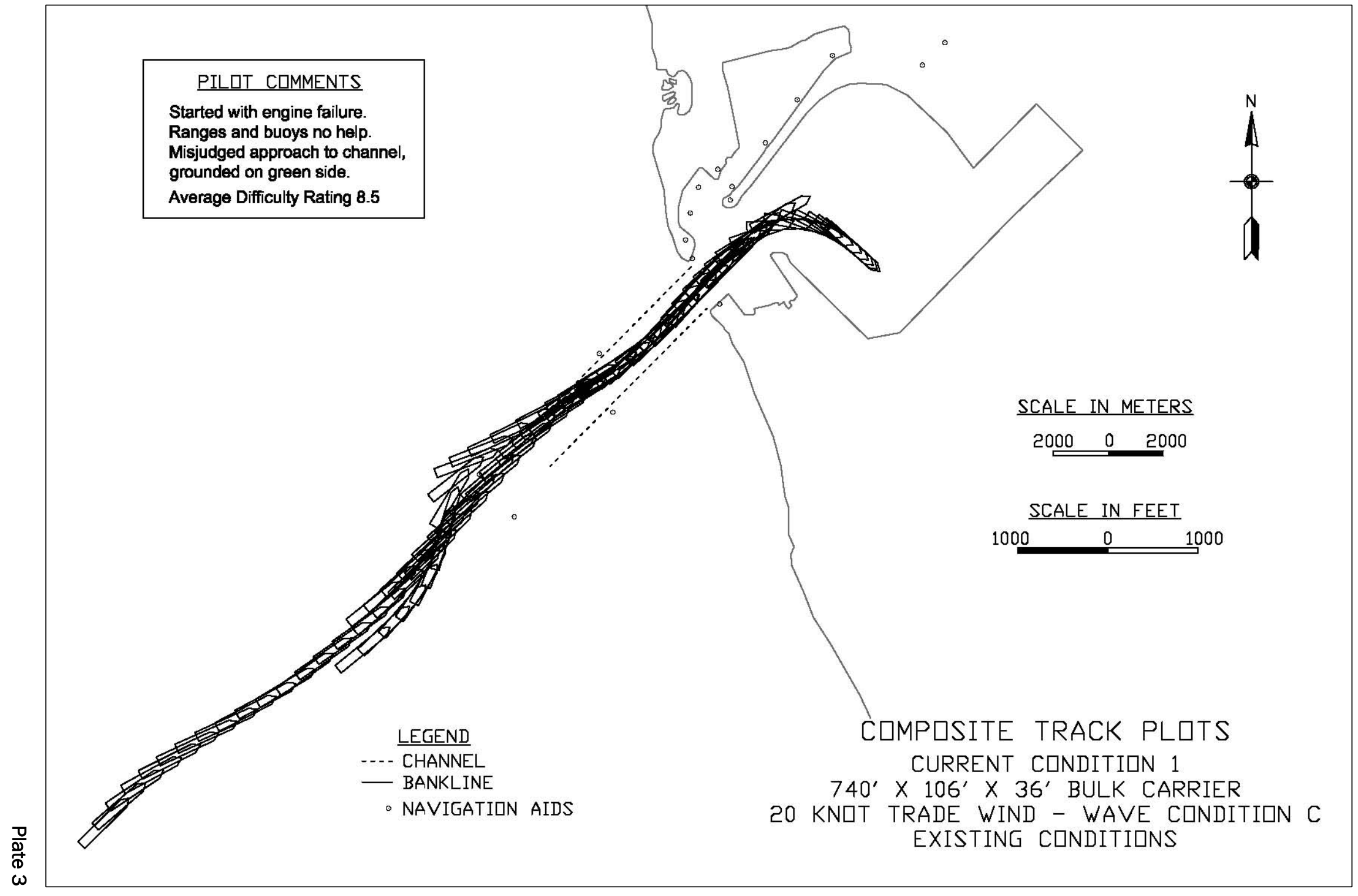




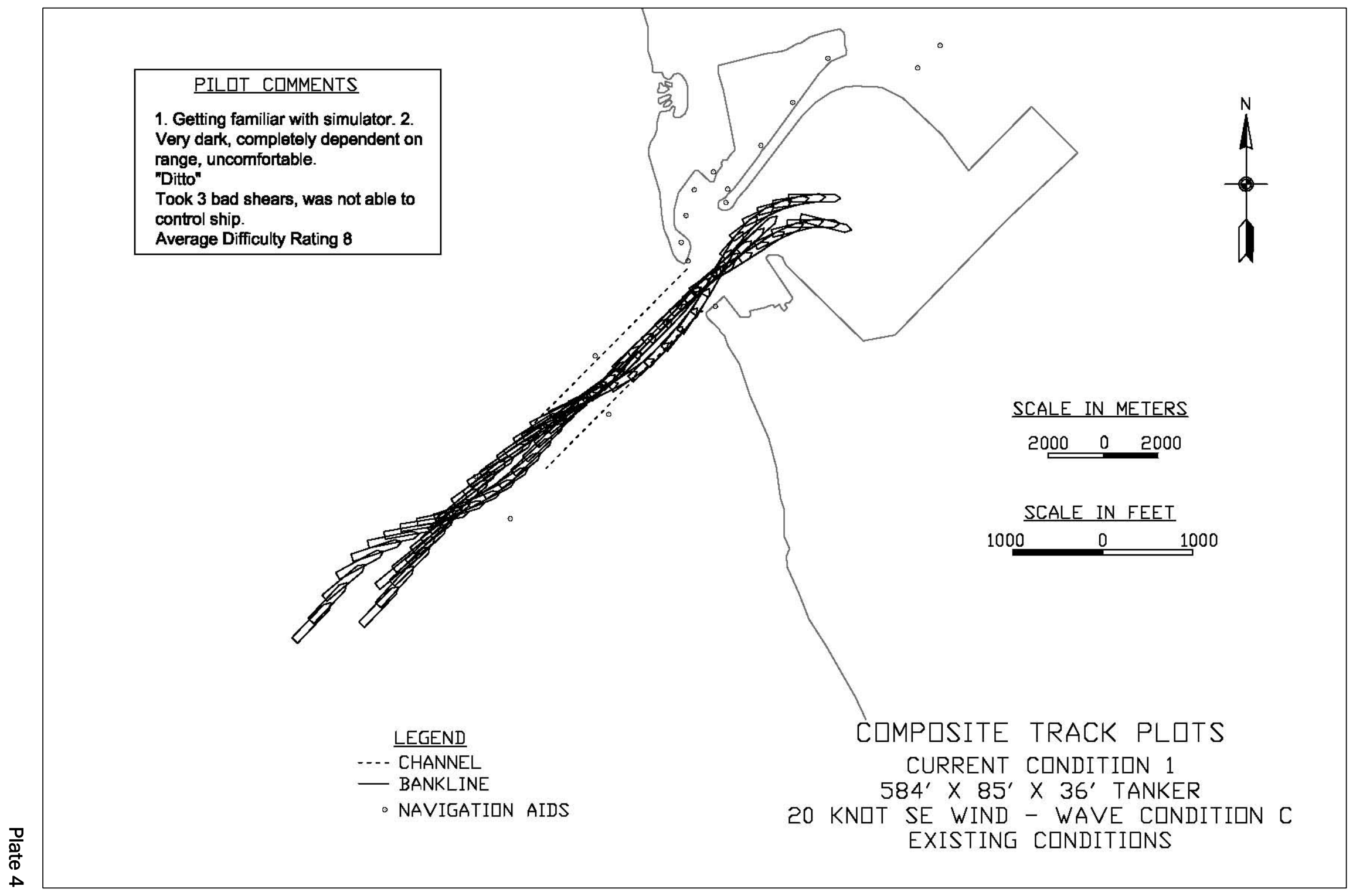




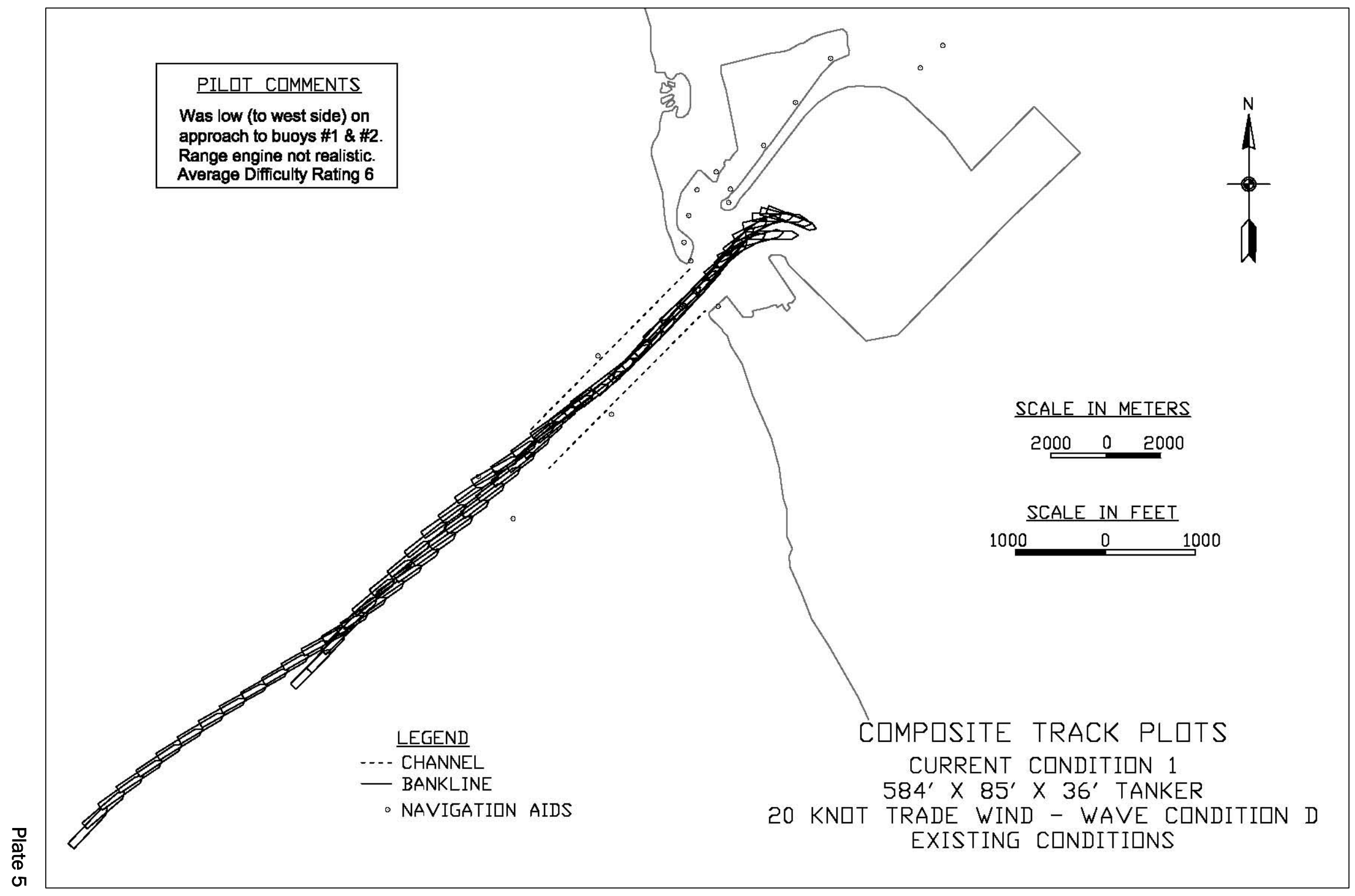




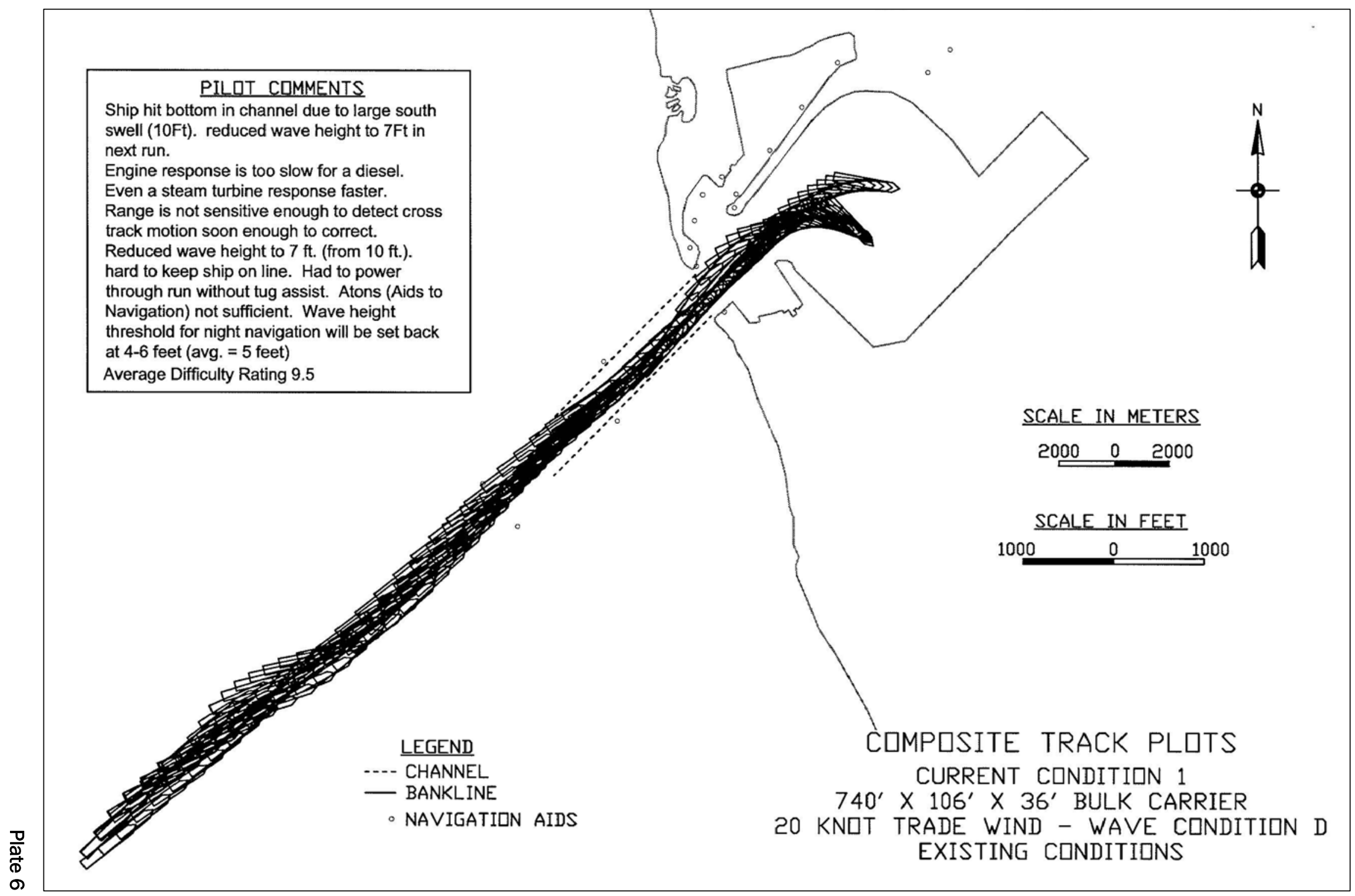




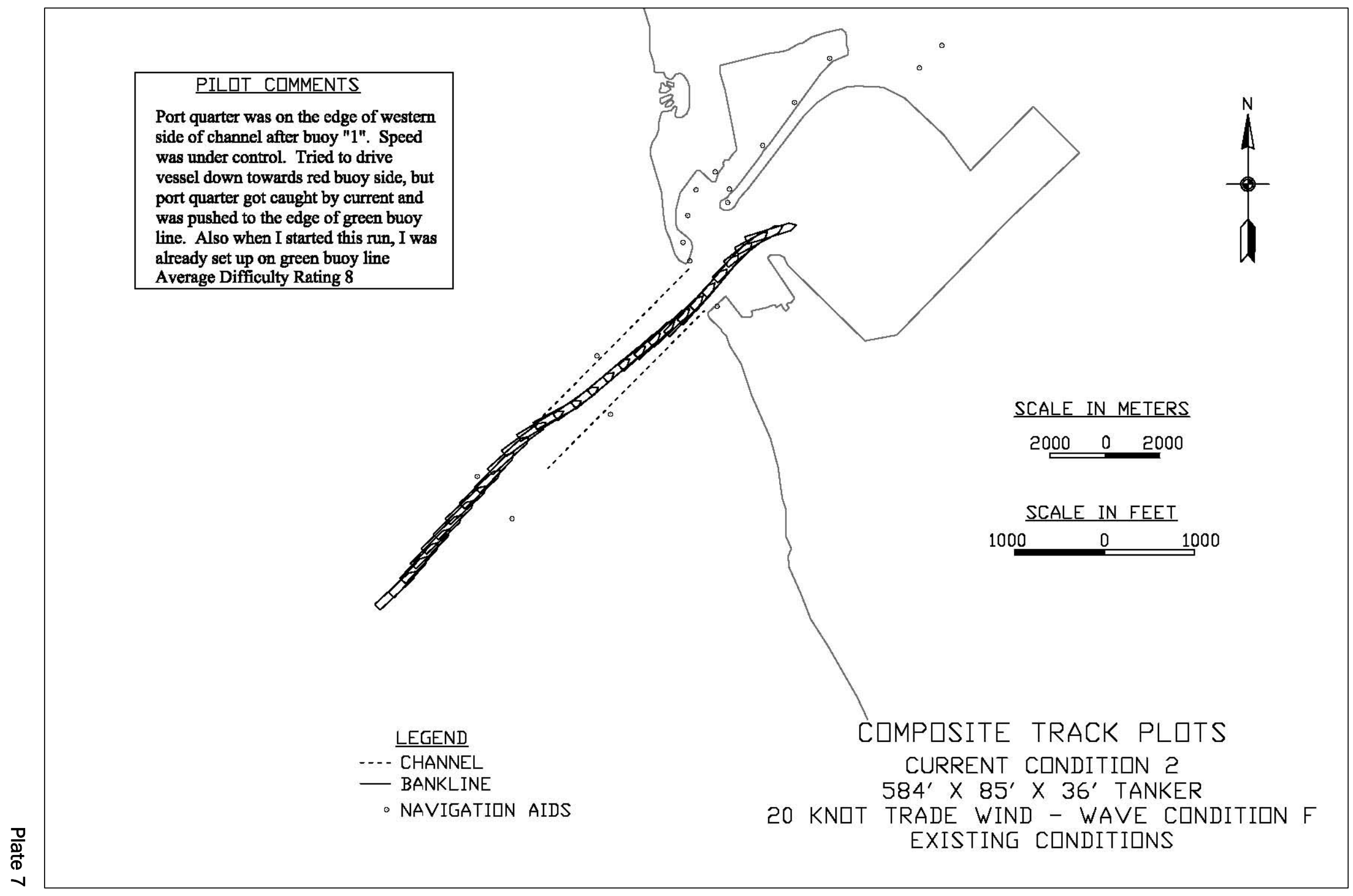




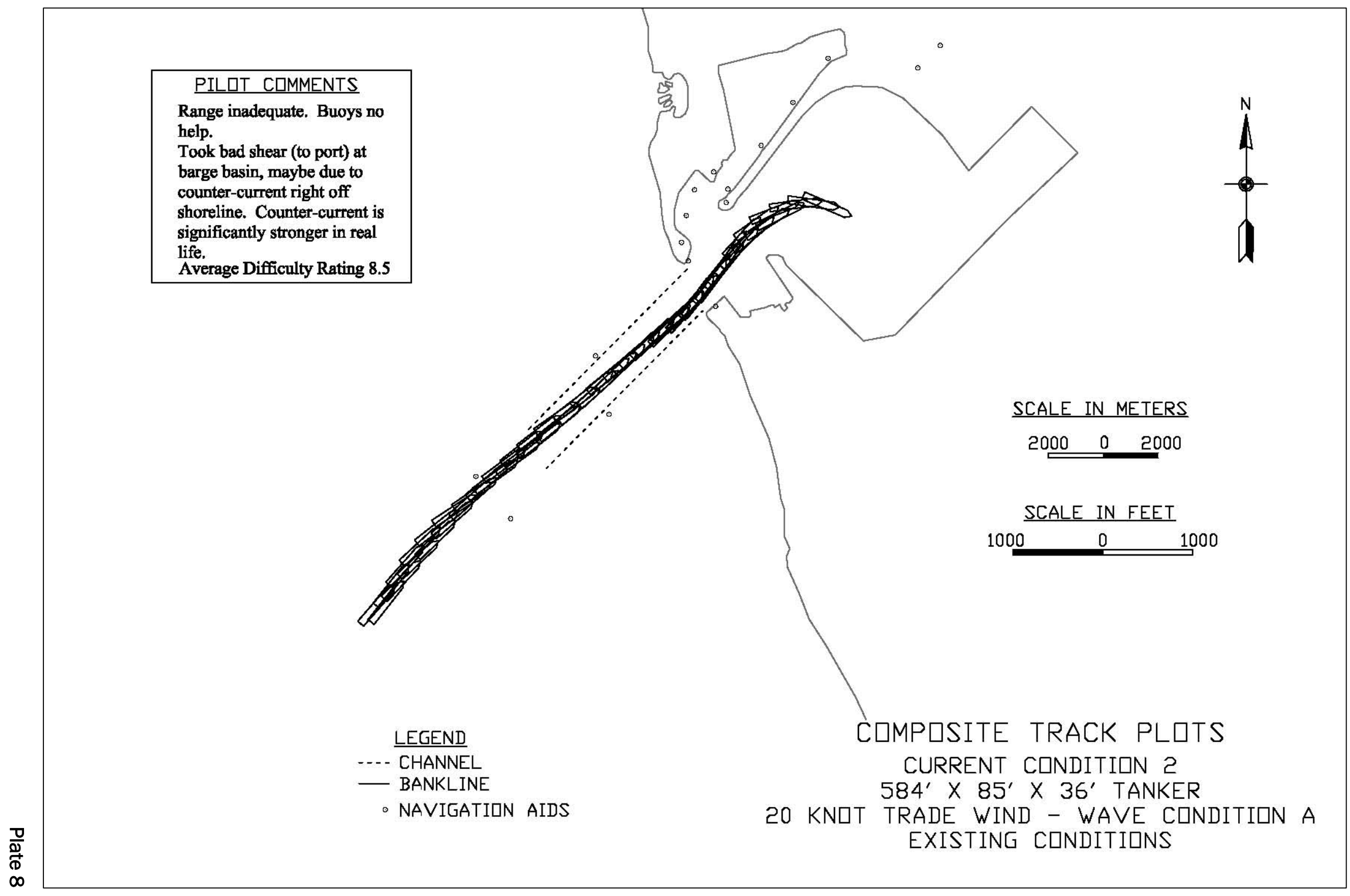




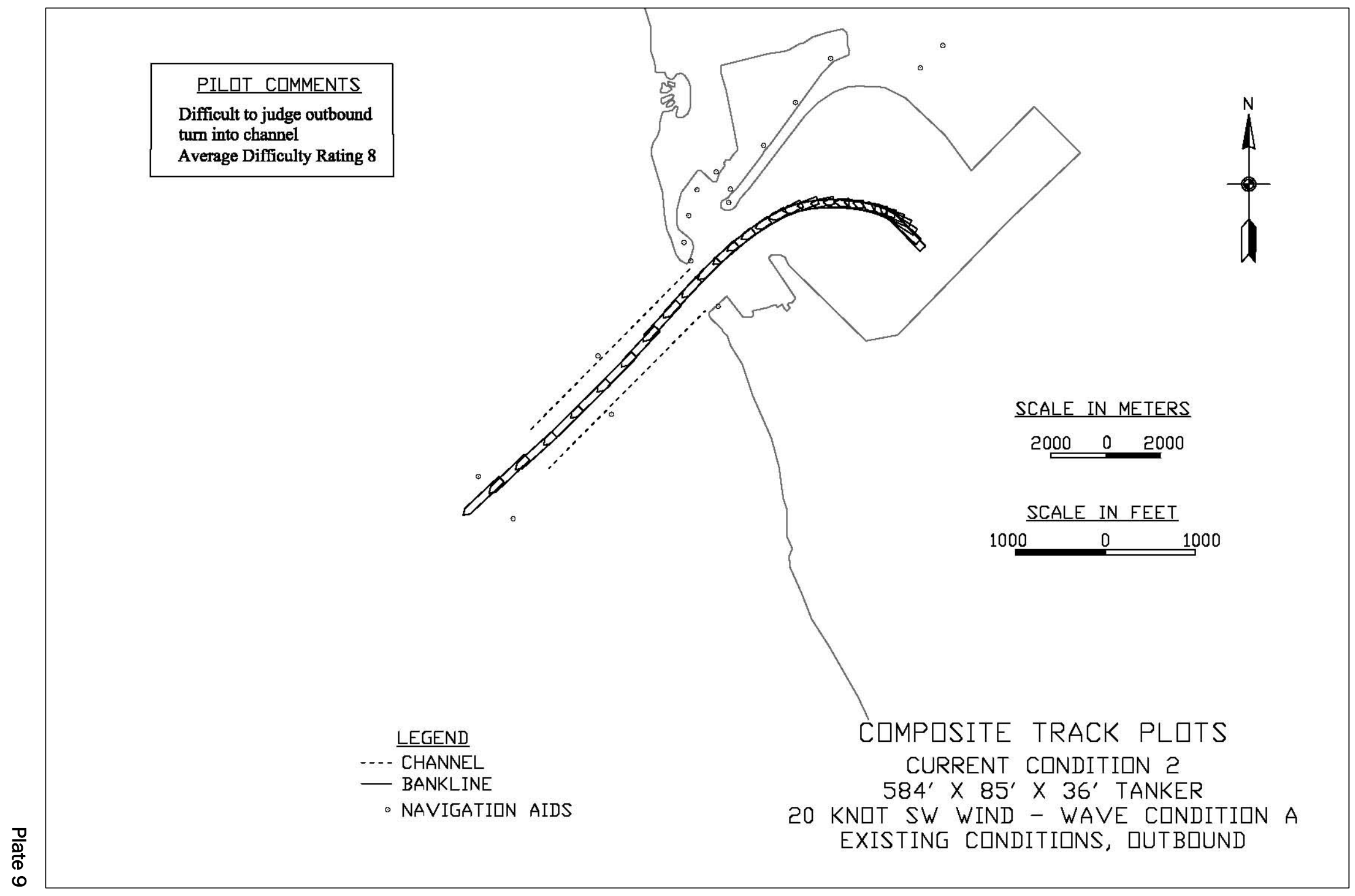




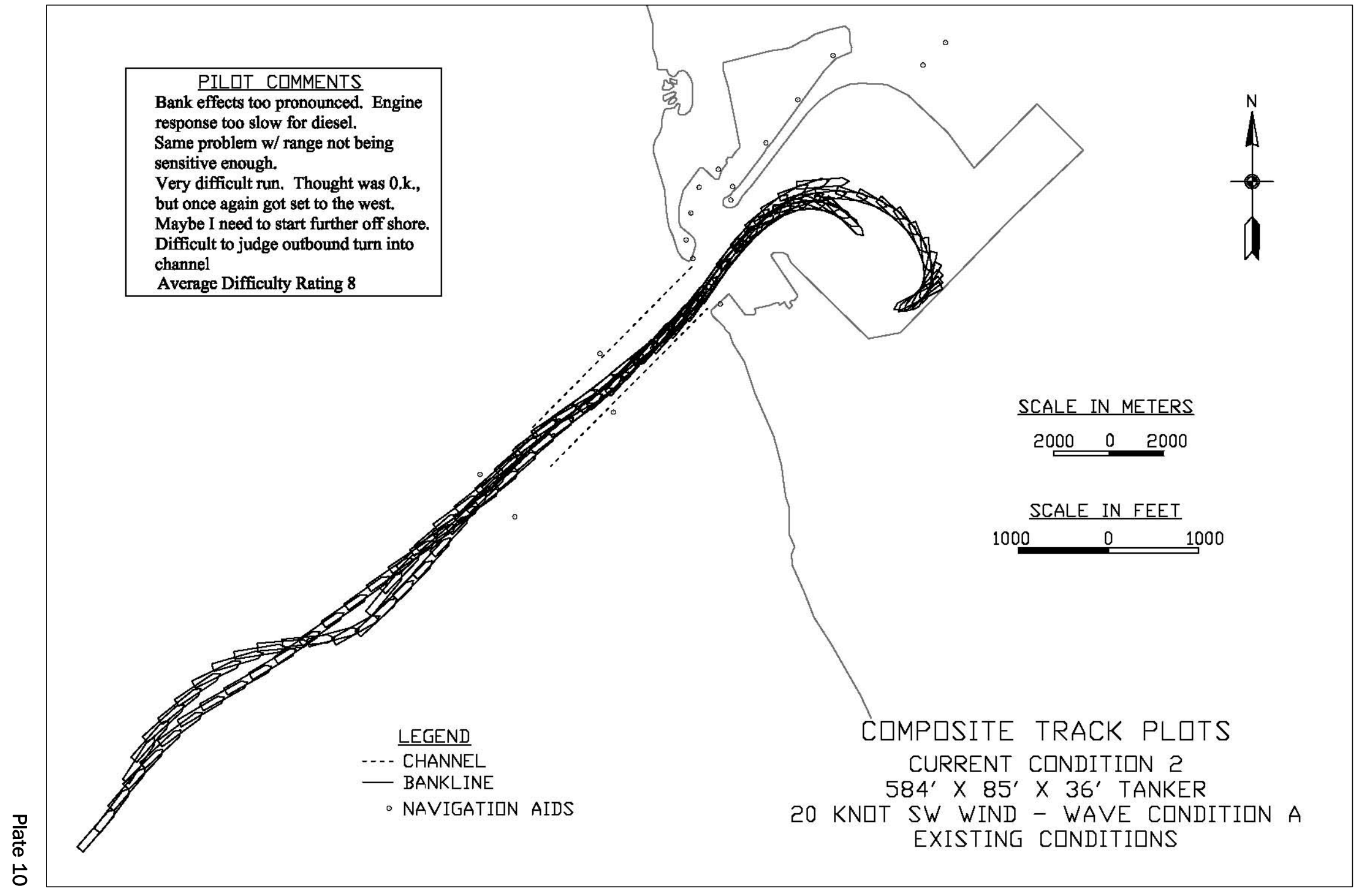




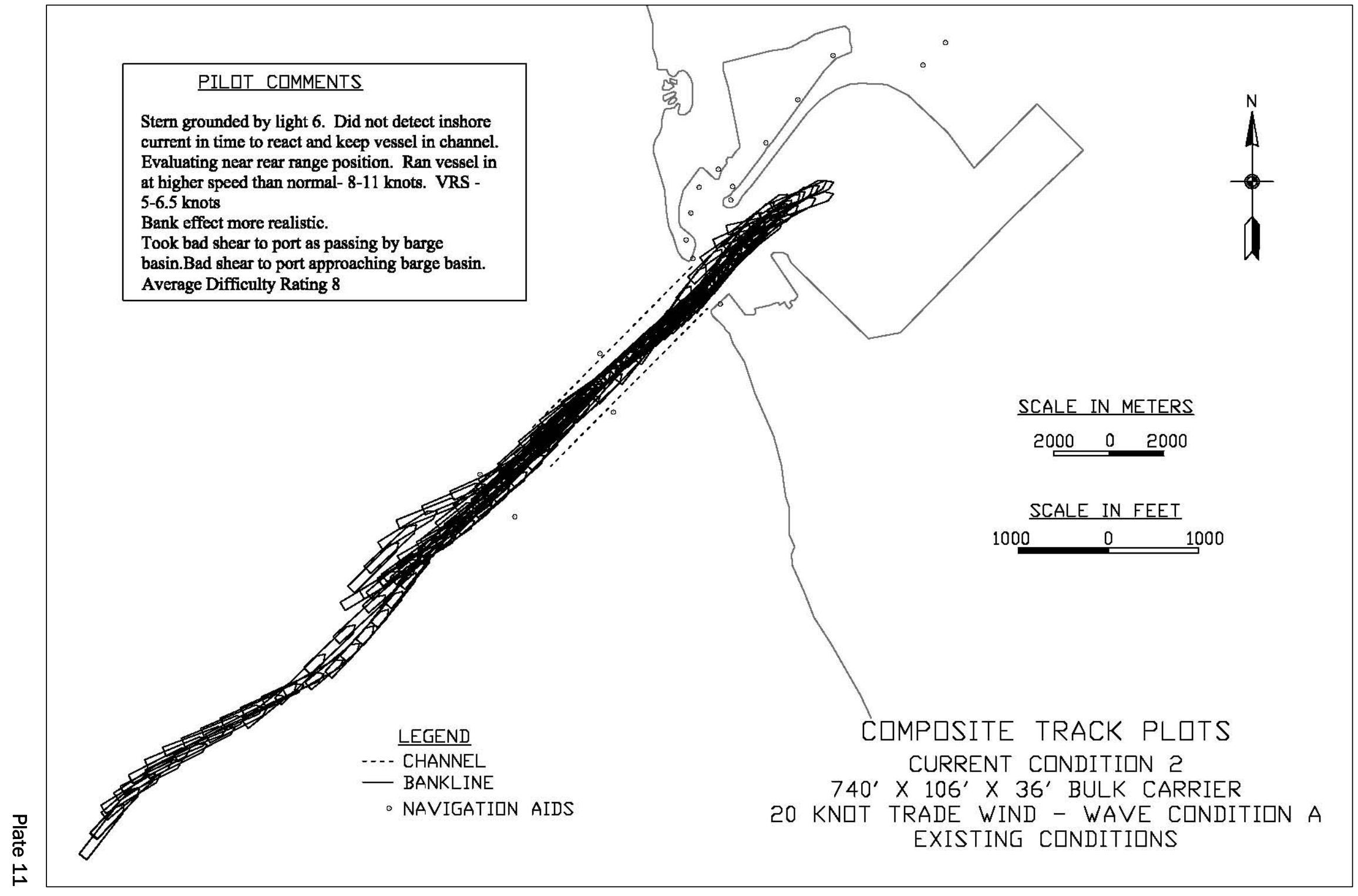




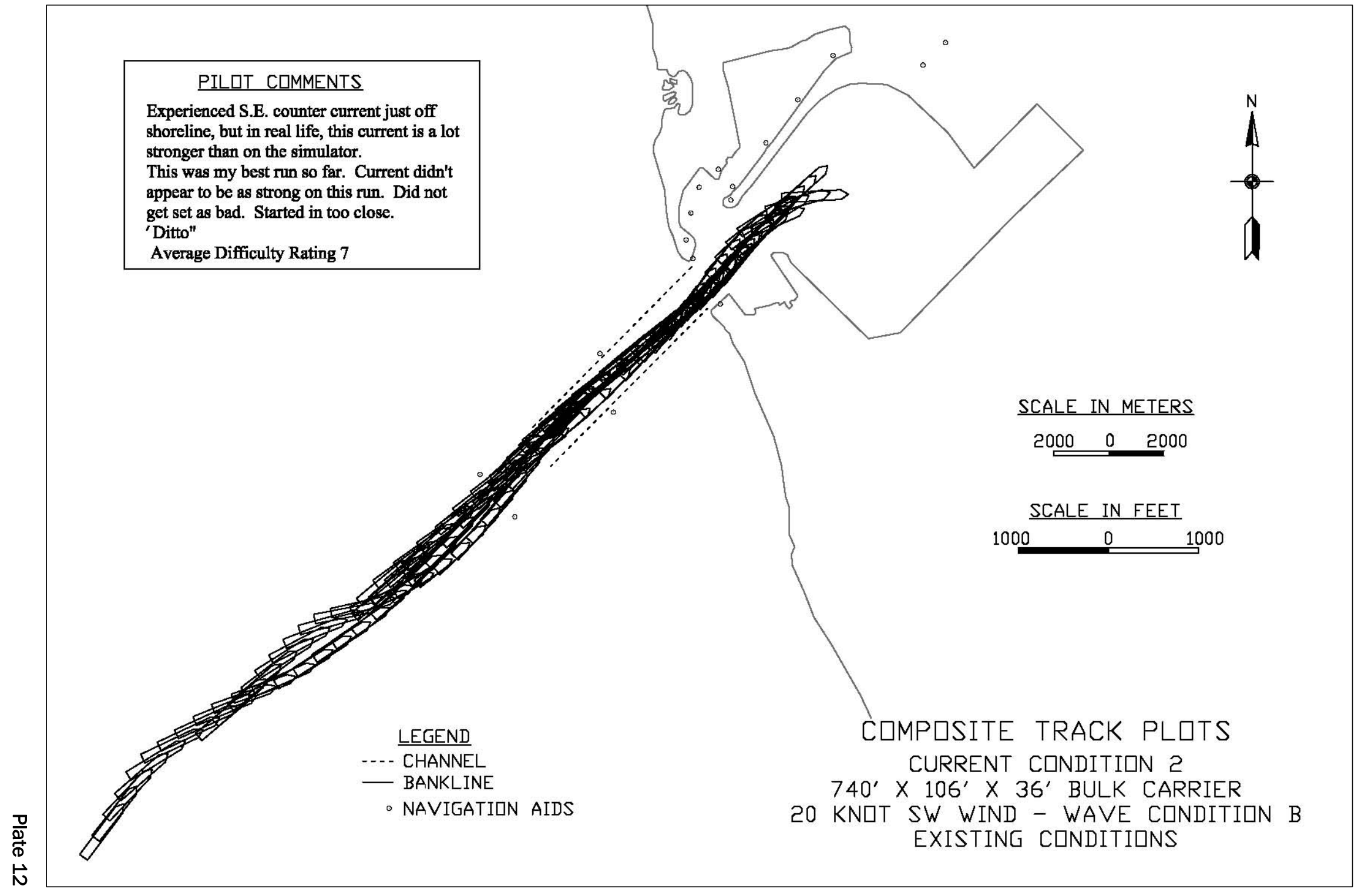




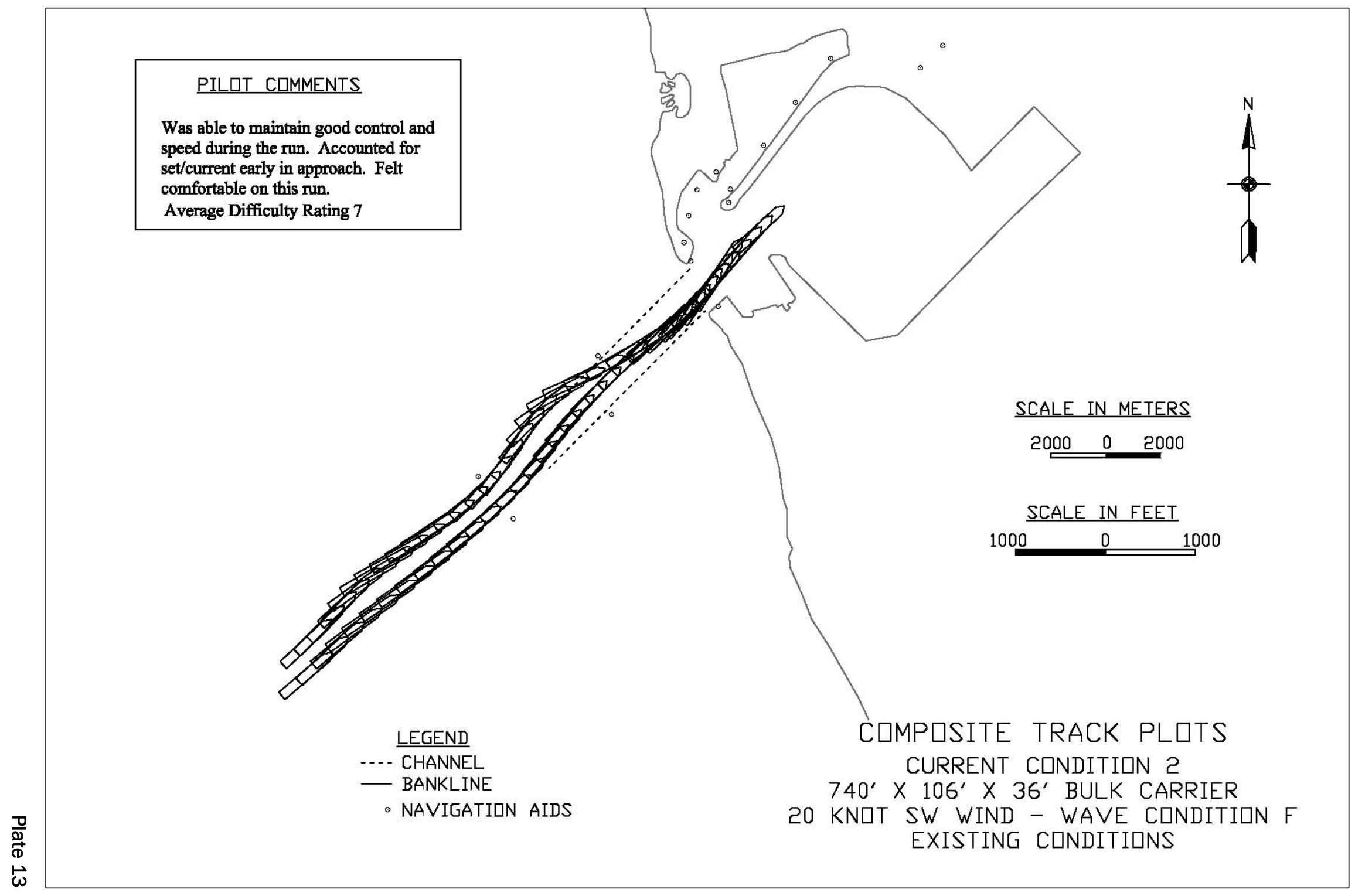




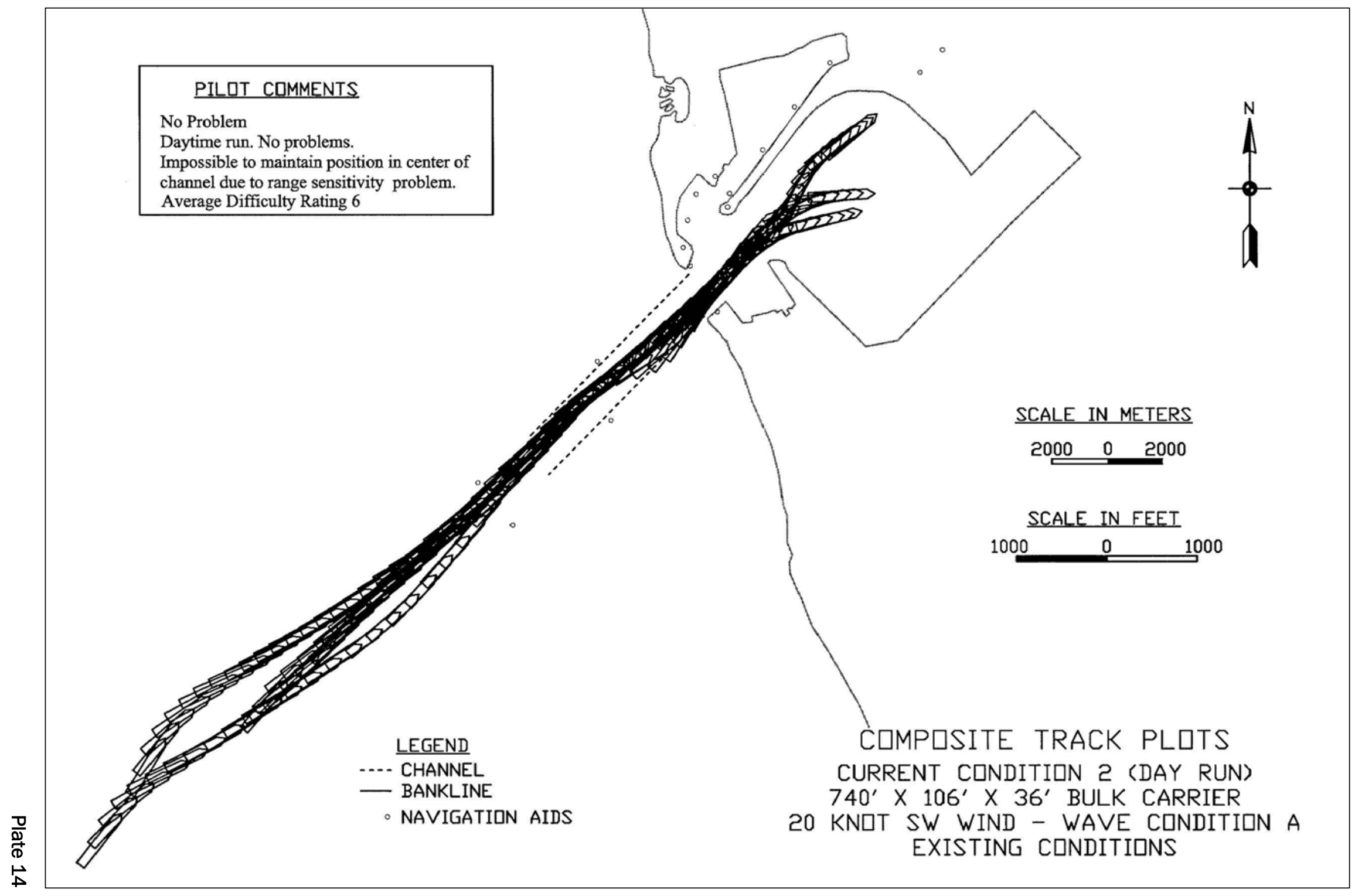




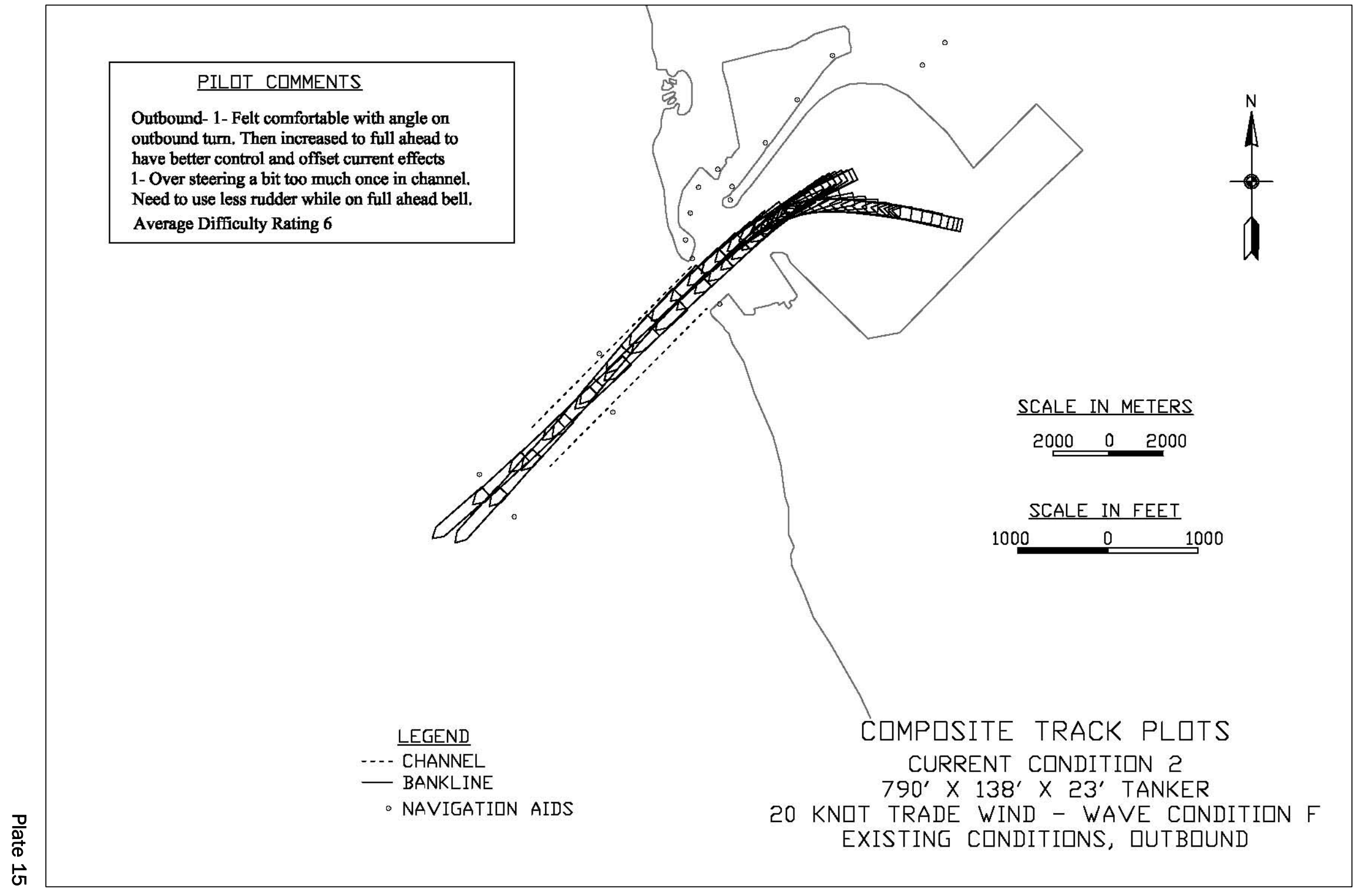




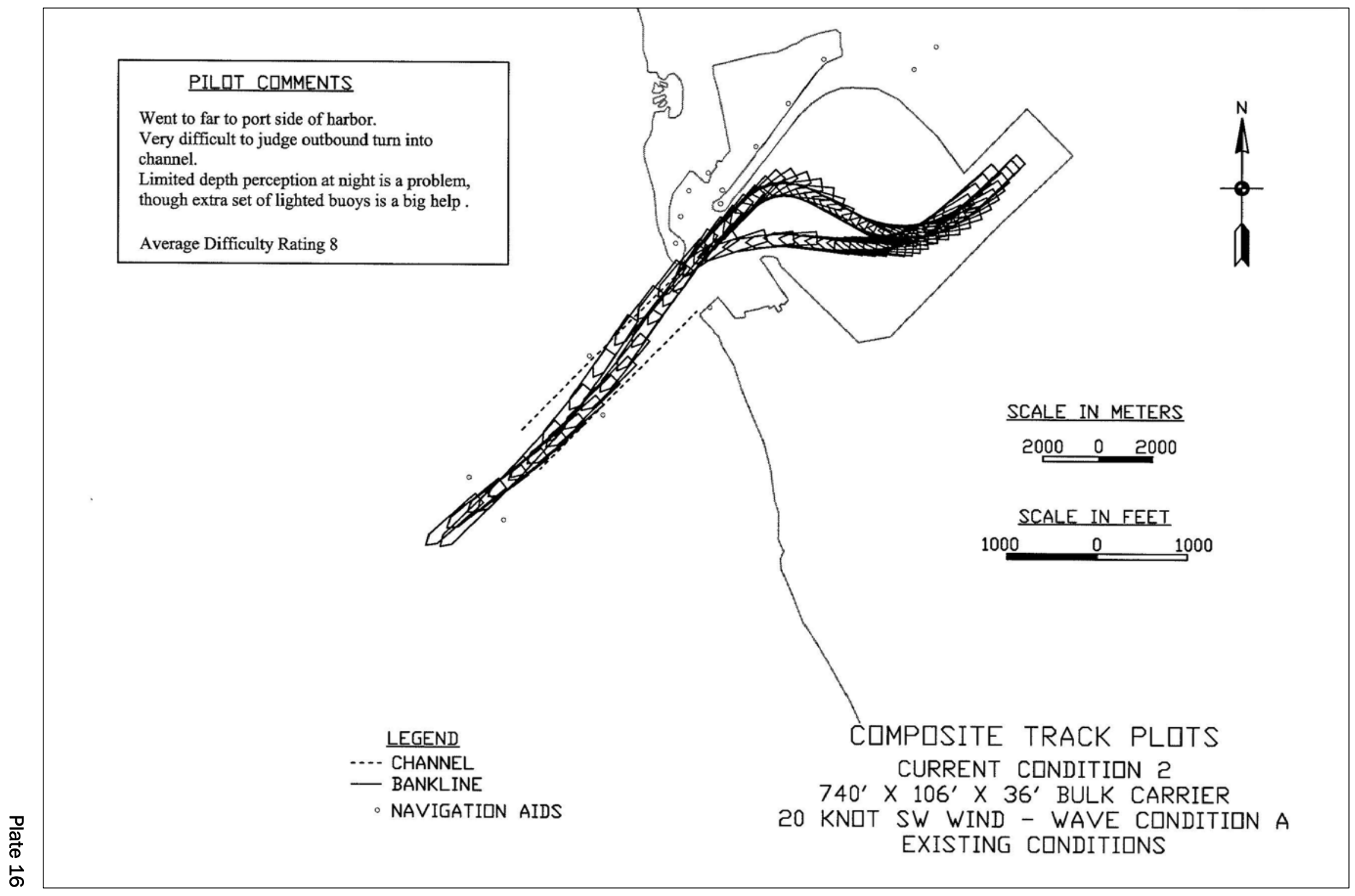




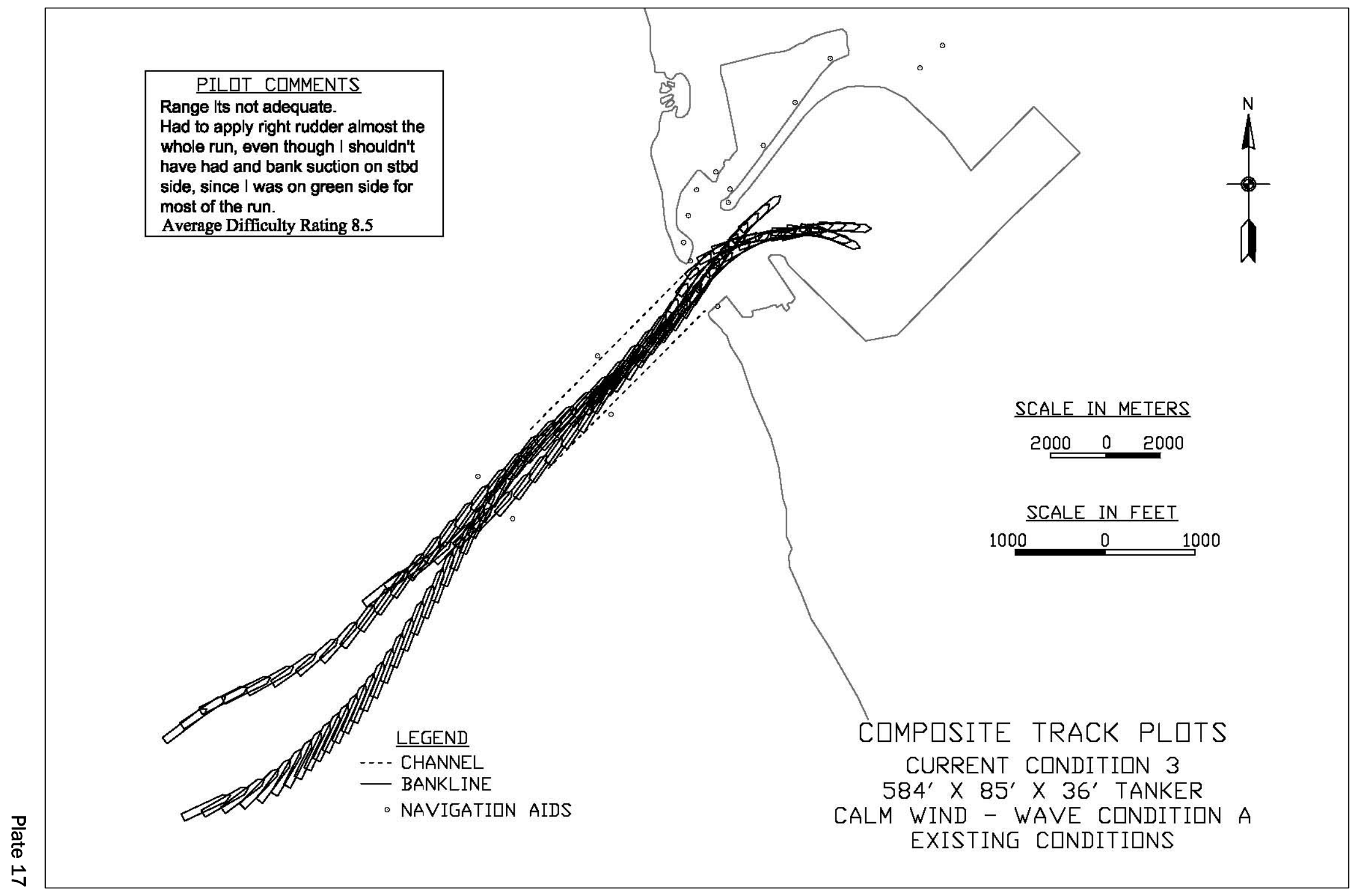




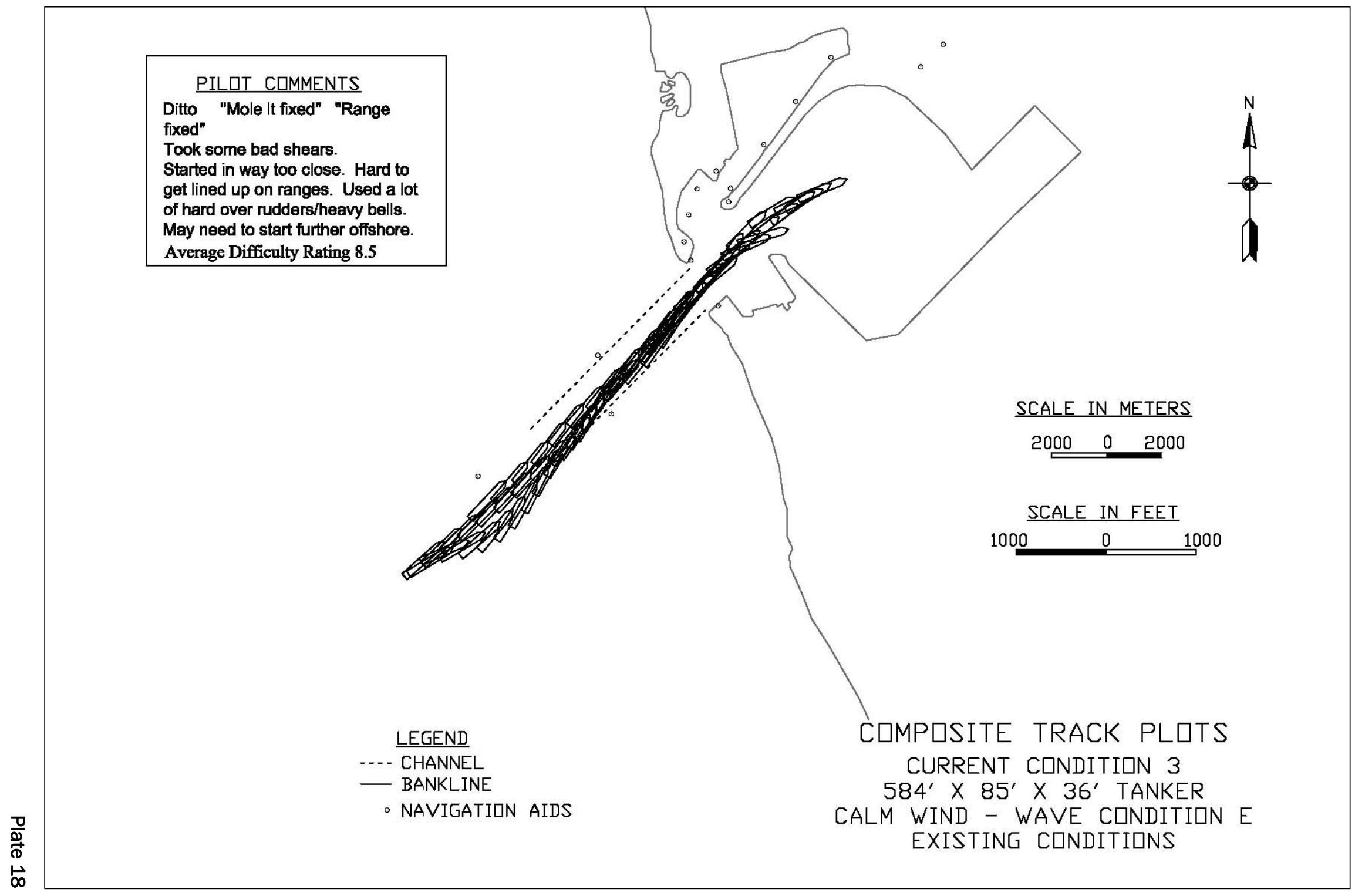




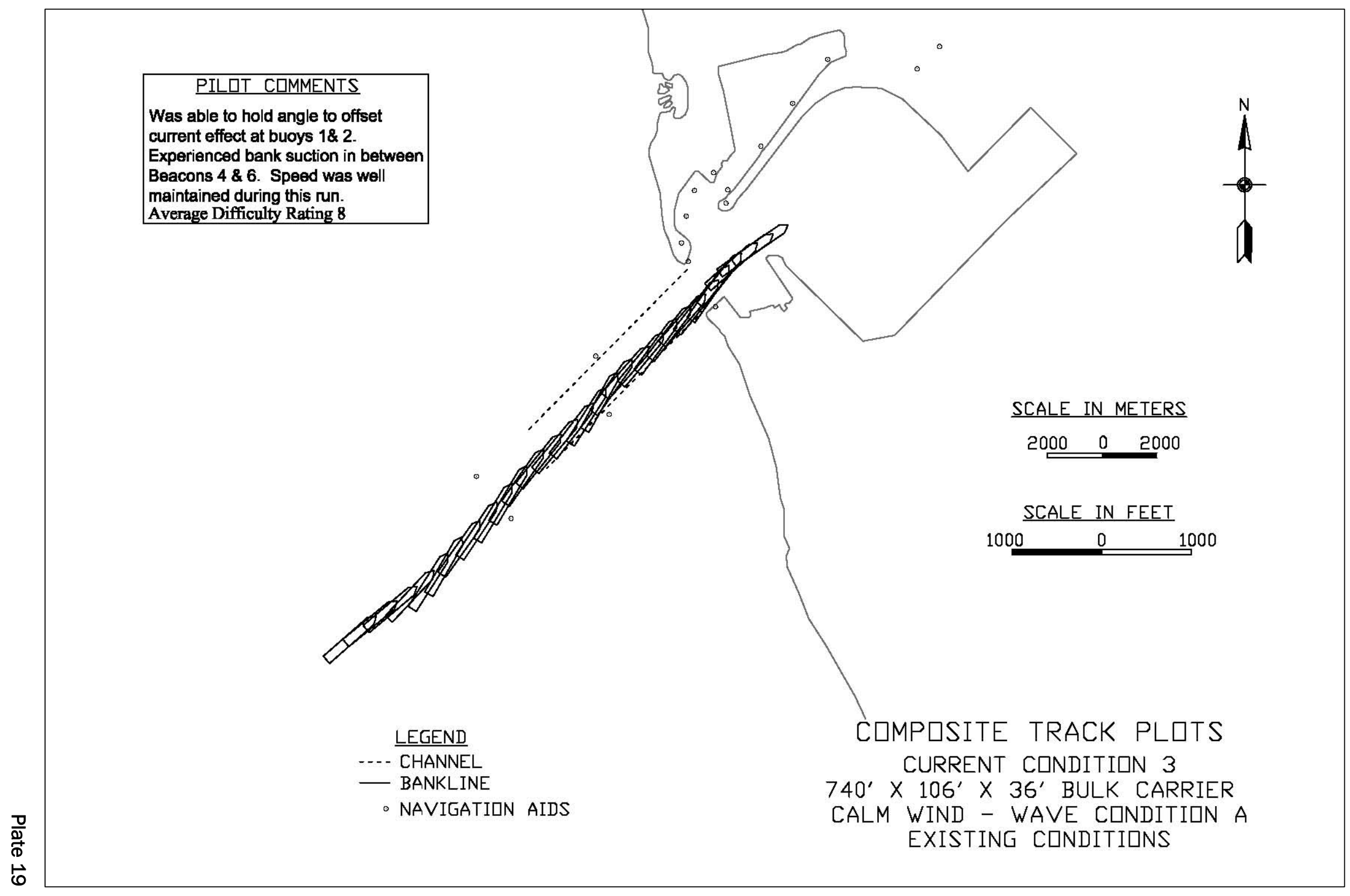




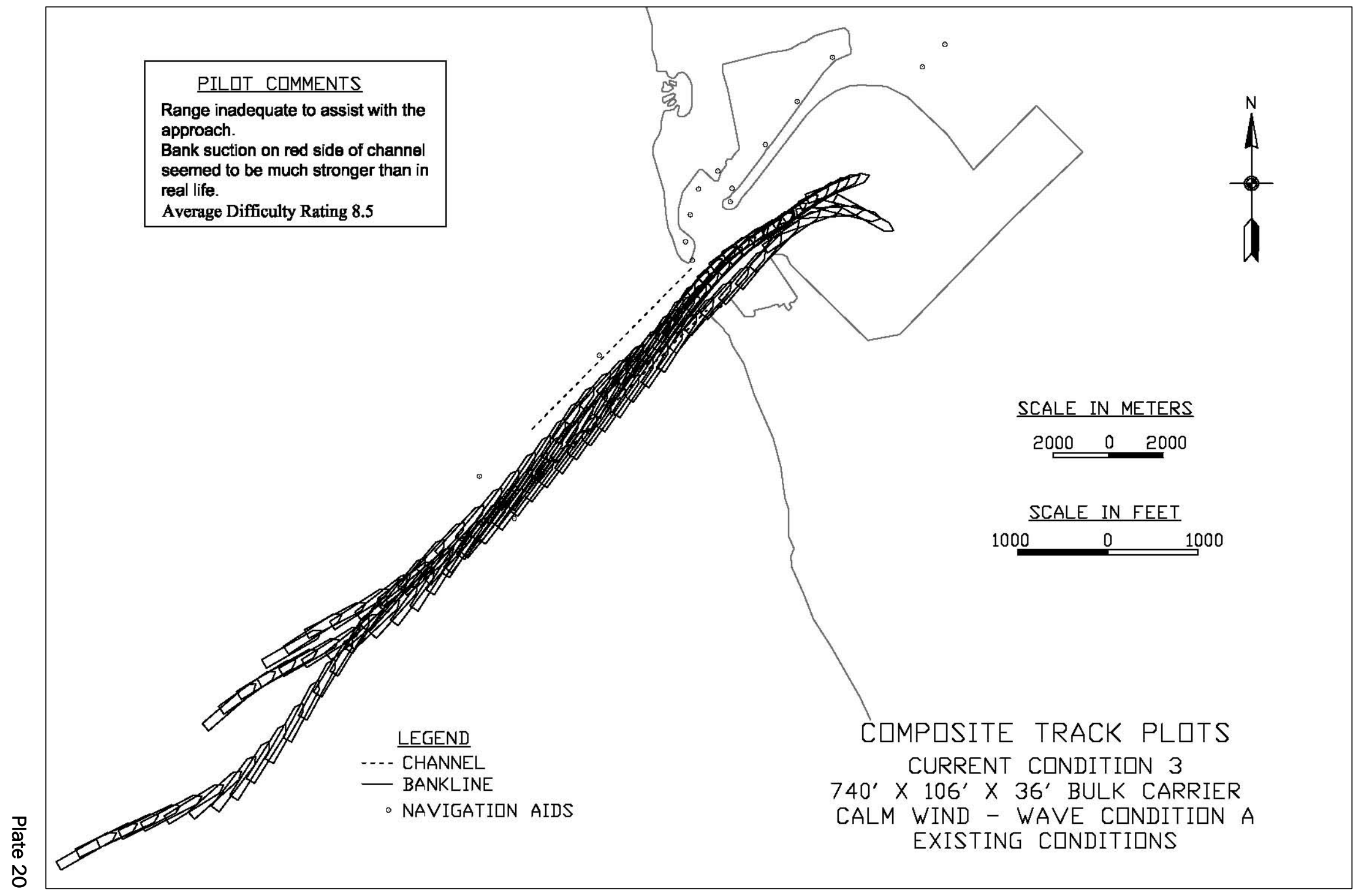




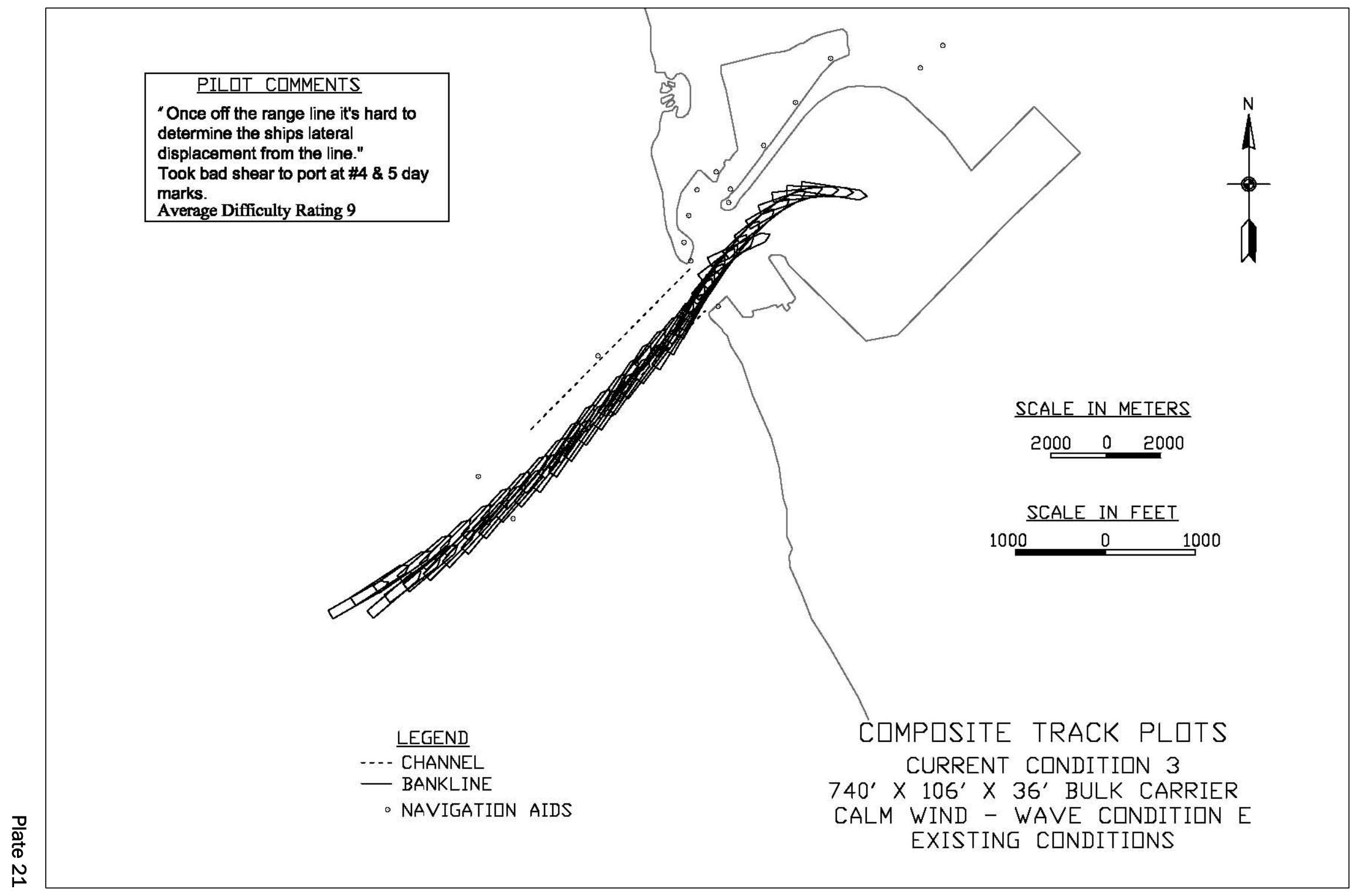




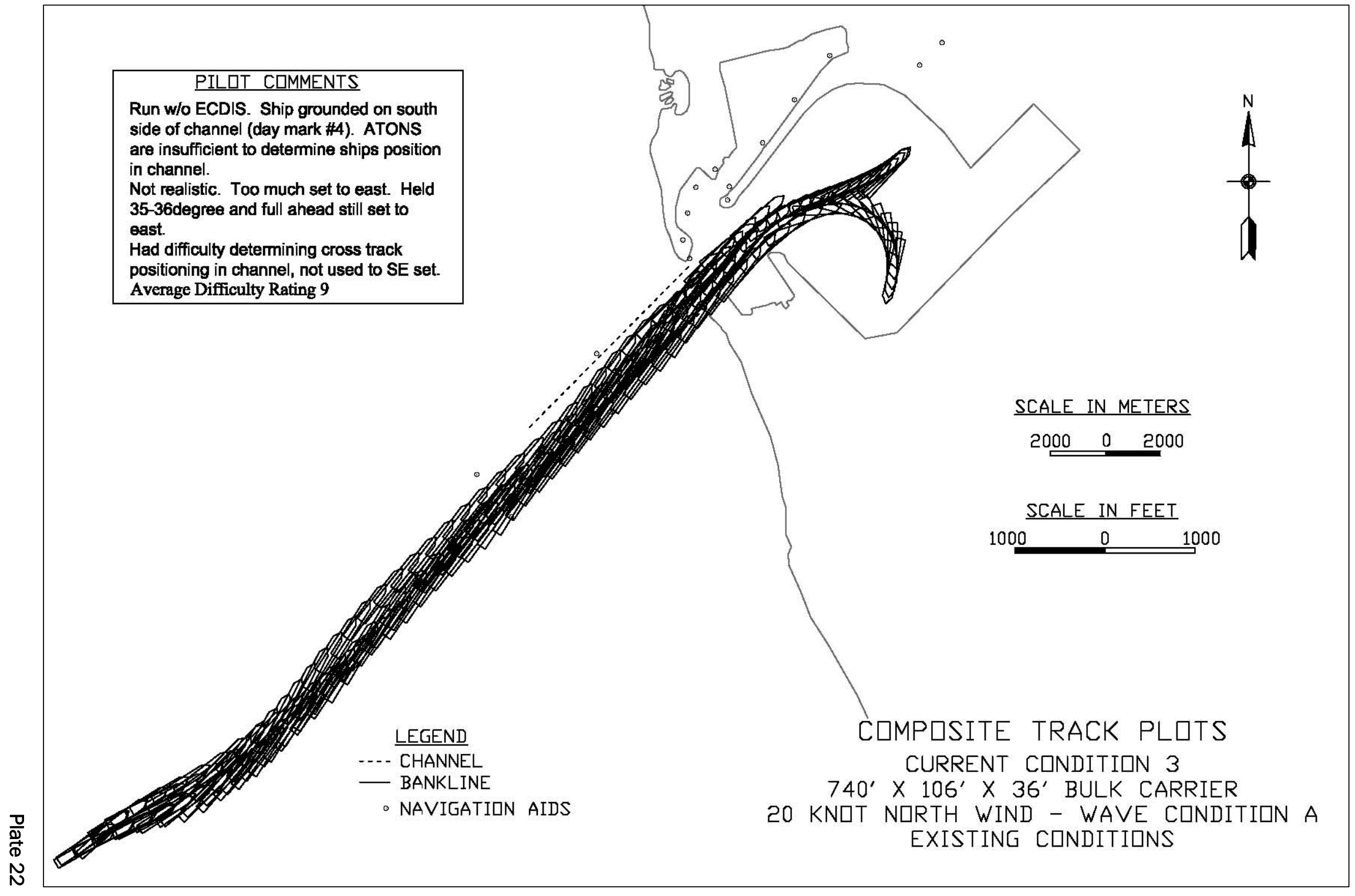




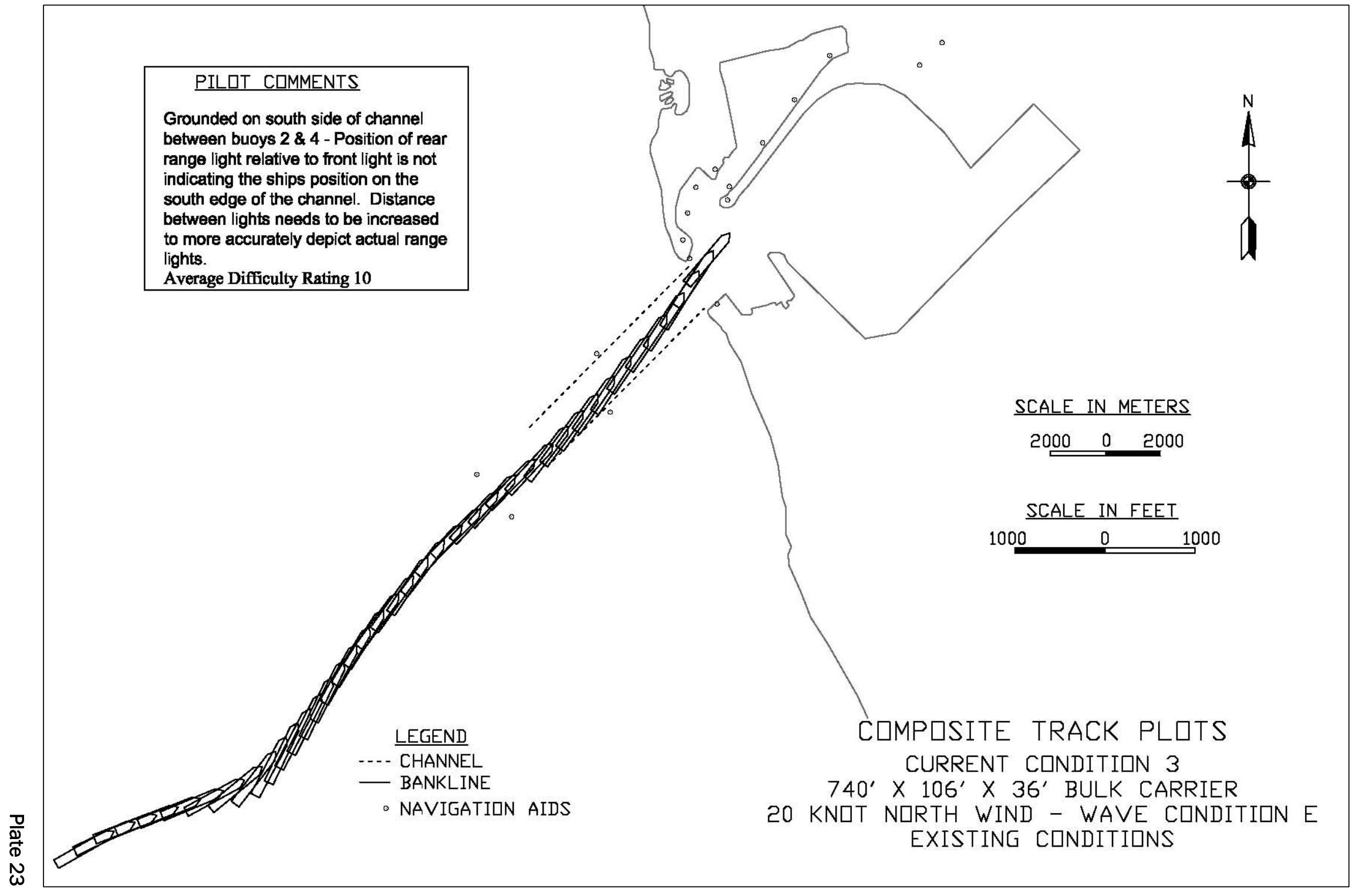




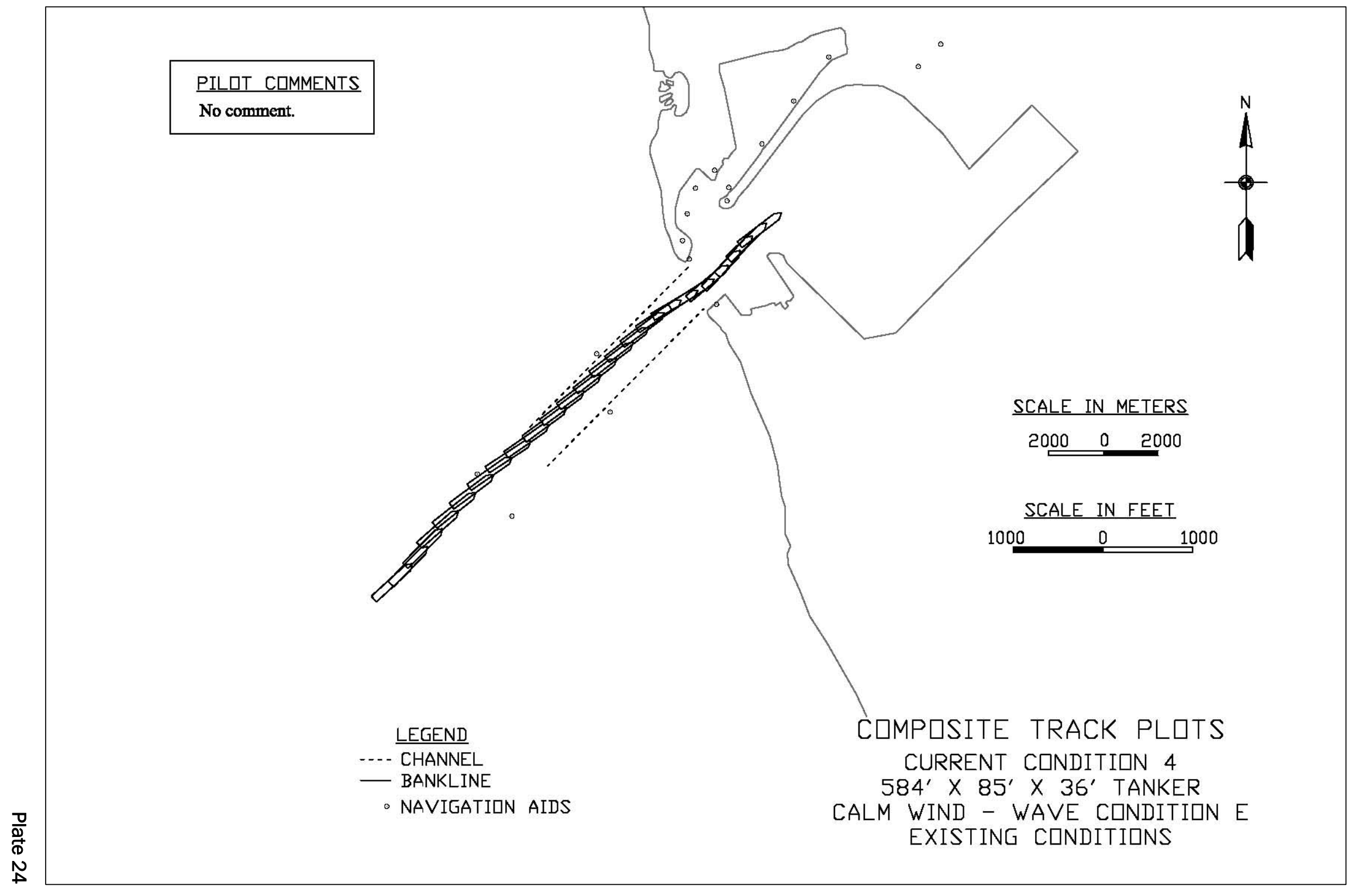




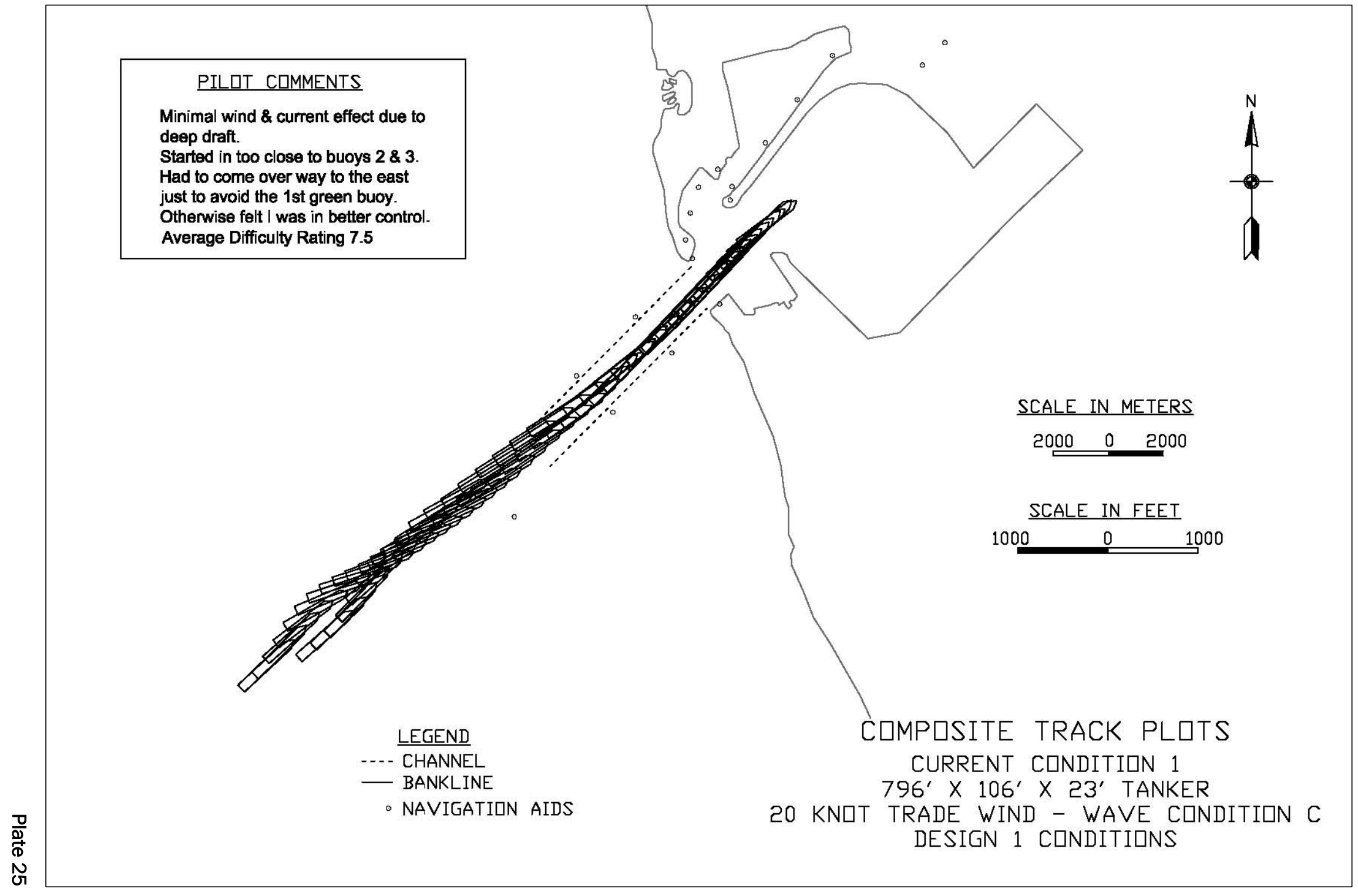




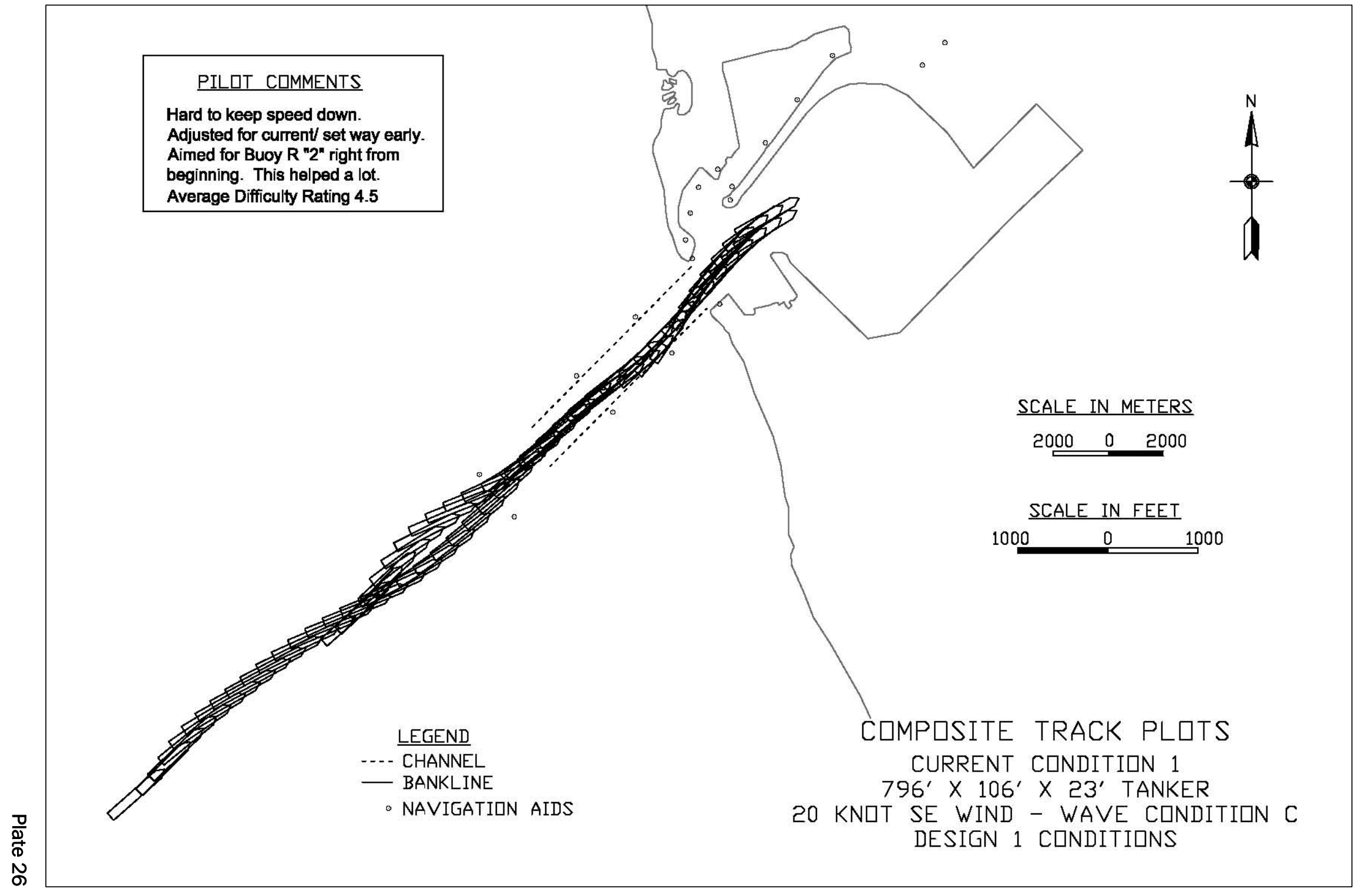




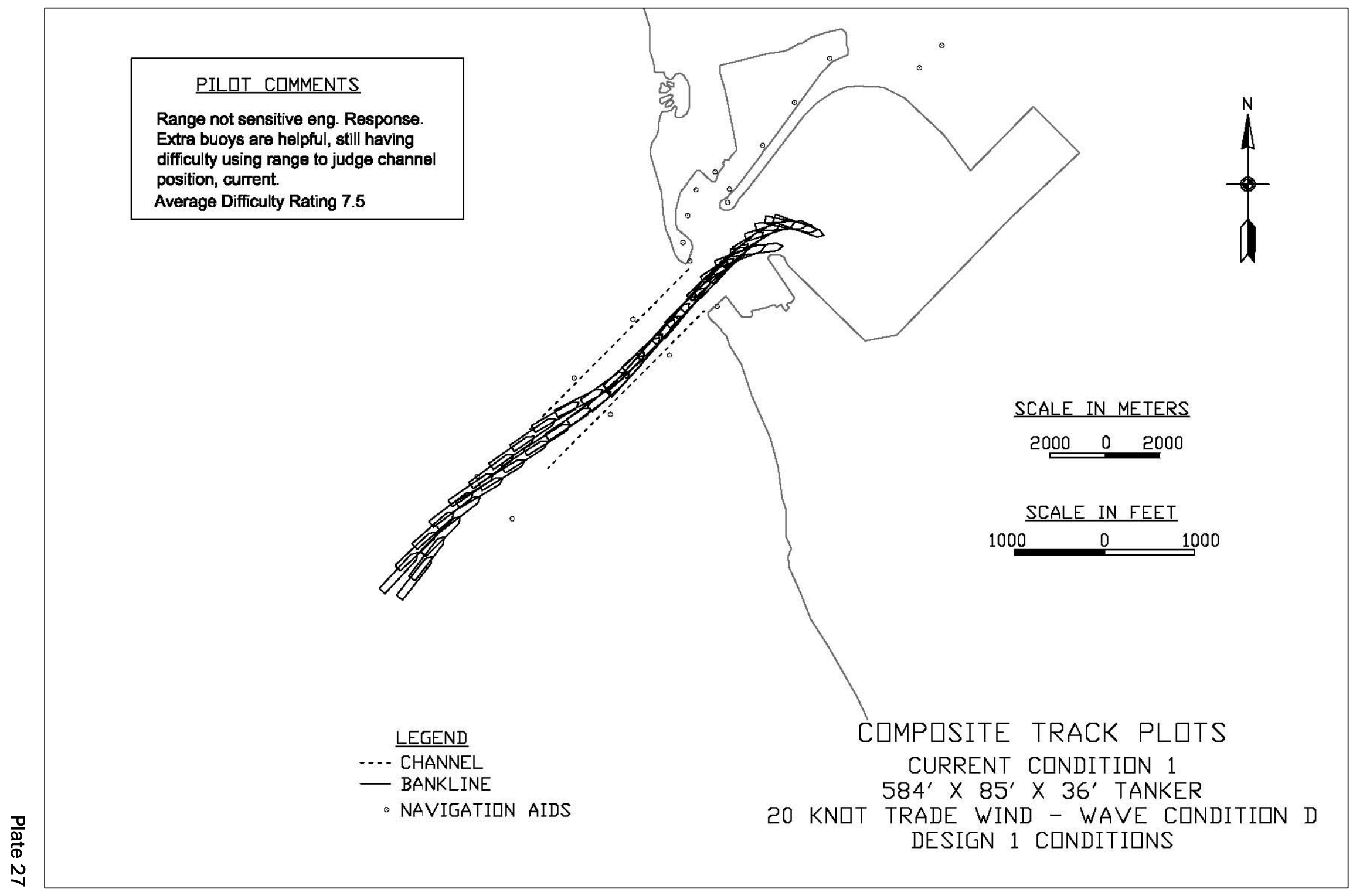




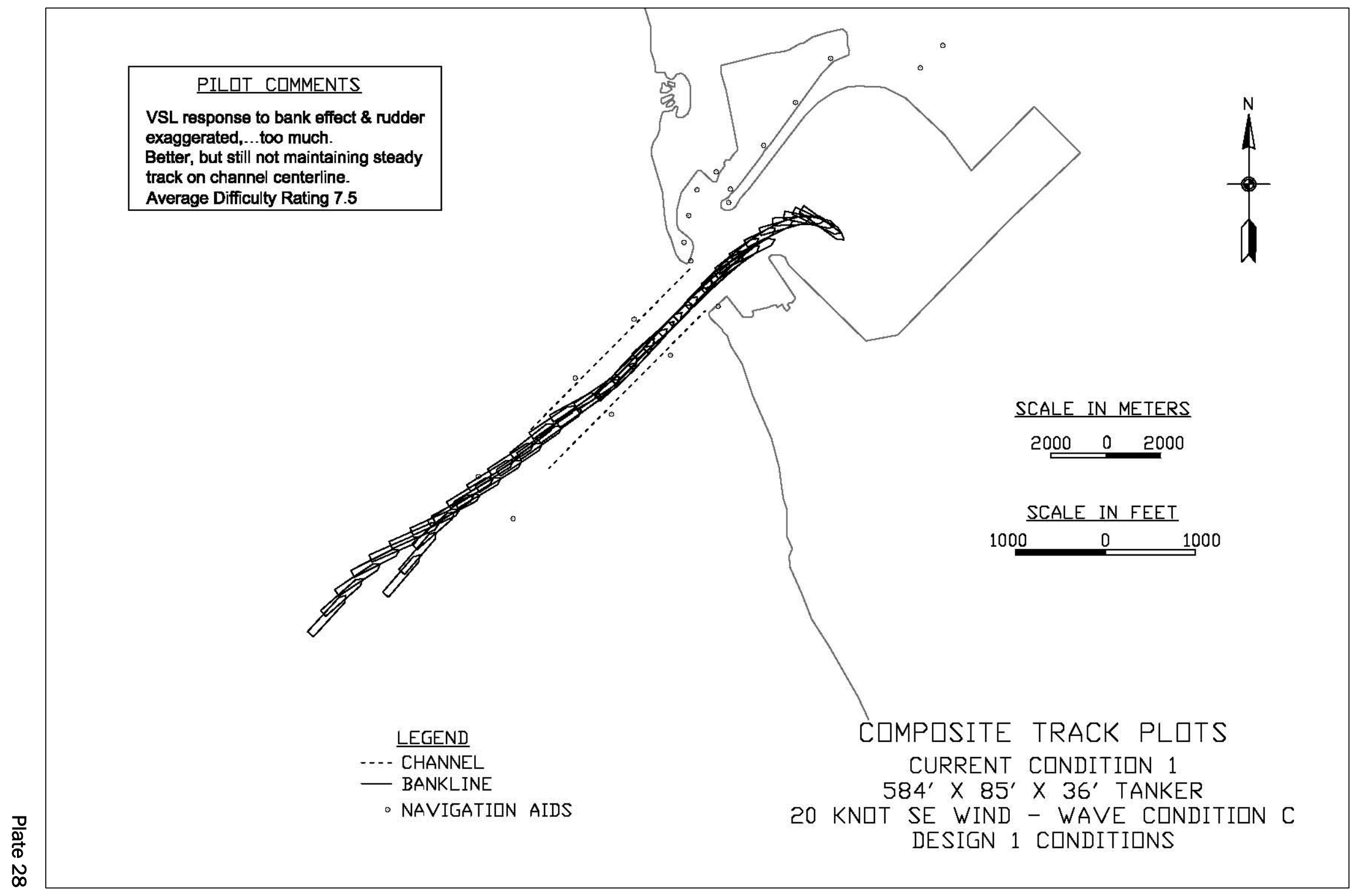




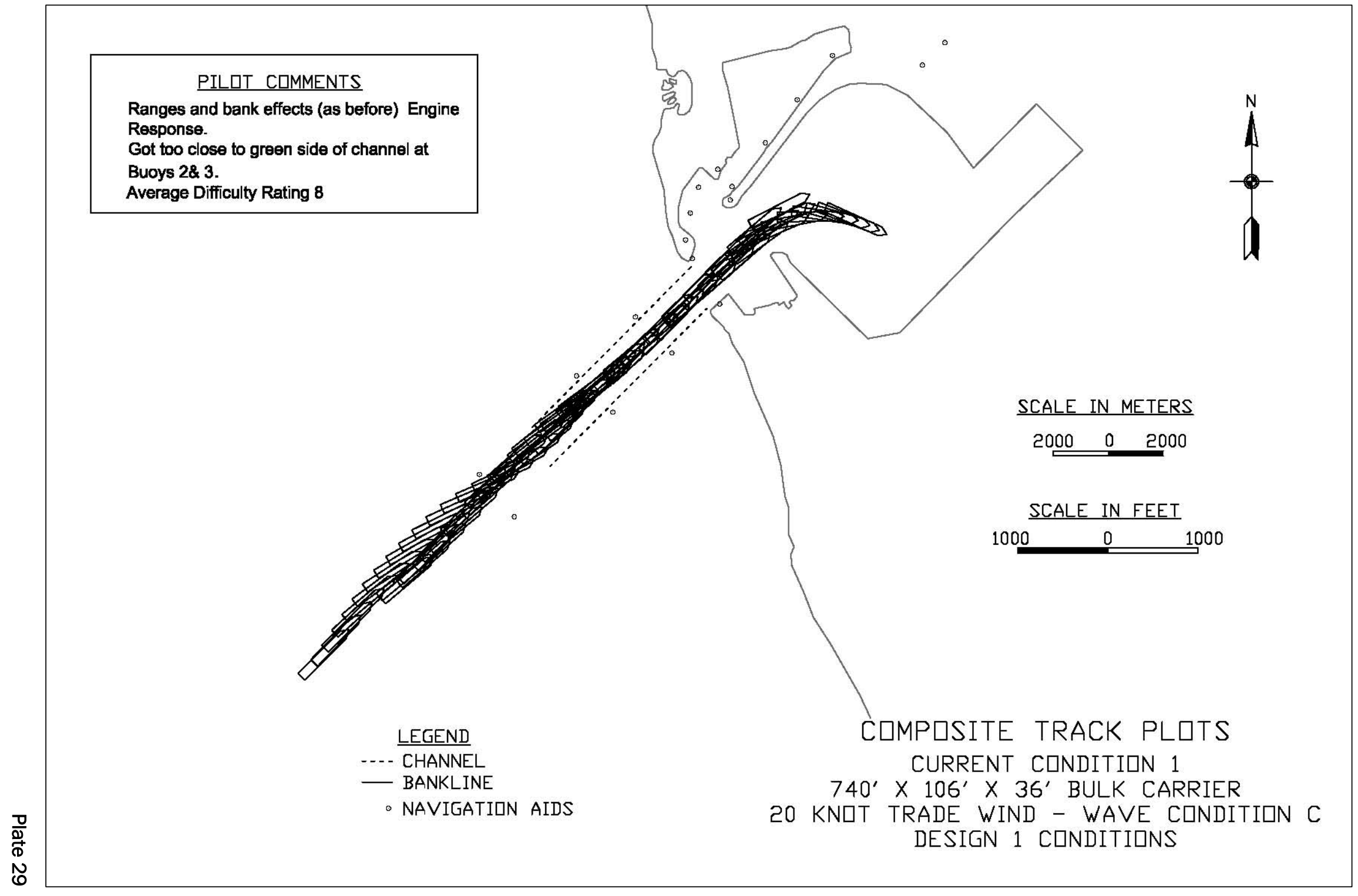




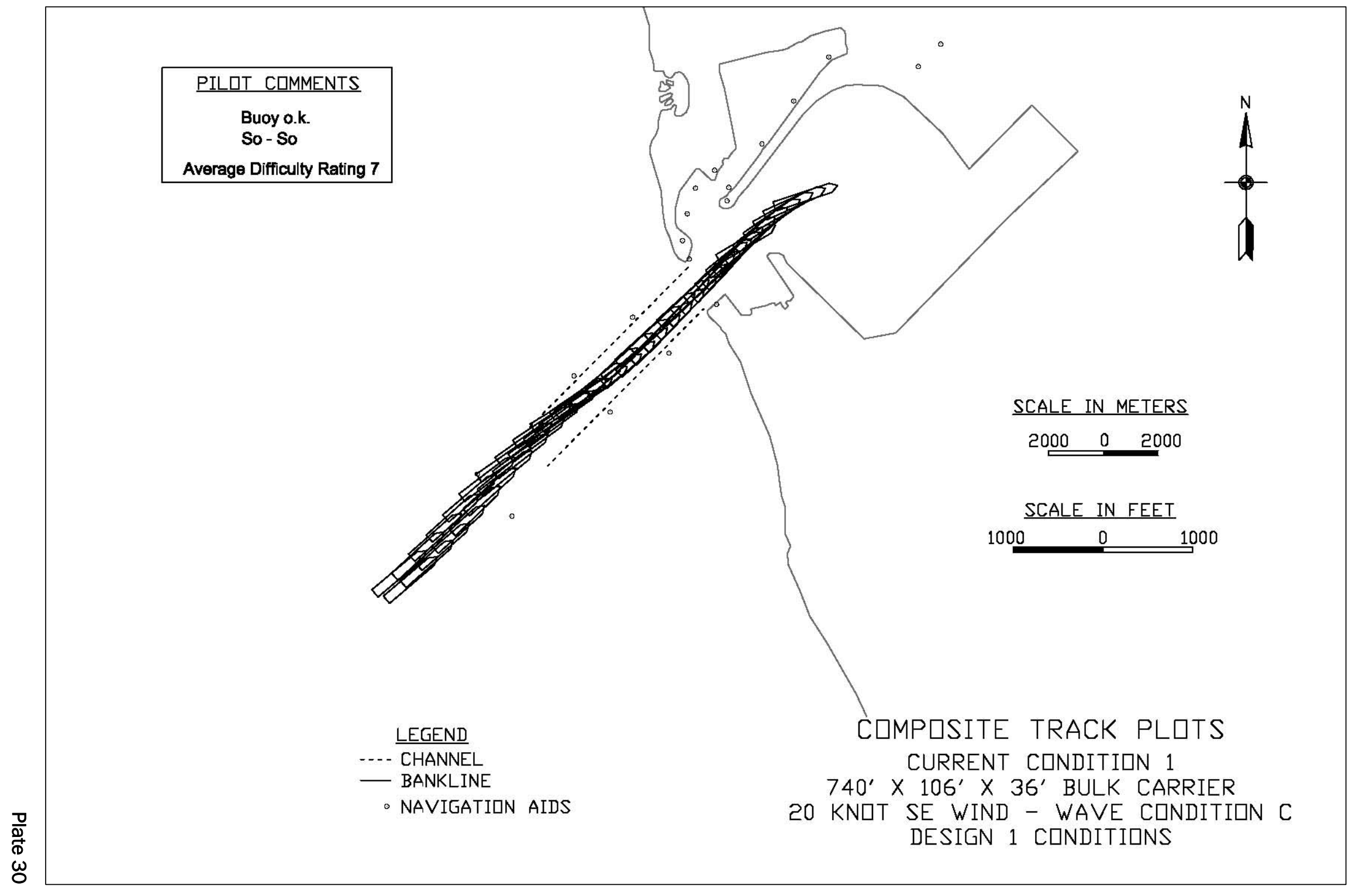




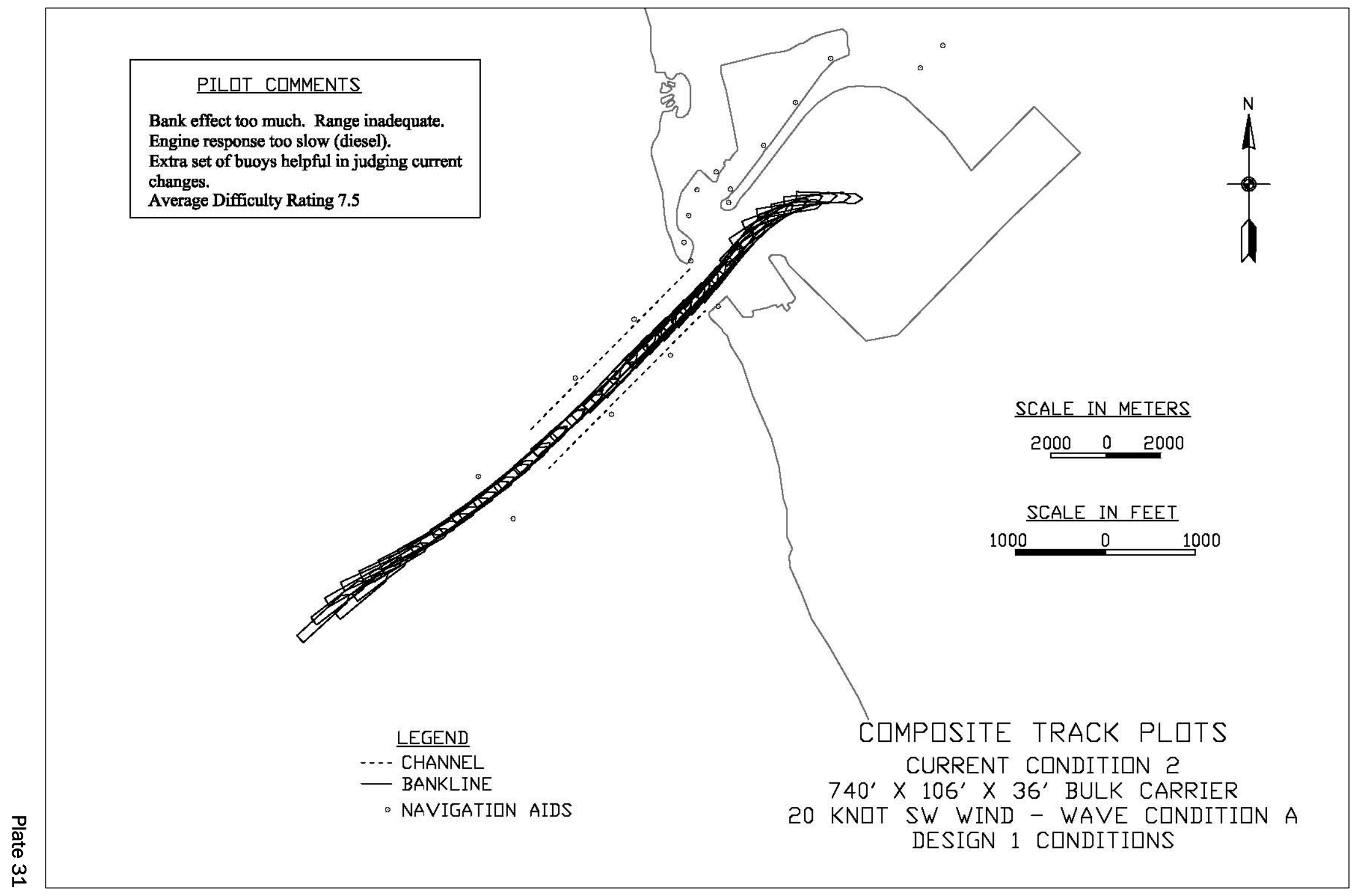




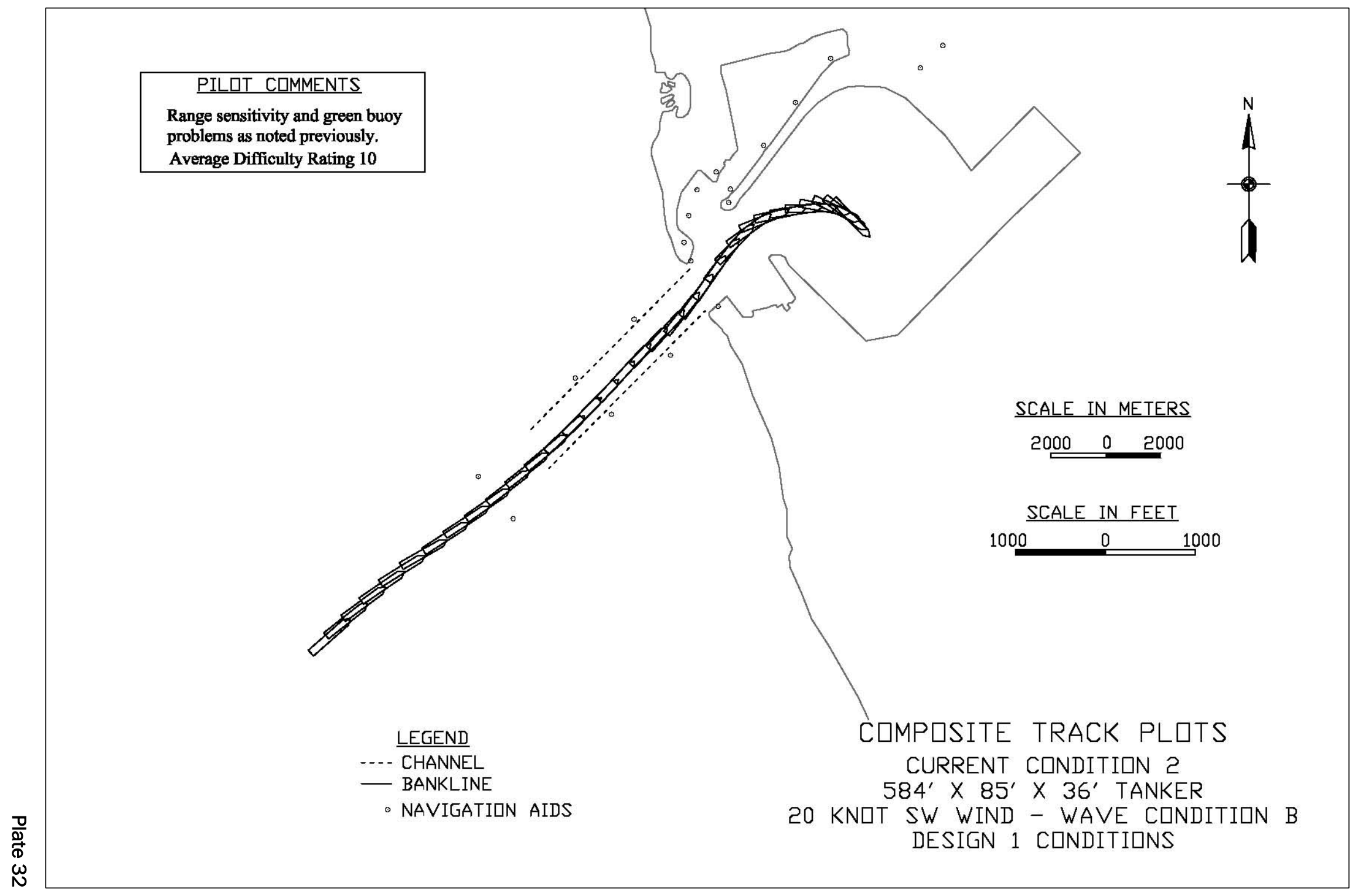




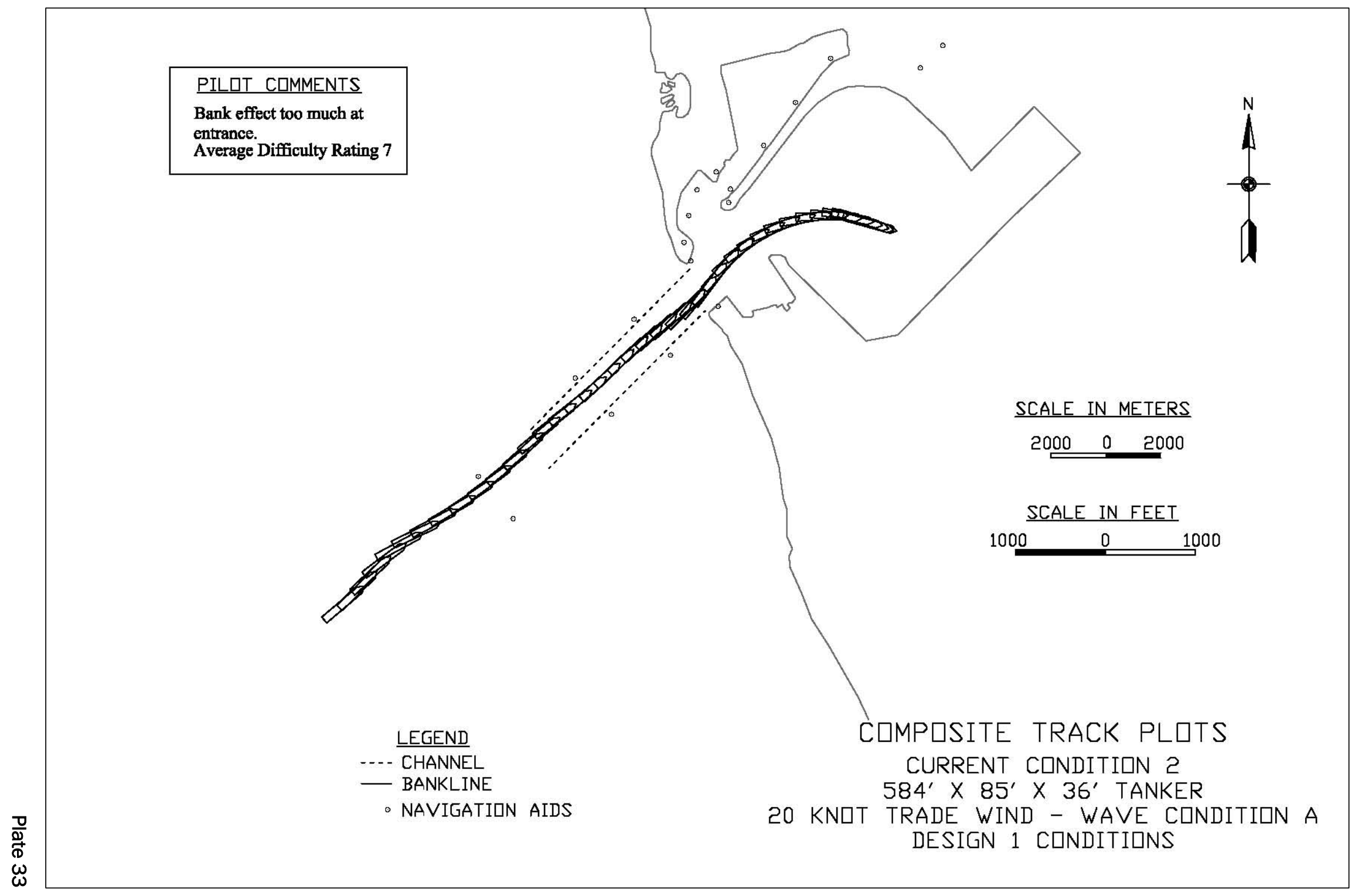




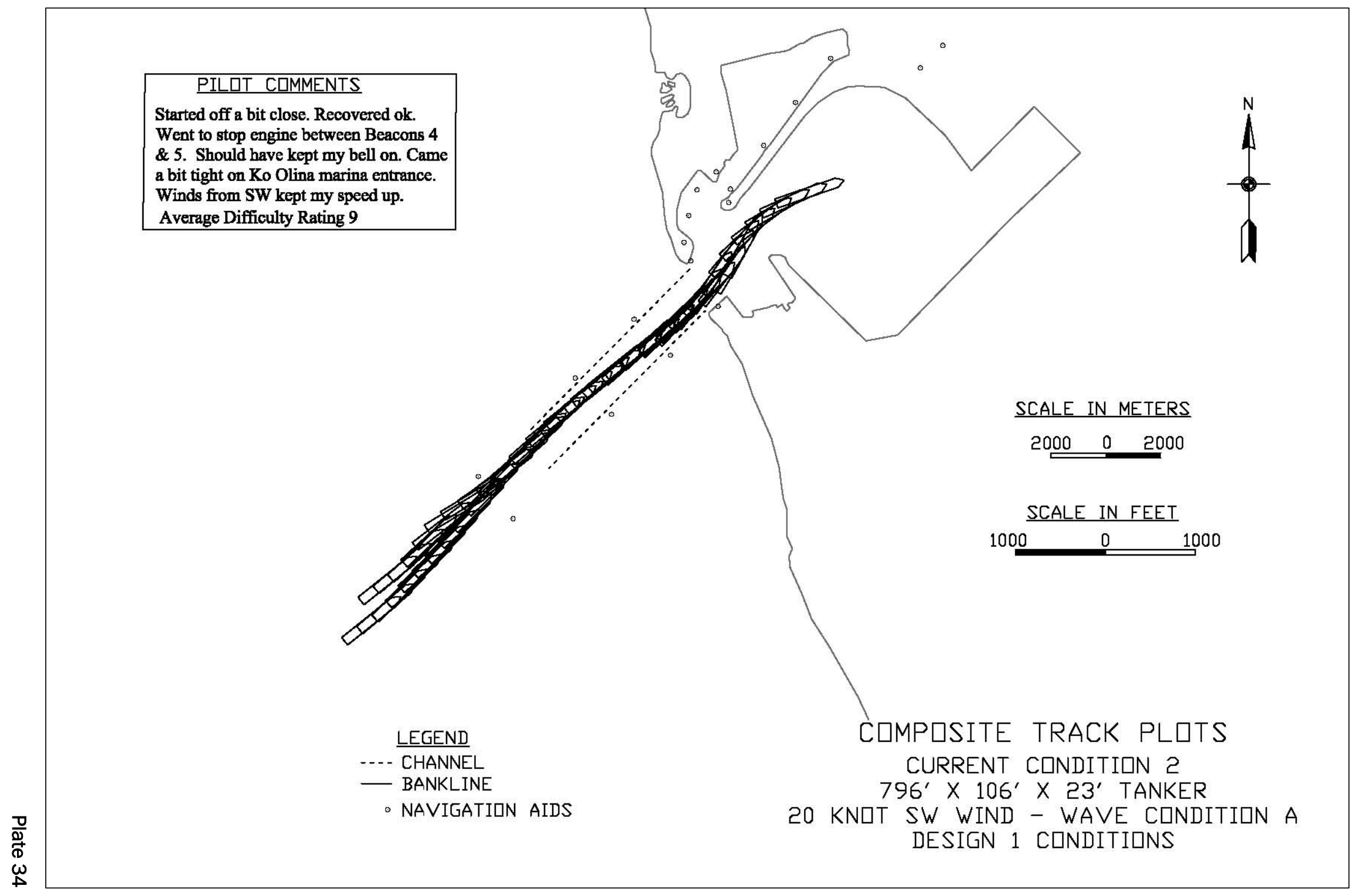




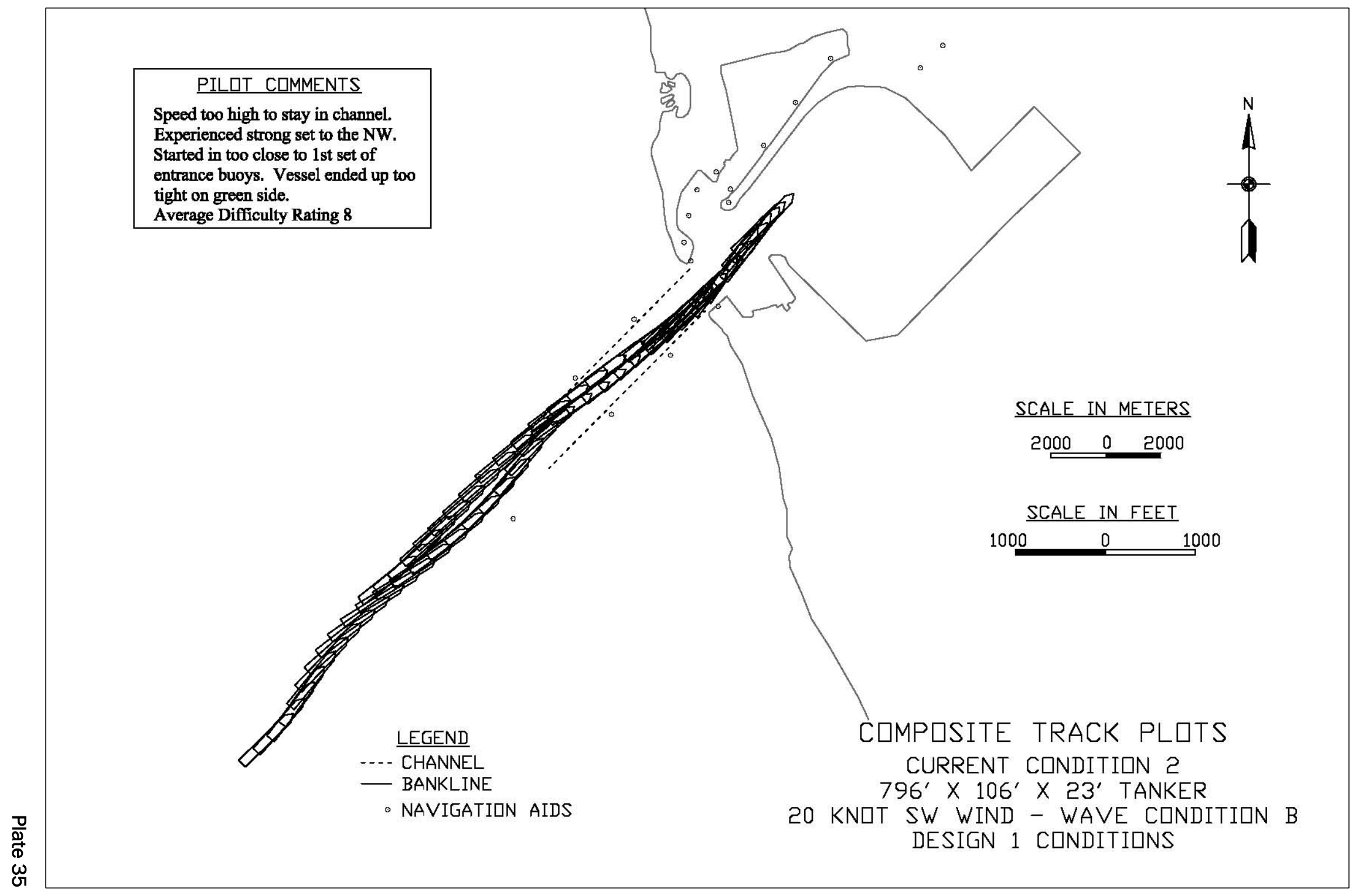




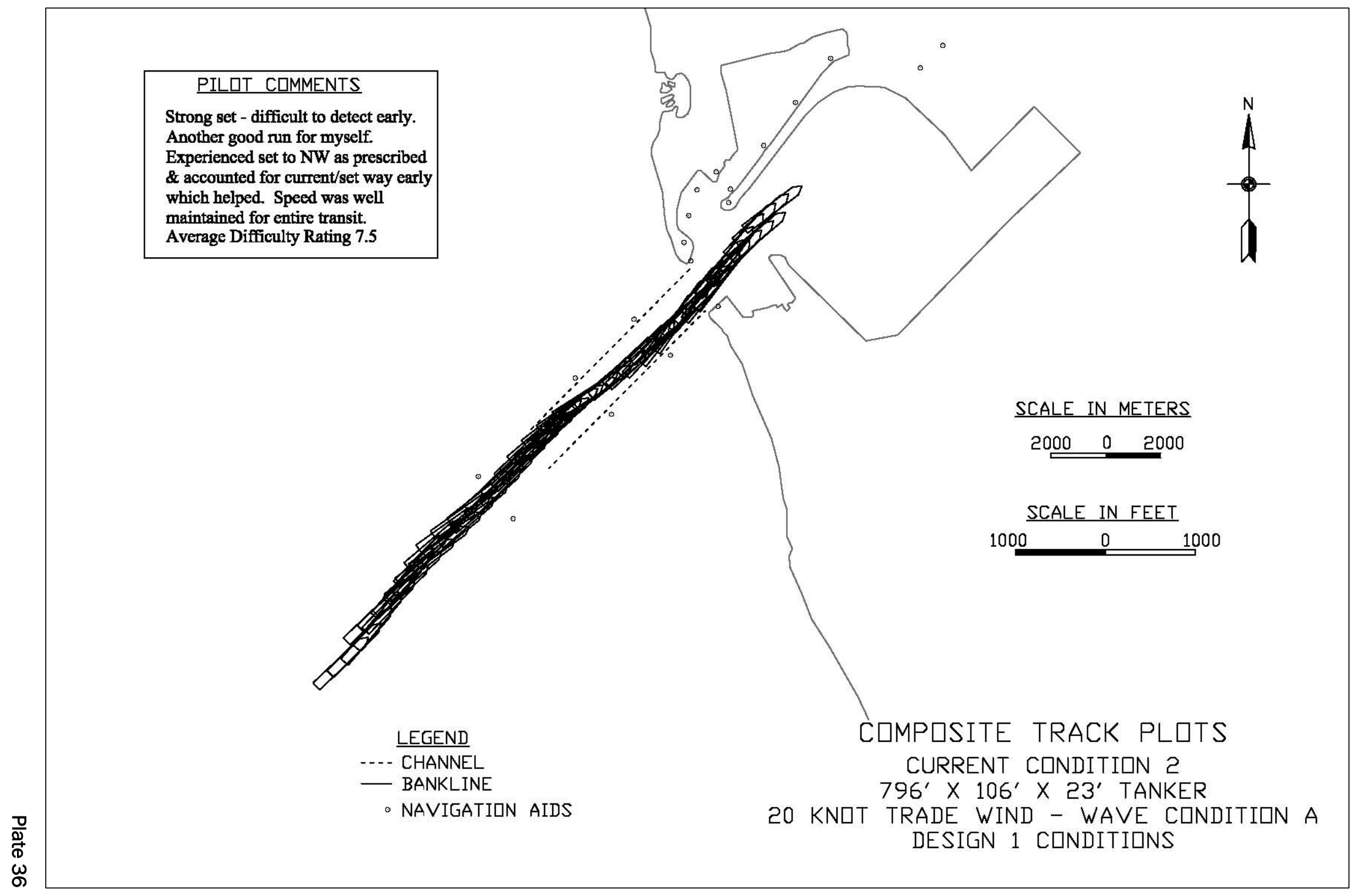




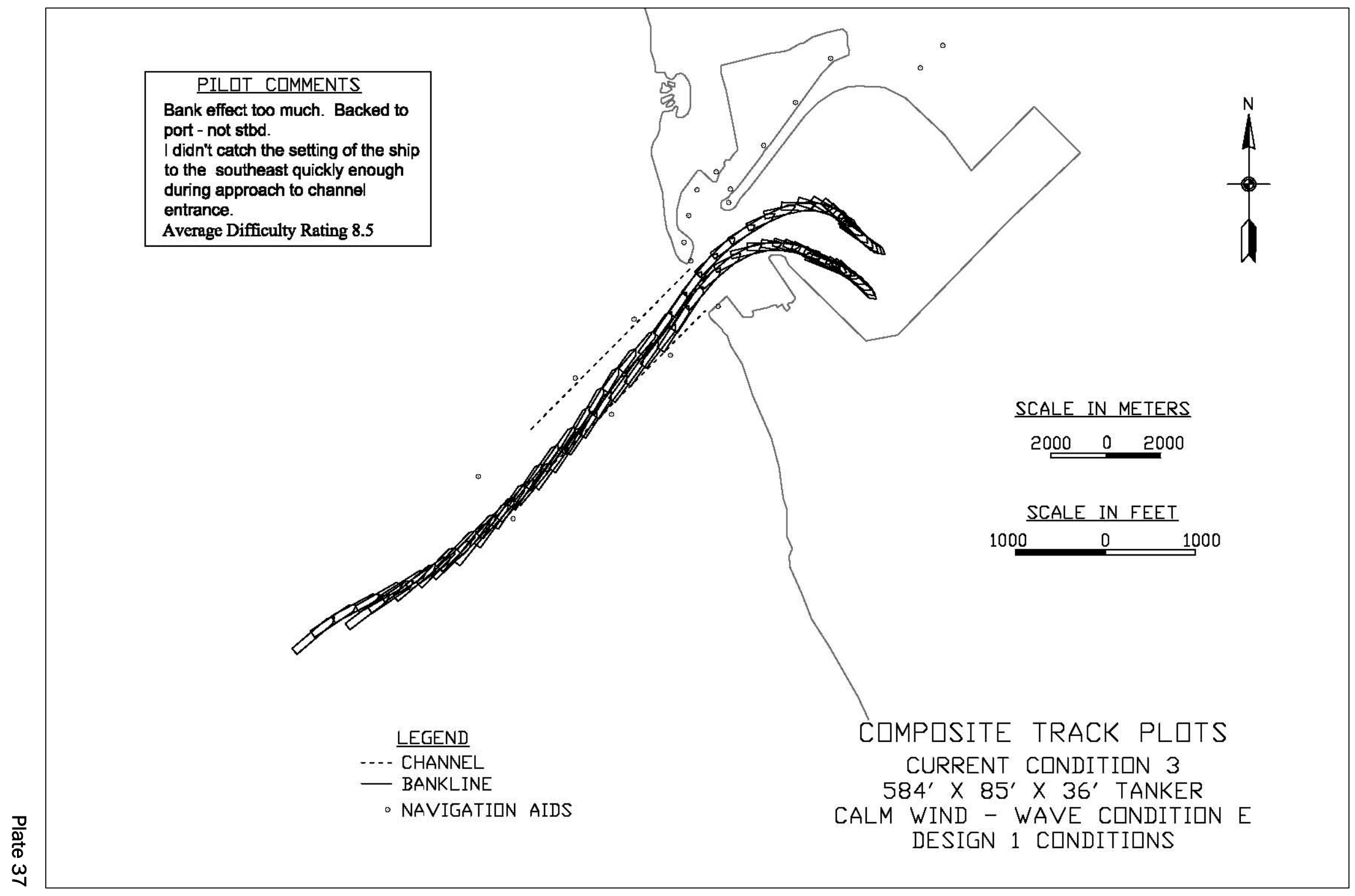




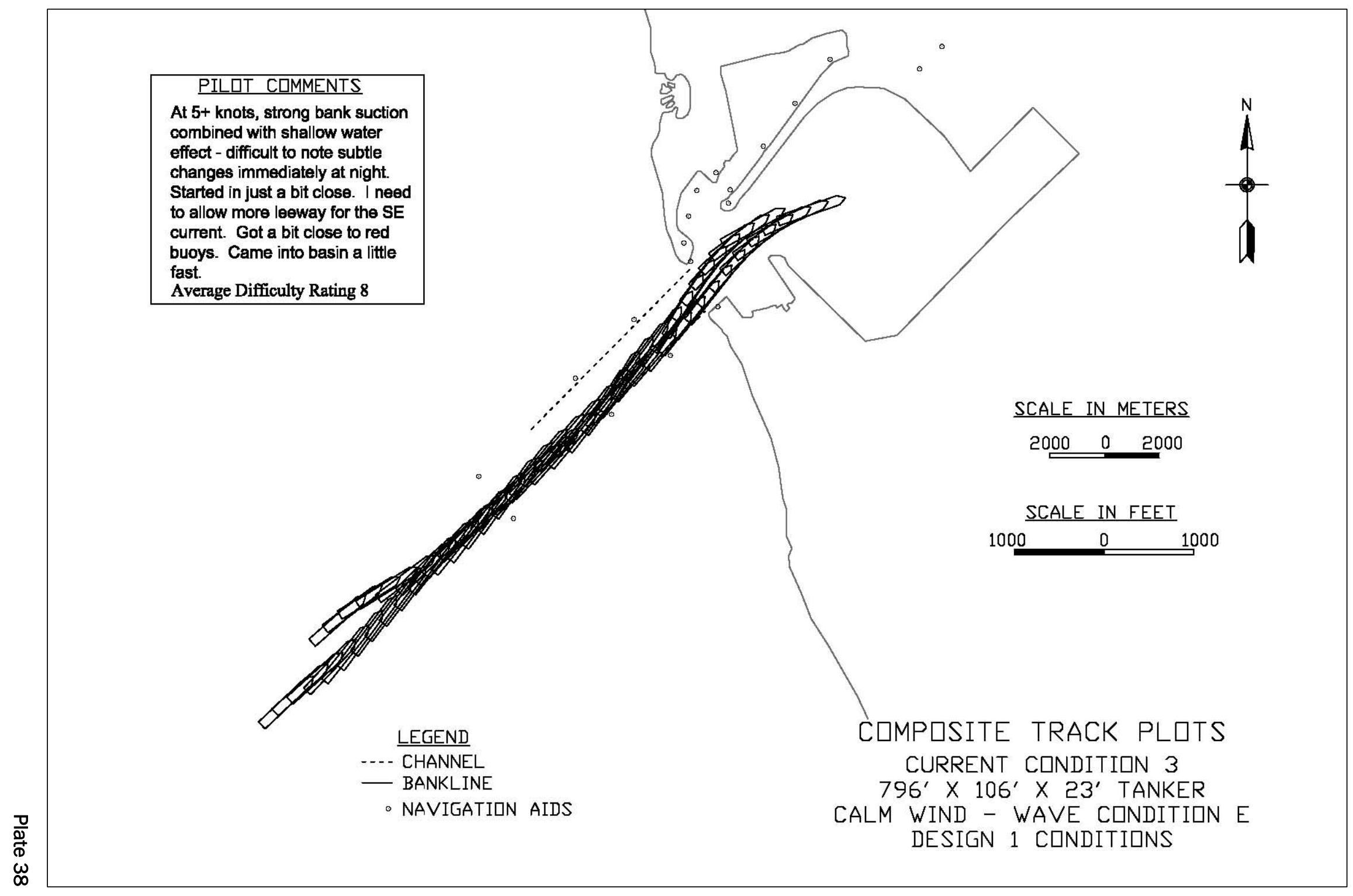




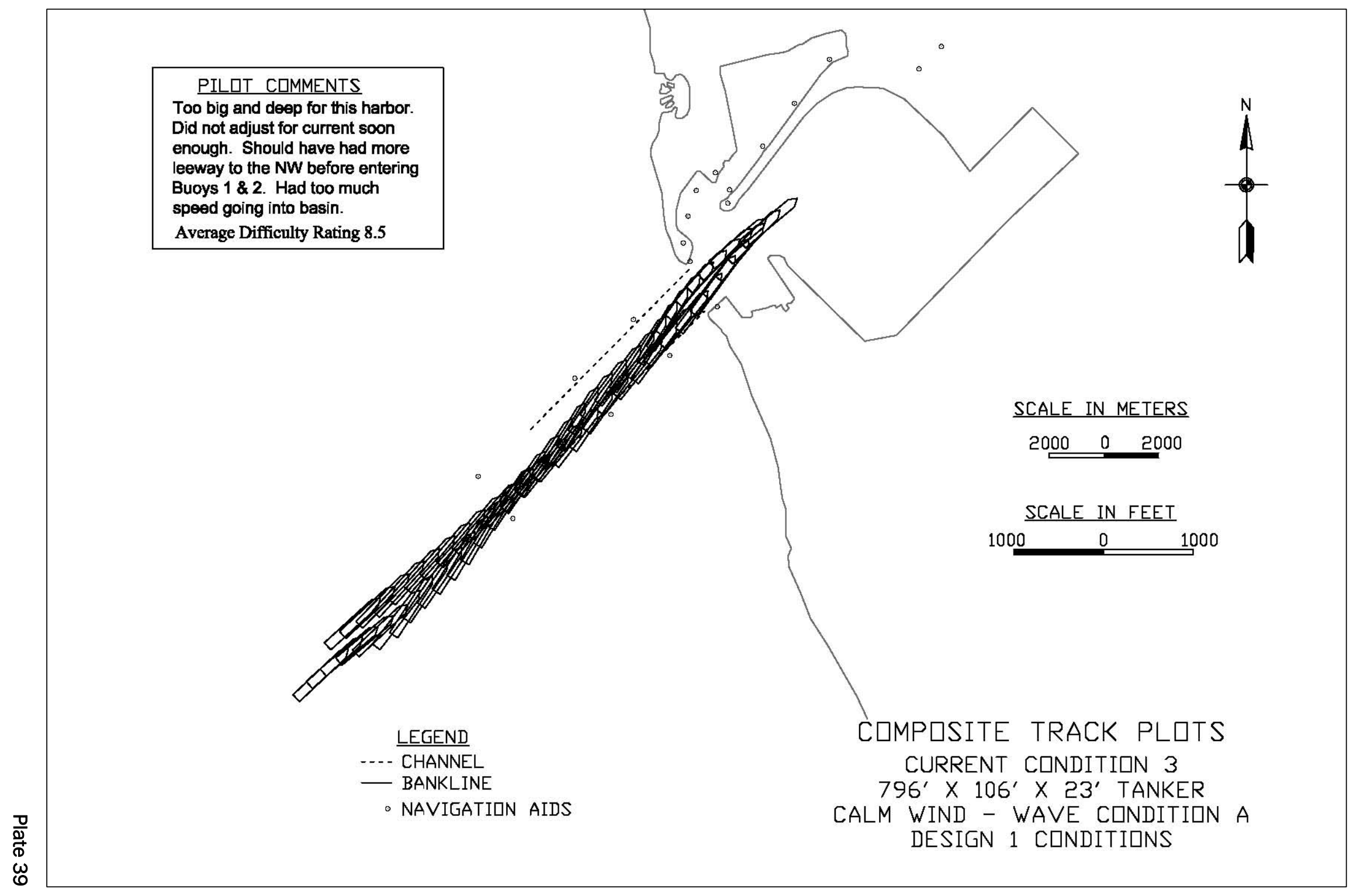




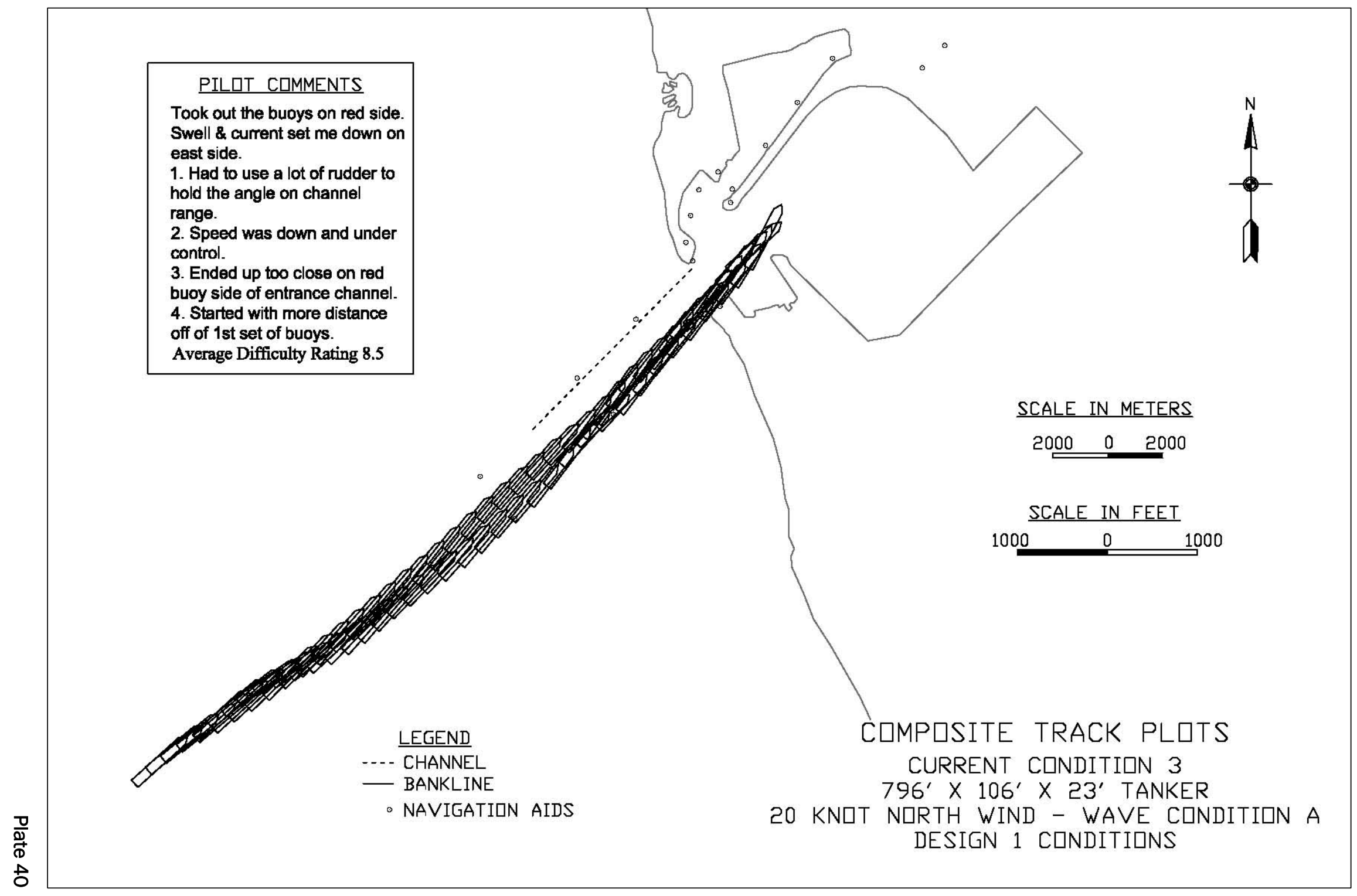




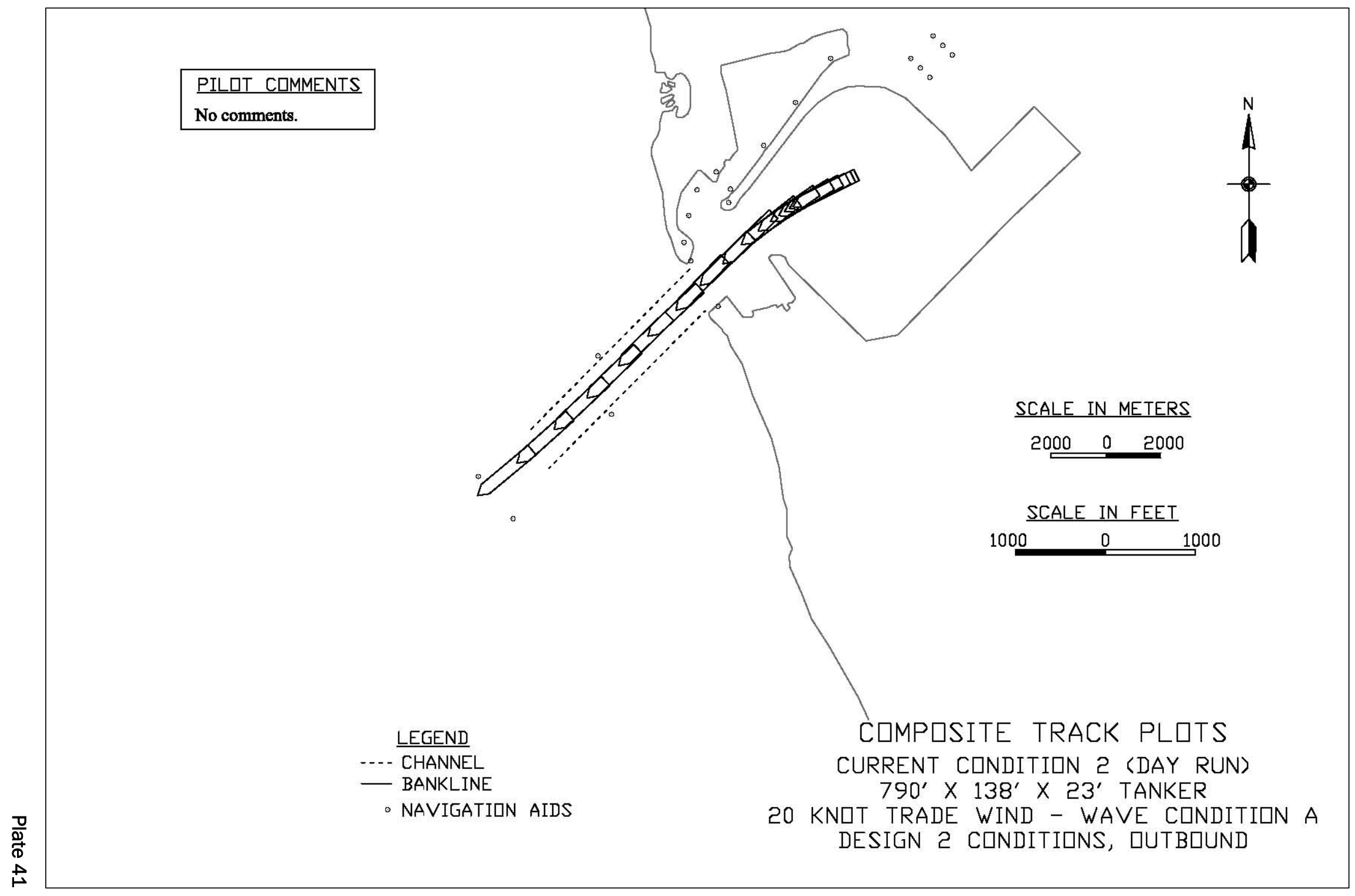




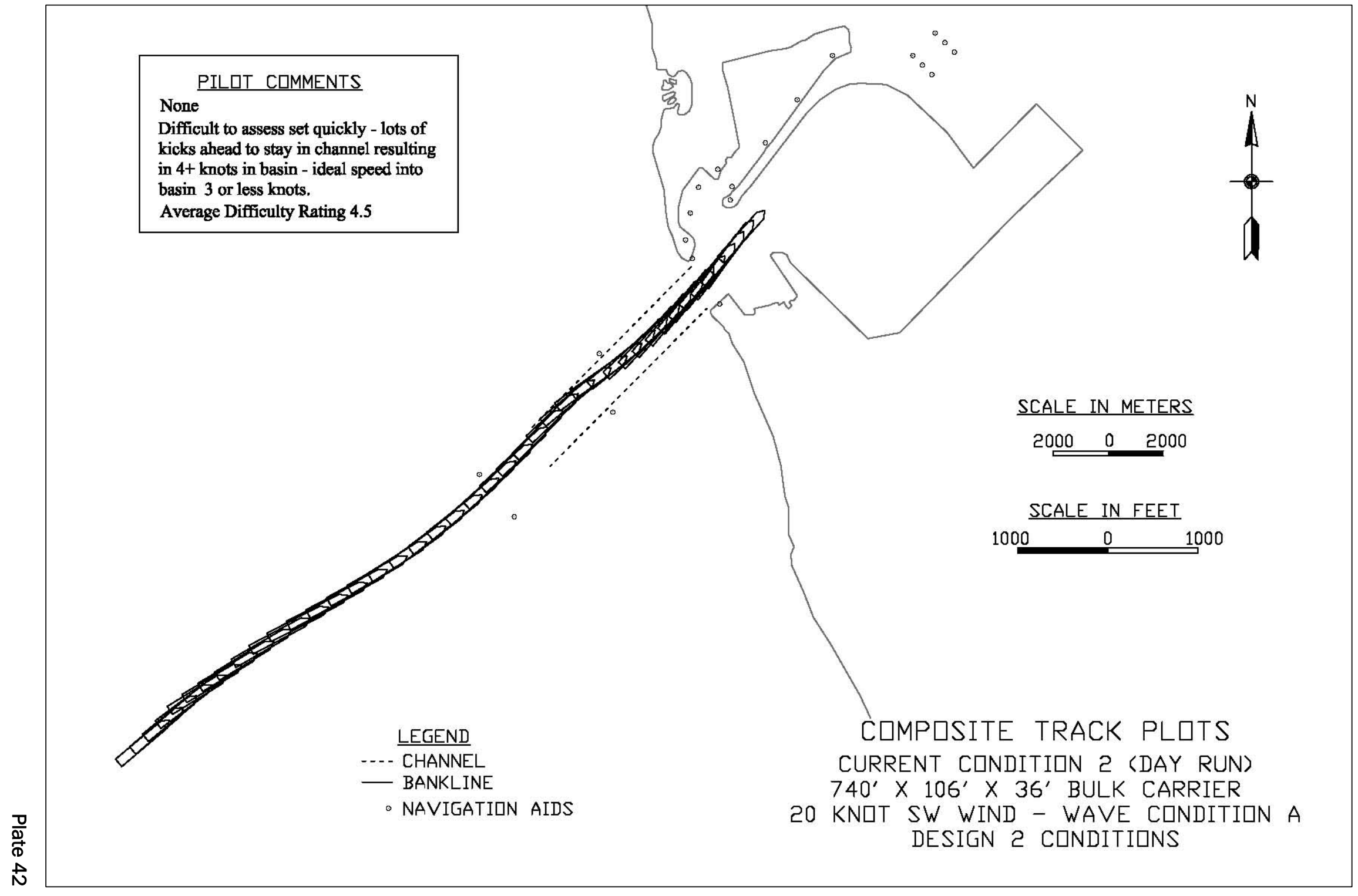




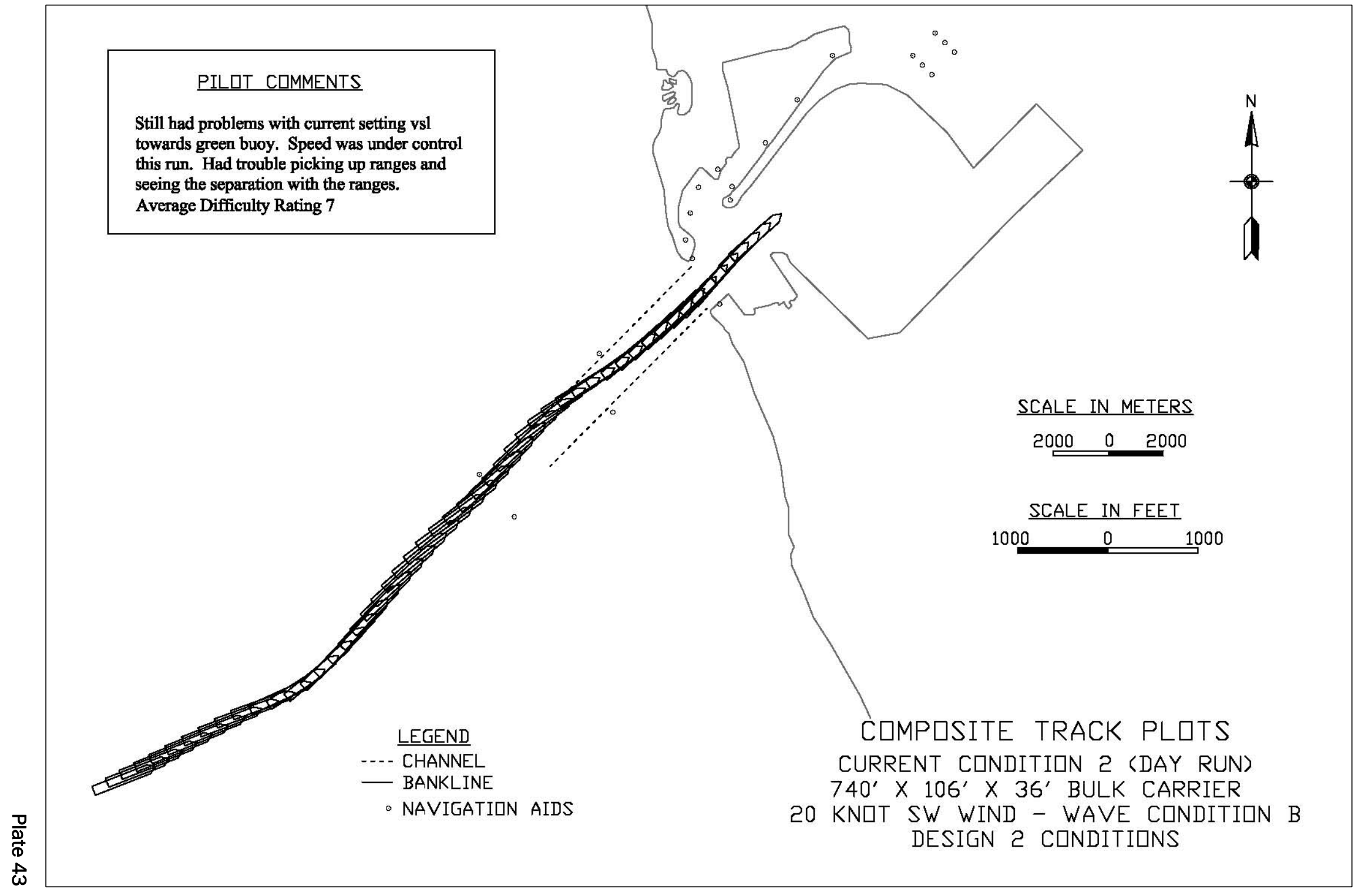




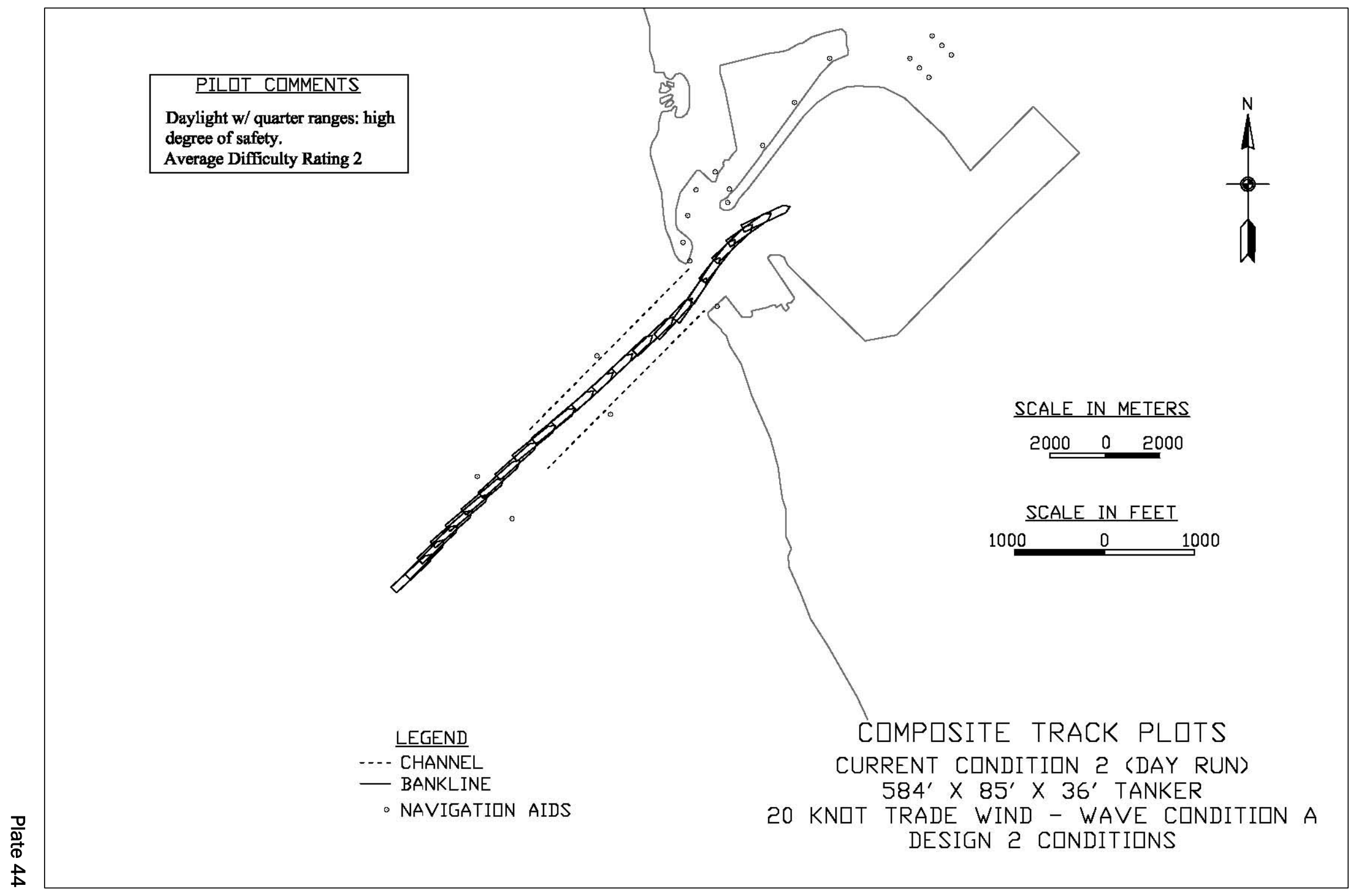




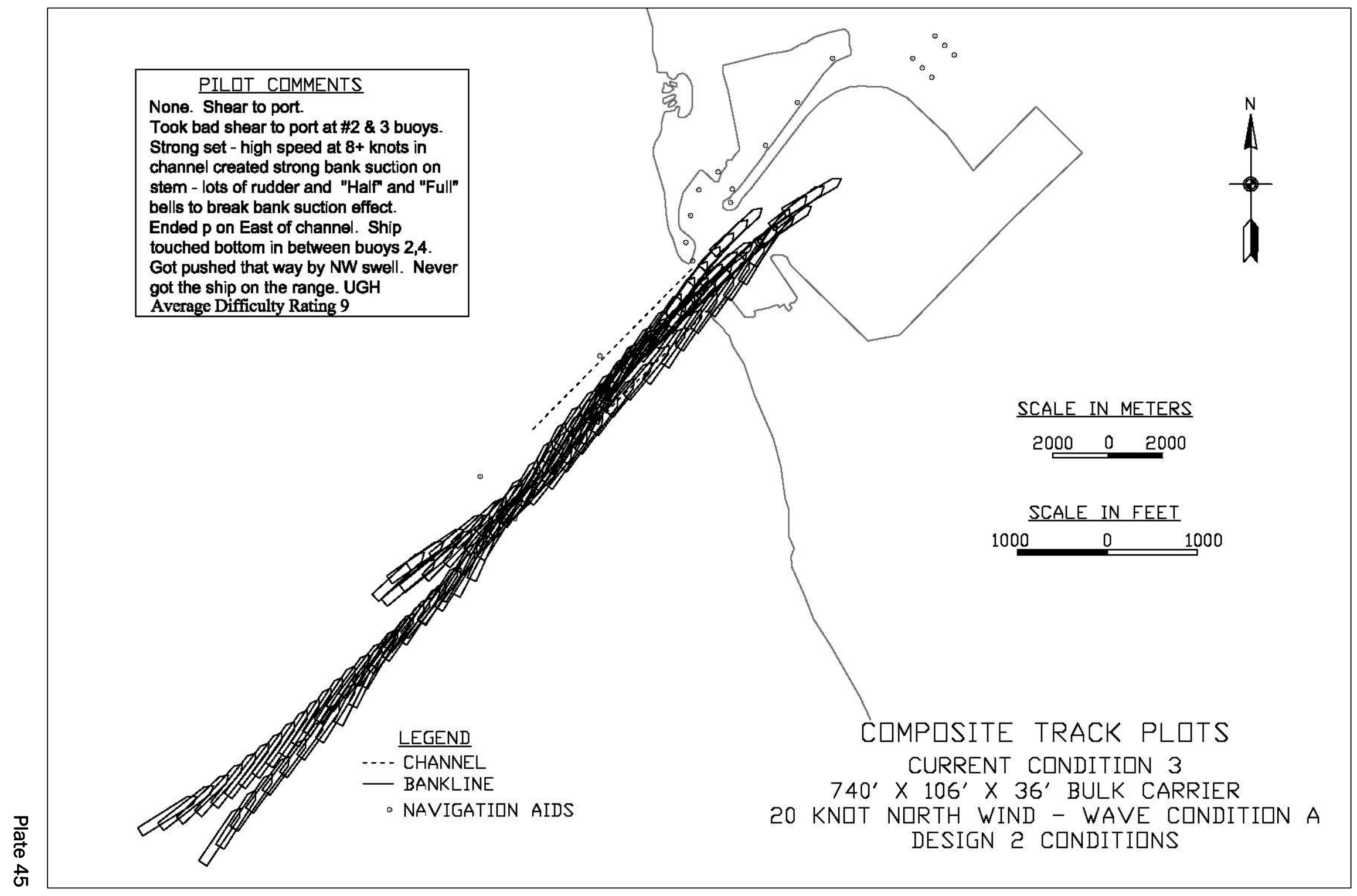




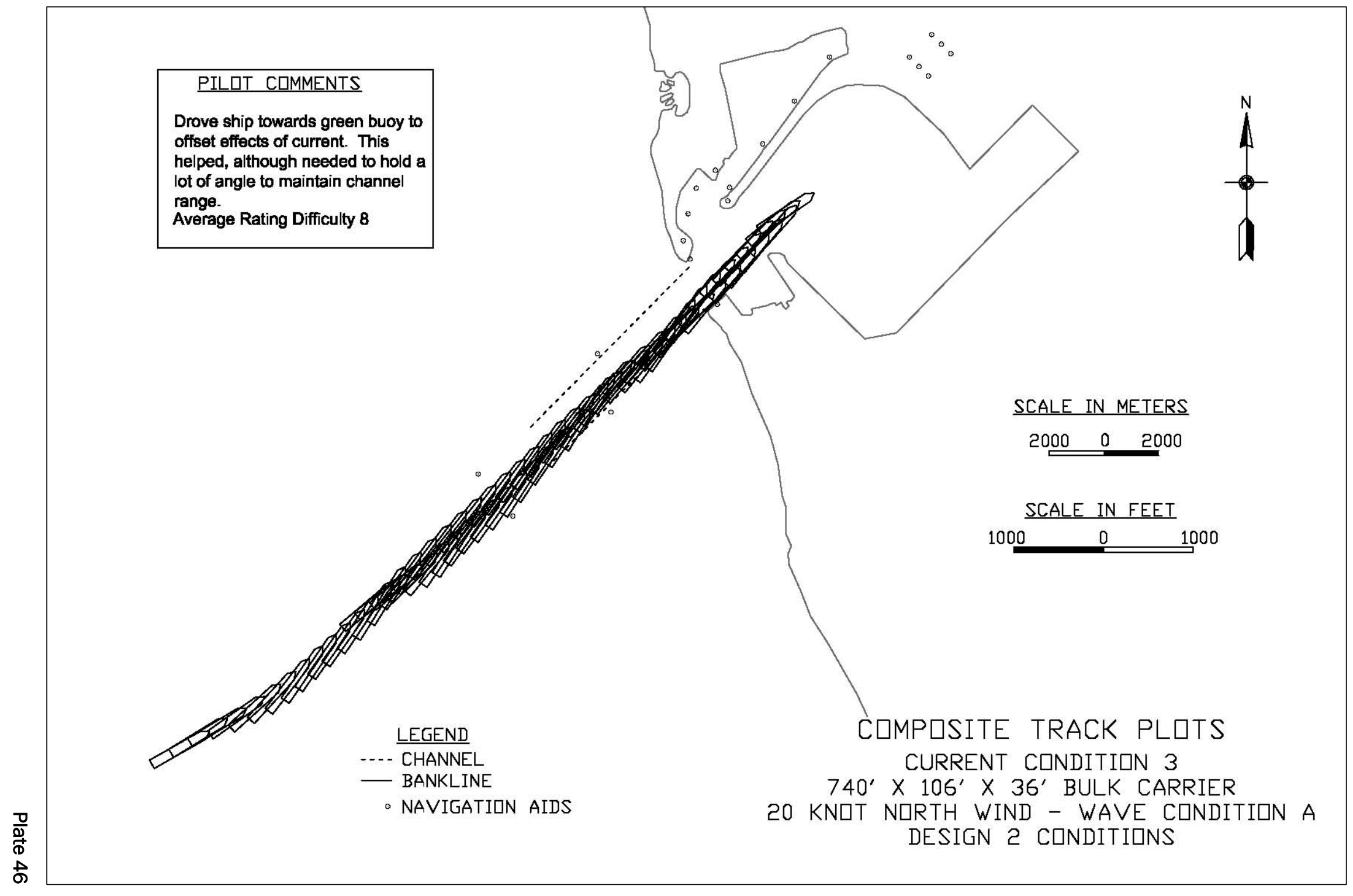




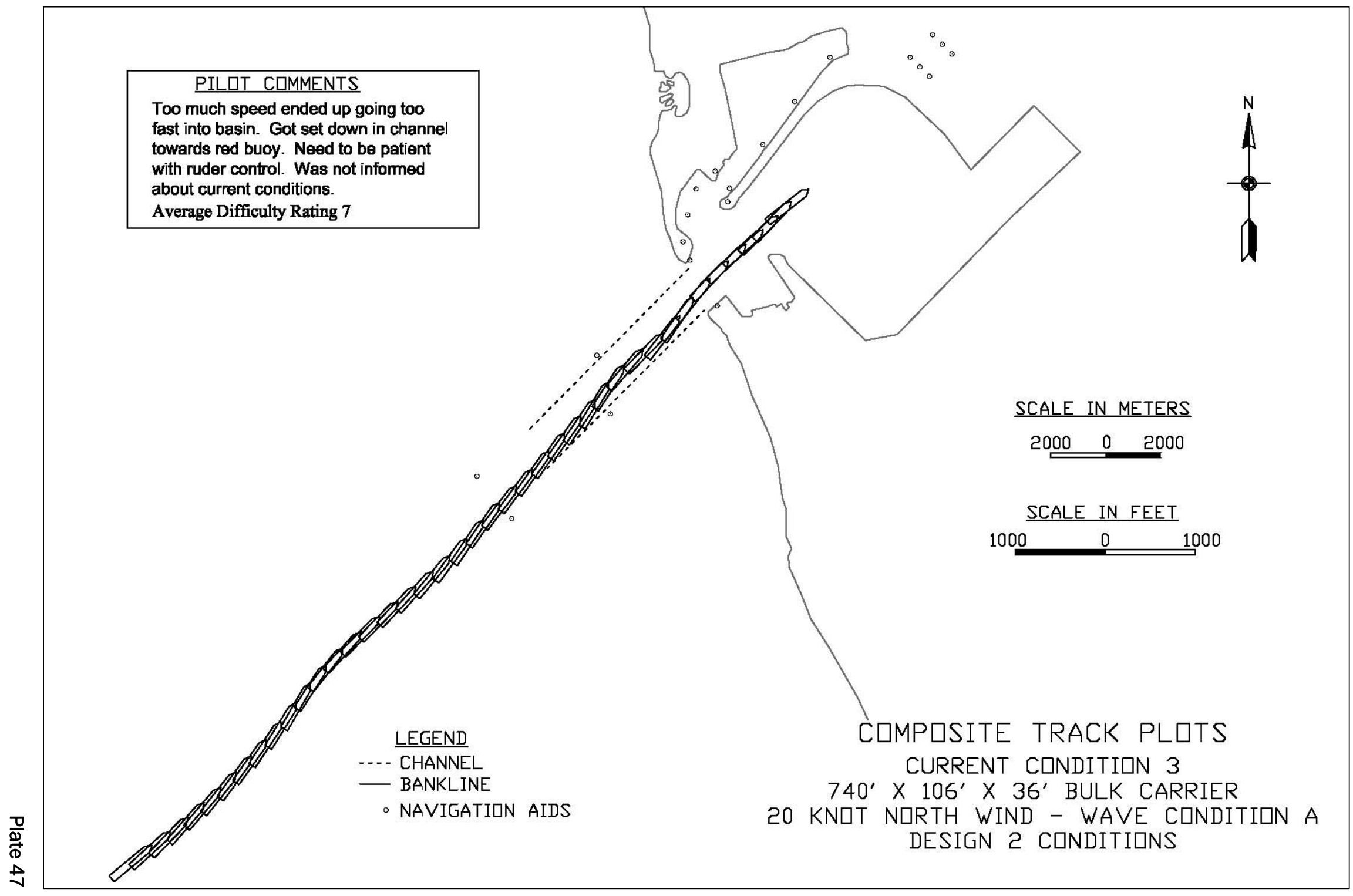




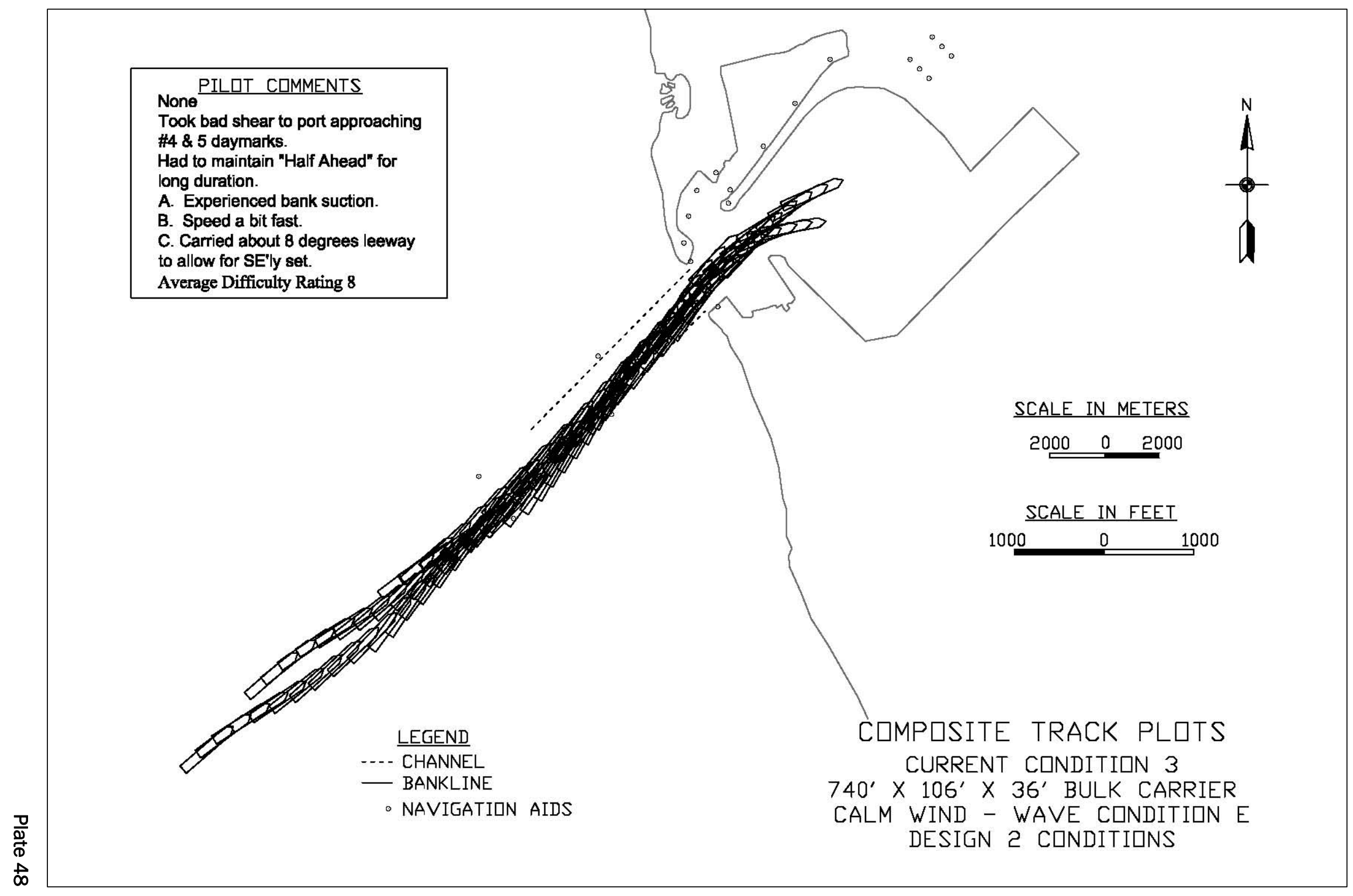




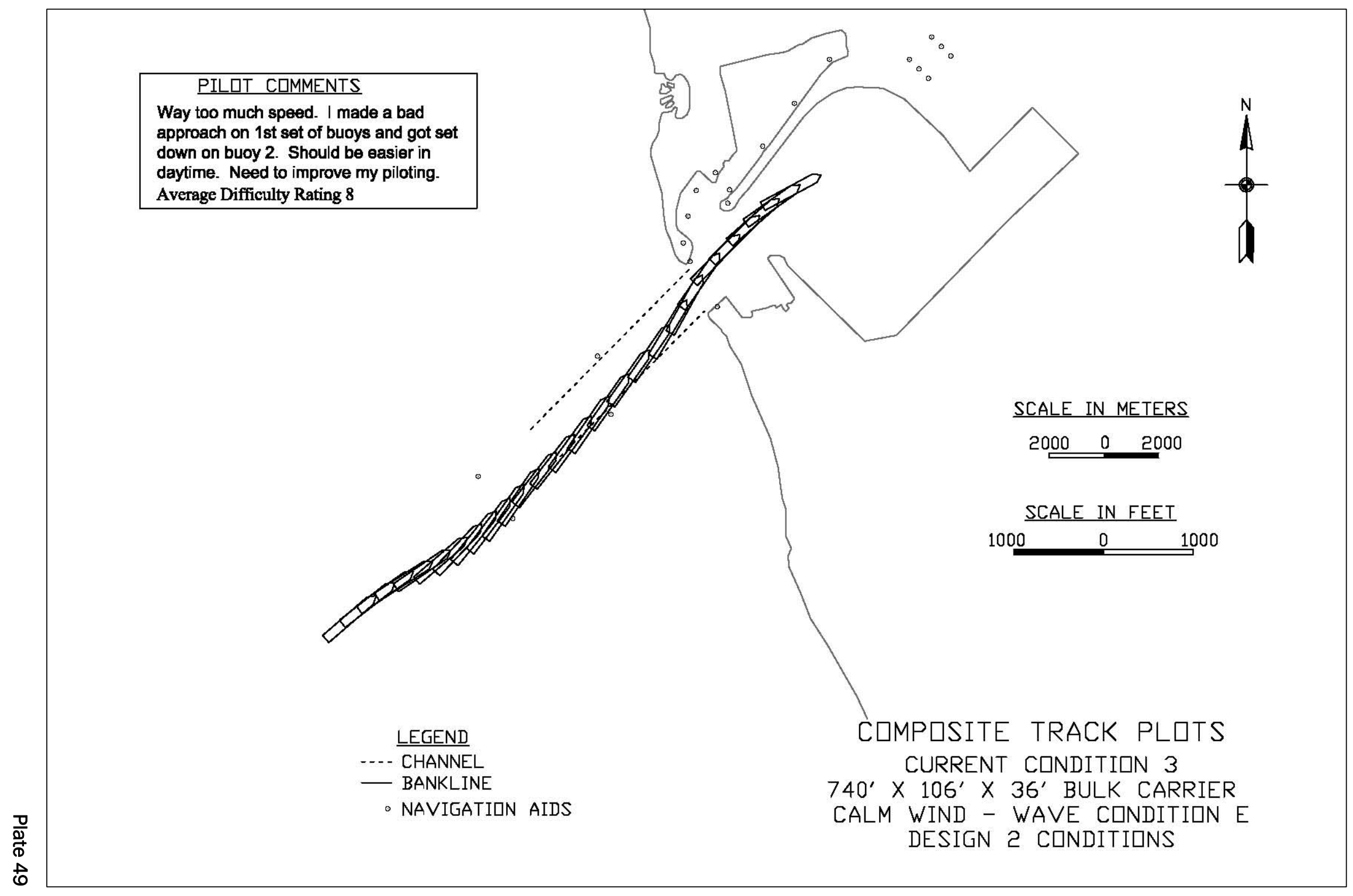




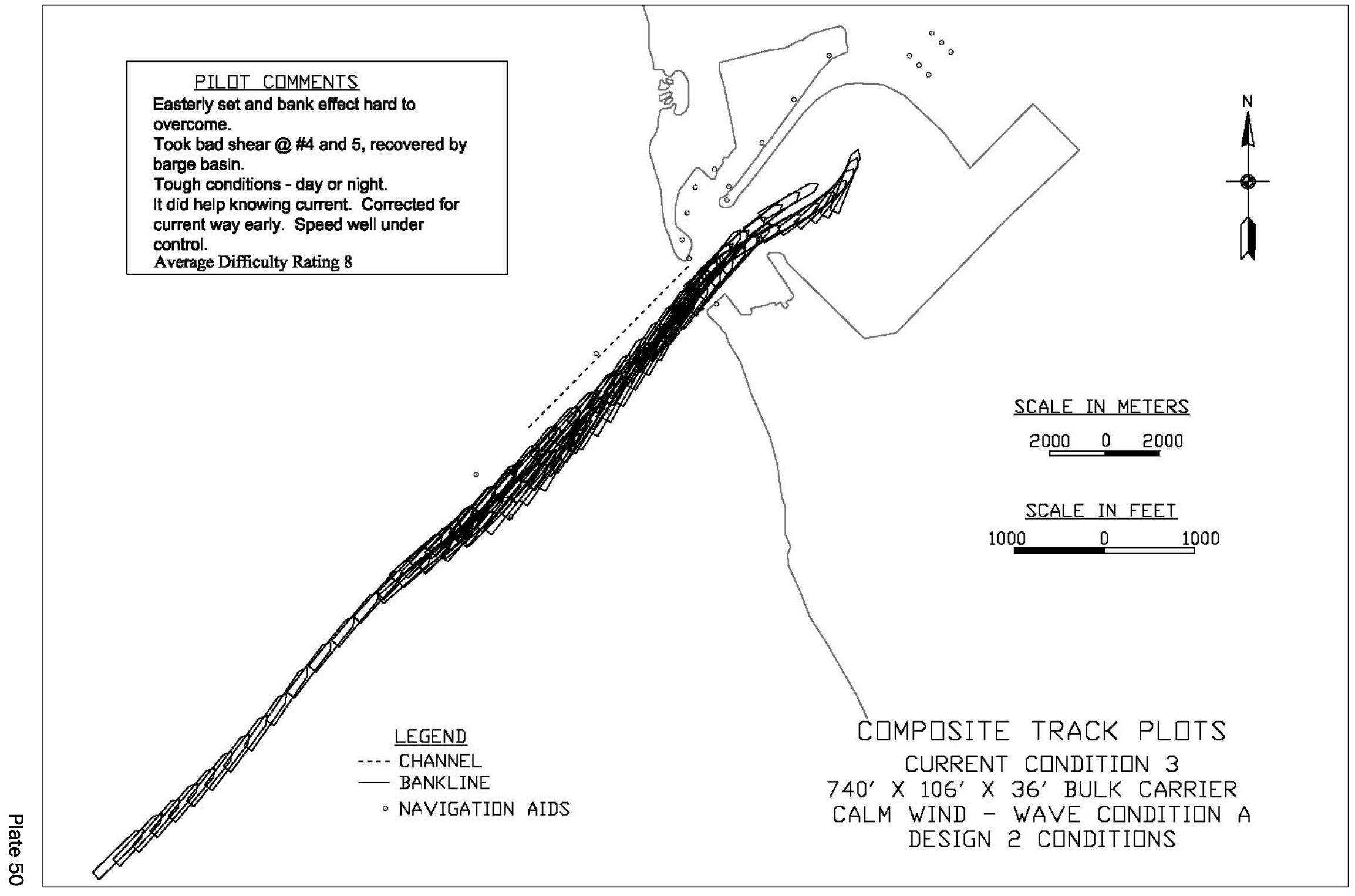




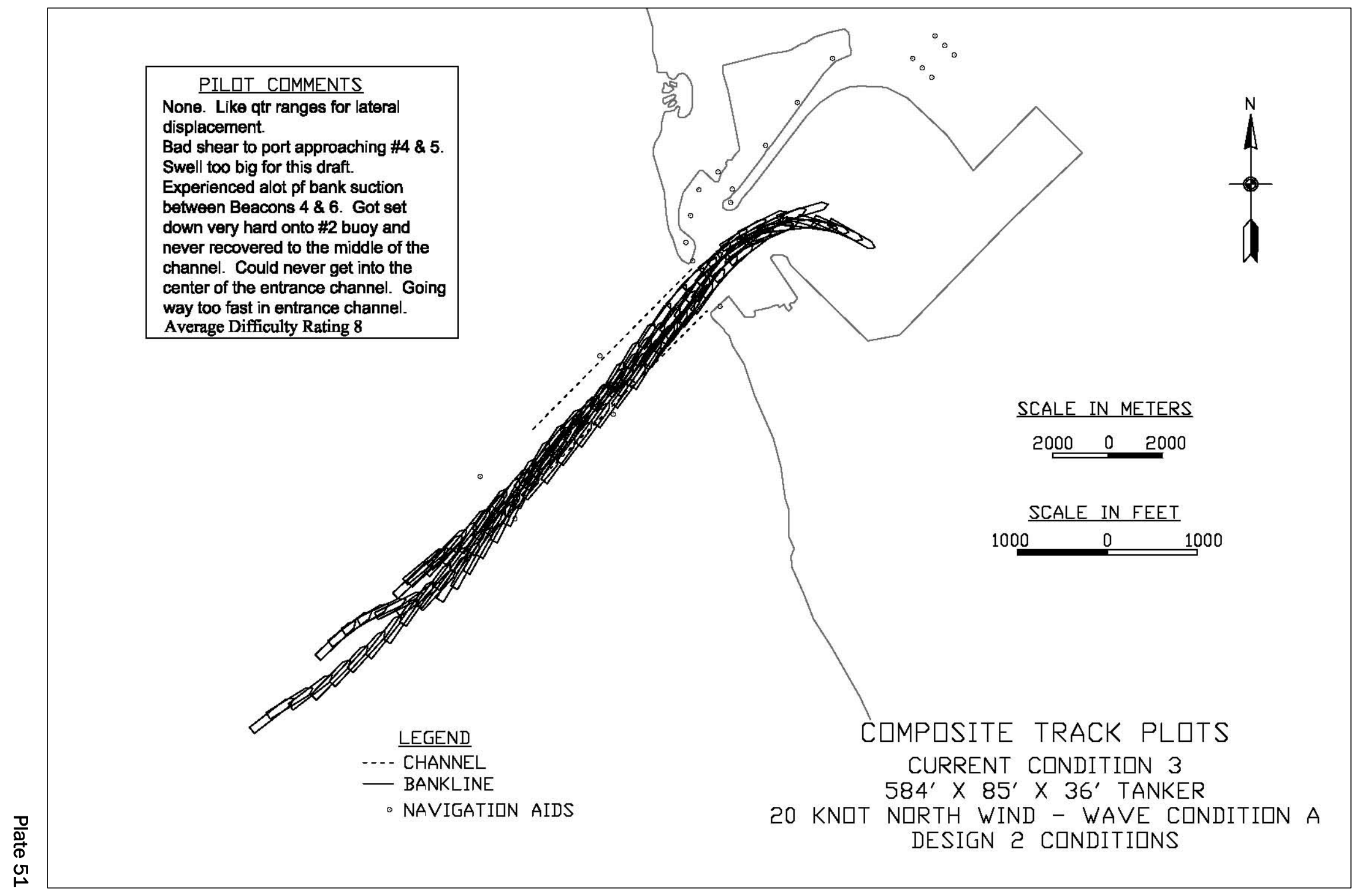




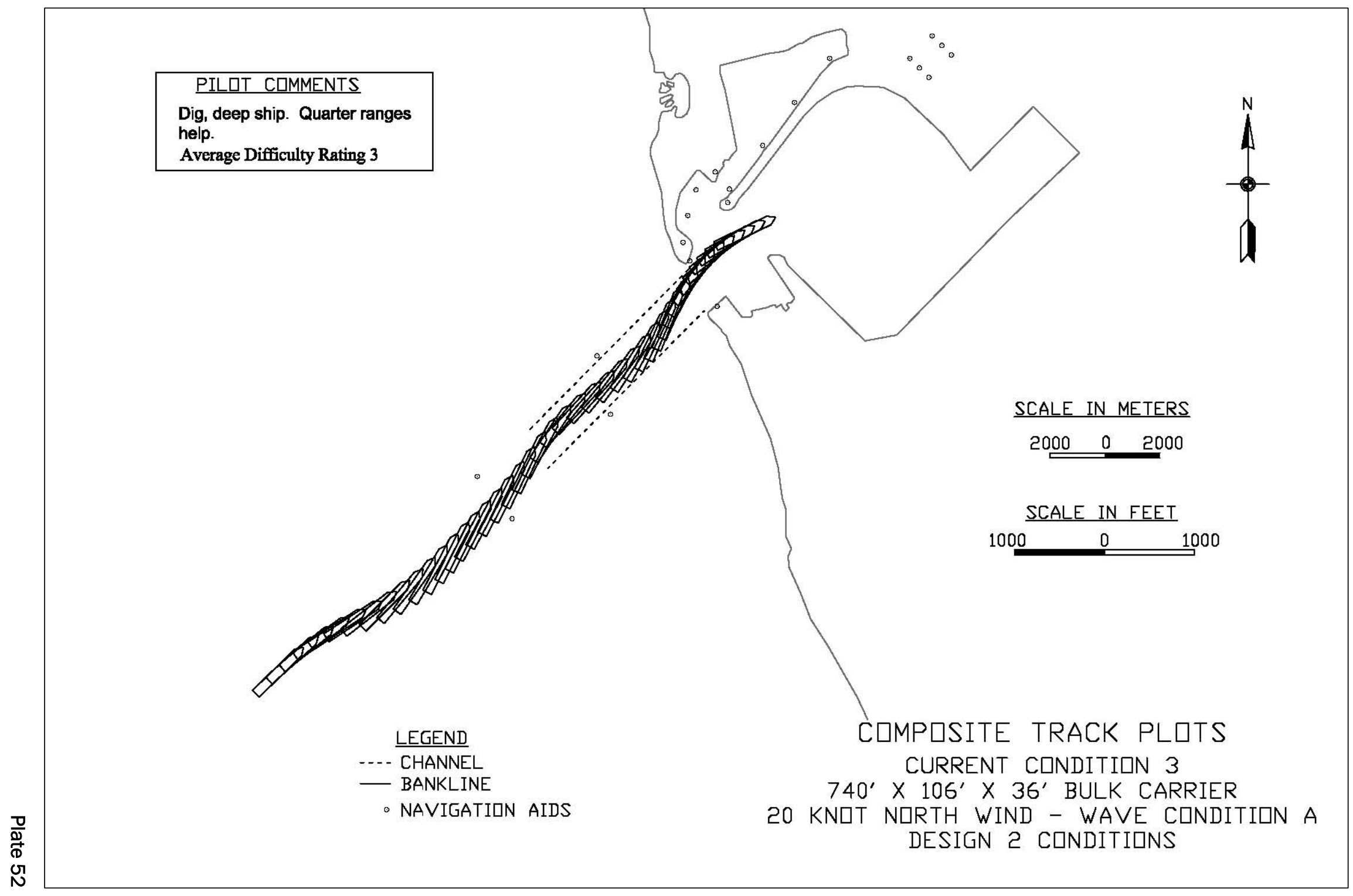




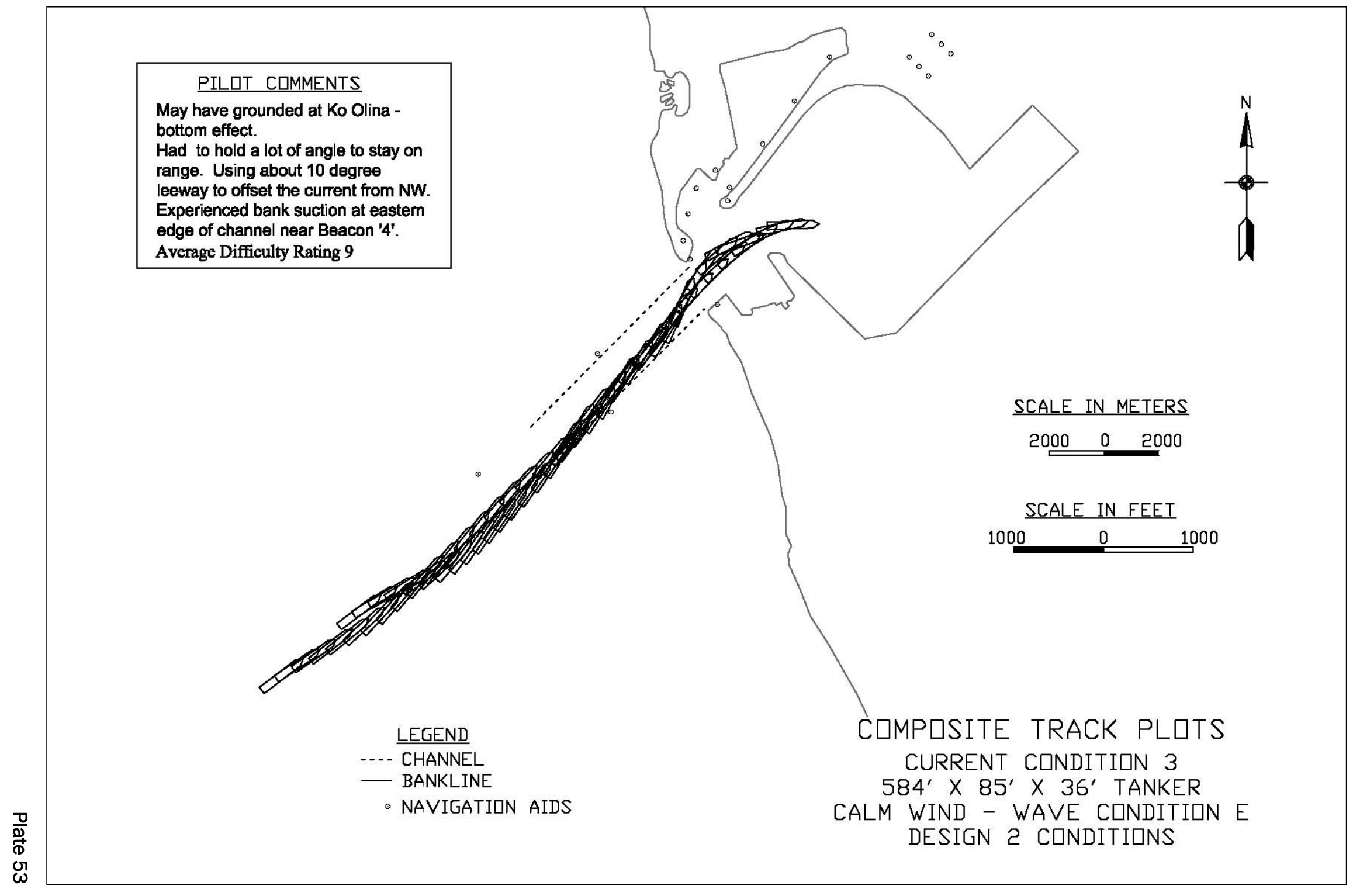




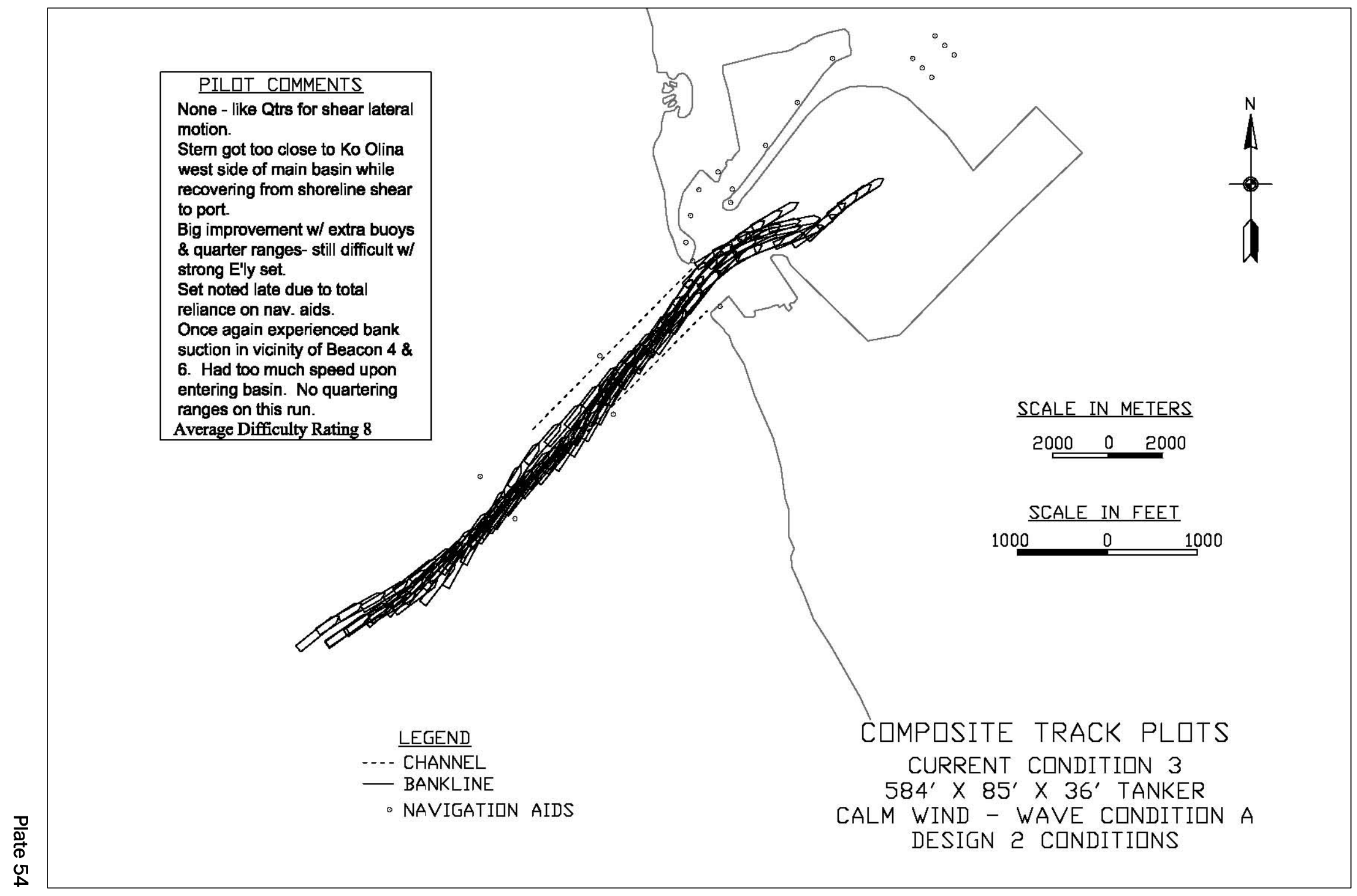




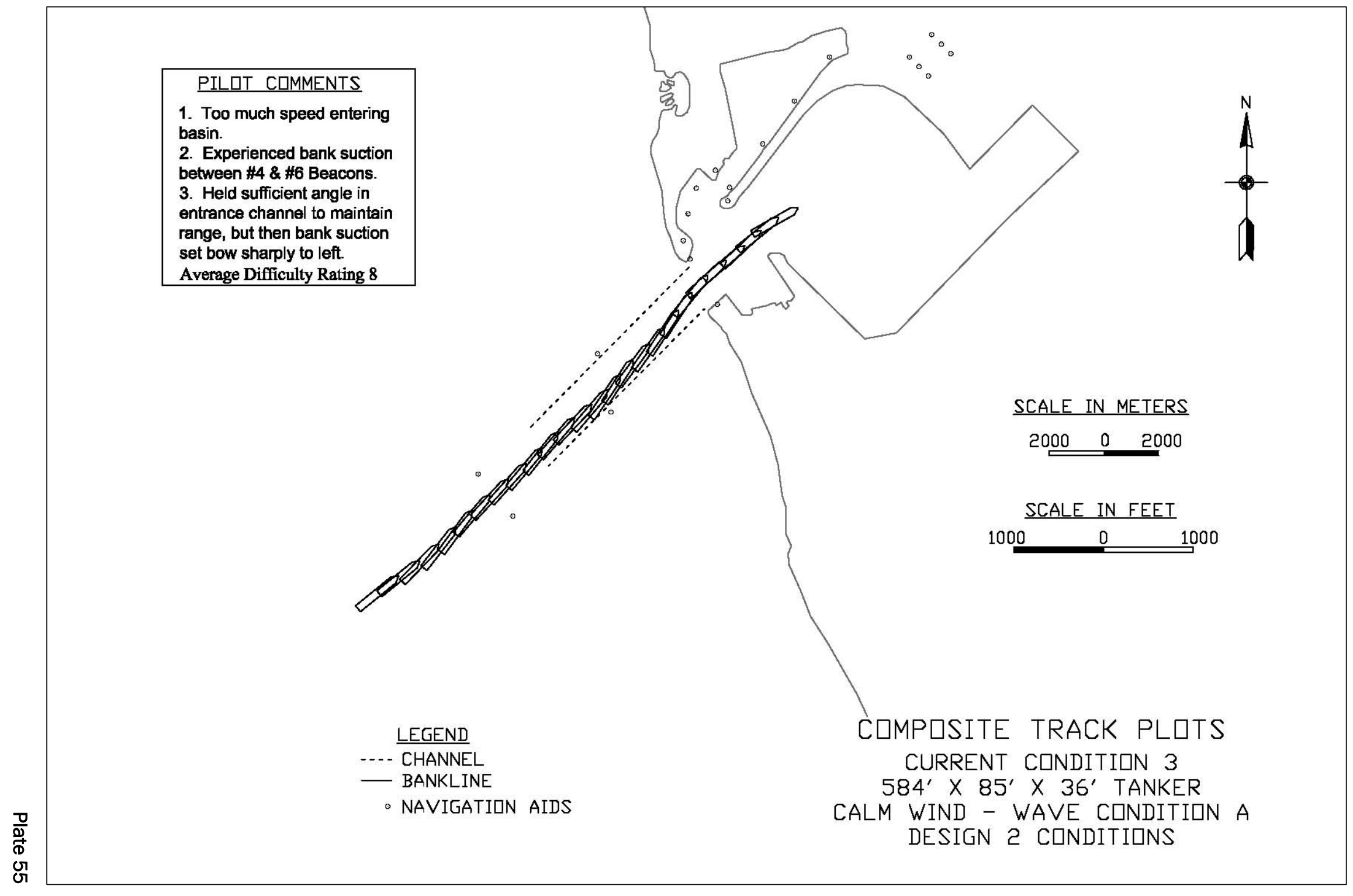




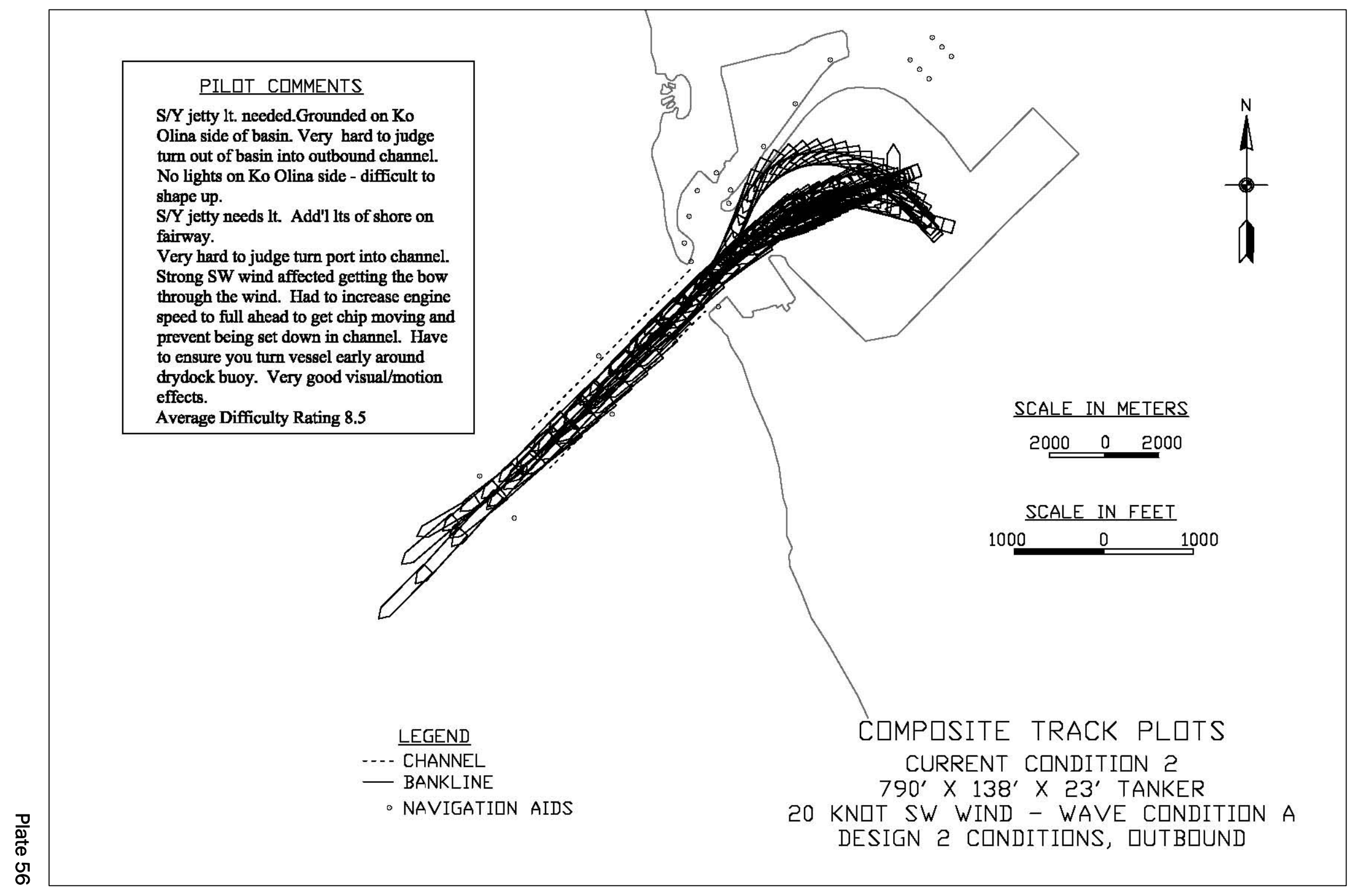




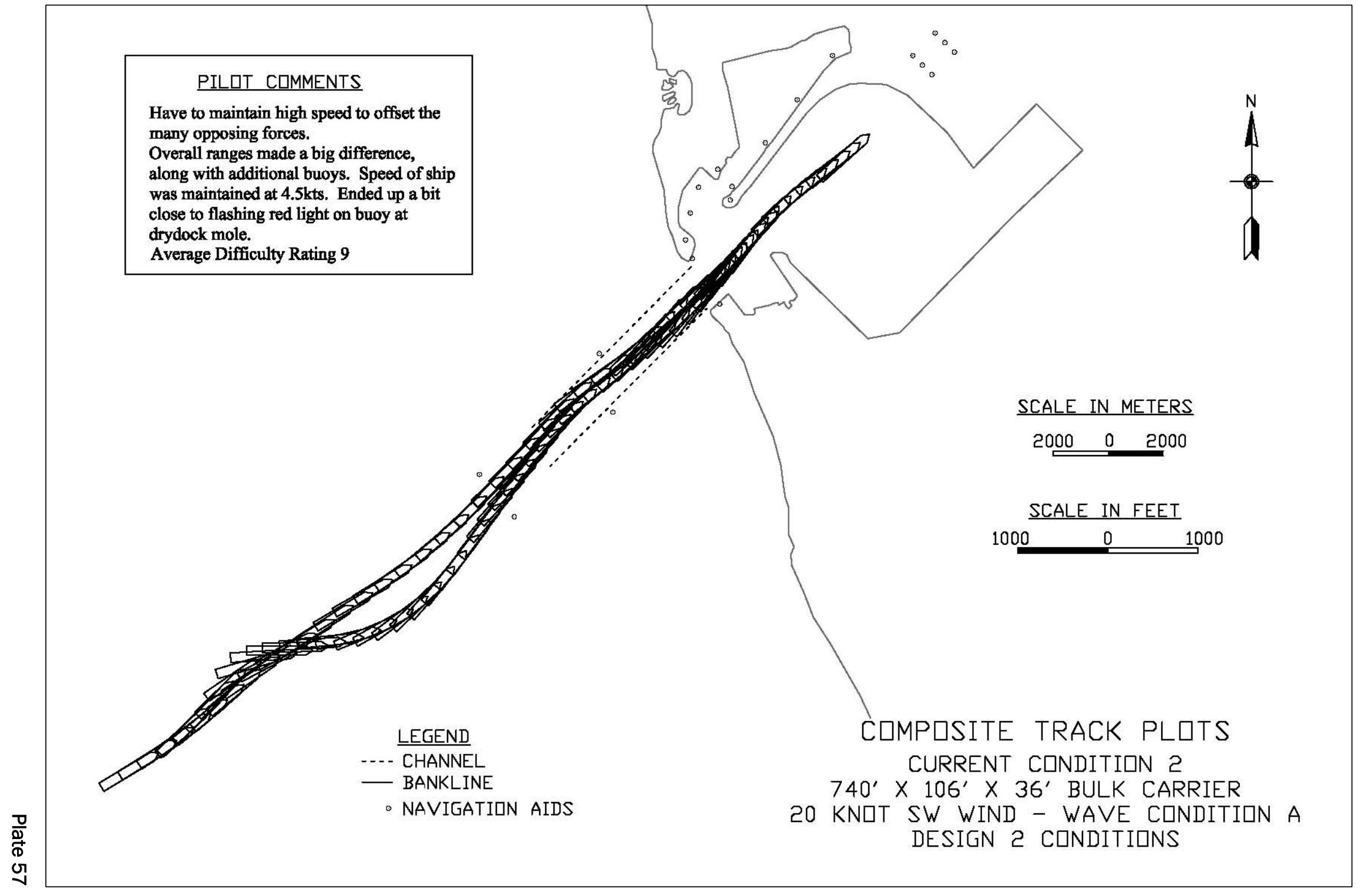




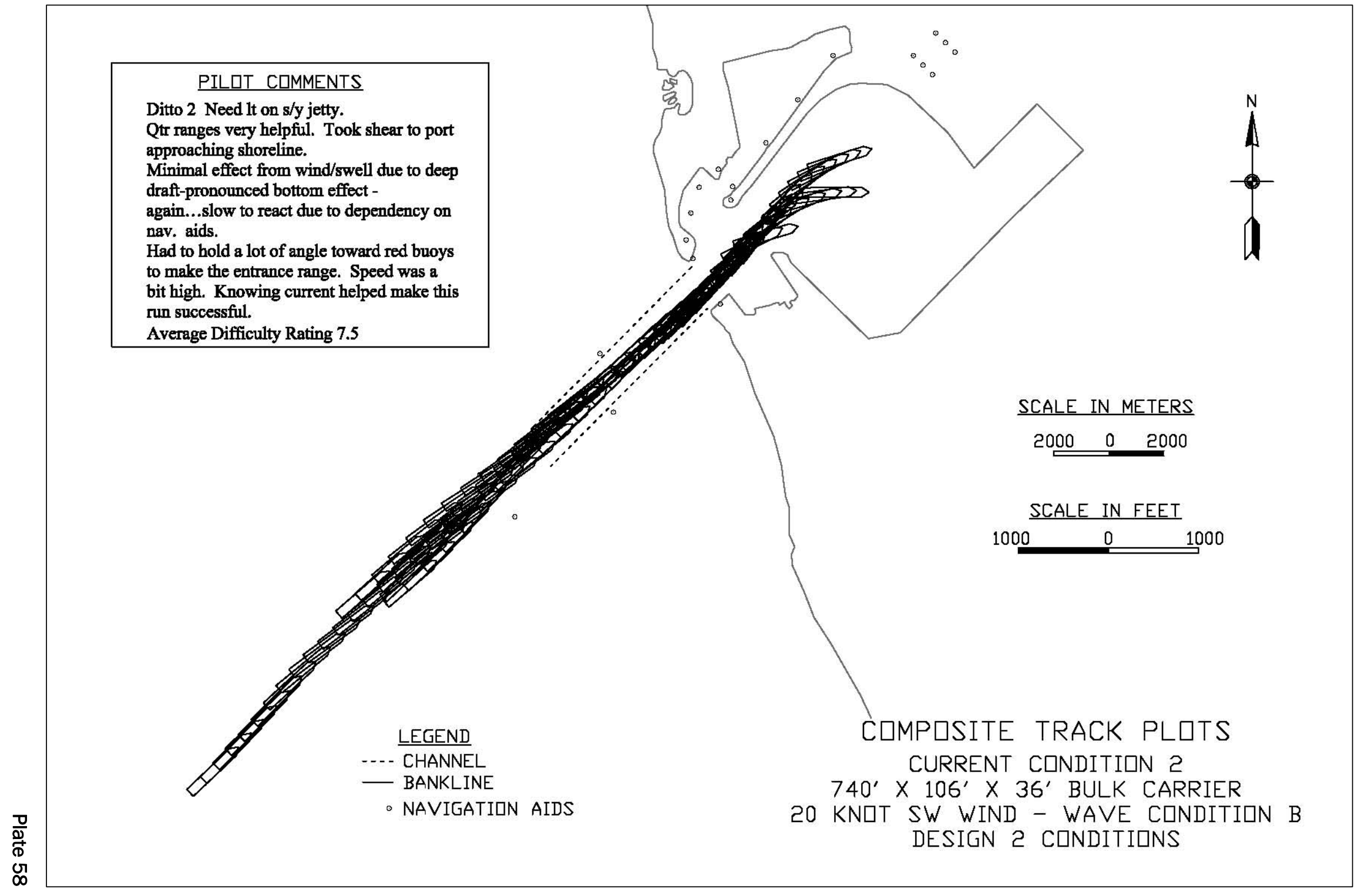




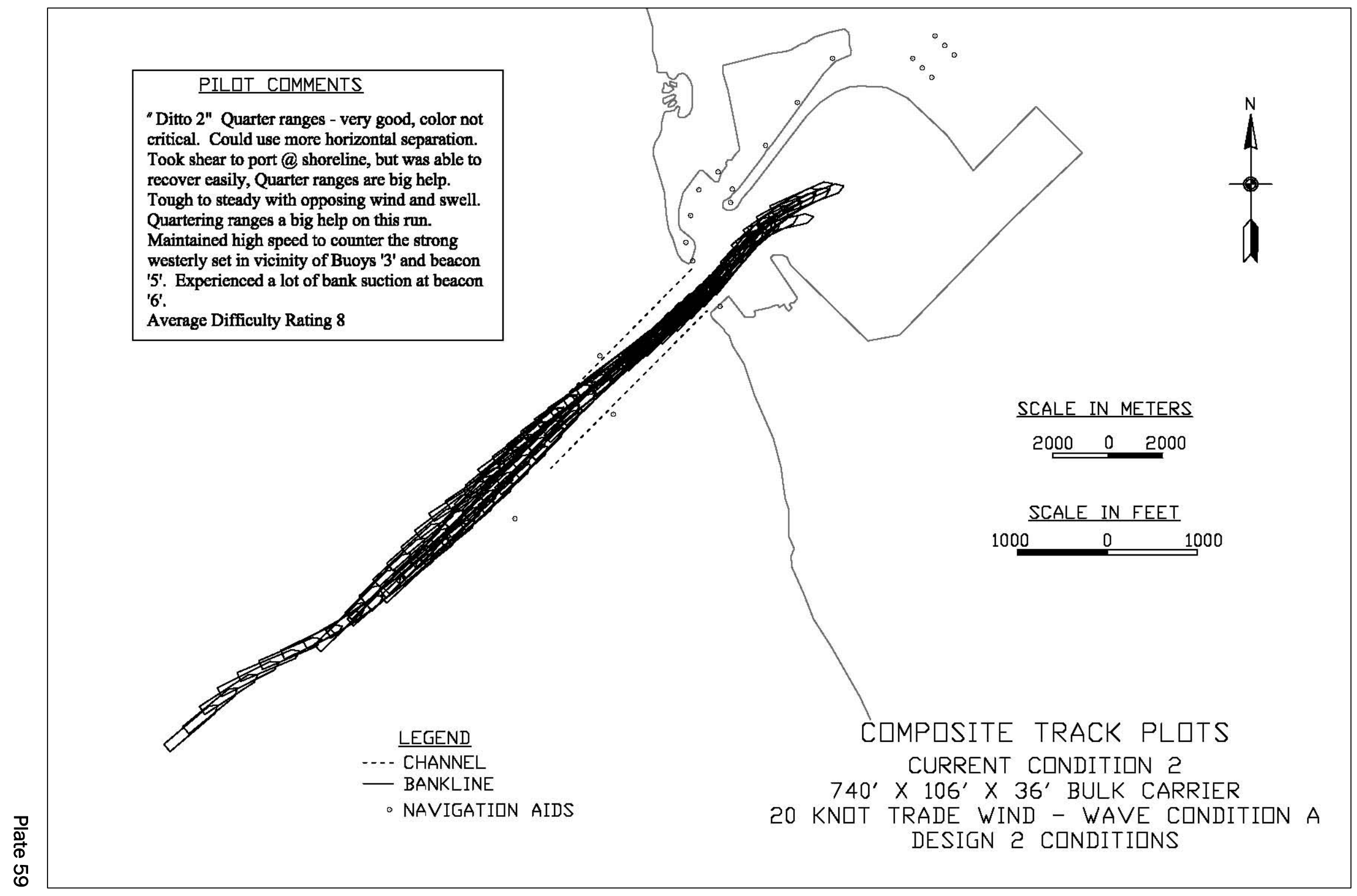




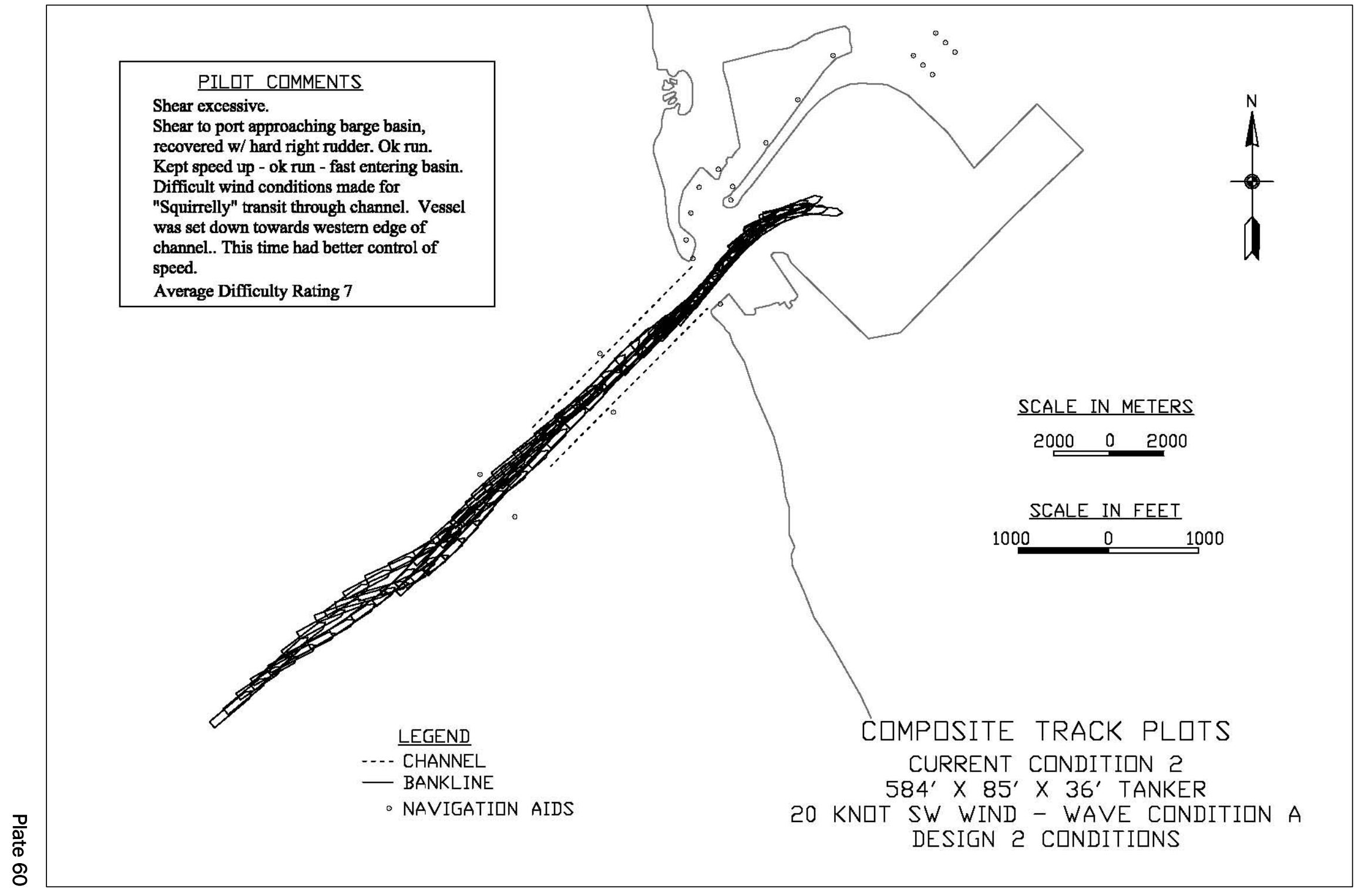




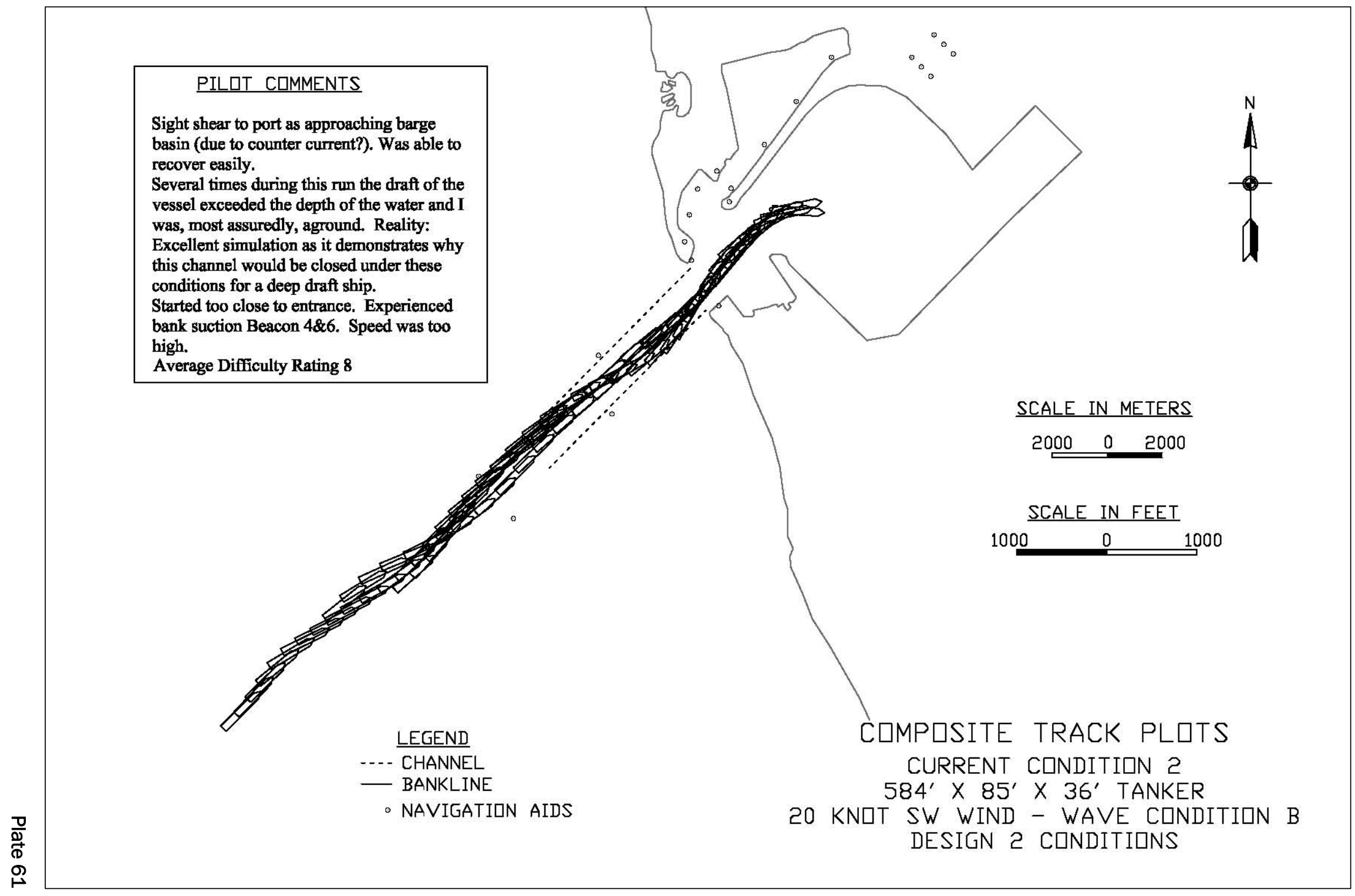




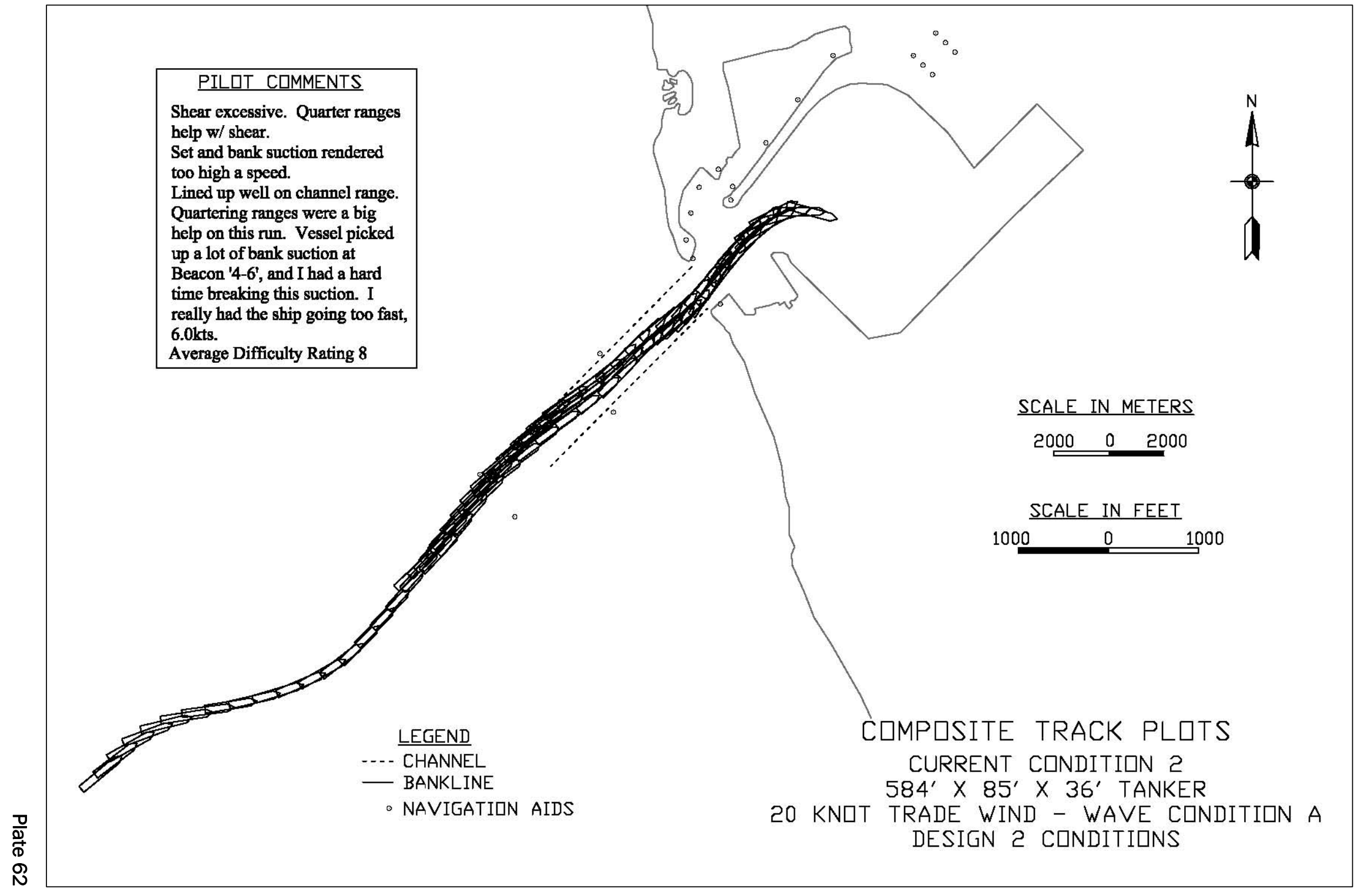




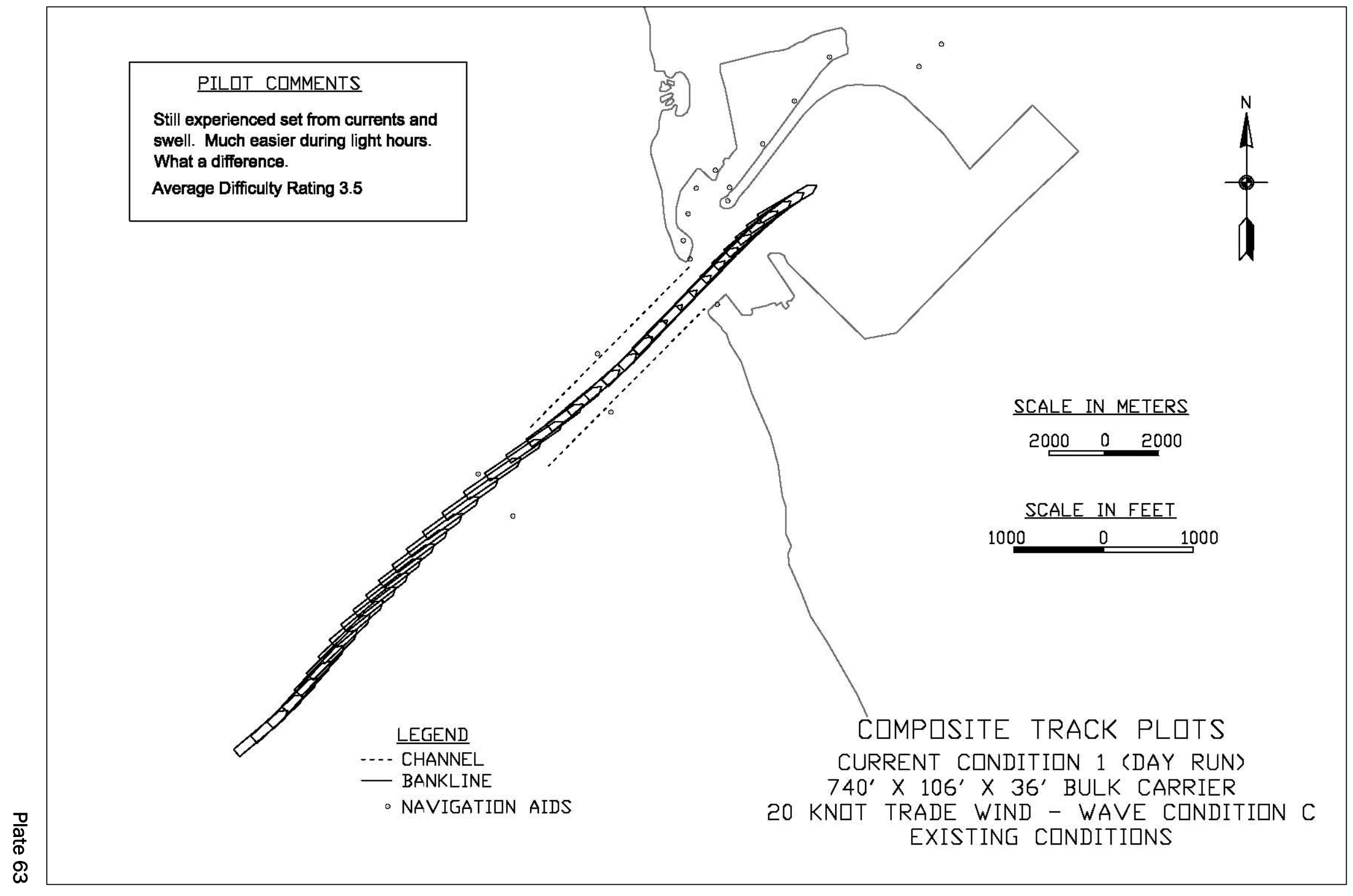




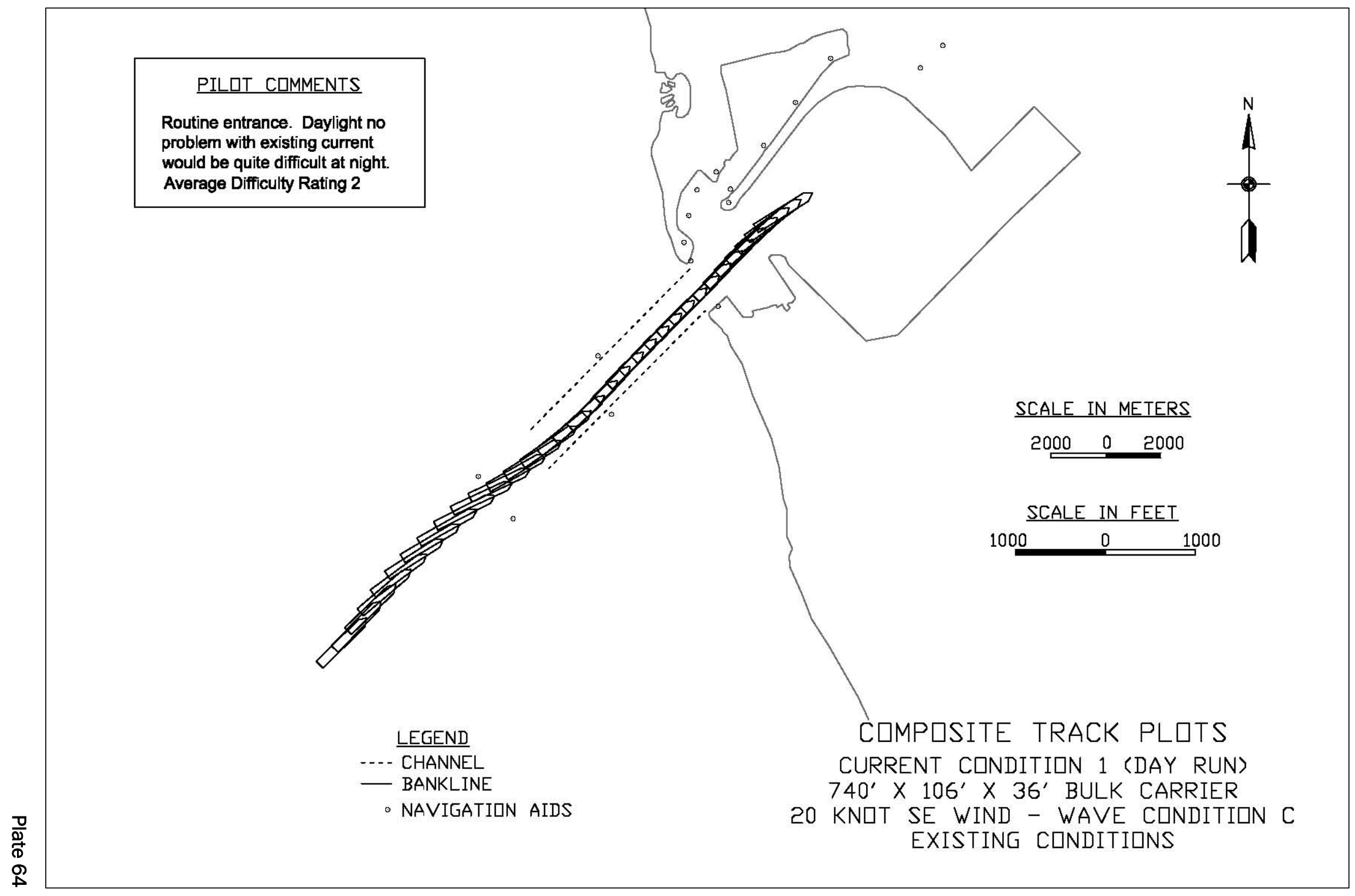




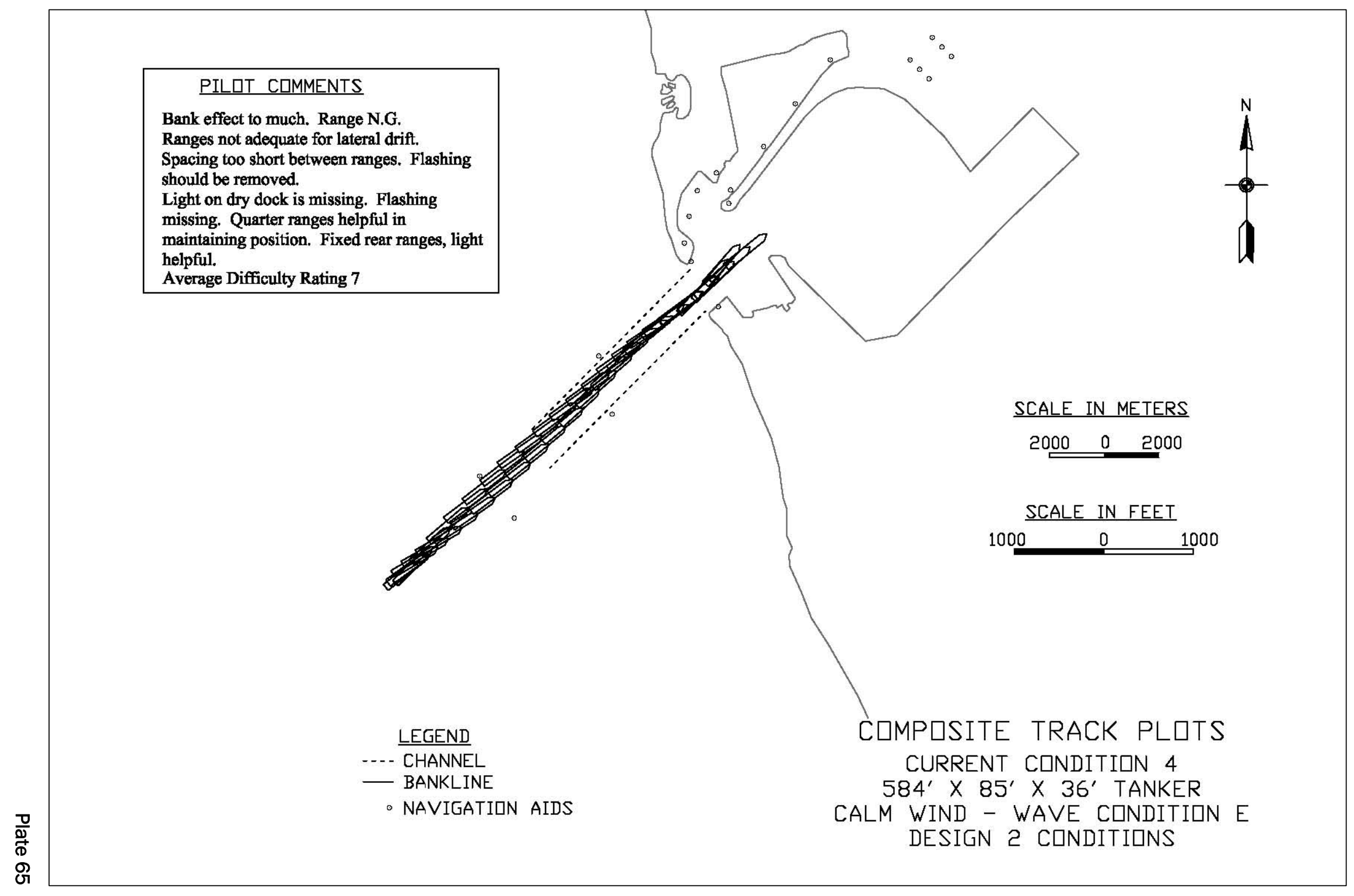




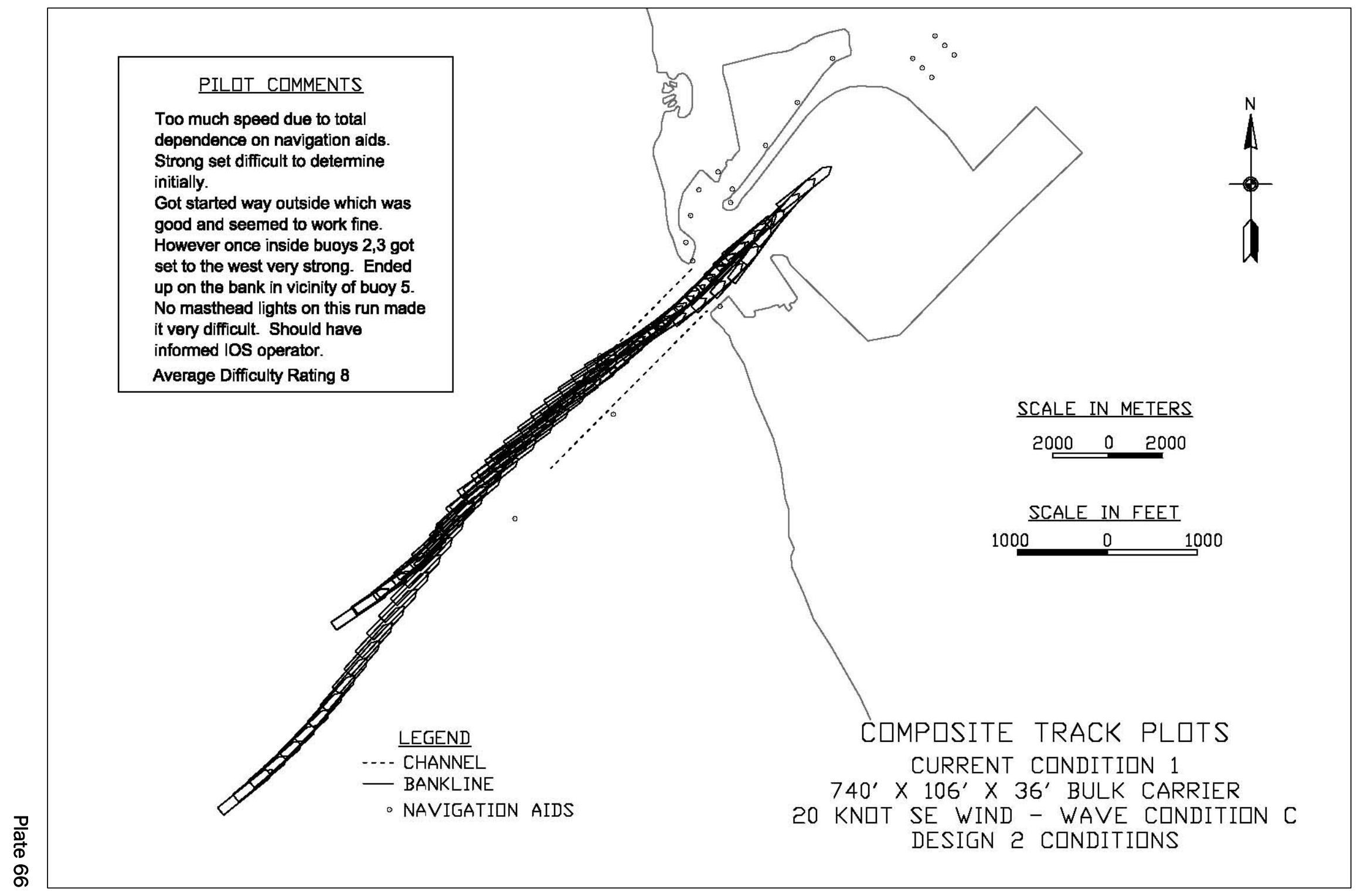




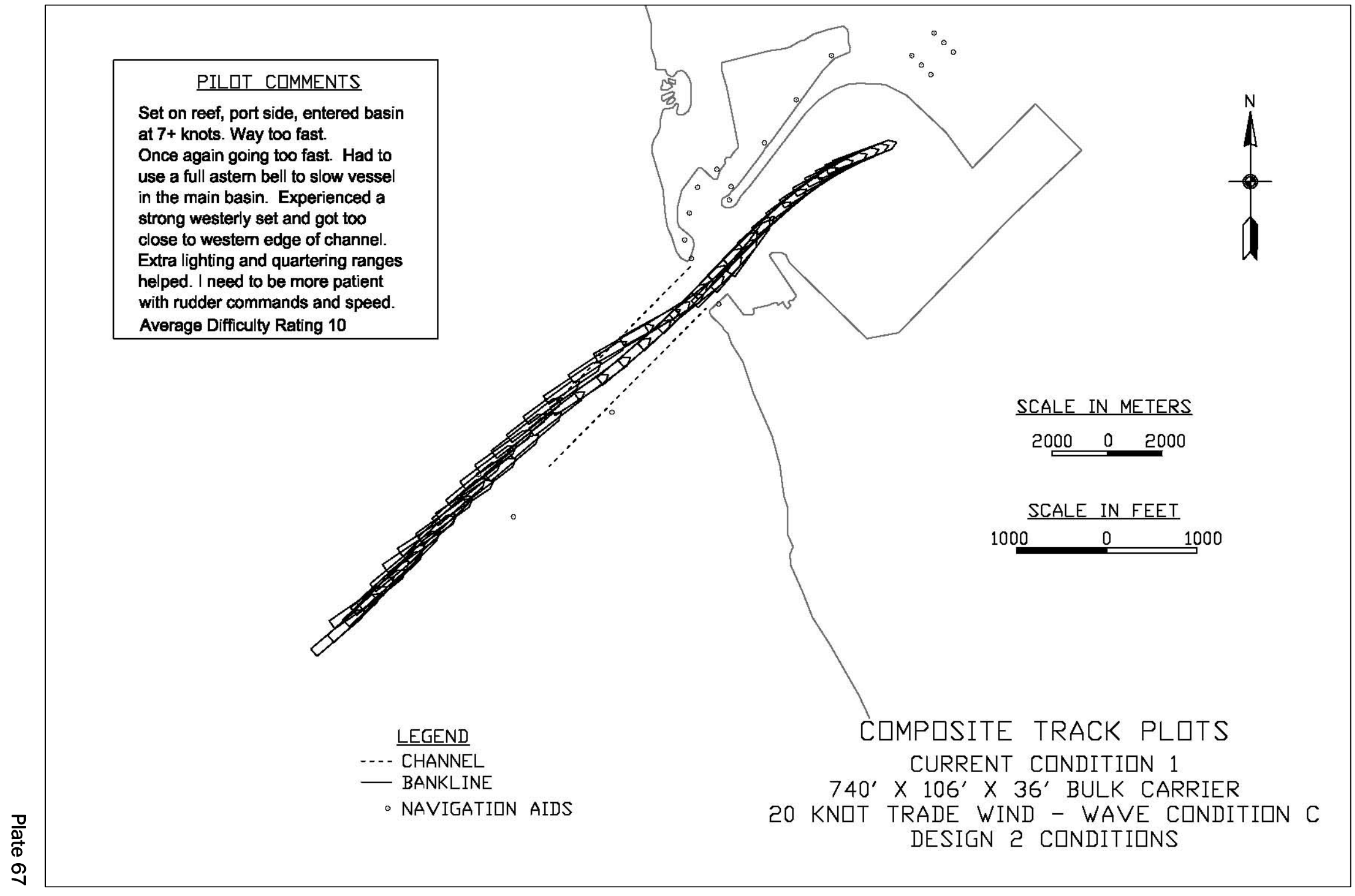




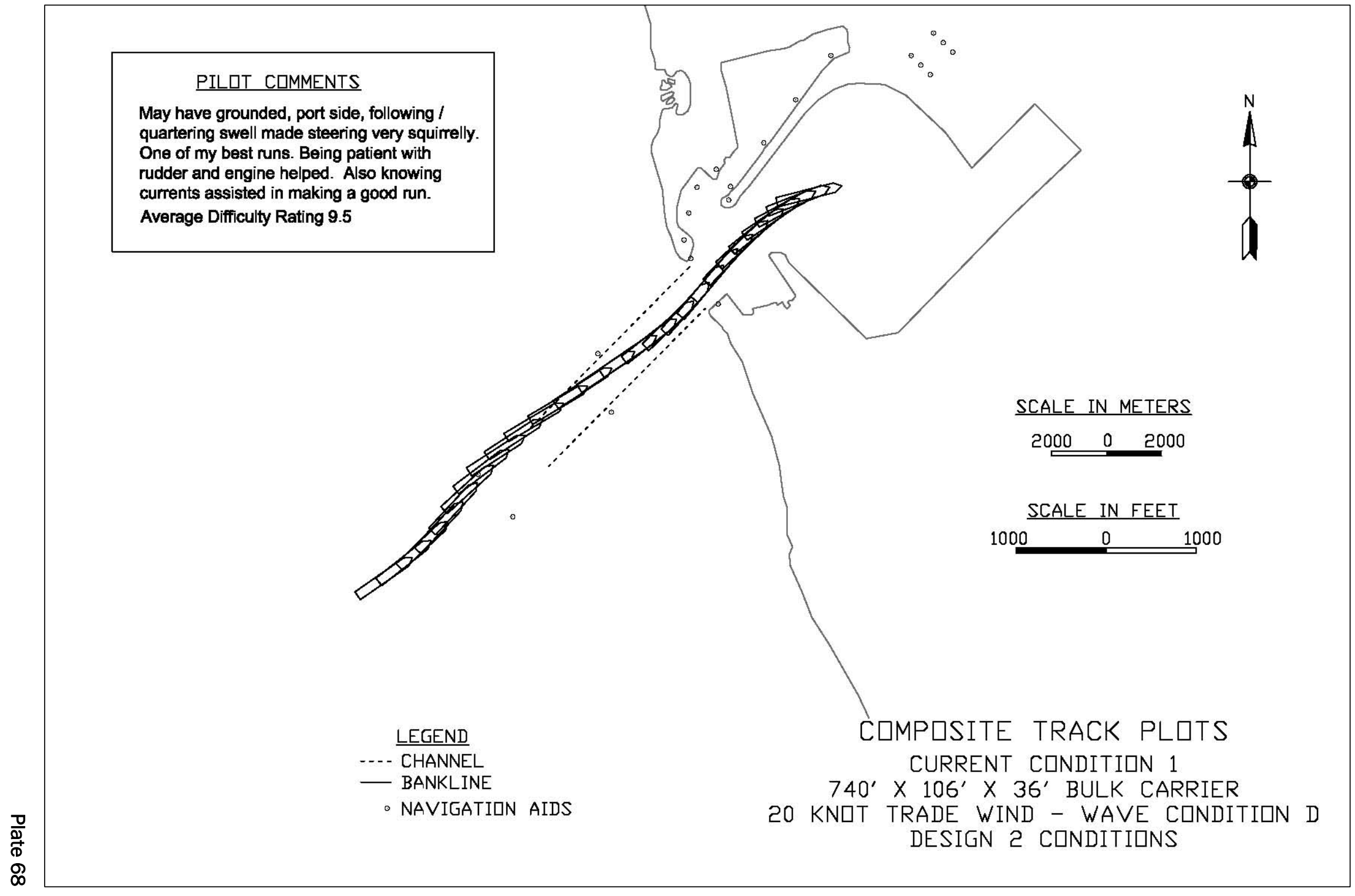




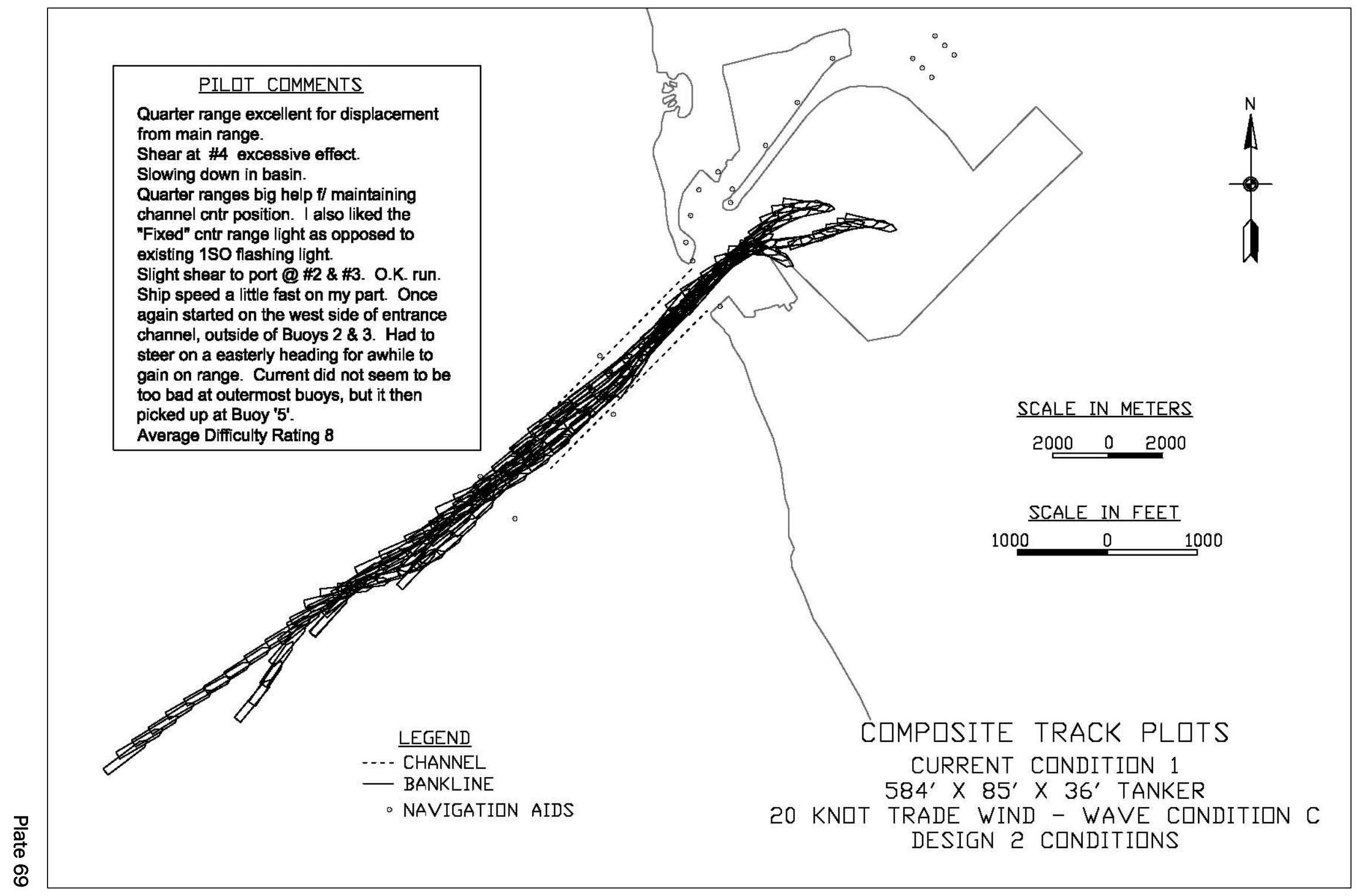




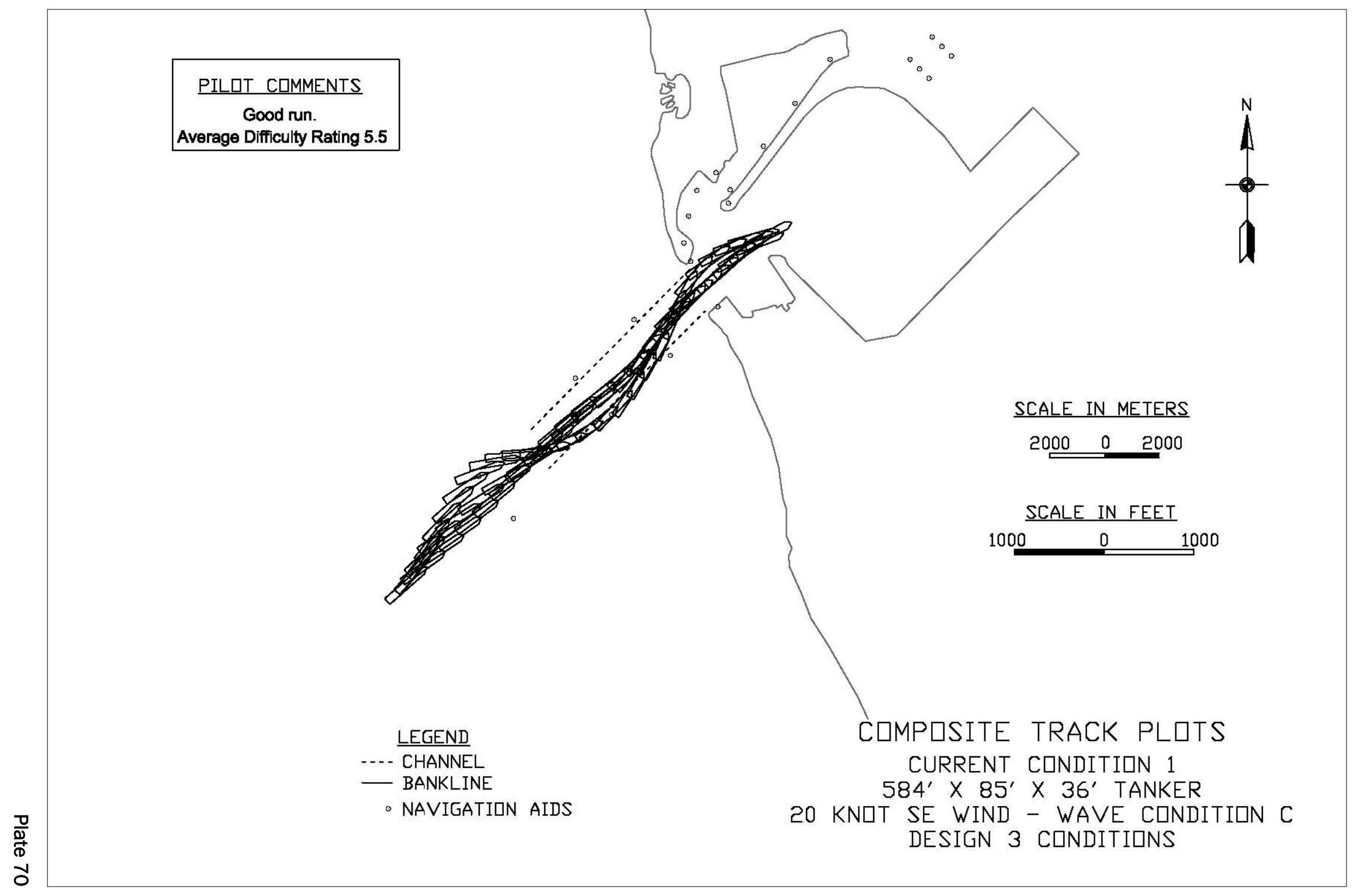




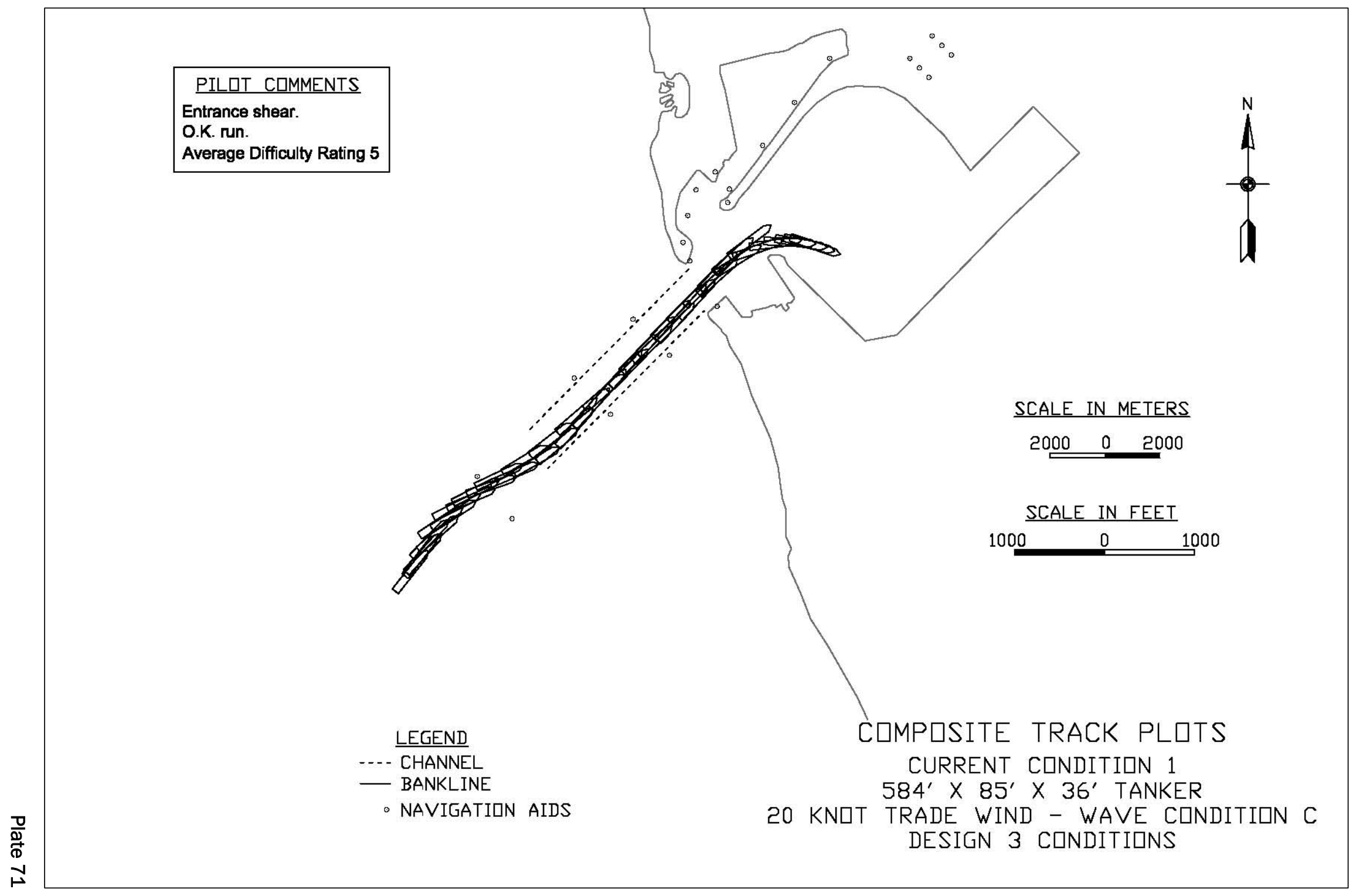




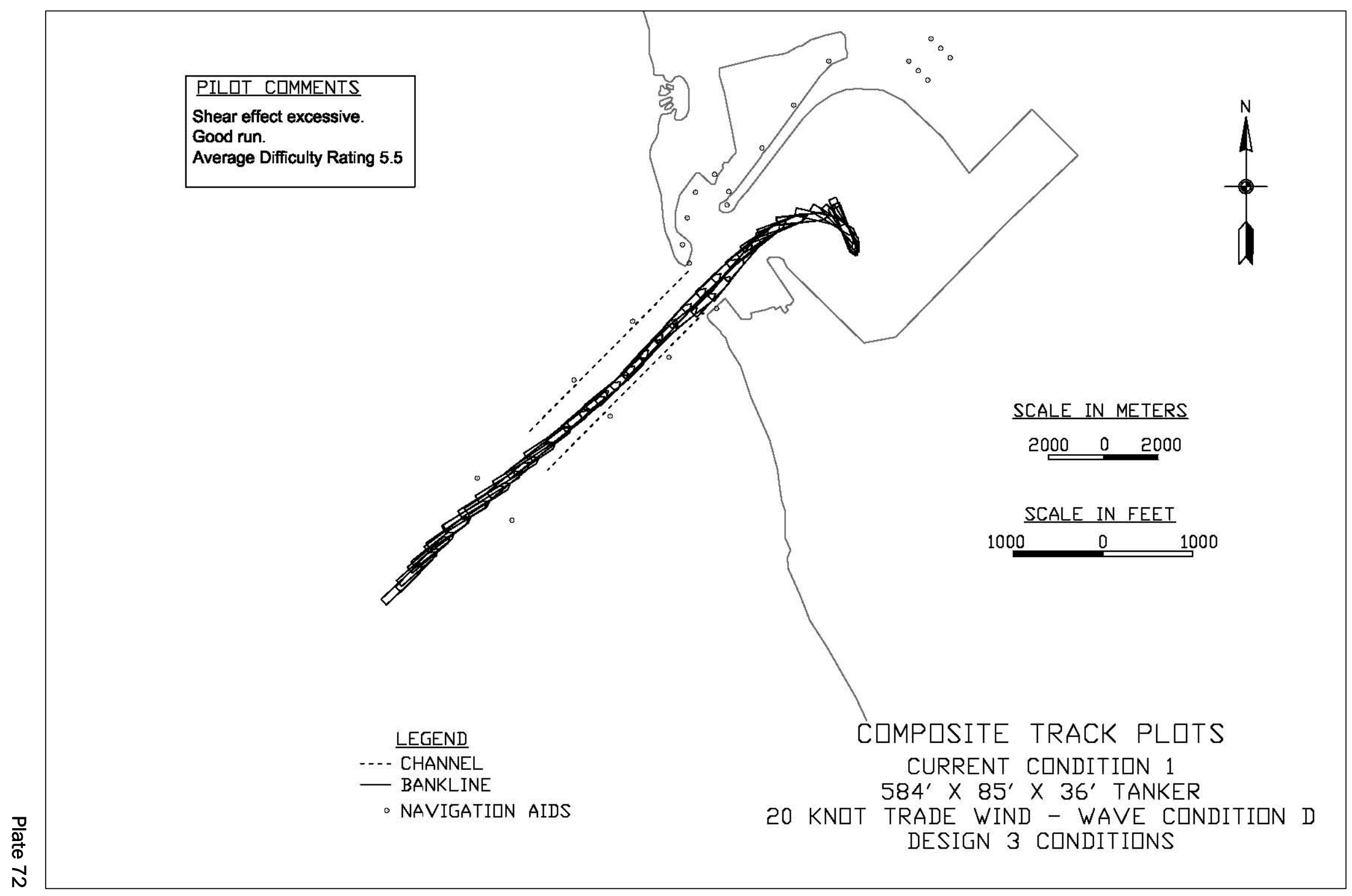




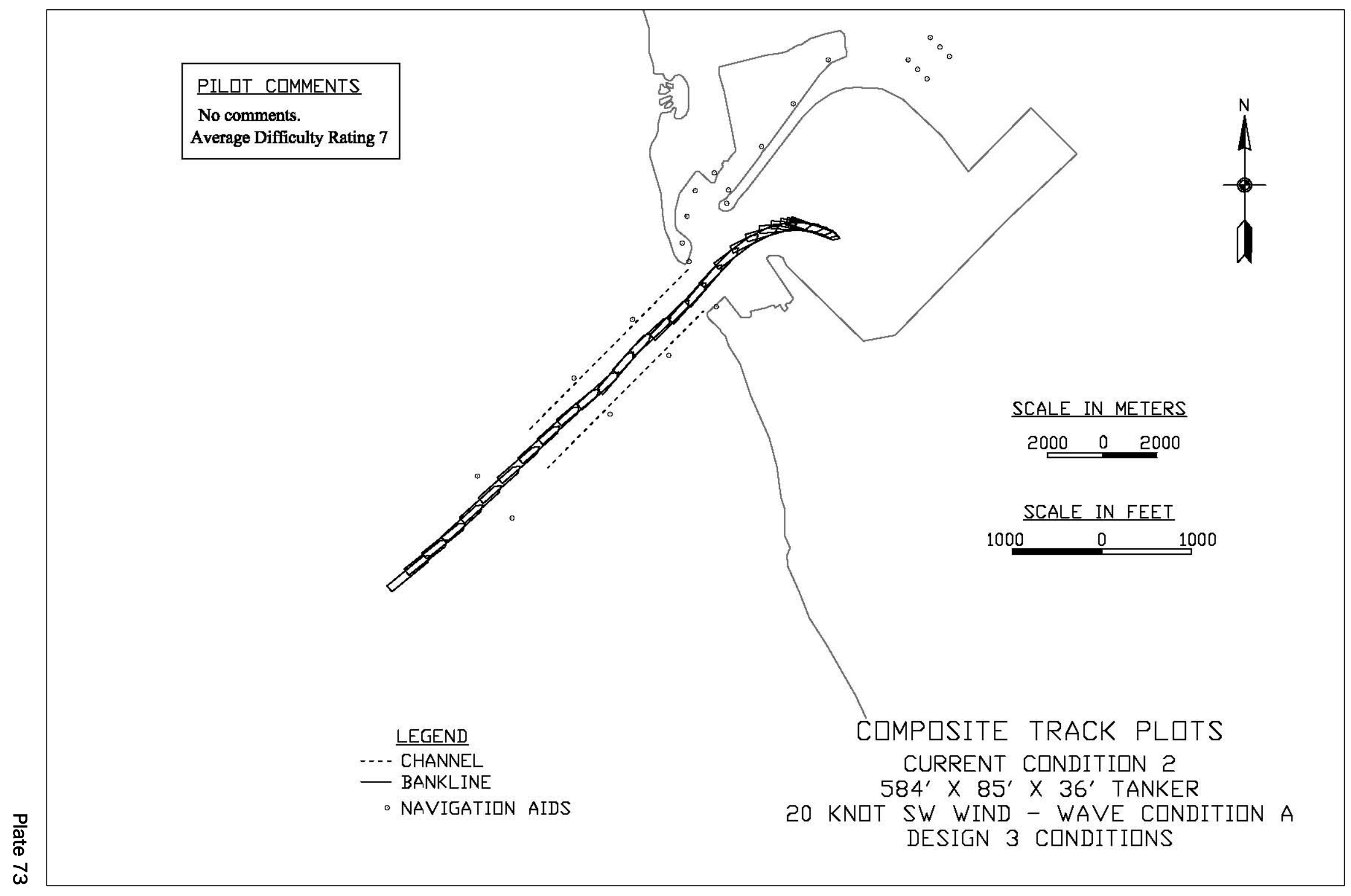




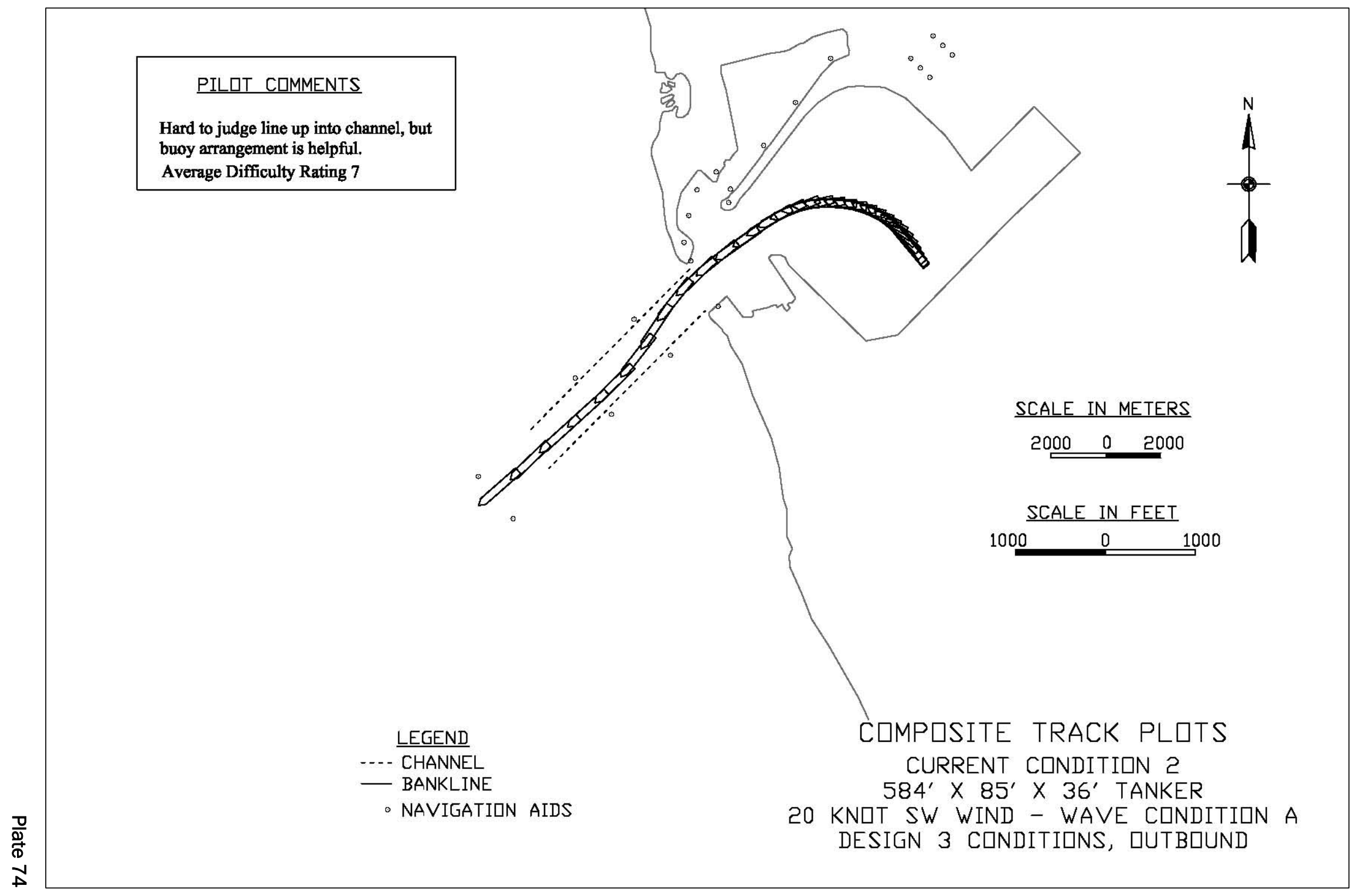




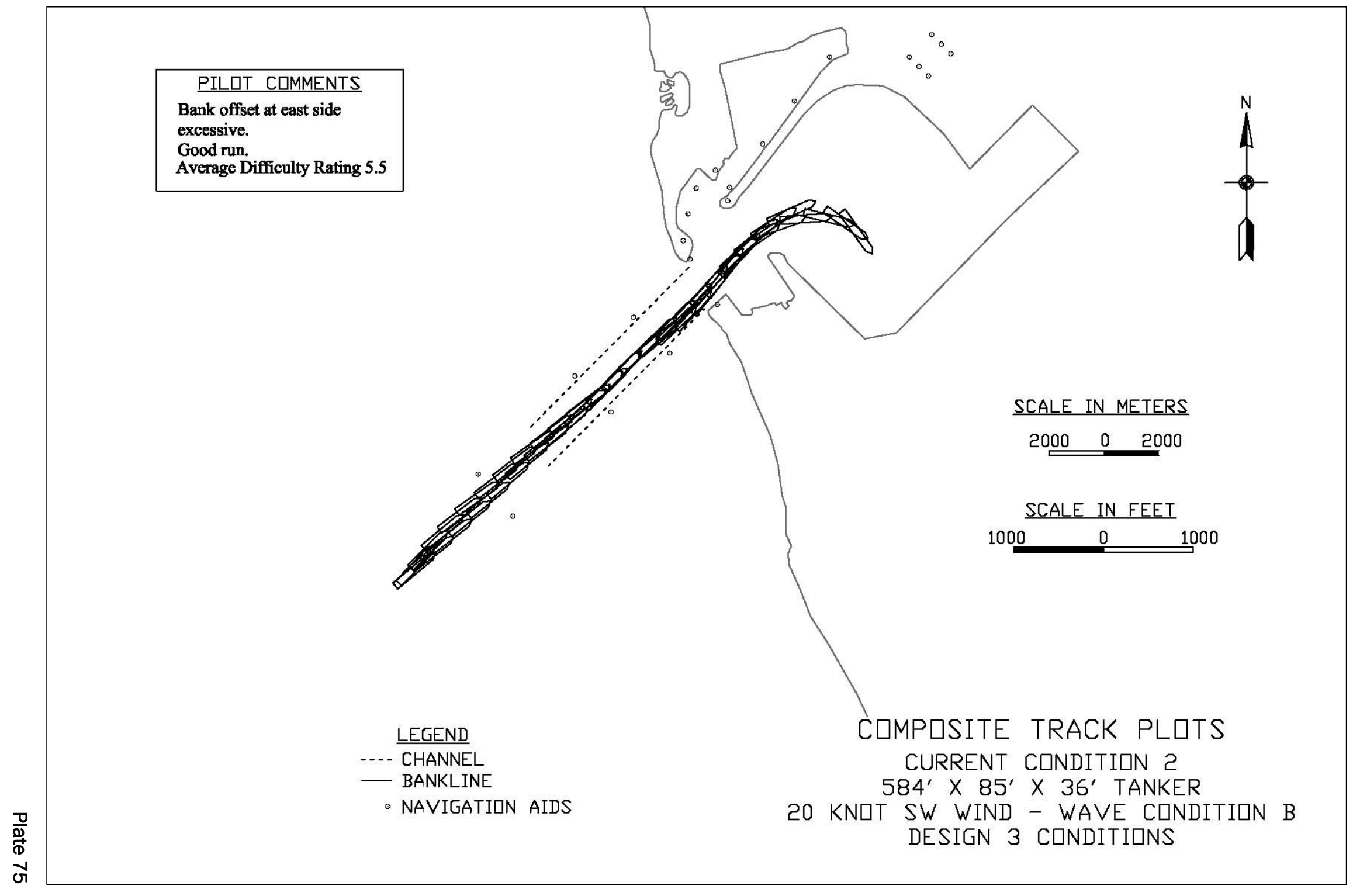




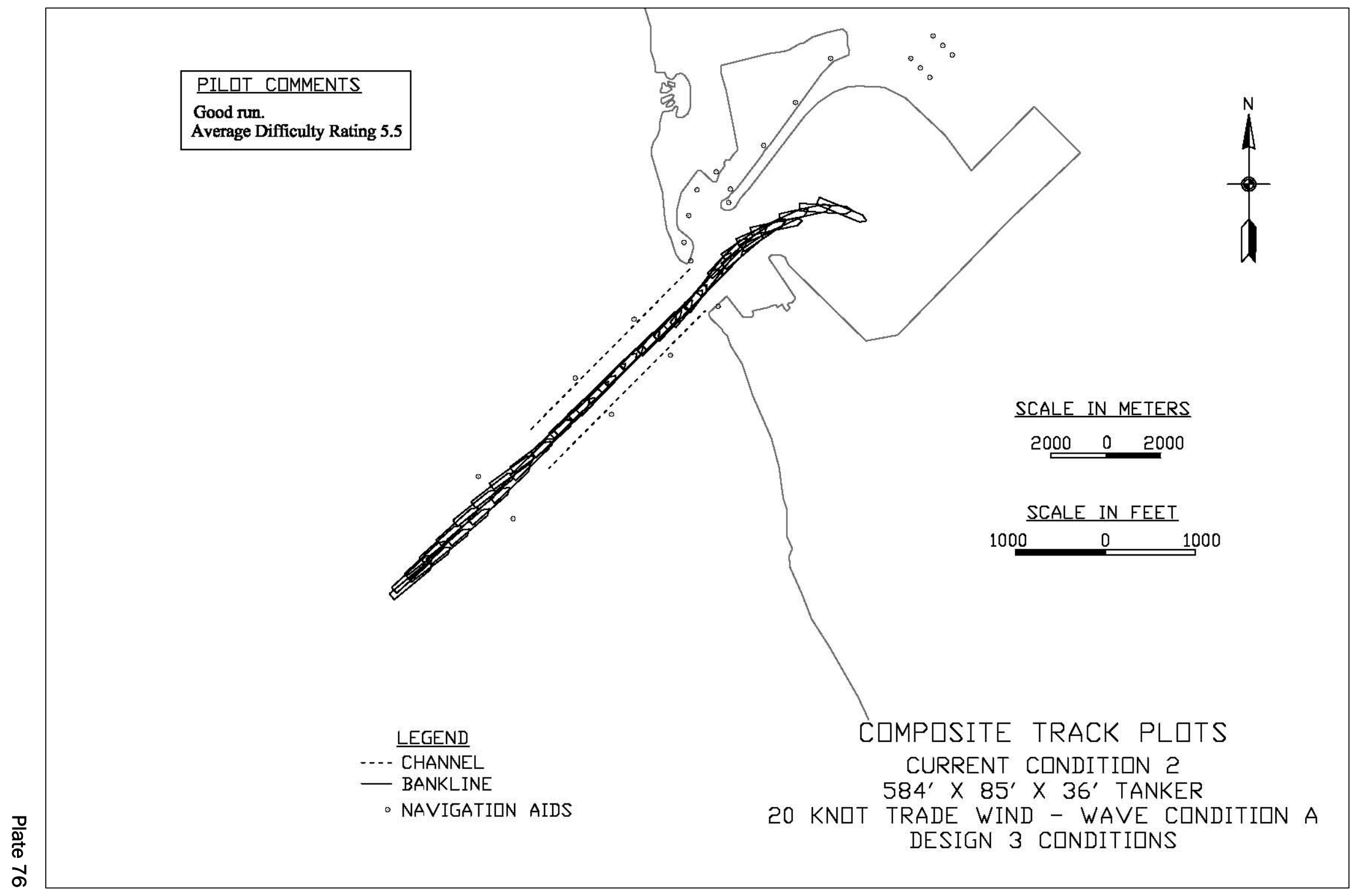




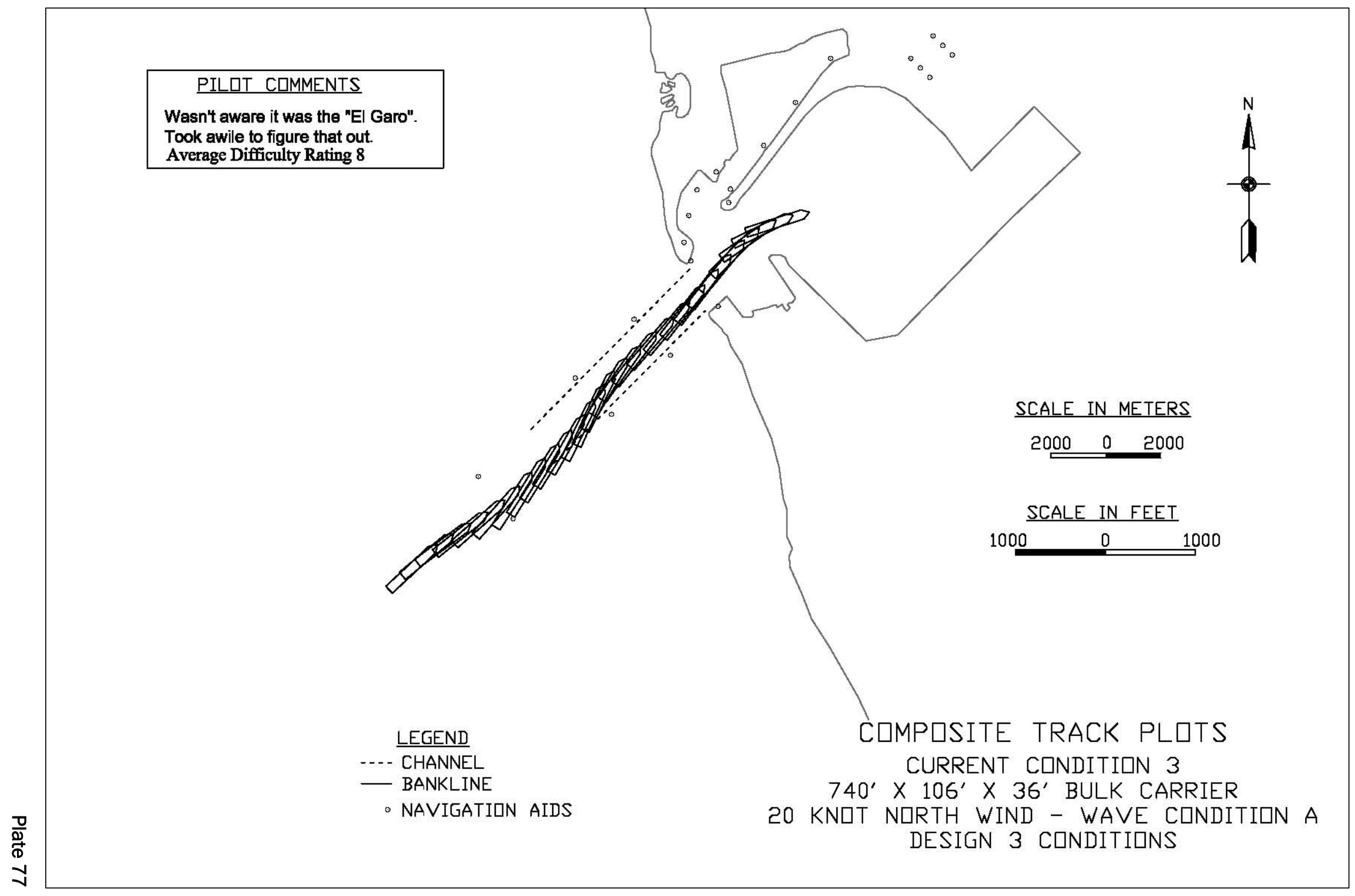




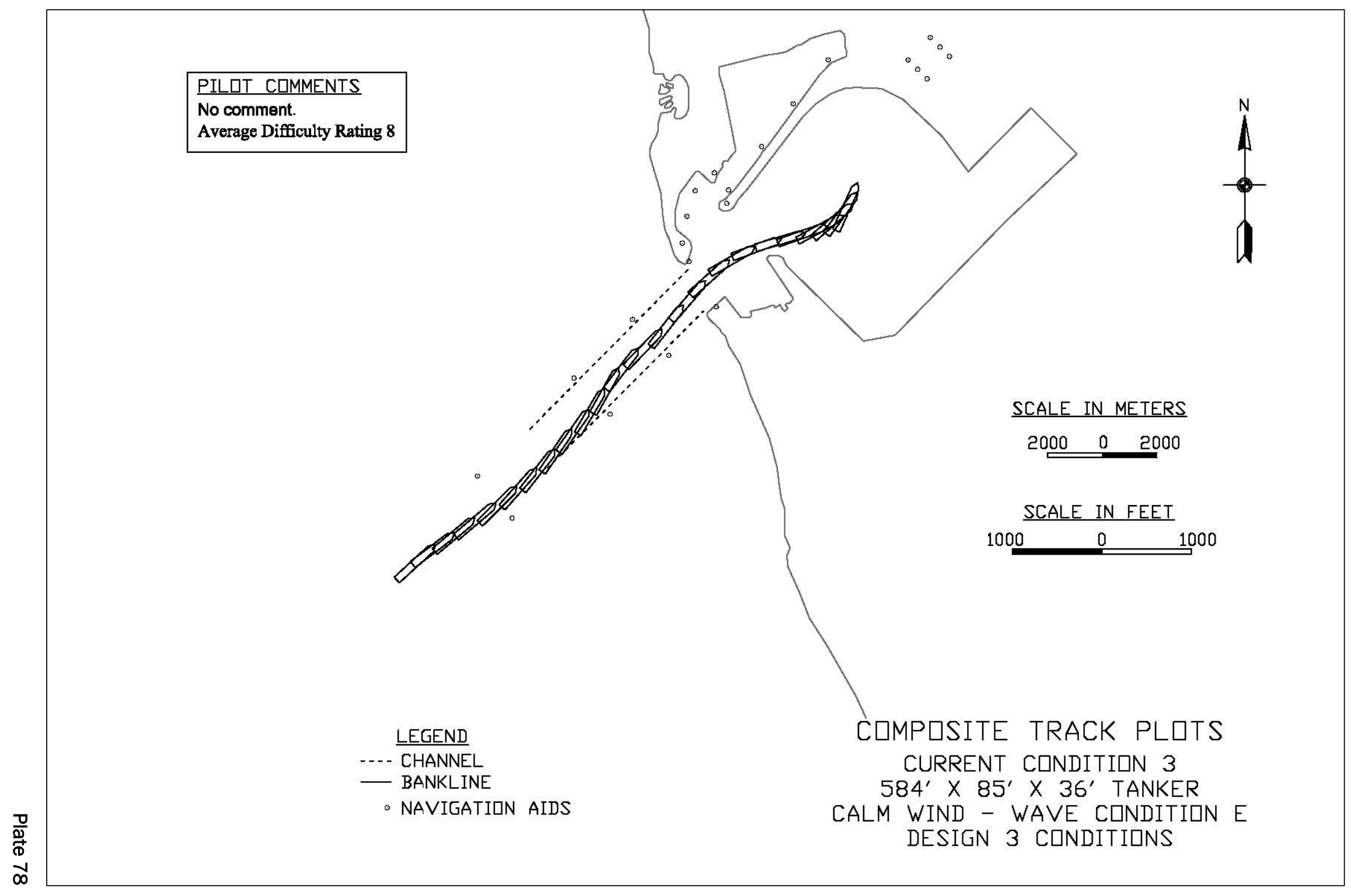




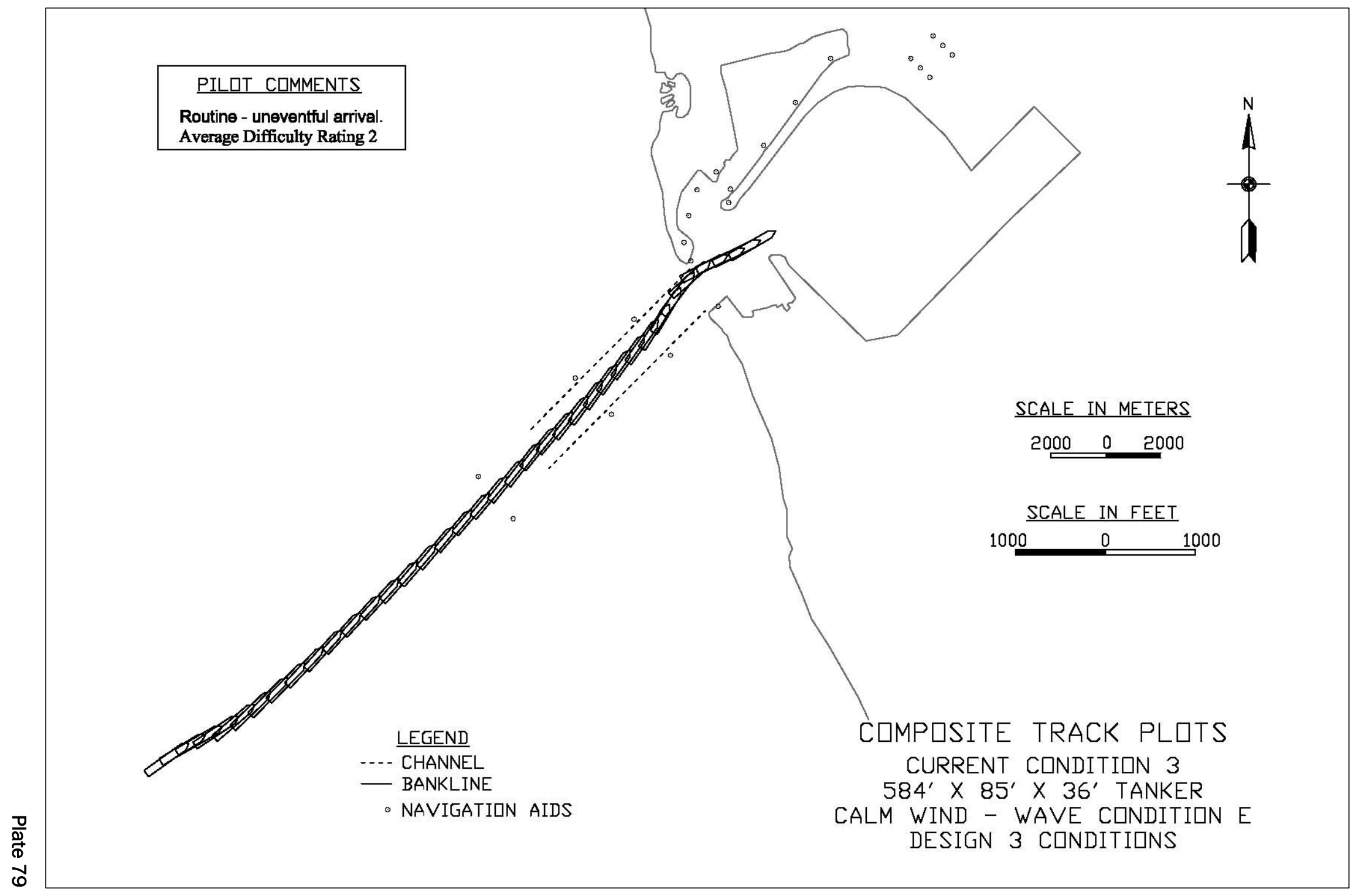




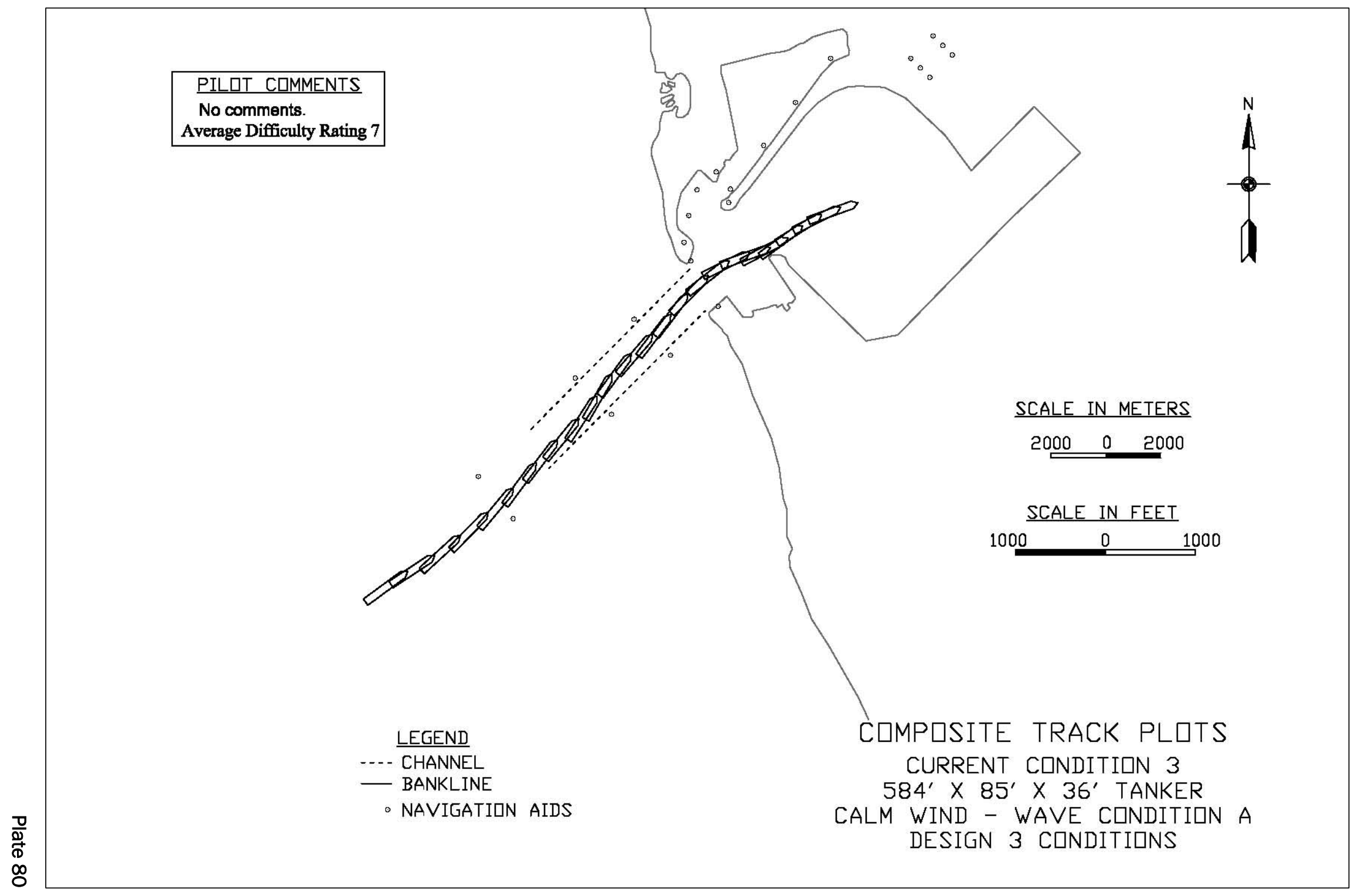




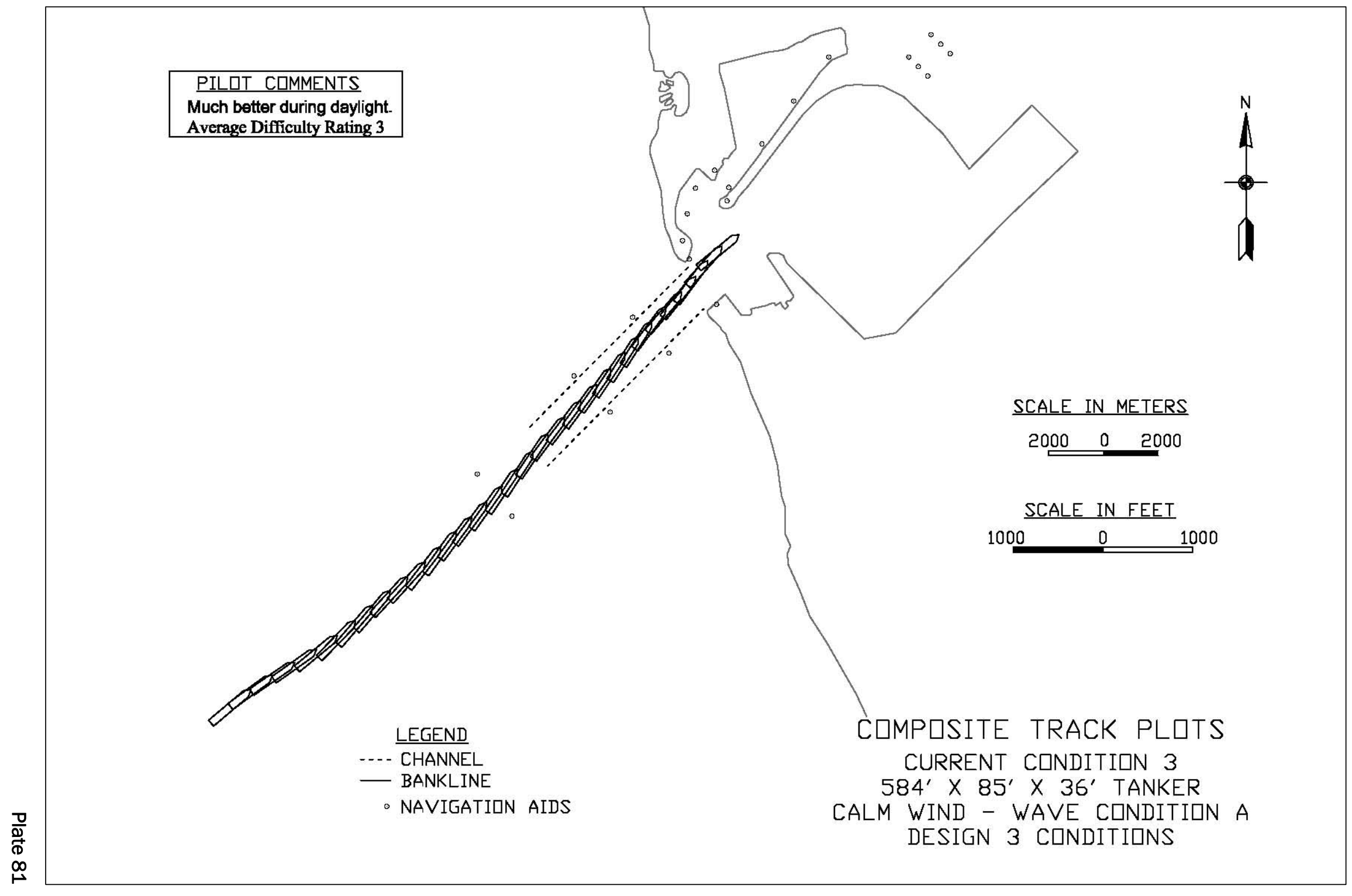




\section{Appendix A: Harbor Master Notices}


November 18,1992

HARBOR MASTER NOTICE NO. 7-92

SUBJECT: VESSEL MOVEMENT AT BARBERS POINT HARBOR

A recent incident has highlighted the need to define more explicitly the restriction on limiting arrivals and departures to daylight hours at Barbers point Harbor for commercial vessels requiring pilotage.

Arriving commercial vessels shall not enter Barbers Point Harbor:

1. earlier chan 30 minutes before sunrise, or

2. later than sunset.

Departing comercial vessels shall not cast off mooring Iines:

1. earlier than 30 minutes before sunrise, or

2. later than sunset.

The pilot may further limit these times due to factors of limited visibility, weather conditions, etc.

In the event of an emergency, the Harbor Master may make an exception to this restriction.

Your cooperation and assistance are solicited. This

supersedes Harbor Master Notice No. 6-91, dated December ?, 1.991.

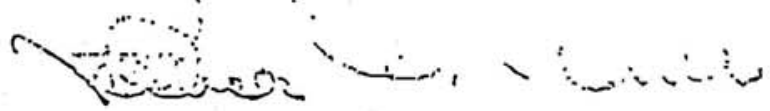

Patrick E. Torres

HonoluJu Harbor Master

Distribution: Shipping Agenes; Shipping Companies; USCG Captain of the Port; Pilots Association;

Terminal Operators; Dil Companies

DC: HAR-O, HAR-OC, HAR-OCI, HAR-OC2, HAR-OC3, HAR-OC'T, HAR-OCB, HAR-OO 
May 29, 1992

HARBOR MASTER NOTICE 5-92

SUBJECT: MINIMUM TUG REQUTREMENTS FOR VESSELS - USING BAREERS POINT HARBOR

This is to establish the minimun" tug requiremerts for vessels 300 feet or more in length and tank barges going in and out of Barbers point Farbor.

These requirements are necessary to increase the margin of safecy for vessels transiting the harbor due to the physical characteristics of the harbor which limit maneuverability, namely, the narrow entrance channel and strong, unpredictable currents which are, at times, prevalent in that area.

Tug requirements:

1. All tankships carrying pet́roleum or similar hazardous cargo will have at least two tugs in atcendance lipon entering or departing the harbor.

2. A.l tank barges carrying petroleum, LPG, or similar hazardous cargo will have at least one assist tug in attendance upon entering the harbor. An assist tug for departing the harbor will be at the discretion of the tug master.

3. All other vessels with a length of 450 feet or less must have ar least one tug in attendance upon entering the harbor.

4. All other vessels with a length of more than 450 feet must have at least two tugs in atcendance upon entering the harbor.

5. All ships with a length of 500 feet or less must have at least. one tug in artendance upon departing the harbor.

6. All ships with a length of more than 500 ieet must have two rugs in attendance upon depazting the harbor. 


\section{Page 2}

If the vessel has an adequate (at least 1,000 horsepower) bow thruster, exceptions to these requirements may be considered by the Harbor Master and the $U$. S. Coast Guard Captain of the port on a case basis.

Your cooperation and assistance will be appreciated.

Patrick E. Torres

Honolulu :arbor Master

Distribution: Shipping Ageñts, Captain of the Port, Pilot Associations, Tug Companies, Oil Companies

bc: HAR-O

HAR-OC

HAR-OCI

HAR $-O C 3$

$H A R-O C B$

HAR-OCT 


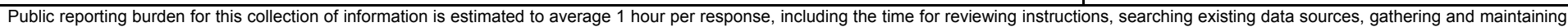

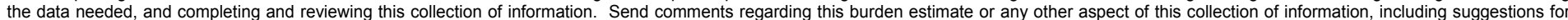

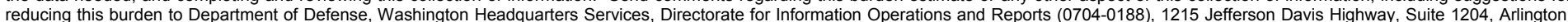

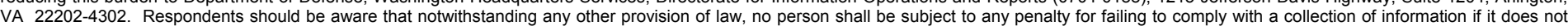
display a currently valid OMB control number. PLEASE DO NOT RETURN YOUR FORM TO THE ABOVE ADDRESS.
1. REPORT DATE (DD-MM-YYYY) May 2007

\section{Final report}

\section{TITLE AND SUBTITLE}

Barbers Point Harbor, Nighttime Simulation

3. DATES COVERED (From - To)

5a. CONTRACT NUMBER

5b. GRANT NUMBER

5c. PROGRAM ELEMENT NUMBER

6. AUTHOR(S)

5d. PROJECT NUMBER

Gary C. Lynch

5e. TASK NUMBER

5f. WORK UNIT NUMBER

8. PERFORMING ORGANIZATION REPORT NUMBER

ERDC/CHL TR-07-1

Coastal and Hydraulics Laboratory

U.S. Army Engineer Research and Development Center

3909 Halls Ferry Road

Vicksburg, MS 39180-6199

9. SPONSORING / MONITORING AGENCY NAME(S) AND ADDRESS(ES)

U.S. Army Engineers District, Honolulu

Fort Shafter, $\mathrm{HI} \quad$ 96858-5440

11. SPONSOR/MONITOR'S REPORT NUMBER(S)

\section{DISTRIBUTION / AVAILABILITY STATEMENT}

Approved for public release; distribution is unlimited.

\section{SUPPLEMENTARY NOTES}

\section{ABSTRACT}

Kalaeloa Barbers Point Harbor is located on the southwestern side of Oahu, HI. The purpose of this study was to analyze the possibility of nighttime transit into and out of the harbor. Changes in navigational aids as well as the addition of shoreline lighting were tested in the U.S. Army Engineer Research and Development Center's Ship/Tow Simulator with the assistance of Pilots from Hawaii. For the possibility of nighttime transit to exist, improvements to the navigational aids, as well as improved methods of predicting the currents at the approach, would first have to be implemented.

\section{SUBJECT TERMS}

Barbers Point

Harbor

16. SECURITY CLASSIFICATION OF:

a. REPORT

UNCLASSIFIED
Hawaii

Navigation

b. ABSTRACT
UNCLASSIFIED

c. THIS PAGE

UNCLASSIFIED

Nighttime

Simulator

17. LIMITATION OF ABSTRACT
18. NUMBER OF PAGES

126 19a. NAME OF RESPONSIBLE PERSON

19b. TELEPHONE NUMBER (include area code) 